\title{
Assessing rumen microbial composition and fibre attachment in dairy cows
}

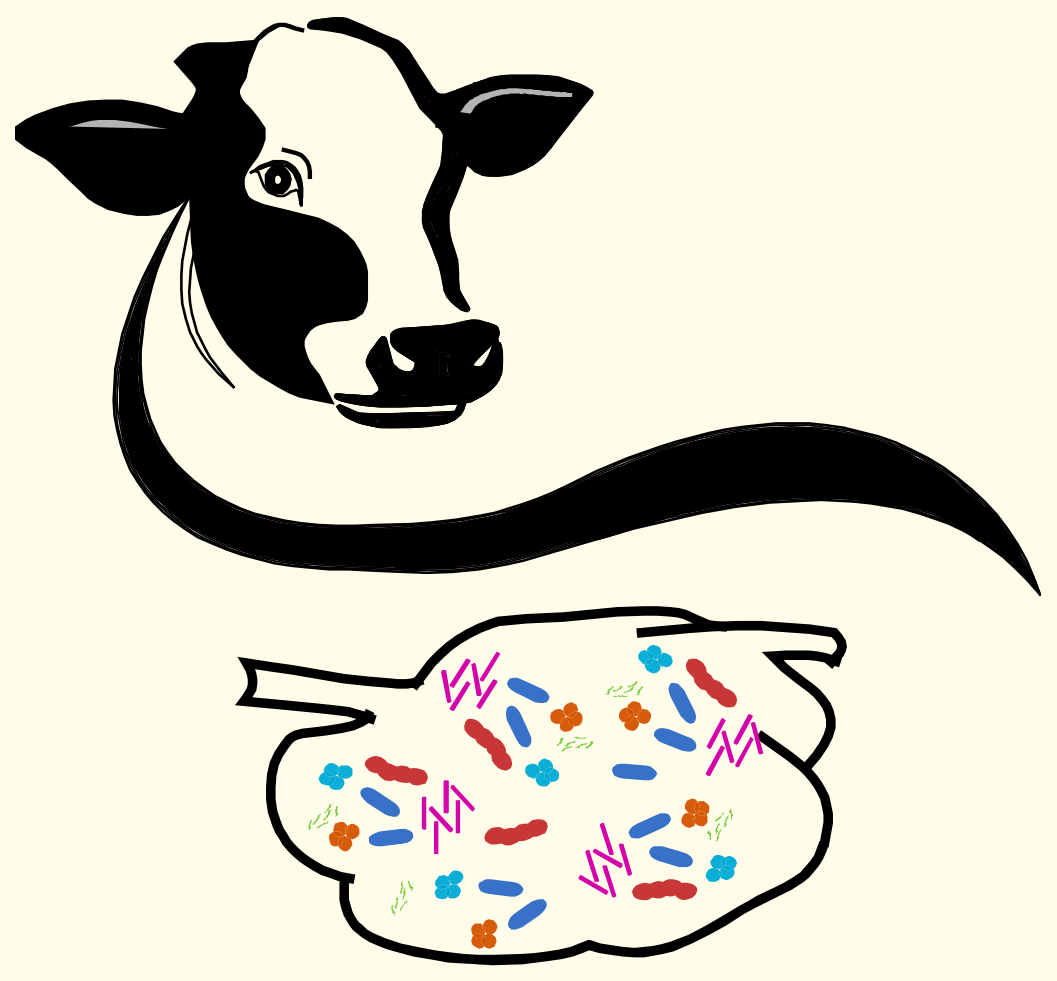

Jueeli Deepak Vaidya 


\section{Propositions}

1) The perfect DNA extraction method does not exist. (this thesis)

2) Fibre degrading bacteria are key players in ruminal methanogenesis. (this thesis)

3) Microbiome studies need equal attention irrespective of the host.

4) Humans are the main cause of biodiversity loss.

5) Every $\mathrm{PhD}$ student should have multiple supervisors.

6) Artificial intelligence lacks the theory of mind.

7) There is underestimation of time and effort for data analysis when compared to laboratory work.

Propositions belonging to the thesis entitled:

"Assessing rumen microbial composition and fibre attachment in dairy cows"

Jueeli Vaidya

Wageningen, 15 November 2018 



\section{Assessing rumen microbial composition and fibre attachment in dairy cows}




\section{Thesis committee}

\section{Promotor}

Prof. Dr Hauke Smidt

Personal chair at the Laboratory of Microbiology

Wageningen University \& Research

\section{Co-promotors}

Dr Caroline M. Plugge

Associate professor, Laboratory of Microbiology

Wageningen University \& Research

Dr Joan E. Edwards

Postdoctoral Research fellow, Laboratory of Microbiology

Wageningen University \& Research

\section{Other members}

Prof. Dr Michiel Kleerebezem, Wageningen University \& Research

Dr Wilbert F. Pellikaan, Wageningen University \& Research

Prof. Dr Qendrim Zebeli, University of Veterinary Medicine, Vienna, Austria

Dr Sharon Huws, Queens University, Belfast, UK

This research was conducted under the auspices of the Graduate School VLAG

(Advanced studies in Food Technology, Agrobiotechnology, Nutrition and Health Sciences) 


\title{
Assessing rumen microbial composition and fibre attachment in dairy cows
}

\author{
Jueeli Deepak Vaidya
}

\section{Thesis}

submitted in fulfilment of the requirements for the degree of doctor at Wageningen University

by the authority of the Rector Magnificus,

Prof. Dr A.P.J. Mol,

in the presence of the

Thesis Committee appointed by the Academic Board

to be defended in public

on Thursday 15 November 2018

at 11 a.m. in the Aula. 
Jueeli Deepak Vaidya

Assessing rumen microbial composition and fibre attachment in dairy cows, 200 pages.

PhD thesis, Wageningen University, Wageningen, the Netherlands (2018)

With references, with summary in English

ISBN: 978-94-6343-358-7

DOI: https://doi.org/10.18174/460705 


\section{Table of contents}

\section{Chapter 1}

General introduction and thesis outline

\section{Chapter 2}

Effect of DNA extraction methods on observed microbial communities in fibrous and liquid fractions in dairy cows

\section{Chapter 3}

Characterization of dairy cow rumen bacterial and archaeal communities associated with grass silage and maize silage based diets

\section{Chapter 4}

Enrichment of rumen fibre associated bacteria derived from ruminal fibrous content in dairy cows fed grass or maize silage

\section{Chapter 5}

Characterization of Propionibacterium ruminifibrarum sp. nov., isolated from cow rumen fibrous content

\section{Chapter 6}

General discussion

\section{Thesis summary}

\section{Appendices}




\section{Chapter 1}

General introduction and Thesis outline 
Temperatures all over the world have been continuously rising for more than a century. Since 1970 , the average surface temperature of the earth has been rising at an average rate of $0.17^{\circ} \mathrm{C}$ per decade. This climate change due to human activities has fuelled increasing concerns. In 2015, greenhouse gas (GHG) emissions were reduced by $22 \%$ when compared with 1990 levels. This reduction was mainly achieved through decreasing fuel combustion as a way to reduce GHG emissions. Currently, the European Union (EU) aims to reduce $20 \%$ of its GHG emissions by 2020 and $30 \%$ by 2030 as compared with 1990 levels. In order to ameliorate the severe impacts of human activities on local and global climate, there is an agreement from the EU wherein the global warming should be kept below $2{ }^{\circ} \mathrm{C}$, indicating that the temperature should not increase $\mathrm{m}$ ore than $1.2{ }^{\circ} \mathrm{C}$ above today's values, with the aim to stop the growth of GHG emissions by 2020 (www.ec.europa.eu/eurostat).

\section{METHANE AS A GREENHOUSE GAS}

When the sun's energy reaches the earth, som e of it is reflected back to space while the rest is absorbed and re-radiated by GHGs, a process often referred to as the GHG effect. Most important GHGs include water vapour, nitrous oxide $\left(\mathrm{N}_{2} \mathrm{O}\right)$, carbon dioxide $\left(\mathrm{CO}_{2}\right)$, methane $\left(\mathrm{CH}_{4}\right)$, ozone $\left(\mathrm{O}_{3}\right)$ and some manmade chlorofluorocarbons (CFCs). While $\mathrm{CO}_{2}$ is considered to be the most important GHG associated with climate change (Steinfield et al., 2006), $\mathrm{CH}_{4}$ is the most abundant non- $\mathrm{CO}_{2}$ GHG in the atmosphere today (Hansen et al., 2000; Montzka et al., 2011). Furthermore, $\mathrm{CH}_{4}$ has 25 times the warming effect of $\mathrm{CO}_{2}$ as it strongly absorbs infrared radiation. As a consequence, $\mathrm{CH}_{4}$ is thought to contribute $4-9 \%$ of the global GHG effect based on its atmospheric concentration and half-life (Forster et al., 2007). There are multiple sources of $\mathrm{CH}_{4}$ (Dean et al., 2018b), and they can be broadly classified as being either natural or anthropogenic (Table 1). Natural sources are dominated by wetlands, fresh water systems, coastal sediments and oceans, $\mathrm{CH}_{4}$ hydrates, geological sources and fauna. Anthropogenic sources mainly include agriculture and waste, as well as combustion of biomass and fossil fuels. Enteric fermentation from ruminants, together with manure, accounts for $56 \%$ of the methane that is produced from agriculture and waste (Dean et al., 2018b). 
Table 1. Identified global natural and anthropogenic $\mathrm{CH}_{4}$ sources and estimates of annual $\mathrm{CH}_{4}$ budget as taken from (Dean et al., 2018b). Values indicate the mean and range of global $\mathrm{CH}_{4}$ (Tg per year) budgets and inventories estim ated from observations at the Earth's surface.

\begin{tabular}{ll}
\hline Sources & $\begin{array}{l}\text { Estimated annual } \mathrm{CH}_{4} \text { Budget in } \mathrm{Tg} \mathrm{CH}_{4} \\
\text { per year }\end{array}$ \\
\hline Total natural sources & $185\left(153^{*}-227^{* *}\right)$ \\
Natural wetlands & $199(104-297)$ \\
Other natural sources & $185(99-272)$ \\
Other land sources & $122(60-180)$ \\
Freshwaters & $40(30-56)$ \\
Geological (onshore) & $10(5-15)$ \\
Wild animals & $9(3-15)$ \\
Termites & $3(1-5)$ \\
Wildfires & $1(0-1)$ \\
Permafrost soils (direct) & $14(5-25)$ \\
Oceanic sources & $12(5-20)$ \\
Geological (offshore) & \\
Total anthropogenic sources & $195(178-206)$ \\
Agriculture and waste & $106(97-111)$ \\
Enteric fermentation and manure & $59(52-63)$ \\
Landfills and waste & $30(24-36)$ \\
Rice cultivation & $121(114-133)$ \\
Fossil fuels & $41(26-50)$ \\
Coal mining & $79(69-88)$ \\
Gas, oil, and industry & $30(27-35)$ \\
Biomass and biofuel burning &
\end{tabular}

Global $\mathrm{CH}_{4}$ emissions are expected to increase by $7 \%$ in 2055 , based on the expected farming and consumer lifestyle practices as compared to 1995 . This makes the decrease of enteric $\mathrm{CH}_{4}$ emissions one of the main targets of GHG mitigation of the ruminant livestock production sector, particularly dairy cows (Hristov et al., 2013). $\mathrm{CH}_{4}$ from ruminants is mainly produced in the rumen $(87 \%)$ as a result of microbial fermentation of feed plant material under anoxic conditions, and is released into the environment via eructation and breath (Boadi et al., 2004). As the $\mathrm{CH}_{4}$ is exhaled, it also represents a loss of ingested feed-derived energy which varies from $\sim 2-12 \%$ depending on diet (Hook et al., 2010). 


\section{RUMEN ANATOMY AND PHYSIOLOGY}

Ruminants possess a complex rumen ecosystem with the resident rumen microbial community known to play vital roles in host productivity and health, as well as with respect to the environmental footprint of ruminant livestock production. Unlike in monogastrics, the stomach (or the fore-gut) of the ruminant animal is composed of the reticulum, rumen, omasum and abomasum (Fig. 1). The reticulum and rumen (reticulo-rumen) are joined by a fold of tissue and various pillars. The reticulo-rumen is the largest part of the fore-gut, and fills three-quarters of the abdominal cavity. The pillars help in contraction of various sacs that help in circulating and mixing of the ingested feed (Dehority, 2002) (Fig. 1). Feed when ingested by ruminant cattle gets mixed with saliva. Saliva is known for high concentrations of sodium and potassium bicarbonate and phosphate and helps in buffering the acid produced during ruminal fermentation (Dehority, 2002). The bolus that is subsequently formed can be easily swallowed, and is then transferred to the rumen from the reticulum. After fermentation in the reticulo-rumen, the feed passes into the omasum which serves as a filter pump to sort liquids and fine particles. Additionally, the omasum absorbs water, minerals and nitrogen. The abomasum is where the gastric juices are formed. The hydrochloric acid and the digestive enzymes needed for breakdown of feeds are secreted into the abomasum, and retention time of the feed in the abomasum does not exceed one to two hours. Further breakdown of particles occurs in the small and large intestine, and the residue that flows out from the large intestine enters the colon and gets excreted as manure.

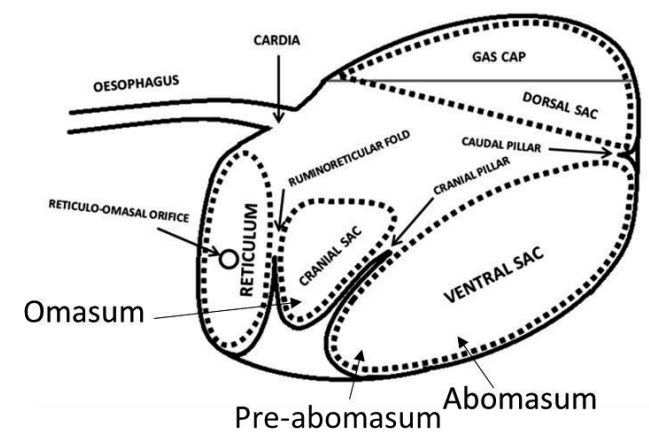

Figure 1. Basic representation of a cow rumen (ecow.co.uk/biology-of-the-rumen/) 
The process of rumination involves regurgitation of the ingesta from the reticulo-rumen, re-chewing of solids accompanied by salivary secretion and finally re-swallowing of the bolus. While the digestion of the feed in the mouth is mostly mechanical, the digestion in the rumen is due to microbial activities. Hence, a combined effect of ruminal mastication, host enzymatic action and microbial activity results in breakdown of plant fibres, thereby reducing the particle size. The time spent for rumination depends on the particle size of the ingested feed, with the average retention time varying from 34 - 40 hours depending on the feed (Dehority, 2002; Huhtanen et al., 2016; Processi et al., 2016).

\section{THE ROLE OF RUMEN MICROBIOTA IN ENTERIC METHANOGENESIS}

Rumen microbes in general degrade plant derived feed in the rumen that can be either fibrous (cellulose and hemicellulose) or non-fibrous (starches and simple sugars) carbohydrates. Rumen microbes function via complex interactions, which help them to sustain their population and activity. Rumen fermentation is carried out by rumen microbes that hydrolyse the polysaccharides into monomers and further ferment them into volatile fatty acids (VFA), succinate, formate, lactate and gases including ammonia $\left(\mathrm{NH}_{3}\right), \mathrm{H}_{2}$ and $\mathrm{CO}_{2}$. The VFA and $\mathrm{NH}_{3}$ are usually absorbed through the walls of the pre-abomasal compartments by diffusion while $\mathrm{H}_{2}$ and $\mathrm{CO}_{2}$ are converted to $\mathrm{CH}_{4}$, which is released via eructation. Additionally a part of the fermentation products is also used by rumen microbes for their nutritional supply (Agarwal et al., 2015). During ruminal fermentation, the metabolites acetate, propionate and butyrate make up more than $95 \%$ of VFAs. The stoichiometry of the production of these aforementioned major VFAs determines the amount of $\mathrm{CO}_{2}$ and $\mathrm{CH}_{4}$ associated with acetate, propionate or butyrate production. For instance, per mole of glucose fermented to 2 moles of acetate, 2 moles of $\mathrm{CO}_{2}$ and 4 moles of $\mathrm{H}_{2}$ are released which enables rumen methanogenic archaea to utilize the 4 moles of $\mathrm{H}_{2}$ and reduce 1 mole of $\mathrm{CO}_{2}$ to 1 mole of $\mathrm{CH}_{4}$. Butyrate production results in 2 moles of $\mathrm{H}_{2}$ and 2 moles of $\mathrm{CO}_{2}$ per mole of glucose and thereby requires a net input of reducing equivalents to produce $\mathrm{CH}_{4}$. Propionate uses $\mathrm{H}_{2}$ for its production thereby acting as a hydrogen sink. Thus, with propionate formation less $\mathrm{CH}_{4}$ is produced by the methanogens and consequently more VFA is available to the ruminant for nutrient supply.

Bacteria are the most diverse microbial group in the rumen, and are capable of utilizing a range of different feed components (Stewart et al., 1997). Rumen studies have consistently 
identified Firmicutes and Bacteroidetes as the pre-dominant bacterial phyla (De Menezes et al., 2011b; Huws et al., 2016). However, distinct members of these phyla are associated with the liquid or fibrous fractions where they are present in higher or lower relative abundances (Klevenhusen et al., 2017). Rumen microbiota in specific micro-environments play different roles in plant feed degradation. The bacteria $\left(10^{10}\right.$ per $\left.\mathrm{ml}\right)$ typically form the largest component of the microbial biomass (Mackie, 1997). Bacteria contribute to $80 \%$ of the degradation activity. In late studies that used next-generation sequencing technology (NGS), differences in the fluid and the fibrous fractions in dairy cows have been reported (Fouts et al., 2012; Mao et al., 2015; Ji et al., 2017). The predominant taxa in the fibrous content of the rumen belonged to Firmicutes and Bacteroidetes in the study of Mao et al. (2015). At genus level, the proportions of Prevotella, unclassified Ruminococcaceae, unclassified Rikenellaceae, unclassified Christensenellaceae and unclassified Bacteroidales were significantly higher in rumen fibrous content than the liquid fraction (Mao et al., 2015). Moreover, in the study of Fouts et al. (2012), seven genera differed significantly between the liquid and the fibrous fractions in dairy cows. Herein, Prevotella was over represented in the liquid fraction which is in contrast to the finding of (Mao et al., 2015). In addition, the liquid fraction also had higher relative abundances of Tannerella than the solid fraction. Conversely, Butyrivibrio and Blautia (both members of the order Clostridiales) were present at significantly higher relative abundance in the solid fraction of the rumen. Furthermore, genuslevel taxa within the Ruminococcaceae, Lachnospiraceae and unclassified Clostridiales were found more abundant in the liquid fraction compared to the fibrous fraction (Fouts et al., 2012). The fibrous fraction has also been shown to have higher relative abundances of Succinivibrio as compared to the liquid fraction in dairy cows (Ji et al., 2017). The difference in fractions can be associated with nutrient digestibility, rumen retention times and biofilm formation. Rumen microorganisms have traditionally been classified in accordance with their main metabolic activity, i.e. fibrolytic which include butyrate, acetate and propionate producers (e.g., Ruminococcus albus, Ruminococcus flavefaciens, Fibrobacter succinogenes, and Butyrivibrio fibrisolvens), amylolytic (e.g., Selenomonas ruminantium, Streptococcus bovis), proteolytic (e.g., Prevotella spp.), lipolytic (e.g., Anaerovibrio lipolytica), lactate producers (e.g., S. bovis and S. ruminantium), and lactate consumers (e.g., Megasphaera elsdenii) (Belanche et al., 2012). Among the numerous ruminal bacteria identified, Ruminococcus and Eubacterium spp. are identified as $\mathrm{H}_{2}$ producers while cellulolytic Fibrobacter spp. do not produce $\mathrm{H}_{2}$ and Bacteroides spp. are considered to be net $\mathrm{H}_{2}$ utilizers. 
More recently, rum en $\mathrm{m}$ icrobiom e analyses have identified 'rum inotypes' depending on $\mathrm{CH}_{4}$ emission measurements (Kittelmann et al., 2014). For instance, in sheep the low $\mathrm{CH}_{4}$ ruminotype Q was characterized by high relative abundance of Quinella ovalis while the low$\mathrm{CH}_{4}$ ruminotype $\mathrm{S}$ was associated with high relative abundances of lactate and succinate utilizers including Fibrobacter spp., Kandleria vitulina, Olsenella spp., Prevotella bryantii, and Sharpea azabuensis. The high $\mathrm{CH}_{4}$ ruminotype was characterized by high relative abundances of Lachnospiraceae, Ruminococcaceae, Alphaproteobacteria, Coprococcaceae, Prevotella and Bacteroidales suggesting that $\mathrm{CH}_{4}$ production is dependent on these $\mathrm{H}_{2}$ producing bacteria. In goats there was increased relative abundance of Prevotella and Selenomonas spp. when chemical inhibition of methanogens took place (Denman et al., 2015). Furthermore, high $\mathrm{CH}_{4}$ emitting beef cattle were characterized by low relative abundances of Succinivibrionaceae (Wallace et al., 2015). Conversely, this suggests that Succinivibrionaceae spp. occur at higher relative abundances in low emitting beef cattle. Interestingly, members from this family have also been found in Tammar wallabies, which are also foregut fermenters (Pope et al., 2011). In the study of Pope et al. (2011), metagenome analyses revealed that $77 \%$ of the recovered proteobacterial sequences could be assigned to the Wallaby group I (WG-1) within the Succinivibrionaceae. Cultured representatives included in this family are Succinivibrio, Prevotella and Anaerobiospirillum. Members of Succinivibrionaceae produce succinate as their principal fermentation end-product and use exogenous $\mathrm{H}_{2}$ to stimulate succinate formation as a way of $\mathrm{H}_{2}$ sink. Genome analysis of WG1 revealed that it is closest to Anaerobiospirillum succiniproducens, which employs an anaplerotic reaction to produce oxaloacetate (OAA) from phosphoenol pyruvate (PEP), subsequently reducing OAA to produce succinate as the end-product. This $\mathrm{H}_{2}$-consuming metabolism helps to explain contributions of WG-1 in the foregut of Tammar Wallabies to low $\mathrm{CH}_{4}$ phenotypes (Pope et al., 2011). It should be noted that individual members of specific genera can be differentially associated with either high or low $\mathrm{CH}_{4}$ emission, suggesting differences in their metabolism and/or ecology, as was observed from the two studies of cattle and Tammar wallabies where some Prevotella related OTUs were associated with high $\mathrm{CH}_{4}$ emitters and some with low $\mathrm{CH}_{4}$ emitters.

Another bacterium that has been associated with low $\mathrm{CH}_{4}$ emissions from dairy cattle is Faecalibacterium prausnitzii (M Ross et al., 2013), which is very rarely observed in rumen studies. This bacterium belonging to Firmicutes is a butyrate producer that uses the butyryl CoA : acetyl CoA transferase enzyme to catalyze the last part of the butyrate pathway. 
Almost all of the archaea in the rumen are methanogenic. Rumen methanogens utilise mainly $\mathrm{H}_{2}$ and $\mathrm{CO}_{2}$ produced by other fermentative rumen microbes (bacteria, protozoa and anaerobic fungi) producing $\mathrm{CH}_{4}$. Formate and methyl compounds are also available as substrates for the methanogens. Methanogens occupy different niches in the rumen, some being ectosymbionts or endosymbionts of protozoa and anaerobic fungi, whereas others occur free living in the liquid or associated with feed particles (Morgavi, 2010; Valle et al., 2015).

Members of the genus Methanobrevibacter are often the most abundant archaea in the bovine rumen (Danielsson et al., 2017). In addition, Methanosphaera spp., Methanimicrococcus spp. and Methanobacterium spp. occur at lower abundances (Hook et al., 2010). Further, a newly proposed methanogenic order, Methanomassillicoccales, has only recently been acknowledged as being the second largest archaeal population in the rumen after Methanobrevibacter (Jin et al., 2011). Methylamines and methanol are substrates for Methanomassillicoccales in the rumen (Friedman et al., 2017). Methanobrevibacter ruminantium, Methanomicrobium mobile, Methanosarcina mazei, Methanosarcina barkeri and Methanobacterium formicicum have all been isolated from the rumen (Janssen and Kirs, 2008). Among these, $M$. ruminantium, $M$. formicicum and $M$. mobile utilize $\mathrm{H}_{2} / \mathrm{CO}_{2}$ and formate to produce $\mathrm{CH}_{4}$ while $M$. mazei and M. barkeri use methyl compounds to produce $\mathrm{CH}_{4}$. The ruminal environment that provides $\mathrm{H}_{2}$ and $\mathrm{CO}_{2}$ contains mostly hydrogenotrophic archaea, rather than acetoclastic methanogens, even though acetate concentrations are high in the rumen. The absence of acetoclastic methanogens is mainly due to the rapid passage rate of the feed. In vivo studies have demonstrated that inhibiting methanogens can lead to decreased acetate-propionate ratios thereby having more reduced VFAs than acetate (Patra et al., 2012; Lopes et al., 2016; Patra et al., 2017). This further underlines the importance to understand the composition of methanogens and their interactions with other rumen microbes in order to provide the necessary basis for strategies to mitigate $\mathrm{CH}_{4}$ emissions.

Rumen protozoa produce $\mathrm{H}_{2}$ in a specialized organelle called the hydrogenosome, which is similar to the mitochondrion of aerobic eukaryotes (Morgavi, 2010). Protozoa that are associated with methanogens as endo- or ectosymbionts, provide the methanogens with this $\mathrm{H}_{2}$ through interspecies $\mathrm{H}_{2}$ transfer (Morgavi, 2010).

Anaerobic fungi are regarded as degraders of fibrous material due to their ability to produce polysaccharide degrading enzymes. Firstly, the enzymatic hydrolysis results in 
opening of the plant fibres which allow the fungi to penetrate complex structural barriers (Ho, 1988; Joblin, 1989; Orpin, 1997). Anaerobic fungi are furthermore known to increase the surface area available for colonisation or attachment of other microbes (bacteria) (Gruninger et al., 2014).

Protozoa ingest rumen bacteria as their main protein source, resulting in increased recycling of ingested $\mathrm{N}$ in the rumen and $20-28 \%$ decreased amino acid supply to the intestine of the animal. Their role in rumen feed degradation has not yet been unequivocally elucidated, however, reducing the number of protozoa has been shown to enhance feed conversion efficiencies (Williams, 1992). Protozoa can also reduce the number of fungi due to their ability to produce chitinases and to predate on fungal zoospores (Widyastuti et al., 1995).

\section{STRATEGIES TO REDUCE ENTERIC METHANOGENESIS THROUGH BIOTECHNOLOGY, ADDITIVES AND FEEDING}

The global concern for $\mathrm{CH}_{4}$ mitigation is increasing as a result of climate change. With this, concerns regarding rumen $\mathrm{CH}_{4}$ emissions have led researchers to study different ruminal fermentation pathways as a way to provide the necessary insights for the development of strategies towards decreasing $\mathrm{CH}_{4}$ emissions. Mitigation strategies can be considered from two related perspectives: (a) improvement of rumen fermentation efficiency and (b) increasing the productivity of animals with respect to milk yield and energy utilization. To this end, efforts are being made in order to increase the productivity by reducing the number of less productive/unproductive animals through dedicated breeding.

Primary strategies proposed to date included altering rumen microbial composition and fermentation using a number of different approaches that are outlined in the following.

\section{Direct fed microbials: Saccharomyces cereviseae (yeast)}

DFM are commonly used for manipulation of biochemical pathways to decrease rumen methanogenesis, and more specifically for re-direction of $\mathrm{H}_{2}$ thereby decreasing $\mathrm{H}_{2}$ production during feed fermentation. Bio-hydrogenation of poly-unsaturated fatty acids utilizes $\mathrm{H}_{2}$ and serves as a promising approach for lowering $\mathrm{CH}_{4}$ formation. However, this pathway accounts for only 1 to $2 \%$ of $\mathrm{H}_{2}$ consumed (Nagaraja et al., 1997). There is a variety of naturally occurring DFM in the rumen that can be classified into bacterial or fungal DFM. 
The most commonly used direct fed microbial (DFM) is yeast that has been successful in increasing ruminant productivity (Weimer, 2015). It improves rumen maturity by stabilising rumen $\mathrm{pH}$ and increasing activities of fibre degrading microbes (bacteria/anaerobic fungi) (Jeyanathan et al., 2014). One of the main factors that could explain the beneficial effects on fibre degrading bacteria is the capacity of live yeasts to scavenge oxygen, as there can be as high as 16 litres of oxygen entering the bovine rumen daily during feed and water intake, rumination and salivation (Fonty and Chaucheyras-Durand, 2006). Moreover, studies have also shown that live yeasts can reduce the redox potential of the rumen liquid suggesting favourable ecological conditions for anaerobic bacterial growth. Furthermore, germination of zoospores of the anaerobic fungus Neocallimastix frontalis and an in vitro filter-paper degradation was stimulated by two strains of S. cerevisiae (Fonty and Chaucheyras-Durand, 2006). Studies on live yeast supplementation have shown that it can stimulate the growth of lactate metabolizing bacteria, namely Megasphaera elsdenii or Selenomonas ruminantium, in vitro. Also, a study on active dry yeasts was performed in dairy cows and sheep, showing that supplementation led to reduced ruminal lactate concentrations, maintaining $\mathrm{pH}$ for an efficient rumen function (Fonty and Chaucheyras-Durand, 2006).

\section{Propionate enhancers}

Propionate formation is associated with $\mathrm{H}_{2}$ utilization. In the rumen propionate is produced via the succinate or acrylate pathway. The succinate pathway involves the intermediates malate and fumarate and produces succinate, which can be further de-carboxylated to propionate. The succinate pathway has been shown to be used by lactate producers (e.g. Selenomonas ruminantium), fumarate reducers (e.g. Wolinella succinogenes), succinate producers (e.g. Fibrobacter succinogenes) and succinate utilisers (e.g. S. ruminantium). The acrylate pathway catalyzes the conversion of lactate to propionate. Megasphaera elsdenii is a major lactate utilizer that produces propionate via the acrylate pathway (Jeyanathan et al., 2014). Prevotella ruminicola can also form propionate via the acrylate pathway, however, the amount of propionate formed by this organism is not significant in the rumen (Wallnofer and Baldwin, 1967). Cows supplemented with M. elsdenii changed the pattern of rumen fermentation favouring propionate with potential benefits on energy balance and animal productivity. Moreover, a study with a mixed culture of Propionibacterium jensii and Lactobacillus spp. has shown to decrease $\mathrm{CH}_{4}$ emissions showing their potential to mitigate rumen $\mathrm{CH}_{4}$ (Jeyanathan et al., 2014). 


\section{Using other inhibitors}

Halogenated aliphatic compounds like bromochloromethane (BCM), bromoethanesulfonate (BES), bromoform, carbon tetrachloride, trichloroacetamide and trichloroethyladipate are known to inhibit $\mathrm{CH}_{4}$ formation. These halogenated compounds serve as electron acceptors and block the function of corrinoid enzymes, thereby inhibiting cobamide dependent methyl group transfer in methanogenesis. A study on $\mathrm{BCM}$ as a $\mathrm{CH}_{4}$ inhibitor observed a negative effect with respect to total bacterial numbers, but growth of methanogens was inhibited in batch and continuous fermenters. These rumen microbial changes were, however, not further investigated (Goel et al., 2009). Chloroform has been shown to decrease $\mathrm{CH}_{4}$ formation in cattle without affecting feed digestion (Knight et al., 2011).

Reduction of nitrate redirects $\mathrm{H}_{2}$ away from methanogenesis. Nitrate serves as an alternative electron acceptor to endogenous fumarate in many propionate producing bacteria. Exposure of ruminal bacteria to nitrate has led to a decrease in ruminal cellulolytic activity, which was mainly attributed to the low numbers of cellulolytic and xylanolytic bacteria. Decreased cellulolytic activity can decrease rates of dry matter intake (Latham et al., 2016). Although nitrate may serve as alternative electron acceptors as well as be responsible for direct inhibition of ruminal methanogenesis, presently the use of nitrate as an electron acceptor is avoided as toxicity is associated with its reduction to nitrite (McAllister et al., 1996; Lee and Beauchemin, 2014). Inhibitors like 3-nitroxypropanol have been shown to bind to the methyl co-enzyme $\mathrm{M}$ reductase (MCR) active site thereby inactivating MCR activity for $\mathrm{CH}_{4}$ formation and have been shown to decrease the 16S rRNA gene copy numbers (absolute count) of methanogens (Romero-Perez et al., 2015).

Other inhibitors such as the ionophores monensin and lasalocoid can be used to reduce ruminal $\mathrm{CH}_{4}$ production (Ellis et al., 2012; Patra et al., 2017). As these compounds are lipophilic ion carriers, they pass through the cell wall of Gram-positive bacteria and penetrate into the cell membrane, thereby serving as $\mathrm{Na}+\mathrm{K}+$ antiporters, dissipating ion gradients for ATP synthesis, nutrient transport and subsequently resulting in delayed cell division and cell death (Tedeschi et al., 2003). Ionophores are shown to inhibit Gram positive bacteria that produce acetate and $\mathrm{H}_{2}$ and Gram negative bacteria as well that produce formate and $\mathrm{H}_{2}($ Patra et al., 2017). Ionophores are thus more related to inhibition of producers of $\mathrm{CH}_{4}$ precursors (formate and $\mathrm{H}_{2}$ ) rather than to a direct effect on methanogens as they are more resistant to 
ionophores than $\mathrm{H}_{2}$ producing bacteria. The reduction in $\mathrm{CH}_{4}$ production that is brought about by ionophores has often been associated with growth inhibition of ciliate protozoa that produce $\mathrm{H}_{2}$ (Nagaraja et al., 1997) In addition, the benefits of adding monensin have been associated to a protein sparing effect via direct inhibition of obligate amino-acid fermenting bacteria (Chen and Wolin, 1979; Mbanzamihigo et al., 1996). Additionally, plant secondary metabolites such as saponins, tannins, flavonoids, essential oils (clove, eucalyptus, garlic oil, peppermint, oreganum) have anti-microbial activities and have been used as potential inhibitors of rumen methanogens and $\mathrm{CH}_{4}$ production (Patra et al., 2017). Moreover, thyme oil or cinnamon oil have been shown to decrease the relative abundances of methanogens (Khorrami et al., 2015).

\section{DIETARY INFLUENCES ON RUMEN MICROBIOTA IN DAIRY COWS}

Diet is considered as one of the major factors that influences composition and activity of the rumen microbiota. Forage has always been the most important energy carrier feed in dairy cows. Dairy feed-stuffs consist of $70 \%$ carbohydrates, with major constituents being starch and cell wall constituents such as cellulose, hemicellulose and pectin.

Cellulose is the most abundant polysaccharide in fibrous feed, and is composed of linear chains of $\beta-1,4-$ linked glucose units. Cellulose in plants does not have side residues as described for hemicellulose (McAllister et al., 1994). Hemicellulose comprises a broad range of hetero-polymers including xylan, glucoronoxylan, arabinoxylan, glucomannan and xyloglucan that are all characterized by a backbone structure of $\beta-1,4$ linked xylose residues. Various side chains are linked to the xylose residues such as acetic acid, arabinose, coumaric acid, ferulic acid, glucuronic acid or 4-O-methylglucuronic acid (McAllister et al., 1994). Pectin is a minor fraction in the plant cell wall and is composed of a backbone of $\alpha-1,4$ linked residues of D-galacturonate (McAllister et al., 1994).

Starches are mainly $\alpha$-glucans composed of two types of molecules: amylose and amylopectin. It is known that an increasing amount of starch in the ruminant diet leads to decreased $\mathrm{CH}_{4}$ emission in dairy cows. The $\mathrm{CH}_{4}$ yield was shown to be reduced when Benchaar et al. (2014) replaced beet pulp (fibrous concentrate) by barley (starchy concentrate). A recent study suggested that a critical dietary concentration of starch is required to alter ruminal methanogenesis (Hassanat et al., 2013). 
Table 2 highlights several diets used for dairy cows and the microbial changes observed in bacterial composition with provided dietary interventions. Despite the range of different feeding treatments, similar predominant rumen phyla were identified, however, they differed in their relative abundances (Table 2). The studies mentioned in Table 2 have in common that they all focus on diets differing in starch and fibre ration, and corresponding effects on rumen microbiota composition were analysed using next generation sequencing of $16 \mathrm{~S}$ ribosomal RNA (rRNA) genes. It should be noted, however, that none of these studies reported $\mathrm{CH}_{4}$ measurements. Many other studies have shown that a high concentrate based diet results in lower $\mathrm{CH}_{4}$ production as compared to a mixed forage-concentrate based diet (Rooke et al., 2014; Roehe et al., 2016; Duthie et al., 2017). However, due to animal to animal variation, the ratio of $\mathrm{CH}_{4}$ to $\mathrm{CO}_{2}$ as a proxy in these studies did not relate well to daily $\mathrm{CH}_{4}$ measurements.

\section{ANIMAL ASSOCIATED FACTORS AFFECTING THE RUMEN MICROBIOTA, FERMENTATION PATTERN AND ENTERIC METHANOGENESIS}

\section{Animal type (breed, age)}

Ruminal $\mathrm{CH}_{4}$ production can be influenced by numerous animal associated factors such as age, breed and geographical region. These factors affect rumen microbiota composition and function, including $\mathrm{CH}_{4}$ production. The effect of age on $\mathrm{CH}_{4}$ production has been investigated earlier in cattle and deer (Molano et al., 2006; Swainson and Clark, 2007), and it was considered likely to be associated with animal characteristics like dry matter intake (DMI), body weight (BW) and rumen retention time (Okine et al., 1989; Angela et al., 2000). Another study exploring the bovine rumen microbial community from birth to adulthood (2year old) concluded that the microbial communities were influenced by age, however, the study did not correlate changes with enteric $\mathrm{CH}_{4}$ production (Jami et al., 2013). 
Table 2. Different dietary interventions and corresponding changes in microbial composition due to fibre/starch ration fed diets to dairy cows.

\begin{tabular}{|c|c|c|c|c|c|}
\hline & $\begin{array}{l}\text { Number } \\
\text { of cows }\end{array}$ & Diet & Period & $\begin{array}{l}\text { Bacterial changes due to dietary } \\
\text { interventions }\end{array}$ & Reference \\
\hline $\begin{array}{l}\text { Cannulated } \\
\text { cows }\end{array}$ & 2 & $\begin{array}{l}2 \times 2 \text { (Pasture }+ \text { Total } \\
\text { mixed ration }(\mathrm{TMR}))\end{array}$ & $\begin{array}{l}14 \text { days } \\
\text { pasture } \\
+\quad 14 \\
\text { days } \\
\text { TMR }\end{array}$ & $\begin{array}{l}\text { 1.Higher abundances of } \\
\text { Fibrobacteriaceae in pasture fed } \\
\text { TMR } \\
\text { 2.Higher abundances of } \\
\text { Prevotellaceae, Erysipelotrichaceae, } \\
\text { Veillonellaceae in pasture fed cows }\end{array}$ & $\begin{array}{l}\text { De Menezes } \\
\text { et al., } 2011\end{array}$ \\
\hline $\begin{array}{l}\text { Holstein } \\
\text { Friesian }\end{array}$ & 12 & 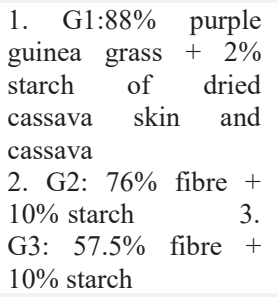 & $\begin{array}{l}2 \\
\text { months }\end{array}$ & $\begin{array}{l}\text { 1.High abundance of Firmicutes } \\
\text { (Lachnospiraceae } \\
\text { Ruminococcaceae) in } \mathrm{G} 1>\mathrm{G} 2>\mathrm{G} 3 \\
\text { 2.High abundance of Prevotella in } \\
\mathrm{G} 2>\mathrm{G} 1 \quad>\quad \mathrm{G} 3 \text {. } \\
\text { 3.High abundances }>\text { of } \\
\text { Proteobacteria Desulfobulbus, } \\
\text { Ruminobacter, } \\
\text { Pseudomonas) in G3 }>\mathrm{G} 1>\mathrm{G} 2\end{array}$ & $\begin{array}{l}\text { Thoetkiattikul } \\
\text { et al., } \\
2013\end{array}$ \\
\hline $\begin{array}{l}\text { Lactating } \\
\text { dairy }\end{array}$ & 3 & $\begin{array}{l}3 \times 3 \quad(47 \% \quad \mathrm{~L} . \\
\text { chinensis, } 11 \% \text { alfalfa } \\
\text { hay and } 42 \% \text { maize } \\
\text { silage (LC), } 42 \% \\
\text { cornstalk, } 11 \% \text { alfalfa } \\
\text { hay } \\
\text { and } 47 \% \text { maize silage } \\
(\mathrm{CS}), 38 \% \text { alfalfa hay, } \\
20 \% \quad \mathrm{~L} \text { chinensis } \\
\text { and } 42 \% \text { maize silage } \\
\text { (AH) }\end{array}$ & $\begin{array}{l}14 \text { day } \\
\text { each } \\
\text { diet }\end{array}$ & $\begin{array}{l}\text { 1.Higher abundances of } \\
\text { Anaerotruncus, Papillibacter, } \\
\text { Thermoactinomyces, } \\
\text { Actinopolyspora, Bacillus and } \\
\text { Streptomyces in CS compared to LC } \\
\text { or AH diet. } \\
\text { 2.Higher abundances of Prevotella } \\
\text { and Pyramidobacter in CS diet as } \\
\text { compared to those fed with AH diet. } \\
\text { 3.Highest proportions of } \\
\text { Selenomonas in AH diet. } \\
\text { 4.Higher abundance of unclassified } \\
\text { Rikenellaceae in CS diet. }\end{array}$ & $\begin{array}{l}\text { Zhang et al., } \\
2014\end{array}$ \\
\hline $\begin{array}{l}\text { Non- } \\
\text { lactating } \\
\text { Kankrej } \\
\text { cows }\end{array}$ & 18 & $\begin{array}{l}\text { Dry/green } \\
\text { roughage:concentrate: } \\
\text { K1 (50:50); K2 } \\
(75: 25) \quad \text { and } \quad \mathrm{K} 3 \\
(100: 0)\end{array}$ & $\begin{array}{l}6 \text { weeks } \\
\text { each } \\
\text { diet }\end{array}$ & $\begin{array}{l}\text { Most abundant phylum Firmicutes } \\
\text { and Bacteroidetes but the } \\
\text { abundances of genera varied } \\
\text { depending on the primer pairs in this } \\
\text { study }\end{array}$ & $\begin{array}{l}\text { Pitta et al., } \\
2014\end{array}$ \\
\hline $\begin{array}{l}\text { Chinese } \\
\text { Holstein }\end{array}$ & 32 & $\begin{array}{l}2 \quad \text { groups }(\text { Mixed } \\
\text { forage diet (MF) and } \\
\text { corn stover diet } \\
(\mathrm{CSA}))\end{array}$ & 91 days & $\begin{array}{l}\text { Succinivibrionaceae lower } \\
\text { abundance in CSA as compared to } \\
\text { MF }\end{array}$ & $\begin{array}{l}\text { Jin et al., } \\
2016\end{array}$ \\
\hline $\begin{array}{l}\text { Holstein } \\
\text { heifers }\end{array}$ & 24 & $\begin{array}{l}\text { Forage:Concentrate } \\
(80: 20,60: 40,40: 60, \\
\text { and } 20: 80 ; \text { the above } \\
\text { ratios mentioned as } \\
\text { C20, C40, C60, and } \\
\text { C80, respectively) } \\
\text { with corn silage as the } \\
\text { sole forage }\end{array}$ & 4 weeks & 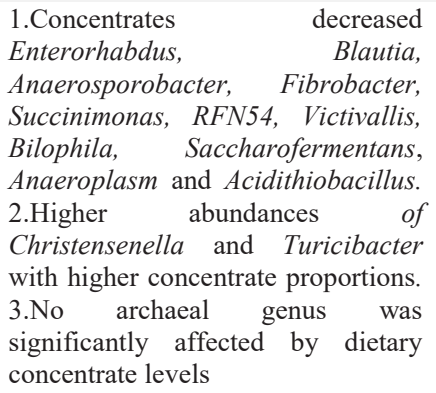 & $\begin{array}{l}\text { Zhang et al., } \\
2017\end{array}$ \\
\hline
\end{tabular}


A later study observed higher $\mathrm{CH}_{4}$ production per DMI in heifers (aged 9 to 10 months) compared with adult cows (aged 45-65 months and 96-120 months), and this difference in $\mathrm{CH}_{4}$ production per DMI was considered to be influenced by developmental physiological changes related to rumen fermentation (Liu et al., 2017). This study also observed changing correlations among bacterial and archaeal phylotypes with increasing age. To this end, Prevotella 2 was strongly correlated with Methanobrevibacter in heifers (Liu et al., 2017). In older cows (96-120 months) Succinivibrio showed an association with Methanobrevibacter (Liu et al., 2017). Network interaction analysis further showed that Prevotella 2 was replaced by a new network cluster of Succinivibrio 1, Ruminobacter 1, Ruminococcus 1 and Bacillus 1 (Liu et al., 2017). This shift may account for the age-related difference in rumen fermentation and $\mathrm{CH}_{4}$ production. Prevotella 2 and Succinivibrio both are known to produce propionate, with propionate production competing with methanogens for hydrogen utilization (Denman et al., 2015), potentially explaining the differences in $\mathrm{CH}_{4}$ production efficiencies at different ages. A few other bacterial taxa that significantly differed with age included Flavonifractor, Ruminococcus and Ruminobacter. Of these, Flavonifractor, which produces acetic and butyric acid as major end products of sugar fermentation (Carlier, 2010), was also positively correlated with Methanobrevibacter (Liu et al., 2017) in addition to the previously described Prevotella 2 and Succinivibrio.

Ruminant studies have also investigated the impact of host genetics in determining key activities of rumen microbiota by looking at the effect of breed type. Differences in the bacterial and archaeal community structure have been observed in Holstein and Jersey cows (King et al., 2011). Based on archaeal 16S rRNA gene clone library analysis, a total of 20 OTUs were common to both the breeds, while 23 OTUs (36 sequences) were found only in the Holstein cows and 12 OTUs (18 sequences) were found only in the Jersey cows. Methanobrevibacter ruminantium and Methanobrevibacter millerae were present at very similar frequencies in lactating Jersey cows, whereas populations with 95 to $97.9 \% 16 \mathrm{~S}$ rRNA gene identity to Methanobrevibacter spp. were more abundant (53.0\% vs. $47.8 \%$ ) in Holstein cows compared to Jersey cows (King et al., 2011). Family level classification of bacteria showed higher relative abundance of OTU's belonging to the Lachnospiraceae and p-253418B5 (rumen fibrolytic and cellulolytic populations) in Holstein cows as compared to Jersey cows. Additionally, an OTU belonging to the Succinivibrionaceae was more abundant in Jersey cows as compared to the Holstein cows (King et al., 2011). Whereas the study did not assess potential links of microbiota composition to $\mathrm{CH}_{4}$ emissions, this was done in a recent 
study on Aberdeen Angus (AA) and Limousin (LIM) sire breed types (Roehe et al., 2016). Significant differences in daily $\mathrm{CH}_{4}$ emissions between the breeds (184 g/day for AA vs. 164 g/day for LIM) were concluded to be due to higher feed intake of AA as compared to LIM. The study also observed higher archaea:bacteria ratios in rumen contents of AA animals compared to LIM animals with both forage and concentrate based diets, and suggested the ratio to be a selection criterion for reduction of $\mathrm{CH}_{4}$ (Roehe et al., 2016).

\section{Host specificity (Animal individuality)}

The rumen of cattle contains a core microbiota which includes Prevotella, Butyrivibrio and Ruminococcus, as well as unclassified Lachnospiraceae, Ruminococcaceae, Bacteroidales, and Clostridiales (Henderson et al., 2015a), with a large variability in their relative abundance. Other non-core microbial taxa also fluctuate in relative abundance. This is particularly obvious in terms of the rumen bacterial species, although inter-animal variation has also been observed in methanogenic archaeal and protozoal communities (Zhou et al., 2012). This suggests that the host has a controlling effect on its own rumen microbial community (Ribeiro et al., 2017). Additionally, the rumen microbiota is also characterized by functional redundancy and resilience (Weimer, 2015) meaning there is an overlap of functions among different species and that there is resistance or capacity to recover from perturbations.

Moreover, lowered $\mathrm{CH}_{4}$ emission has most often been related to differences in the size/volume of the rumen (Goopy et al., 2014), and a smaller rumen size has been associated with faster passage rate of the feed (Smuts et al., 1995; Barnett et al., 2012). As a result less feed is digested inside the rumen, resulting in less $\mathrm{CH}_{4}$. Therefore, one should be careful in interpreting microbiota analyses which can be associated with methanogenesis but not necessarily be the cause of decrease in methanogenesis. Furthermore, differences with respect to the time between regurgitation and sampling can also affect animal to animal variation of the rumen microbiota (Pinares-Patino et al., 2007). The lactation status of a cow can also affect $\mathrm{CH}_{4}$ production due to increasing nutritional demands, leading to increase in feed intake and meal frequency but shortened duration. This results in shortened rumination and retention times in the rumen causing lower fibre digestibility and lower $\mathrm{CH}_{4}$ yield as compared to dry cows (Gibb et al., 1999).

\section{METHODS TO STUDY RUMEN MICROBIOTA}




\section{Culturing techniques}

Traditionally, rumen microbiota was studied via cultivation based techniques. Microbial cultivation has enabled to observe different microbial morphologies, physiology and metabolism involved in plant polymer degradation (Hungate, 1966a). In the late 1970's, researchers also used microscopy to distinguish between different microorganisms based on their different sizes. For instance, Lampropedia (1 to $1.5 \mu \mathrm{m}$ by 1 to $2.5 \mu \mathrm{m}$ ), Oscillospira (3 to $6 \mu \mathrm{m}$ by 10 to $40 \mu \mathrm{m}$ ) and Quinella (2.5 to $3 \mu \mathrm{m}$ by 4 to $9 \mu \mathrm{m})$ have different sizes and could be distinguished using microscopy (Clarke, 1979). Lampropedia and Oscillospira were also seen associated with plant fragments and the epidermial plant cells which were digested partially, although the attraction of these two bacteria to the cuticular surface of the plant leaf has not yet been explained fully (Clarke, 1979). Additionally, culturing techniques using roll tube methods were introduced by Hungate (Hungate et al., 1969) and modified (Eller et al., 1971) for isolation and enumeration of anaerobic microbes. Later Olsen in 1992, developed a modified agar bottle plate for cultivation and isolation of strict anaerobes. The development of plastic anaerobic glove boxes further facilitated colony isolation, which enabled researchers to perform streak and spread plating and dispensing of medium within an anoxic environment. Besides isolating microorganisms, direct counting of microbial cells was introduced in the late 1980's to provide total counts of m icrobes by roll tubes as well as MPN (m ost probable number) approaches. However, this was only possible for studying the rumen liquid associated microorganisms but is not suitable for the microorganisms associated with the fibrous content in the rumen (Zhou et al., 2015).

The fibrous content is problematic to study with culture-based techniques due to microbial cells being tightly attached to the biomass, and as a consequence, many of the fibre associated microorganisms remain uncultured (Krause et al., 2003). Fibre-degrading bacteria, such as F. succinogenes and Ruminococcus spp. have been isolated and have been extensively studied in terms of their fibre degrading ability and mechanisms. Most recently, media supplemented with azo-carboxymethyl cellulose have been utilized to culture cellulolytic rumen bacteria, identifying members of the Firmicutes as the major fibre degrading bacteria. Additionally, members of Clostridium cluster IV have been identified to degrade filter paper, whereas Butyrivibrio and Pseudobutyrivibrio have been identified to degrade xylan and carboxymethyl cellulose, suggesting that these rumen bacteria are involved in fibre degradation (Nyonyo et al., 2014). 
Enrichment batch cultivation would normally result in fast growers unless the conditions are selective (for instance different $\mathrm{pH}$ or temperature). An alternative to avoid this would be dilution to extinction which would give abundant microbes a chance to grow for instance in biofilms that would allow to enrich for slow growing microbes best adapted to the conditions independent of growth rates. Further steps of isolation that include plating the culture on autoclaved solid agar can produce by-products (by autoclaving the agar) that kill many cells and prevent the cultivation of sensitive microorganisms (Tanaka et al., 2014). As a result nowadays researchers have focussed on using gellan gum instead of agar. However, irrespective of the different strategies used to culture, there is lack in cultivating all - a phenom enon that has been coined as "The Great Plate Count Anom aly"(Tanaka et al., 2014). This limits culture based techniques to serve as a tool to study the total rumen microbiota in detail as it identifies only a smaller subset of microbes.

\section{Molecular techniques}

To overcome the limitations associated with cultivation based techniques, researchers started to use culture independent tools, mostly including fingerprinting and sequencing techniques based on the small sub-unit rRNA (16S/18S). Moreover, molecular techniques enable quantification of rumen microbial populations using quantitative PCR (qPCR) with great sensitivity and precision (Singh et al., 2014). qPCR has been used to estimate the size of bacterial, archaeal, anaerobic fungal and protozoal populations (Sylvester, 2004; Denman, 2006; Jeyanathan et al., 2011). Fingerprinting techniques have been used to profile microbial communities, with a wide range of different techniques used that all rely on separation of PCR-amplified DNA fragments that differ in sequence and/or size: temperature gradient gel electrophoresis (TGGE), temporal temperature gradient gel electrophoresis (TTGGE), single strand conformation polymorphism (SSCP), terminal-restriction fragment length polymorphism (T-RFLP) analysis, automated ribosomal intergenic spacer analysis (ARISA) and denaturing gradient gel electrophoresis (DGGE). Of all these methods, DGGE has probably been most extensively used for animal gastrointestinal tract microbiota analysis. In addition to the separation of amplicons that differ in nucleotide sequence, the intensities of a band can also be used as a semi-quantitative measure for the relative abundance of a certain sequence in the community. Furthermore, individual bands can be excised from the gel and re-amplified for sequencing and for identification of microbes. However, this technique normally allows to detect microbes only above a relative abundance of $1 \%$. In order to further 
increase specificity and sensitivity of molecular fingerprinting, phylogenetic microarrays were developed that were generally based on DNA oligonucleotide probes attached to a solid surface, providing more comprehensive insights into the structure and population dynamics of complex microbial eco-systems. One problem with microarrays is that they will only identify microbes for which probes have been included on the array, and thus they are limited in the detection of yet unknown microbial taxa. This limitation of microarrays has brought nextgeneration technology sequencing methods such as 454-pyrosequencing, and Illumina MiSeq and HiSeq sequencing into attention. These sequencing methods are able to provide novel insights into the composition of microbial communities, including those that reside in the rumen (Zoetendal et al., 2004; Deng et al., 2008) as they provide more comprehensive coverage of yet undescribed microbial taxa. It should be noted, however, that taxonomic annotation at species and even genus level is often problematic as the resolution of these short read sequencing methods is generally not good.

\section{EXPERIMENTAL FACTORS AFFECTING THE ANALYSIS OF RUMEN MICROBIOTA}

With an increasing number of ruminal microbial genomes becoming available it is easier to understand their physiology, how these microbes interact within the rumen and their impact on ruminant health and animal performance. To be able to study the microbial composition and function, it is important to validate the methods that are used.

\section{Sampling and Sample storage}

Sampling techniques, sample storage, sample handling and collection times have been shown to affect the observed rumen microbial community structure (Geishauser and Gitzel, 1996; Fliegerova et al., 2014). Nevertheless, until now, there has been no standardized rumen sample storage method nor subsequent nucleic acid extraction methods (Granja-Salcedo et al., 2017). In a recent study, rumen samples were collected using oral tubing and the fibrous fraction was collected via a fistula (Henderson et al, 2013). The fraction after squeezing provided a liquid fraction for further comparison. The samples were frozen, freeze-dried and homogenized prior to DNA extraction. With respect to the observed composition of the bacterial community, oral tubing derived samples were characterized by higher relative abundance of Prevotellaceae, whereas Lachnospiraceae (Butyrivibrio and Coprococcus) were observed at lower relative abundance as compared to the samples collected through the rumen 
fistula. Furthermore, higher abundance of Methanobrevibacter ruminantium was observed in the samples collected through the fistula (Henderson et al, 2013). In addition to the effect of DNA extraction methods, the influence of sampling (cheese cloth squeezed, centrifuged and filtered) and sample storage at room temperature versus $-80^{\circ} \mathrm{C}$ was investigated by Fliegerova et al. (2014). It was concluded that the bacterial diversity was optimally represented by using a bead beating based DNA extraction method with cheesecloth sieved rumen contents (Fliegerova et al., 2014).

In a recent study, the effect of three storage methods and four storage times on ruminal fibrous content were evaluated based on quality parameters and yield of metagenomic DNA extracted as well as the observed composition of the rumen bacterial community (GranjaSalcedo et al., 2017). In that study, rumen content samples were either pelleted or lyophilized and stored for three, six or 12 months. The pelleted samples were stored at $-80{ }^{\circ} \mathrm{C}$ and $-20{ }^{\circ} \mathrm{C}$ whereas the lyophilized samples were only stored at $-20^{\circ} \mathrm{C}$. The study concluded that the storage time significantly reduced the yield of DNA extracted. Higher relative abundances of Ruminococcaceae was observed in both, pelleted and lyophilized samples stored at $-20{ }^{\circ} \mathrm{C}$ and $-80{ }^{\circ} \mathrm{C}$ while Lachnospiraceae remain unchanged in all samples compared to its controls. Relative abundances of Prevotellaceae were higher in pelleted samples stored at -20 and -80 ${ }^{\circ} \mathrm{C}$ while they were lower in lyophilized samples stored at $-20{ }^{\circ} \mathrm{C}$ as compared to its control. Furthermore, the study of (Petri et al., 2013) showed that the sample storage and cryoprotectants (in PBS-glycerol or $-80{ }^{\circ} \mathrm{C}$ storage) did not affect the bacterial composition structure.

\section{DNA extraction method}

DNA extraction is a critical step in enabling accurate assessment of the complexity of the rumen microbiota. Many studies have observed significant differences in rumen microbial community structure due to biases of the extraction methods used ( $\mathrm{Yu}$ and Morrison, 2004; Henderson et al, 2013). An important aspect of DNA extraction has always been the amount of DNA yielded, however, there are cases when certain bacteria are harder to lyse than others. Therefore, in order to allow for direct comparison of rumen community structure between different studies, standardizing DNA extraction methods is crucial. In the study of Henderson (2013), the choice of extraction method affected both the observed bacterial composition as well as that of the archaeal fraction. Methanoplasmatales as Rumen Cluster $\mathrm{C}$ were found at lower abundance in DNA extracted using a bead beating method as opposed to less physical 
methods (PSP ${ }^{\circledR}$ Spin Stool DNA Kit). In turn, efficient lysis of Methanosphaera cells was shown to require mechanical disruption (Henderson et al, 2013). Overall the study showed that the method with less physical disruption was associated with lower DNA quality with a bias towards the Gram negative Bacteroidetes (Henderson et al, 2013). Another aspect is that the extraction method can also be affected by the nature of sample. Therefore, depending on the nature of the sample, the mechanical disruption cycles should be optimized.

\section{Textbox 1: Top Institute Food and Nutrition project Reduced methane emissions from} dairy cows

This research was conducted within the framework of a TI Food and Nutrition (TIFN) funded collaborative interdisciplinary ruminant project focussed on reducing methane emission from dairy cows. The TIFN project included aspects of microbiology, animal nutrition, animal genomics and metabolomics. The TIFN project had five work packages (WP):

1. Indicator for methane emission in milk

2. Explore the (genetic) variation in methane emission in the Dutch dairy cow population

3. Characterizing rumen microbiota composition and studying fibre attachment from dairy cows

4. Understand the interplay between cow (genetics), rumen microbiota and feed by performing an experiment in climate respiration chambers.

5. Developing a model of methane emission in dairy cows 


\section{AIM AND OUTLINE OF THE THESIS}

The aim of the research described in this thesis is to characterize rumen microbial composition from Holstein Friesian dairy cows, including potential biases associated with DNA extraction, differences in composition between different rumen fractions as well as the impact of diet. In addition, this thesis also looked at the fibre fermentation, including the enrichment, isolation and identification of potential fibre attached rumen bacteria.

Chapter 1 gives an introduction on the role of microbiota in rumen feed degradation with a particular emphasis on $\mathrm{CH}_{4}$ as well as the different microbiota associated with rumen fluid and the fibrous fraction. The pros and the cons of culture dependent and culture independent methods are discussed, along with strategies used to date for improving the rumen fermentation efficiency and mitigating $\mathrm{CH}_{4}$. Current understanding of experimental, dietary and animal associated factors that influence rumen microbiota, fermentation patterns and enteric methanogenesis are also reviewed.

Chapter 2 addresses the impact of DNA extraction methods on the observed rumen microbial community structure from four Holstein-Friesian dairy cows fed different ratios of grass and maize silage. To this end, both the liquid and the fibrous fraction were sampled in order to obtain a more comprehensive picture of ruminal microbial community composition. Focus is given to DNA extraction methods routinely used at the Laboratory of Microbiology, Wageningen University, for matrices ranging from mammalian intestinal content and faeces, marine invertebrates to soil and sediment samples. The resulting microbial composition using four DNA extraction methods was assessed using 454 pyrosequencing of barcoded PCR amplicons targeting bacteria, archaea and anaerobic fungi.

Subsequently, the impact of diet (different ratios of grass and maize silage) and time after introduction of the different diets on the microbial community structure has been evaluated in Chapter 3. The aim of this study was (1) to investigate the effect of replacing fibre-rich grass silage with starch-rich maize silage on the rumen bacterial and archaeal diversity using samples collected after 10 and 17 days of the diets being fed, and (2) to place the findings in context of ruminal fermentation and previously reported $\mathrm{CH}_{4}$ emission findings (van Gastelen et al., 2015). 
Besides increasing the knowledge on ruminal microbial composition using culture independent techniques, there has also been a focus on enriching ruminal fibre associated populations responsible for fibre degradation and/or attachment in chapter 4. Pre-autoclaved ruminal fibres were used as a matrix for attachment and as carbon source to identify fibre attached or associated populations. We enriched fibre associated populations, however, we were not able to dem onstrate the enriched consortia's distinct role in fibre attachm ent.

In chapter 5, an effort to isolate a fibre attached microorganism was made by using preautoclaved ruminal fibre as a source of carbon for the growth of biomass. An effective method was to use methyl cellulose as a way to first detach the biomass from the fibres and use the suspension for a classical enrichment and isolation approach. A novel bacterium, Propionibacterium ruminifibrarum strain $\mathrm{JV}^{\mathrm{T}}$ was isolated, that was most closely related to Propionibacterium australiense.

The final chapter of this thesis, chapter 6, provides an integrated overview and discussion of results obtained in the research described in this thesis as well as findings from other studies. In addition, this chapter provides future directions of research in the rumen microbial manipulations to mitigate $\mathrm{CH}_{4}$ and improve ruminal fermentation. 


\section{REFERENCES}

Agarwal, N., Kamra, D.N., and Chaudhary, L.C. (2015). Rumen microbial ecosystem of domesticated ruminants. Rumen Microbiology: From Evolution to Revolution, 17-30. doi: 10.1007/978-81-322-2401-3_2.

Angela, R.M., Jean-Pierre, J., and Newbold, J.R. (2000). Methane production by ruminants: its contribution to global warming. Ann. Zootech. 49(3), 231-253. doi: 10.1051/animres:2000119

Barnett, M.C., Goopy, J.P., McFarlane, J.R., Godwin, I.R., Nolan, J.V., and Hegarty, R.S. (2012). Triiodothyronine influences digesta kinetics and methane yield in sheep. Animal Prod Sci 52(6-7), 572-577. doi: 10.1071/AN11303.

Belanche, A., Doreau, M., Edwards, J.E., Moorby, J.M., Pinloche, E., and Newbold, C.J. (2012). Shifts in the rumen microbiota due to the type of carbohydrate and level of protein ingested by dairy cattle are associated with changes in rumen fermentation. $J$ Nutr 142(9), 1684-1692. doi: 10.3945/jn.112.159574.

Benchaar, C., Hassanat, F., Gervais, R., Chouinard, P.Y., Petit, H.V., and Masse, D.I. (2014). Methane production, digestion, ruminal fermentation, nitrogen balance, and milk production of cows fed corn silage- or barley silage-based diets. J Dairy Sci 97(2), 961-974. doi: 10.3168/jds.2013-7122.

Boadi, D., Benchaar, C., Chiquette, J., and Masse, D. (2004). Mitigation strategies to reduce enteric methane emissions from dairy cows: Update review. Canad J of Anim Sci 84(3), 319-335. doi: 10.4141/A03-109.

Carlier, J.P., Bedora-Faure, M., K'Ouas, G., Alauzet, C., Mory, F (2010). Proposal to unify Clostridium orbiscindens Winter et al. 1991 and Eubacterium plautii (Seguin 1928) Hofstad and Aasjord 1982, with description of Flavonifractor plautii gen. nov., comb. nov., and reassignment of Bacteroides capillosus to Pseudoflavonifractor capillosus gen. nov., comb. nov. Int J Syst Evol Microbiol 60(Pt 3), 585-590. doi: 10.1099/ijs.0.016725-0.

Chen, M., and Wolin, M.J. (1979). Effect of monensin and lasalocid-sodium on the growth of methanogenic and rumen saccharolytic bacteria. App Environ Microbiol 38(1), 72-77. doi: 0099-2240/79/07-0072/06\$02.00/0.

Clarke, R.T. (1979). Niche in pasture-fed ruminants for the large rumen bacteria Oscillospira, Lampropedia, and Quin's and Eadie's Ovals. Appl Environ Microbiol 37(3), 654-657. doi: 0099-2240/79/03-0654/04\$02.00/0.

Danielsson, R., Dicksved, J., Sun, L., Gonda, H., Muller, B., Schnurer, A., et al. (2017). Methane production in dairy cows correlates with rumen methanogenic and bacterial community structure. Front Microbiol 8, 226. doi: 10.3389/fmicb.2017.00226.

De Menezes, A.B., Lewis, E., O'Donovan, M., O'Neill, B.F., Clipson, N., and Doyle, E.M. (2011). Microbiome analysis of dairy cows fed pasture or total mixed ration diets. FEMS Microbiol Ecol 78(2), 256-265. doi: 10.1111/j.1574-6941.2011.01151.x.

Dean, J.F., Middelburg, J.J., Rockmann, T., Aerts, R., Blauw, L.G., Egger, M., et al. (2018). Methane feedbacks to the global climate system in a warmer world. Rev of Geophys 56(1), 207-250. doi: 10.1002/2017RG000559.

Dehority, B.A. (2002). Gastrointestinal tracts of herbivores, particularly the ruminant: Anatomy, physiology and microbial digestion of plants. J Appl Anim Res 21(2), 145160. doi: 10.1080/09712119.2002.9706367.

Deng, W., Xi, D., Mao, H., and Wanapat, M. (2008). The use of molecular techniques based on ribosomal RNA and DNA for rumen microbial ecosystem studies: a review. Mol Biol Rep 35(2), 265-274. doi: 10.1007/s11033-007-9079-1. 
Denman, S.E., Martinez Fernandez, G., Shinkai, T., Mitsumori, M., and McSweeney, C.S. (2015). Metagenomic analysis of the rumen microbial community following inhibition of methane formation by a halogenated methane analog. Front Microbiol 6, 1087. doi: 10.3389/fmicb.2015.01087.

Denman, S.E.M., C. S. (2006). Development of a real-time PCR assay for monitoring anaerobic fungal and cellulolytic bacterial populations within the rumen. FEMS Microbiol Ecol 58(3), 572-582. doi: 10.1111/j.1574-6941.2006.00190.x.

Duthie, C.A., Haskell, M., Hyslop, J.J., Waterhouse, A., Wallace, R.J., Roehe, R., et al. (2017). The impact of divergent breed types and diets on methane emissions, rumen characteristics and performance of finishing beef cattle. Animal 11(10), 1762-1771. doi: $10.1017 / \mathrm{s} 1751731117000301$.

Eller, C., Crabill, M.R., and Bryant, M.P. (1971). Anaerobic roll tube media for nonselective enumeration and isolation of bacteria in human feces. Appl Microbiol 22(4), 522-529.

Ellis, J.L., Dijkstra, J., Bannink, A., Kebreab, E., Hook, S.E., Archibeque, S., et al. (2012). Quantifying the effect of monensin dose on the rumen volatile fatty acid profile in high-grain-fed beef cattle. J Anim Sci 90(8), 2717-2726. doi: 10.2527/jas.2011-3966.

Fliegerova, K., Tapio, I., Bonin, A., Mrazek, J., Callegari, M.L., Bani, P., et al. (2014). Effect of DNA extraction and sample preservation method on rumen bacterial population. Anaerobe 29, 80-84. doi: 10.1016/j.anaerobe.2013.09.015.

Fonty, G., and Chaucheyras-Durand, F. (2006). Effects and modes of action of live yeasts in the rumen. Biologia 61(6), 741-750. doi: DOI 10.2478/s11756-006-0151-4.

Forster, P.R., V., Artaxo, P., Berntsen, T., Betts, R., Fahey, D.W., Haywood, J., et al. (2007). Changes in atmospheric constituents and in radiative forcing. Chapter 2. In: Solomon, S., Qin, D., Manning, M., Chen, Z., Marquis, M., Averyt, K.B., Tignor, M., Miller, H.L. (Eds.), Climate Change 2007: The physical science basis. Contribution of working group I to the fourth assessment report of the intergovernmental panel on climate change. cambridge, University Press, Cambridge, UK/New York, NY, USA. Clim Change.

Fouts, D.E., Szpakowski, S., Purushe, J., Torralba, M., Waterman, R.C., MacNeil, M.D., et al. (2012). Next generation sequencing to define prokaryotic and fungal diversity in the bovine rumen. PLoS One 7(11), e48289. doi: 10.1371/journal.pone.0048289.

Friedman, N., Jami, E., and Mizrahi, I. (2017). Compositional and functional dynamics of the bovine rumen methanogenic community across different developmental stages. Environ Microbiol 19(8), 3365-3373. doi: 10.1111/1462-2920.13846.

Geishauser, T., and Gitzel, A. (1996). A comparison of rumen fluid sampled by oro-ruminal probe versus rumen fistula. Sma Rumin Res 21(1), 63-69. doi: 10.1016/09214488(95)00810-1.

Gibb, M.J., Huckle, C.A., Nuthall, R., and Rook, A.J. (1999). The effect of physiological state (lactating or dry) and sward surface height on grazing behaviour and intake by dairy cows. Applied Animal Behaviour Science 63(4), 269-287. doi: 10.1016/S01681591(99)00014-3.

Goel, G., Makkar, H.P., and Becker, K. (2009). Inhibition of methanogens by bromochloromethane: effects on microbial communities and rumen fermentation using batch and continuous fermentations. Br J Nutr 101(10), 1484-1492. doi: $10.1017 /$ S0007114508076198.

Goopy, J.P., Donaldson, A., Hegarty, R., Vercoe, P.E., Haynes, F., Barnett, M., et al. (2014). Low-methane yield sheep have smaller rumens and shorter rumen retention time. $\mathrm{Br} J$ Nutr 111(4), 578-585. doi: 10.1017/S0007114513002936.

Granja-Salcedo, Y.T., Ramirez-Uscategui, R.A., Machado, E.G., Duarte Messana, J., Takeshi Kishi, L., Lino Dias, A.V., et al. (2017). Studies on bacterial community composition 
are affected by the time and storage method of the rumen content. PLoS One 12(4), e0176701. doi: 10.1371/journal.pone.0176701.

Gruninger, R.J., Puniya, A.K., Callaghan, T.M., Edwards, J.E., Youssef, N., Dagar, S.S., et al. (2014). Anaerobic fungi (phylum Neocallimastigomycota): advances in understanding their taxonomy, life cycle, ecology, role and biotechnological potential. Fems Microbiol Ecol 90(1), 1-17. doi: 10.1111/1574-6941.12383.

Hansen, J., Sato, M., Ruedy, R., Lacis, A., and Oinas, V. (2000). Global warming in the twenty-first century: an alternative scenario. Proc Natl Acad Sci U S A 97(18), 98759880. doi: 10.1073/pnas.170278997.

Hassanat, F., Gervais, R., Julien, C., Masse, D.I., Lettat, A., Chouinard, P.Y., et al. (2013). Replacing alfalfa silage with corn silage in dairy cow diets: Effects on enteric methane production, ruminal fermentation, digestion, $\mathrm{N}$ balance, and milk production. J Dairy Sci 96(7), 4553-4567. doi: 10.3168/jds.2012-6480.

Henderson, G., Cox, F., Ganesh, S., Jonker, A., Young, W., Janssen, P.H., et al. (2015). Rumen microbial community composition varies with diet and host, but a core microbiome is found across a wide geographical range. Sci Rep 5, 14567. doi: Artn1456710.1038/Srep14567.

Henderson, G., Cox, F., Kittelmann, S., Miri, V. H., Zethof, M., Noel, S. J., Waghorn, G. C., Janssen, P. H., Kittelmann, S., Miri, V. H., Zethof, M., Noel, S. J., Waghorn, G. C., Janssen, P. H (2013). Effect of DNA extraction methods and sampling techniques on the apparent structure of cow and sheep rumen microbial communities. PLoS One 8(9), e74787. doi: 10.1371/journal.pone.0074787.

Ho, Y.W., Abdullah, N., Jalaludin, S (1988). Penetrating structures of anaerobic rumen fungi in cattle and swamp buffalo. Microbiol 134(1), 177-181. doi: 10.1099/00221287-134$1-177$.

Hook, S.E., Wright, A.D., and McBride, B.W. (2010). Methanogens: methane producers of the rumen and mitigation strategies. Archaea 2010, 945-785. doi: $10.1155 / 2010 / 945785$.

Hristov, A.N., Ott, T., Tricarico, J., Rotz, A., Waghorn, G., Adesogan, A., et al. (2013). Mitigation of methane and nitrous oxide emissions from animal operations: III. A review of animal management mitigation options. J Anim Sci 91(11), 5095-5113. doi: 10.2527/jas.2013-6585.

Huhtanen, P., Ramin, M., and Cabezas-Garcia, E.H. (2016). Effects of ruminal digesta retention time on methane emissions: a modelling approach. Animal Production Science 56(2-3), 501-506. doi: 10.1071/AN15507.

Hungate, R.E. (1966). in The Rumen and its Microbes. Academic Press

Hungate, R.E., Norris, J.R., and Ribbons, D.W. (1969). Chapter IV A roll tube method for cultivation of strict anaerobes," in Methods in Microbiology. Academic Press, 117132.

Huws, S.A., Edwards, J.E., Creevey, C.J., Rees Stevens, P., Lin, W., Girdwood, S.E., et al. (2016). Temporal dynamics of the metabolically active rumen bacteria colonizing fresh perennial ryegrass. FEMS Microbiol Ecol 92(1). doi: 10.1093/femsec/fiv137.

Jami, E., Israel, A., Kotser, A., and Mizrahi, I. (2013). Exploring the bovine rumen bacterial community from birth to adulthood. ISME J 7(6), 1069-1079. doi: 10.1038/ismej.2013.2.

Janssen, P.H., and Kirs, M. (2008). Structure of the archaeal community of the rumen. Appl Environ Microbiol 74(12), 3619-3625. doi: 10.1128/AEM.02812-07.

Jeyanathan, J., Kirs, M., Ronimus, R.S., Hoskin, S.O., and Janssen, P.H. (2011). Methanogen community structure in the rumens of farmed sheep, cattle and red deer fed different diets. FEMS Microbiol Ecol 76(2), 311-326. doi: 10.1111/j.1574-6941.2011.01056.x. 
Jeyanathan, J., Martin, C., and Morgavi, D.P. (2014). The use of direct-fed microbials for mitigation of ruminant methane emissions: a review. Animal 8(2), 250-261. doi: 10.1017/S1751731113002085.

Ji, S., Zhang, H., Yan, H., Azarfar, A., Shi, H., Alugongo, G., et al. (2017). Comparison of rumen bacteria distribution in original rumen digesta, rumen liquid and solid fractions in lactating Holstein cows. J Anim Sci Biotechnol 8(1), 16. doi: 10.1186/s40104-0170142-z.

Jin, D., Zhao, S.G., Zhang, Y.D., Sun, P., Bu, D.P., Beckers, Y., et al. (2016). Diversity shifts of rumen bacteria induced by dietary forages in dairy cows and quantification of the changed bacteria using a new primer design strategy. J Integrat Agri 15(11), 25962603. doi: 10.1016/S2095-3119(16)61346-1.

Jin, W., Cheng, Y.F., Mao, S.Y., and Zhu, W.Y. (2011). Isolation of natural cultures of anaerobic fungi and indigenously associated methanogens from herbivores and their bioconversion of lignocellulosic materials to methane. Bioresour Technol 102(17), 7925-7931. doi: 10.1016/j.biortech.2011.06.026.

Joblin, K.N. (1989). Physical disruption of plant fibre by rumen fungi of the Sphaeromonas group. The roles of protozoa and fungi in ruminant digestion (NolanJVLengRADemeyerDI, eds), pp. 259-260. Penambul Books, Armidale.

Khorrami, B., Vakili, A.R., Mesgaran, M.D., and Klevenhusen, F. (2015). Thyme and cinnamon essential oils: Potential alternatives for monensin as a rumen modifier in beef production systems. Anim Feed Sci and Techn 200, 8-16. doi: 10.1016/j.anifeedsci.2014.11.009.

King, E.E., Smith, R.P., St-Pierre, B., and Wright, A.D. (2011). Differences in the rumen methanogen populations of lactating Jersey and Holstein dairy cows under the same diet regimen. Appl Environ Microbiol 77(16), 5682-5687. doi: 10.1128/AEM.0513011.

Kittelmann, S., Pinares-Patino, C.S., Seedorf, H., Kirk, M.R., Ganesh, S., McEwan, J.C., et al. (2014). Two different bacterial community types are linked with the low-methane emission trait in sheep. PLoS One 9(7), e103171. doi: 10.1371/journal.pone.0103171.

Klevenhusen, F., Petri, R.M., Kleefisch, M.T., Khiaosa-Ard, R., Metzler-Zebeli, B.U., and Zebeli, Q. (2017). Changes in fibre-adherent and fluid-associated microbial communities and fermentation profiles in the rumen of cattle fed diets differing in hay quality and concentrate amount. FEMS Microbiol Ecol 93(9). doi: 10.1093/femsec/fix 100.

Knight, T., Ronimus, R.S., Dey, D., Tootill, C., Naylor, P., Evans., et al. (2011). Chloroform decreases rumen methanogenesis and methanogen populations without altering rumen function in cattle. Anim Feed Sci and Tech 166-67, 101-112. doi: 10.1016/j.anifeedsci.2011.04.059.

Krause, D.O., Denman, S.E., Mackie, R.I., Morrison, M., Rae, A.L., Attwood, G.T., et al. (2003). Opportunities to improve fiber degradation in the rumen: microbiology, ecology, and genomics. FEMS Microbiol Rev 27(5), 663-693. doi: 10.1016/s01686445(03)00072-x.

Latham, E.A., Anderson, R.C., Pinchak, W.E., and Nisbet, D.J. (2016). Insights on alterations to the rumen ecosystem by nitrate and nitrocompounds. Front Microbiol 7, 228. doi: 10.3389/fmicb.2016.00228.

Lee, C., and Beauchemin, K.A. (2014). A review of feeding supplementary nitrate to ruminant animals: nitrate toxicity, methane emissions, and production performance. Canad J Anim Sci 94(4), 557-570. doi: 10.4141/Cjas-2014-069. 
Liu, C., Meng, Q., Chen, Y., Xu, M., Shen, M., Gao, R., et al. (2017). Role of Age-Related Shifts in Rumen Bacteria and Methanogens in Methane Production in Cattle. Front Microbiol 8, 1563. doi: 10.3389/fmicb.2017.01563.

Lopes, J.C., De Matos, L.F., Harper, M.T., Giallongo, F., Oh, J., Gruen, D., et al. (2016). Effect of 3-nitrooxypropanol on methane and hydrogen emissions, methane isotopic signature, and ruminal fermentation in dairy cows. J Dairy Sci 99(7), 5335-5344. doi: 10.3168/jds.2015-10832.

M Ross, E., Moate, P., Marett, L., Cocks, B., and J Hayes, B. (2013). Investigating the effect of two methane-mitigating diets on the rumen microbiome using massively parallel sequencing.

Mackie, R.I., White, B.A., Isaacson, R.E (1997). Gastrointestinal microbiology. New York: Chapman \& Hall J Applied Bacteriol.

Mao, S., Zhang, M., Liu, J., and Zhu, W. (2015). Characterising the bacterial microbiota across the gastrointestinal tracts of dairy cattle: membership and potential function. Sci Rep 5, 16116. doi: 10.1038/srep16116.

Mbanzamihigo, L., Van Nevel, C.J., and Demeyer, D.I. (1996). Lasting effects of monensin on rumen and caecal fermentation in sheep fed a high grain diet. Anim Feed Sci and Tech 62(2-4), 215-228. doi: 10.1016/S0377-8401(96)00966-2.

McAllister, T.A., Bae, H.D., Jones, G.A., and Cheng, K.J. (1994). Microbial attachment and feed digestion in the rumen. J Anim Sci 72(11), 3004-3018.

McAllister, T.A., Okine, E.K., Mathison, G.W., and Cheng, K.J. (1996). Dietary, environmental and microbiological aspects of methane production in ruminants. Canadian Journal of Animal Science 76(2), 231-243. doi: 10.4141/cjas96-035.

Molano, G., Clark, H., and Knight, T.W.C., A. (2006). Methane emissions from growing beef cattle grazing hill country pasture. Proc of the New Zeal Soci of Anim Produc 66, 172175.

Montzka, S.A., Dlugokencky, E.J., and Butler, J.H. (2011). Non-CO2 greenhouse gases and climate change. Nature 476(7358), 43-50. doi: 10.1038/nature10322.

Morgavi, D.P., Forano, E., Martin, C., Newbold, C. J (2010). Microbial ecosystem and methanogenesis in ruminants. Animal 4(7), 1024-1036. doi: 10.1017/S1751731110000546.

Nagaraja, T.G., Newbold, C.J., van Nevel, C.J., and Demeyer, D.I. (1997). "Manipulation of ruminal fermentation," in The rumen microbial ecosystem, eds. P.N. Hobson \& C.S. Stewart. (Dordrecht: Springer Netherlands), 523-632.

Nyonyo, T., Shinkai, T., and Mitsumori, M. (2014). Improved culturability of cellulolytic rumen bacteria and phylogenetic diversity of culturable cellulolytic and xylanolytic bacteria newly isolated from the bovine rumen. FEMS Microbiol Ecol 88(3), 528-537. doi: 10.1111/1574-6941.12318.

Okine, E.K., Mathison, G.W., and Hardin, R.T. (1989). Effects of changes in frequency of reticular contractions on fluid and particulate passage rates in cattle. J Anim Sci 67(12), 3388-3396. doi: 10.2527/jas1989.67123388x.

Orpin, C.G., Joblin, K.N (1997). The rumen anaerobic fungi. The rumen microbial ecosystem (HobsonPNStewartCS, eds), pp. 145-195. Chapman \& Hall, London.

Patra, A., Min, B.R., and Saxena, J. (2012). Dietary tannins on microbial ecology of the gastrointestinal tract in ruminants. Diet Phytochem and Mic, 237-262. doi: 10.1007/978-94-007-3926-0 8.

Patra, A., Park, T., Kim, M., and Yu, Z. (2017). Rumen methanogens and mitigation of methane emission by anti-methanogenic compounds and substances. J Anim Sci Biotechnol 8, 13. doi: 10.1186/s40104-017-0145-9. 
Petri, R.M., Schwaiger, T., Penner, G.B., Beauchemin, K.A., Forster, R.J., McKinnon, J.J., et al. (2013). Characterization of the core rumen microbiome in cattle during transition from forage to concentrate as well as during and after an acidotic challenge. PLoS One 8(12), e83424. doi: 10.1371/journal.pone.0083424.

Pinares-Patino, C.S., Waghorn, G.C., Machmuller, A., Vlaming, B., Molano, G., Cavanagh, A., et al. (2007). Methane emissions and digestive physiology of non-lactating dairy cows fed pasture forage. Canad J Anim Sci 87(4), 601-613. doi: 10.4141/Cjas06023.

Pitta, D.W., Parmar, N., Patel, A.K., Indugu, N., Kumar, S., Prajapathi, K.B., et al. (2014). Bacterial diversity dynamics associated with different diets and different primer pairs in the rumen of Kankrej cattle. PLoS One 9(11), e111710. doi: 10.1371/journal.pone.0111710.

Pope, P.B., Smith, W., Denman, S.E., Tringe, S.G., Barry, K., Hugenholtz, P., et al. (2011). Isolation of Succinivibrionaceae implicated in low methane emissions from Tammar wallabies. Science 333(6042), 646-648. doi: 10.1126/science.1205760.

Processi, E.F., Fontes, C.A.D., Vieira, R.A.M., Bendia, L.C.R., Rocha, T.C., Fernandes, A.M., et al. (2016). Degradability and kinetics of fibrous particles in cattle fed diets based on corn silage and concentrates with or without addition of lipids. Revis Bras De Zootec-Brazili J Anim Sci 45(12), 773-780. doi: 10.1590/S1806-92902016001200007.

Ribeiro, G.O., Oss, D.B., He, Z., Gruninger, R.J., Elekwachi, C., Forster, R.J., et al. (2017). Repeated inoculation of cattle rumen with bison rumen contents alters the rumen microbiome and improves nitrogen digestibility in cattle. Sci Rep 7(1), 1276. doi: 10.1038/s41598-017-01269-3.

Roehe, R., Dewhurst, R.J., Duthie, C.A., Rooke, J.A., McKain, N., Ross, D.W., et al. (2016). Bovine host genetic variation influences rumen microbial methane production with best selection criterion for low methane emitting and efficiently feed converting hosts based on metagenomic gene abundance. PLoS Genet 12(2), e1005846. doi: 10.1371/journal.pgen.1005846.

Romero-Perez, A., Okine, E.K., McGinn, S.M., Guan, L.L., Oba, M., Duval, S.M., et al. (2015). Sustained reduction in methane production from long-term addition of 3nitrooxypropanol to a beef cattle diet. J Anim Sci 93(4), 1780-1791. doi: $10.2527 /$ jas.2014-8726.

Rooke, J.A., Wallace, R.J., Duthie, C., McKain, N., Motta de Souza, S., Hyslop, J.J., et al. (2014). Hydrogen and methane emissions from beef cattle and their rumen microbial community vary with diet, time after feeding and genotype. Brit J Nutr 112(3), 398407. doi: 10.1017/S0007114514000932.

Singh, K.M., Pandya, P.R., Tripathi, A.K., Patel, G.R., Parnerkar, S., Kothari, R.K., et al. (2014). Study of rumen metagenome community using qPCR under different diets. Meta Gene 2, 191-199. doi: 10.1016/j.mgene.2014.01.001.

Smuts, M., Meissner, H.H., and Cronje, P.B. (1995). Retention time of digesta in the rumen: its repeatability and relationship with wool production of Merino rams. J Anim Sci 73(1), 206-210. doi: 10.2527/1995.731206x.

Steinfield, H., Gerber, P., Wassenaar, T., Castel, V., and De Haan, C. (2006). Livestock's long shadow: environmental issues and options. Food \& Agriculture Org.

Stewart, C.S., Flint, H.J., and Bryant, M.P. (1997). "The rumen bacteria," in The Rumen Microbial Ecosystem, eds. P.N. Hobson \& C.S. Stewart. (Dordrecht: Springer Netherlands), 10-72.

Swainson, N.M.H., S. O. , and Clark, H.L.V., N. (2007). The effect of age on methane emissions from young, weaned red deer (Cervus elaphus) stags grazing perennial-ryegrass (Lolium perenne)-based pasture. New Zealand Journal of Agricultural Research 50(3), 407-416. doi: 10.1080/00288230709510308. 
Sylvester, J.T., Karnati, S.K., Yu, Z., Morrison, M., Firkins, J.L (2004). Development of an assay to quantify rumen ciliate protozoal biomass in cows using real-time PCR. J Nutr 134(12), 3378-3384. doi: 10.1093/jn/134.12.3378.

Tanaka, T., Kawasaki, K., Daimon, S., Kitagawa, W., Yamamoto, K., Tamaki, H., et al. (2014). A hidden pitfall in the preparation of agar media undermines microorganism cultivability. Appl Environ Microbiol 80(24), 7659-7666. doi: 10.1128/AEM.0274114.

Tedeschi, L.O., Fox, D.G., and Tylutki, T.P. (2003). Potential environmental benefits of ionophores in ruminant diets. $J$ Environ Qual 32(5), 1591-1602. doi: 10.2134/jeq2003.1591.

Thoetkiattikul, H., Mhuantong, W., Laothanachareon, T., Tangphatsornruang, S., Pattarajinda, V., Eurwilaichitr, L., et al. (2013). Comparative analysis of microbial profiles in cow rumen fed with different dietary fiber by tagged $16 \mathrm{~S}$ rRNA gene pyrosequencing. Curr Microbiol 67(2), 130-137. doi: 10.1007/s00284-013-0336-3.

Valle, E.R., Henderson, G., Janssen, P.H., Cox, F., Alexander, T.W., and McAllister, T.A. (2015). Considerations in the use of fluorescence in situ hybridization (FISH) and confocal laser scanning microscopy to characterize rumen methanogens and define their spatial distributions. Can J Microbiol 61(6), 417-428. doi: 10.1139/cjm-20140873.

van Gastelen, S., Antunes-Fernandes, E.C., Hettinga, K.A., Klop, G., Alferink, S.J., Hendriks, W.H., et al. (2015). Enteric methane production, rumen volatile fatty acid concentrations, and milk fatty acid composition in lactating Holstein-Friesian cows fed grass silage- or corn silage-based diets. J Dairy Sci 98(3), 1915-1927. doi: $10.3168 /$ jds.2014-8552.

Wallace, R.J., Rooke, J.A., McKain, N., Duthie, C.A., Hyslop, J.J., Ross, D.W., et al. (2015). The rumen microbial metagenome associated with high methane production in cattle. BMC Genomics 16(1), 839. doi: 10.1186/s12864-015-2032-0.

Weimer, P.J. (2015). Redundancy, resilience, and host specificity of the ruminal microbiota: implications for engineering improved ruminal fermentations. Front Microbiol 6, 296. doi: 10.3389/fmicb.2015.00296.

Widyastuti, Y., Newbold, C.J., Stewart, C.S., and Orskov, E.R. (1995). Interactions between rumen anaerobic fungi and ciliate protozoa in the degradation of rice straw cell-walls. Lett in App Microbiol 20(1), 61-64. doi: 10.1111/j.1472-765X.1995.tb00408.x.

Williams, A.G.C., G. S. (1992). The Rumen Protozoa. New York: Springer-Verlag.

$\mathrm{Yu}, \mathrm{Z}$., and Morrison, M. (2004). Improved extraction of PCR-quality community DNA from digesta and fecal samples. Biotechniques 36(5), 808-812. doi: 10.2144/04365ST04.

Zhang, J., Shi, H., Wang, Y., Li, S., Cao, Z., Ji, S., et al. (2017). Effect of dietary forage to concentrate ratios on dynamic profile changes and interactions of ruminal microbiota and metabolites in holstein heifers. Front Microbiol 8(2206), 2206. doi: 10.3389/fmicb.2017.02206.

Zhang, R., Zhu, W., Zhu, W., Liu, J., and Mao, S. (2014). Effect of dietary forage sources on rumen microbiota, rumen fermentation and biogenic amines in dairy cows. J Sci Food Agric 94(9), 1886-1895. doi: 10.1002/jsfa.6508.

Zhou, M., Chen, Y., and Guan, L.L. (2015). Rumen microbiology: From evolution to revolution, New Delhi, India. Springer 20157996.

Zhou, M., Hunerberg, M., Beauchemin, K.A., McAllister, T.A., Okine, E.K., and Guan, L.L. (2012). Individuality of ruminal methanogen/protozoa populations in beef cattle fed diets containing dried distillers' grain with solubles. Acta Agr Scand a-An 62(4), 273 288. doi: 10.1080/09064702.2013.788206. 
Zoetendal, E.G., Collier, C.T., Koike, S., Mackie, R.I., and Gaskins, H.R. (2004). Molecular ecological analysis of the gastrointestinal microbiota: a review. J Nutr 134(2), 465472. doi: $10.1093 / \mathrm{jn} / 134.2 .465$. 
Chapter 1 


\section{Chapter 2}

\section{The effect of DNA extraction methods on observed microbial communities from fibrous and liquid rumen fractions of dairy cows}

Jueeli D. Vaidya ${ }^{1,2}$, Bartholomeus van den Bogert ${ }^{1,2 \#}$, Joan Edwards ${ }^{1,2}$, Jos Boekhorst ${ }^{3}$, Sanne van Gastelen ${ }^{1,4}$, Edoardo Saccenti ${ }^{5}$, Caroline M. Plugge ${ }^{2}$ and Hauke Smidt ${ }^{2}$

\# Current address: BaseClear B.V, Leiden, the Netherlands

${ }^{1}$ Top Institute Food and Nutrition, Wageningen, the Netherlands

${ }^{2}$ Laboratory of Microbiology, Wageningen University \& Research, Wageningen, the Netherlands

${ }^{3}$ NIZO food research BV, Ede, the Netherlands

${ }^{4}$ Animal Nutrition Group, Wageningen University \& Research, Wageningen, the Netherlands

${ }^{5}$ Laboratory of Systems and Synthetic Biology, Wageningen University \& Research, the Netherlands

Frontiers in Microbiology (2018) 9:92 


\section{ABSTRACT}

DNA based methods have been widely used to study the complexity of the rumen microbiota, and it is well known that the method of DNA extraction is a critical step in enabling accurate assessment of this complexity. Rumen fluid (RF) and fibrous content (FC) fractions differ substantially in terms of their physical nature and associated microorganisms. The aim of this study was therefore to assess the effect of four DNA extraction methods (RBB, PBB, FDSS, PQIAmini) differing in cell lysis and/or DNA recovery methods on the observed microbial diversity in RF and FC fractions using samples from four rumen cannulated dairy cows fed 100 $\%$ grass silage (GS100), $67 \%$ GS and $33 \%$ maize silage (GS67MS33), $33 \%$ GS and $67 \%$ MS (GS33MS67), or $100 \%$ MS (MS100). An ANOVA statistical test was applied on DNA quality and yield measurements, and it was found that the DNA yield was significantly affected by extraction method $(p<0.001)$ and fraction $(p<0.001)$. The $260 / 280$ ratio was not affected by extraction $(p=0.08)$ but was affected by fraction $(p=0.03)$. On the other hand, the $260 / 230$ ratio was affected by extraction method $(\mathrm{p}<0.001)$ but not affected by fraction $(\mathrm{p}=0.8)$. However, all four extraction procedures yielded DNA suitable for further analysis of bacterial, archaeal and anaerobic fungal communities using quantitative PCR and pyrosequencing of relevant taxonomic markers. Redundancy analysis (RDA) of bacterial 16S rRNA gene sequence data at the family level showed that there was a significant effect of rumen fraction $(\mathrm{p}=0.012)$, and that PBB $(\mathrm{p}=$ $0.012)$ and FDSS $(p=0.024)$ also significantly contributed to explaining the observed variation in bacterial community composition. Whilst the DNA extraction method affected the apparent bacterial community composition, no single extraction method could be concluded to be ineffective. No obvious effect of DNA extraction method on the anaerobic fungi or archaea was observed, although fraction effects were evident for both. In summary, the comprehensive assessment of observed communities of bacteria, archaea and anaerobic fungi described here provides insight into a rational basis for selecting an optimal methodology to obtain a representative picture of the rumen microbiota.

\section{KEYWORDS}

DNA extraction methods, Rumen fluid, Fibrous content, Bacteria, Archaea, Fungi, 454

Pyrosequencing, Principal co-ordinate analysis, qPCR 


\section{INTRODUCTION}

The bovine rumen is a complex microbial eco-system consisting of bacteria, archaea, protozoa and anaerobic fungi (Neocallimastigomycota). These microbes interact with each other to break down ruminant feed components, such as plant fibres. Bacteria are the predominant microorganisms in the rumen and hydrolyse feed-derived plant polysaccharides into short chain fatty acids (SCFAs), amino acids and gases, namely $\mathrm{H}_{2}$ and $\mathrm{CO}_{2}$ (Russell, 1981). The majority of the SCFAs are rapidly absorbed by the animal host for energy. Anaerobic fungi (Neocallimastigomycota) form a significant part of the rumen microbiota and play an important role in fibre digestion (Bauchop, 1979; Liggenstoffer et al., 2010; Gruninger et al., 2014). These anaerobic fungi were overlooked in early rumen studies due to their intimate association with the plant material during their extensive vegetative life cycle phase, with only the transient zoospores characteristic of their motile life cycle phase being detectable in the rumen fluid (RF) (Gruninger et al., 2014). Although ruminal methanogenic archaea cannot utilise dietary plant polysaccharides directly and comprise only approximately $0.3-3 \%$ of the total microbial biomass in the rumen, their functional relevance to rumen metabolism is significant. Archaea form methane $\left(\mathrm{CH}_{4}\right)$ by utilizing $\mathrm{CO}_{2}, \mathrm{H}_{2}$, formate, and methanol, which are produced during fermentation of dietary material by other rumen microbes (Hungate, 1966c; Marvin-Sikkema, 1990; Teunissen, 1992). Methane is a potent greenhouse gas and represents a loss of dietary energy to the ruminant (Meale, 2012).

The study of rumen microbial diversity is essential for in-depth understanding of the complex microbial interactions that shape the rumen ecosystem. This understanding can then be used to beneficially improve ruminant productivity, whilst decreasing the environmental footprint of ruminant livestock production (Zhou et al., 2009). Previously, much of the pioneering work by Robert Hungate was performed using traditional microbiological methods, involving isolation and characterization of pure strains to assess the diversity and functionality of rumen microbial communities. These strains, however, represented only a relatively small proportion of the total rumen microbial diversity (Hungate, 1966b). The importance of using culture independent studies to allow identification of uncultured and novel taxa within the rumen microbiota was previously confirmed (Edwards J.E., 2004; Creevey et al., 2014). Archaea which utilize the products from bacteria, are difficult to culture (Paul, 2012). For anaerobic fungi, only a limited number of the identified genera have been recovered in culture to date (Haitjema et al., 2014). 
Although culture independent methods overcome some biases associated with culture dependent methods, they also introduce a new set of biases related to extraction and PCR. Several studies have shown that methods used to extract DNA from rumen-derived samples had a significant effect on the apparent microbial diversity observed using various different molecular techniques targeting the $16 \mathrm{~S}$ ribosomal RNA (rRNA) gene. These techniques include single strand conformation polymorphism (SSCP), denaturing gradient gel electrophoresis (DGGE), quantitative PCR (qPCR) and next generation technology amplicon sequencing (Yu and Morrison, 2004; Henderson et al, 2013; Villegas-Rivera et al., 2013).

In terms of DNA extraction, RF and fibrous content (FC) fractions represent very different types of physical matrices for processing. A recent study by Henderson et al. (2013) showed that the bacterial communities associated with these two fractions differed from each other. For example, the predominant bacterial phyla in the rumen observed were Firmicutes and Bacteroidetes (Fouts et al., 2012), but the relative abundance of these phyla differed between the RF and FC fractions (Henderson et al., 2013). In the liquid fraction, the predominant bacterial community member was Prevotella, belonging to the Bacteroidetes phylum. In contrast, bacterial taxa belonging to the phyla Fibrobacteres and Firmicutes, particularly Butyrivibrio, Succiniclasticum and Lachnospiraceae, were relatively more abundant in the solid fraction. However, when the effects of different DNA extraction methods and two rumen digesta sampling methods were compared to each other, the choice of DNA extraction method affected the apparent microbial community structure significantly more than the sampling method (Henderson et al, 2013). Another study by Fliegerová et al. (2014) observed the clustering of microbial communities based on the type of RF processing (cheesecloth squeezed, centrifuged or filtered), storage conditions and DNA extraction method.

Differences in observed bacterial patterns due to extraction methods are often caused by the differences in cell lysis efficiency associated with the characteristic cell wall structure of Gram positive and Gram negative bacteria (Fliegerova et al., 2014). However, information on the biases associated with DNA extraction of the rumen FC relative to RF is limited. As primary fibre-degrading microbes are mainly attached to the dietary plant material (Dehority, 1991), it is important to assess the effect of DNA extraction methods on the observed FC and RF microbiota, and to what extent the extracts generated are reflective of the actual microbiota. 
In this study, we evaluated the effect of four DNA extraction methods that differ in cell lysis and/or DNA recovery procedures on the outcome of microbiota compositional analysis of both RF and FC fractions. Description and discussion of the fraction effect was, therefore, also performed in order to place the DNA extraction method effects in context. Sample fractions were collected from four rumen cannulated dairy cows each fed different roughage-based diets that were previously shown to result in differences in methane emission (van Gastelen et al., 2015). Quality and quantity of the extracted genomic DNA was evaluated prior to assessment of bacterial, archaeal and fungal communities with quantitative PCR (qPCR) and 454 based pyrosequencing of barcoded 16S rRNA gene and ITS PCR amplicons.

\section{MATERIALS AND METHODS}

\section{Animals and diet}

The samples used in this study were a subset of a larger study, of which the details have been described elsewhere (van Gastelen et al., 2015). This study was conducted in accordance with Dutch law and approved by the Animal Care and Use Committee of Wageningen University \& Research. Briefly, in the larger study 12 rumen cannulated cows were grouped into three blocks according to lactation stage, parity and milk production. The cows within each block were subsequently randomly assigned to one of four dietary treatments. All dietary treatments had a roughage to concentrate ratio of 80:20 based on dry matter. On a dry matter basis, the roughage consisted of either $100 \%$ grass silage (GS100), $67 \%$ GS and $33 \%$ maize silage (GS67MS33), $33 \%$ GS and $67 \%$ MS (GS33MS67), or $100 \%$ MS (MS100). One block of four cows was randomly selected from the above mentioned larger study to sample the RF and FC fractions in order to assess the effect of DNA extraction method on rumen microbiota analysis.

\section{Sample collection, preservation and preparation}

After 12 days of adaptation to the diet, the four rumen cannulated cows, i.e. one per dietary treatment, were sampled for RF and FC 3 hours after morning feeding. RF was directly collected using a suction tube through the rumen fistula, and collected in 3 equal ( $\sim 200 \mathrm{ml})$ amounts from the front and middle of the ventral sac and from the cranial sac. After collection, the RF samples were pooled, thoroughly mixed, divided into aliquots of $\sim 50 \mathrm{ml}$, and immediately frozen on dry ice. The solid (fibrous) fraction was collected via the rumen cannula, and then firmly squeezed by hand. All samples were collected within a time span of $30 \mathrm{~min}$, after which they were 
transported to the laboratory and stored at $-80^{\circ} \mathrm{C}$ until DNA extraction. In order to facilitate DNA extraction in $2 \mathrm{ml}$ lysis tubes, approximately $7.5 \mathrm{~g}$ of fibrous content (FC) was ground using a mortar and pestle with liquid nitrogen, after which $0.2 \mathrm{~g} \mathrm{FC}$ was weighed and used for extraction of DNA. RF samples were thawed, $1 \mathrm{ml}$ aliquots centrifuged for $5 \mathrm{~min}$ at $9,000 \times g$, and the cell pellets used as the starting material for DNA extractions.

\section{DNA extraction}

Four different DNA extraction methods were compared in this study to represent different types and combinations of cell lysis mechanisms and/or DNA recovery procedures. All extractions were performed by one person. Each DNA extraction method was performed with eight samples, i.e. a RF and FC sample derived from four different cows, each of which were fed different diets. All extractions were performed once, with the exception of the sample from the cow fed the GS100 diet for which duplicate DNA extractions were performed. DNA extraction was performed using $0.2 \mathrm{~g}$ of ground $\mathrm{FC}$ or the cell pellet from $1 \mathrm{ml}$ of RF.

Repeated bead beating (RBB) - Genomic DNA was extracted using the repeated bead beating plus column method, which was previously developed for bovine faeces and rumen digesta $\mathrm{Yu}$ and Morrison, 2004). Briefly, the prepared sample was mixed with $0.5 \mathrm{~g}$ of zirconium beads ( 0.1 $\mathrm{mm}$; Biospec products), 4 glass beads (2.5 mm; Biospec products) and $1 \mathrm{ml}$ of lysis buffer (500 $\mathrm{mM} \mathrm{NaCl}, 50 \mathrm{mM}$ Tris-HCl (pH 8), $50 \mathrm{mM}$ EDTA, 4 \% (w/v) SDS) in $2 \mathrm{ml}$ lysis tubes with screw caps (BIOplastics BV) and then processed as the published protocol. The final genomic DNA was eluted in $100 \mu \mathrm{l}$ AE buffer (10 mM Tris-Cl, 0.5 mM EDTA; pH 9.0).

Phenol dependent bead beating (PBB) - Prepared samples were mixed with $940 \mu 1$ TE buffer (10 mM Tris-HCl pH 7.6, 1 mM EDTA pH 8.0), followed by addition of $50 \mu 110 \%$ (w/v) SDS and $10 \mu \mathrm{l}$ Proteinase $\mathrm{K}(20 \mathrm{mg} / \mathrm{ml})$, and then incubated at $55^{\circ} \mathrm{C}$ for 1 hour. The mixture was then transferred to a $2 \mathrm{ml}$ lysis tube containing 4 glass beads and $0.5 \mathrm{~g}$ zirconium beads (as used for the RBB protocol). Subsequently, $150 \mu 1$ of buffered phenol (pH 7-8; Sigma Aldrich) was added, followed by bead beating for $3 \mathrm{~min}$ using the bead beater (Precellys 24, Bertin technologies) at $5.5 \mathrm{~m} / \mathrm{s}$ and cooled immediately on ice. The aqueous phase containing the nucleic acids was further mixed with $150 \mu$ l chloroform-isoamyl alcohol (24:1), and excess phenol was removed through centrifugation at $14,000 \times g$ for $10 \mathrm{~min}$ at $4^{\circ} \mathrm{C}$. The upper aqueous phase was removed and transferred to a new tube. The extraction with buffered phenol and chloroform-isoamyl 
alcohol was repeated. The nucleic acids were then precipitated from the combined aqueous fractions by adding 0.1 volume of $3 \mathrm{M}$ sodium acetate and 1 volume of isopropanol, and incubating at $4{ }^{\circ} \mathrm{C}$ for 30 min followed by centrifugation. The pellets were washed once with $70 \%(\mathrm{v} / \mathrm{v})$ ethanol and allowed to air-dry before being rehydrated in $100 \mu 1$ of TE buffer.

Fast SPIN DNA kit for Soil (FDSS) - Genomic DNA extraction was performed using the FastDNA SPIN kit for soil (MP Bio medicals, Solon, OH, USA) following the m anufacturer's instructions. Cell lysis in this kit was performed with sodium phosphate buffer and MT buffer in Lysing matrix E tube using the Precellys 24 bead beater for $40 \mathrm{~s}$ at a speed of $6.0 \mathrm{~m} / \mathrm{s}$, and the DNA purification was done using a binding matrix. DNA was eluted in $50 \mu 1$ of DES (DNase/Pyrogen free water) that was provided with the kit.

PQIAmini - Genomic DNA was extracted following the method described by (Zoetendal et al., 2006) with minor modifications (van den Bogert et al., 2013). Briefly, prepared samples were mixed with $500 \mu \mathrm{l}$ of TE buffer, and the genomic DNA was extracted from the re-suspended sample according to the Macaloid-based DNA isolation protocol with the use of Phase Lock Gel heavy tubes (5 Prime $\mathrm{GmbH}$ ) and phenol during the phase separation step. To remove contam inating RNA, $250 \mu \mathrm{l}$ of the aqueous phase was pretreated with $3 \mu 1$ RNAse A $(10 \mathrm{mg} / \mathrm{ml}$; QIAGEN GmbH) at $37{ }^{\circ} \mathrm{C}$ for $15 \mathrm{~min}$. Subsequent steps employed a modified version of the QIAamp DNA Stool Mini Kit (QIAGEN) protocol (Leimena et al., 2013). Initially, $22.5 \mu 1$ proteinase $\mathrm{K}(20 \mathrm{~m} \mathrm{~g} / \mathrm{m} \mathrm{l}$; Am bion) and $300 \mu \mathrm{l}$ buffer AL from the QIAm $\mathrm{p}$ kit were added to the DNA extract followed by incubation at $70{ }^{\circ} \mathrm{C}$ for $10 \mathrm{~min}$. The rest of the protocol was performed following the protocol guidelines. DNA was finally eluted in $30 \mu 1$ of nuclease free water.

\section{Quality control of DNA extracts}

The quality and quantity of the DNA was assessed using a NanoDrop ND-1000 spectrophotometer (NanoDrop ${ }^{\circledR}$ Technologies). The integrity of the DNA was visualized using

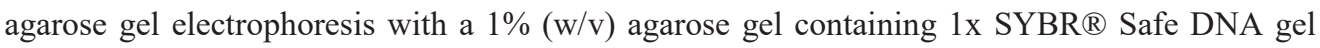
stain (Invitrogen).

\section{qPCR analysis}

DNA extracted from RF and FC samples was used for quantification of bacteria, archaea and anaerobic fungi by qPCR. The amplification of bacterial and archaeal 16S rRNA genes, and 
anaerobic fungal 5.8S rRNA genes was performed in a Bio-Rad CFX96 system (Bio-Rad Laboratories). All qPCR reactions were performed in triplicate. The resulting qPCR data was then processed, and principal component analysis (PCA) was performed using Canoco 5.0 (Ter Braak, 2012). The R software (version 3.0.2) was used for plotting and visualization purposes.

Bacteria and Archaea qPCR - To quantify bacterial 16S rRNA genes, the forward and reverse qPCR prim ers BAC 1369F (5' CGGTGAATACGTTCYCGG 3') and PROK 1492R (5' GGWTACCTTGTTACGACTT 3') were used (Suzuki et al., 2001). Archaeal 16S rRNA gene copies were quantified using prim ers 787F (5' ATTAGATACCCSBGTAGTCC 3') and 1059R (5' GCCATGCACCWCCTC 3') (Yu et al., 2005). The reproducibility of the bacterial qPCR assay (primers BAC 1369F and PROK 1492R) has been recently successfully confirmed for rumen fluid samples in our lab (van Lingen et al., 2017). The reproducibility of the archaeal qPCR assay (primers $787 \mathrm{~F}$ and 1059R) has been shown in a study focussing on bioreactor performance from methanogenic communities in microbial electrolysis cells ( $\mathrm{Lu}, 2012)$, and the archaeal primers have been tested for their coverage by (Yu et al., 2005). For bacteria and archaea the qPCR reaction m ixture $(25 \mu \mathrm{l})$ contained $12.5 \mu \mathrm{l} 2 \mathrm{X}$ iTaq Universal SYBR Green Supermix (Bio-Rad Laboratories), $200 \mathrm{nM}$ forward prim er, $200 \mathrm{nM}$ reverse prim er, $10.5 \mu 1$ nuclease free water, and $1 \mu \mathrm{l}$ of $0.2 \mathrm{ng} / \mu 1$ (for bacteria) or $2 \mathrm{ng} / \mu 1$ tem plate DNA (for archaea). The thermal cycling conditions for the bacterial and archaeal primer pairs included a predenaturing step at $95^{\circ} \mathrm{C}$ for $10 \mathrm{~m}$ in, followed by 35 cycles of $95^{\circ} \mathrm{C}$ for $20 \mathrm{~s}$, annealing at $56.3{ }^{\circ} \mathrm{C}$ (for bacteria) or $60{ }^{\circ} \mathrm{C}$ (for archaea) for $30 \mathrm{~s}$ and extension at $72{ }^{\circ} \mathrm{C}$ for $30 \mathrm{~s}$. The fluorescent products were detected at the last step of each cycle. Following amplification, melting temperature analysis of PCR products was performed to determine the specificity of the PCR. The melting curves were obtained by slow heating at $0.5^{\circ} \mathrm{C} / \mathrm{s}$ increments from 60 to $95^{\circ} \mathrm{C}$, with continuous fluorescence collection.

Anaerobic fungi qPCR - The quantification of ruminal anaerobic fungi was carried out using the Neocallimastigales probe-based qPCR assay as previously described (Edwards et al., 2008). Briefly, prim ers Neo qPCR For (5' TTG ACA ATG GAT CTC TTG GTT CTC 3') and Neo qPCR Rev (5' GTG CAA TAT GCG TTC GAA GAT T 3') prim ers were used, targeting a conserved region (110 bp) of the 5.8S rRNA gene, along with a TaqMan probe (Neo: 5' FAMCAA AAT GCG ATA AGT ART GTG AAT TGC AGA ATA CG -TAMRA-3'). The reaction m ixture $(25 \mu \mathrm{l})$ contained $1 \times$ TaqMan Universal PCR Probe Mix (Applied Biosystem s), $750 \mathrm{nM}$ of each prim er, $200 \mathrm{nM}$ of the probe and $1 \mu \mathrm{l}$ of $2 \mathrm{ng} / \mu \mathrm{l}$ tem plate DNA. The therm al cycling 
programme was $50{ }^{\circ} \mathrm{C}$ for $2 \mathrm{~min}, 95^{\circ} \mathrm{C}$ for $10 \mathrm{~min}$ (initial denaturation), followed by 40 cycles of $95{ }^{\circ} \mathrm{C}$ for $15 \mathrm{~s}$ (denaturation) and $60{ }^{\circ} \mathrm{C}$ for $1 \mathrm{~min}$ (primer annealing and extension). At the end of each cycle, the accumulation of PCR products was detected by monitoring the fluorescence signal from the probe.

Standard curve preparation - Standard curves were generated using purified PCR products as a template. The bacterial 16S rRNA gene PCR product was obtained with universal bacterial primers 27F and 1492R (Suzuki et al., 2000), using DNA extracted from Ruminococcus albus SY3 (kindly provided by Prof. R. John Wallace from the Rowett Research Institute (now part of the University of Aberdeen)). The archaeal 16S rRNA gene PCR product was obtained with universal archaeal primers 25F and 1492R (Dojka et al., 1998; Suzuki et al., 2000), using DNA extracted from Methanosarcina mazei MC3 (DSM-2907). The anaerobic fungal 5.8S rRNA gene PCR product was obtained with the Neo qPCR Rev and Neo qPCR Rev primers using DNA extracted from a FC sample from the cow which was fed GS100. All the PCR products were purified with a Purelink PCR Purification kit (Invitrogen), with high-cut off binding buffer B3, and the concentration was measured using Nanodrop. The DNA concentration and amplicon size was used to calculate the number of amplicon copies, and then 10-fold serial dilutions in water were made from $10^{8}$ to $10^{2}$ amplicon copies $/ \mu 1$.

\section{Amplification of target regions for pyrosequencing}

Bacterial community assessment - Bacterial community composition was assessed as described previously (van den Bogert et al., 2013). Briefly, a PCR was performed to obtain barcoded amplicons from the V1-V2 region of the 16S rRNA gene, using the 27F-DegS forward primer (5' GTtYGATYMTGGCTCAG 3') (van den Bogert et al., 2011) appended with the pyrosequencing titanium A adapter A CCATCTCATCCCTGCGTGTCTCCGACTCAG-3) and an 8 nt sample specific barcode (Hamady et al., 2008) and an equimolar mix of two reverse primers 338R I - (5' GCWGCCTCCCGTAGGAGT 3') and 338R II - (5' GCWGCCACCCGTAGGTGT 3') that were appended with the pyrosequencing titanium adapter B (5'CCTATCCCCTGTGTGCCTTGGCAGTCTCAG-3') at the 5' end (Guss et al., 2011). The reverse primers are based on three previously published EUB 338 probes (Daims et al., 1999b). PCRs were performed using a thermocycler (G storm) in a total volume of $100 \mu 1$ containing 20 $\mu 15 \times$ HF buffer (Finnzymes), $2 \mu$ PCR Grade Nucleotide Mix ( 2 mM each), 2 units Phusion ${ }^{\circledR}$ 
Hot Start II High Fidelity DNA polymerase (Finnzymes), $500 \mathrm{nM}$ of both the barcoded forward and reverse primer, $65 \mu 1$ nuclease free water and $2 \mu 1$ of $20 \mathrm{ng} / \mu 1$ template DNA. The PCR program consisted of an initial denaturation step at $98{ }^{\circ} \mathrm{C}$ for $30 \mathrm{~s}$, followed by 30 cycles of 98 ${ }^{\circ} \mathrm{C}$ for $10 \mathrm{~s}, 56{ }^{\circ} \mathrm{C}$ for $20 \mathrm{~s}$ and $72{ }^{\circ} \mathrm{C}$ for $20 \mathrm{~s}$, with a final extension step at $72{ }^{\circ} \mathrm{C}$ for $10 \mathrm{~min}$. Expected PCR product size (311 bp) was confirmed by agarose gel electrophoresis using $5 \mu 1$ of PCR product on a $1 \%(\mathrm{w} / \mathrm{v})$ agarose gel containing $1 \times$ SYBR ${ }^{\circledR}$ Safe. Non-template negative control PCR reactions were performed alongside each PCR amplification, and were confirmed to yield no product. PCR products were purified with the High PCR Pure Clean-up Micro kit (Roche) followed by quantification using the Qubit dsDNA BR assay kit (Invitrogen). Purified PCR products were mixed in equimolar amounts (400 ng per sample), and the pooled amplicons were purified using a DNA gel extraction kit (Millipore) according to m anufacturer's guidelines. The pooled amplicons were then quantified using the Qubit dsDNA BR assay kit, and the sequences determined with a 454 Life Sciences GS-FLX platform using Titanium sequencing chemistry (GATC-Biotech, Konstanz, Germany).

Archaeal community assessment - A method adapted from Jaeggi et al. (2014) was used for archaeal composition analysis. Briefly, barcoded amplicons of 16S rRNA genes were generated by PCR using the 340F forward primer (5'-CCCTAYGGGGYGCASCAG-3') (Gantner et al., 2011) that was 5'- extended with the titanium adaptor A and an $8 \mathrm{nt}$ sample specific barcode, and the 1000R reverse prim er (5'GGCCATGCACYWCYTCTC-3' (Gantner et al., 2011)) that was appended with the titanium adaptor B at the 5'-end. PCRs were performed in a total volume of $50 \mu \mathrm{l}$ containing $20 \mathrm{ng}$ of template DNA, $200 \mathrm{nM}$ of each of the forward and reverse primer, $1 \mathrm{U}$ KOD Hot Start DNA Polymerase (Novagen), $5 \mu$ KOD-buffer (10×), $3 \mu \mathrm{l} \mathrm{MgSO}_{4}(25 \mathrm{mM}), 5$ $\mu \mathrm{l}$ dNTP mix (2 $\mathrm{mM}$ each), and $33 \mu \mathrm{l}$ nuclease free water. PCR conditions were: initial denaturation step at $98{ }^{\circ} \mathrm{C}$ for $30 \mathrm{~s}$ followed by 25 cycles of $98{ }^{\circ} \mathrm{C}$ for $10 \mathrm{~s}, 52{ }^{\circ} \mathrm{C}$ for $20 \mathrm{~s}$, and $72{ }^{\circ} \mathrm{C}$ for $20 \mathrm{~s}$, and a final extension step of $72{ }^{\circ} \mathrm{C}$ for $10 \mathrm{~min}$. PCR product size (660 bp) was confirmed by agarose gel electrophoresis using $5 \mu \mathrm{l}$ of PCR product on a $1 \%(\mathrm{w} / \mathrm{v})$ agarose gel containing 1x SYBR ${ }^{\circledR}$ Safe. Non-template negative control PCR reactions were performed alongside each PCR amplification and were confirmed to yield no product. The PCR amplicon (approx. $660 \mathrm{bp}$ ) was subsequently purified using the MSB Spin PCRapace kit (Invitek), and the concentration was determined using the Qubit dsDNA BR assay kit. Purified PCR products were mixed in equimolar amounts by pooling $200 \mathrm{ng}$ of the purified PCR products of each sample. The pooled sample was purified using the Purelink PCR Purification kit, with high-cut off 
binding buffer B3, and pyrosequenced on the 454 Life Sciences GS-FLX platform using Titanium sequencing chemistry (GATC-Biotech, Konstanz, Germany).

Fungal community assessment - PCR was performed to obtain barcoded amplicons from the fungal ITS1 region, using the ITS1FA.001 (5'-CTTGGTCATTTAGAGGAAGTAA-3') forward prim er appended at the 5'-end with titanium sequencing adapter B and the reverse prim er (5TCCTCCGCTTATTGATATGC-3') appended with titanium sequencing adapter A and a $6 \mathrm{nt}$ sample specific barcode. PCRs were performed using a thermocycler (Biometra) in a total volume of $50 \mu \mathrm{l}$ containing $5 \mu \mathrm{l} 10 \mathrm{x}$ KOD buffer, $5 \mu \mathrm{l}$ dNTP mix ( $2 \mathrm{mM}$ each), $3 \mu 1 \mathrm{MgSO}_{4}$ (25mM), $1 \mu 1 \mathrm{KOD}$ polymerase, $400 \mathrm{nM}$ of both the forward and the reverse primer, nuclease free water, and 20-50 ng of template DNA. The PCR program consisted of an initial denaturation step at $95^{\circ} \mathrm{C}$ for $2 \mathrm{~min}$, followed by 35 cycles of $95^{\circ} \mathrm{C}$ for $20 \mathrm{~s}, 51^{\circ} \mathrm{C}$ for $10 \mathrm{~s}$, and elongation at $70^{\circ} \mathrm{C}$ for $15 \mathrm{~s}$, with a final extension step at $70^{\circ} \mathrm{C}$ for $5 \mathrm{~min}$. Expected PCR product size (variable between 350-750 bp) was confirmed by agarose gel electrophoresis using $5 \mu 1$ of PCR product on a $1 \%(\mathrm{w} / \mathrm{v})$ agarose gel containing ethidium bromide. Non-template negative control PCR reactions were performed alongside each PCR amplification, and were confirmed to yield no product. PCR products were purified with MSB spin PCRapace kit followed by quantification using Nanodrop. Purified PCR products were mixed in equimolar amounts (200 ng per sample), and the pooled amplicons were purified using MSB spin PCRapace kit according to manufacturer's guidelines. The pooled amplicons were then quantified by Nanodrop and pyrosequenced on the 454 Life Sciences GS-FLX platform using Titanium sequencing chemistry (GATC-Biotech, Germany).

\section{Pyrosequencing data analysis}

The pyrosequencing data analysis for bacteria and archaea was carried out with a workflow employing the Quantitative Insights Into Microbial Ecology (QIIME) pipeline (Caporaso et al., 2010) using settings as recommended in the QIIME 1.2 tutorial. De-multiplexing and initial sequence quality filtering were done with the "split_libraries.py" script provided by QIIME using the default settings. OTU picking, alignment and taxonomic classification were done using the workflow script "pick_otus_through_otu_table.py" provided by QIIME using the default settings. Reads were filtered for chimeric sequences using Chimera Slayer (Haas et al., 2011), and clustering of Operational Taxonomic Units (OTUs) was performed with a similarity threshold of $97 \%$. Additional data handling was done using in-house developed Python and Perl 
scripts. Taxonomic classification of bacteria and archaea was done using Ribosomal Database Project (RDP) classifier version 2.2 (Wang et al., 2007) using the database GreenGenes set gg_97_otus_6oct2010 as provided with QIIME 1.2. In order to obtain the most likely genus-level identification, sequences were compared to the corresponding RDP reference set using NCBI BLAST (Altschul et al., 1990). Data analysis for fungi was done using a workflow based on QIIME 1.8, using the BLAST method for taxonomic classification of ITS reads against the UNITE database (Abarenkov et al., 2010), using the training set of 07-04-2014. Shannon's index and Chaol richness index were calculated as implemented in QIIME using bacterial OTU-level data. Principal coordinate analysis (PCoA) analysis of weighted and unweighted UniFrac distances between samples was performed using QIIME with both the bacterial and archaeal OTU-level data. Redundancy analysis (RDA) was performed using Canoco 5 (Smilauer, 2014) to assess the relationship between family-level like phylogenetic groupings of OTU and DNA extraction methods or rumen fractions. The raw sequence data for the bacterial, archaeal and fungal composition analysis is deposited as a project available at https://github.com/jdvaidya/rumenmicrobiotadata. In addition, the sequences are also deposited in ENA under accession number PRJEB22996.

\section{Statistical Analysis}

The significance of potential differences in the relative abundances of bacterial taxa between the different sample groups (e.g. different extraction methods, different rumen fractions) was assessed using the non-parametric rank Mann-Whitney test as implemented in Sci-Phy (Jones, 2001). Significance of explanatory variables included in constrained analyses (RDA) was assessed using an unrestricted Monte Carlo permutation test with a total of 999 permutations, and results were visualized in an ordination biplot obtained from Canoco 5. P-values were corrected for multiple testing using Bonferroni correction and those lower than 0.05 were regarded as significant.

Two 1-way ANOVA model were fitted separately to DNA yield and quality (260/280 and 260/230) measurements with extraction method (4 levels: RBB, PBB, FDSS and PQIAmini, see Section 2.3 for detailed explanation of the extraction methods) and rumen fraction (2 levels: fibrous and liquid) as factors, using R software (version 3.0.2). Data was log-transformed before analysis to correct for skewness. The rationale behind the use of two separate 1-way ANOVA instead of a 2-way ANOVA is that we did not consider the Extraction method $\mathrm{x}$ Fraction 
interaction term, due to large sample heterogeneity (i.e. each of the four cows were fed a different diet).

\section{RESULTS.}

\section{Quality and quantity of genomic DNA from four extraction methods}

Both RF and FC samples yielded high molecular weight ( $>3 \mathrm{~kb})$ DNA as confirmed by agarose gel electrophoresis (Fig S1). The integrity of the DNA was best for the RBB method, as less DNA degradation was observed compared to the other three methods. Statistical analysis using ANOVA confirmed that the DNA yield was significantly affected by extraction method ( $\mathrm{p}<$ $0.001)$ and fraction $(\mathrm{p}<0.001)$. For the RF samples the highest quantities of DNA were obtained with PBB, which on average yielded 9.0, 3.0 and, 3.5 times more DNA than the RBB, FDSS and PQIAmini methods, respectively (Table 1). PBB also yielded the highest quantities of DNA with the FC samples, and yielded 9.5, 2.5 and 2.2 times more DNA than RBB, FDSS and PQIAmini methods, respectively (Table 1). Assessment of purity of DNA found that the 260/280 ratio was not affected by extraction $(p=0.08)$ but was affected by fraction $(p=0.03)$. On the other hand, the $260 / 230$ ratio was affected by extraction method $(\mathrm{p}<0.001)$ but not affected by fraction $(\mathrm{p}=$ 0.8). Some DNA extracts of the RF and FC samples had a ratio of absorbance at $260 \mathrm{~nm}$ and 280 $\mathrm{nm}\left(\mathrm{A}_{260 / 280}\right)$ that was below 1.8, indicating the presence of contaminants (typically proteins and/or phenol) that absorb at a slightly higher wavelength than DNA (Table 1). This was most evident with the PBB method DNA extracts from the FC samples. The A260/230 was lower than 2.0 (maximal value for pure DNA) for virtually all of the samples, but in particular for the FDSS DNA extracts. However, all DNA extraction methods provided DNA of sufficient quality and quantity to proceed with PCR based approaches as described in the following sections.

\section{qPCR analysis of bacteria, archaea and anaerobic fungi}

All DNA extracts from RF and FC samples were used for qPCR analysis of total bacteria, archaea and anaerobic fungi (Fig. S2). The PCA of the qPCR data revealed separate clustering of the FC and RF fractions in PC1 (Fig. 1A). These two clusters were separated by anaerobic fungal 5.8S rRNA gene concentrations along the first principal component axis (PC1). There was also evidence of clustering of the extraction methods in the second principal component axis (PC2), with the RBB and FDSS methods clustered to the top half of the plot and PBB and PQIAmini to the bottom (Fig. 1A). Archaeal 16S rRNA gene concentrations were associated with the separation of these two clusters in PC2 (Fig. 1B). 

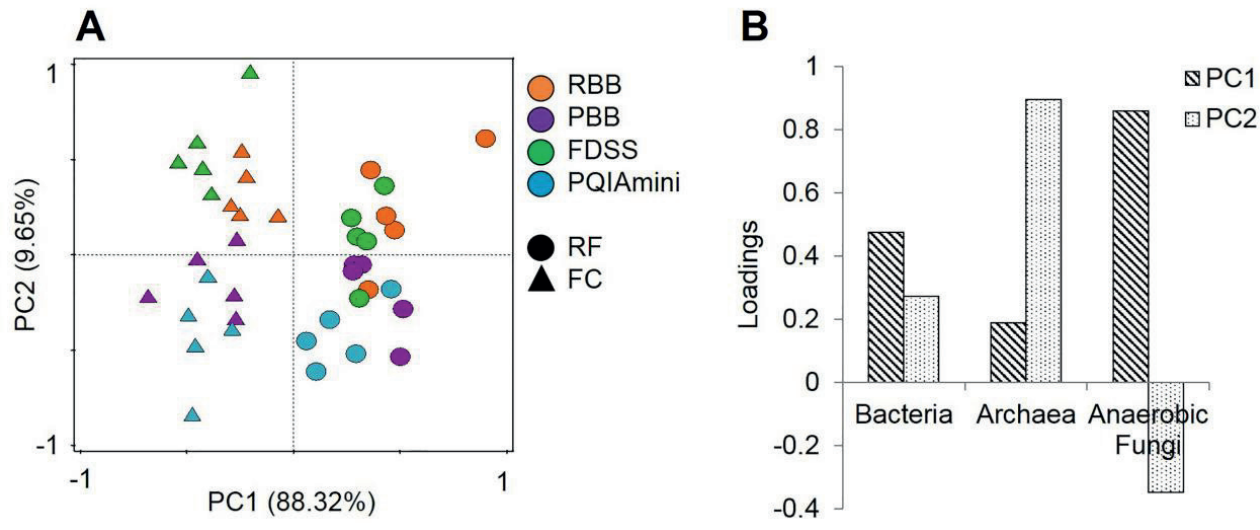

Figure 1. (A) Principal component analysis (PCA) of the combined bacterial (16S rRNA gene), archaeal (16S rRNA gene) and anaerobic fungal (5.8S rRNA gene) qPCR data for rumen fluid $(\mathrm{RF}, \mathrm{O})$ and fibrous content $(\mathrm{FC}, \triangle)$ samples. The GS100 diet has duplicate DNA extracts presented as individual datapoints. The percentages provided at the axes indicate the variation explained. (B) The corresponding loadings for the principal components indicate that anaerobic fungi are the major cause of sample separation in PC1, and archaea in PC2.

\section{Impact of DNA extraction methods and fractions on observed bacterial community composition}

On average only $26.3 \%$ of the annotations for the bacterial taxa included genus level identification. Therefore, mainly the OTU and family level (average of 56.2\% annotation) was used in the data analysis. Weighted UniFrac distance based PCoA at the OTU-level showed that the bacterial communities observed in RBB, FDSS, and PQIAmini-derived extracts generally grouped together, whereas the bacterial communities associated with PBB-derived extracts clustered separately (Fig S3A). This was not seen in the unweighted UniFrac distance based PCoA, however, samples appeared to cluster more by rumen fraction instead (Fig. S3A and $\mathrm{S} 3 \mathrm{~B})$.

In order to test to what extent different extraction methods and rumen fractions contributed to explaining the observed variation in bacterial community composition, redundancy analysis (RDA) was applied using family-level relative abundance data. This analysis showed that the 
$\operatorname{PBB}(\mathrm{p}=0.012)$ and FDSS $(\mathrm{p}=0.024)$ DNA extraction methods were separated relative to RBB and PQIAmini on the first canonical axis (Fig. 2). On the second canonical axis samples were separated by fraction $(\mathrm{p}=0.012$ ) (Fig. 2). Ruminococcaceae appeared to be positively associated with the PBB method and the fibrous content. The following three families were positively associated with the FDSS method and fibrous content: Fibrobacteraceae, Unclassified Synergistetes and Unclassified Bacteroidales (Fig. 2). The Prevotellaceae were positively associated with the FDSS method and rumen fluid fraction.

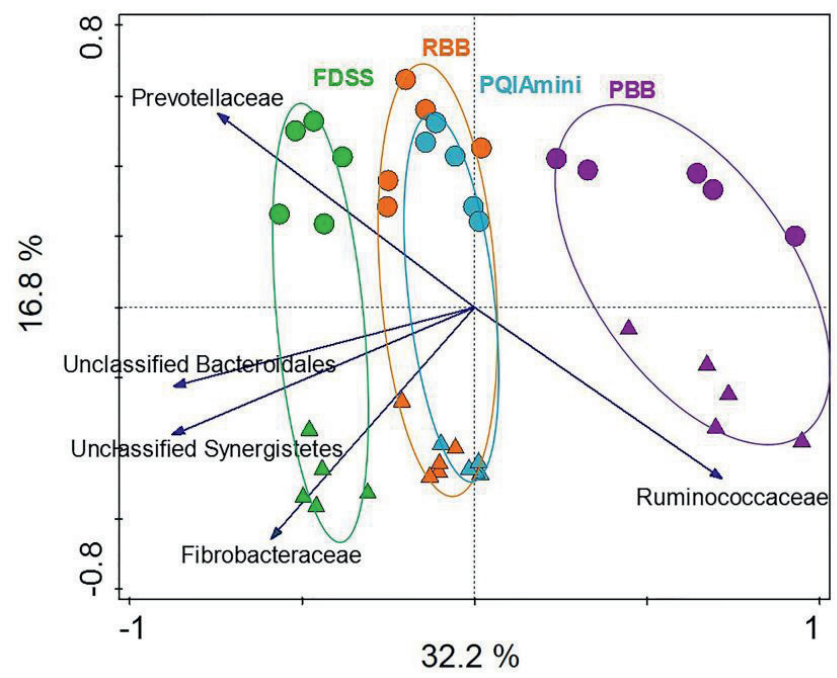

Figure 2. Redundancy analysis triplot (RDA) showing the relationship between the top five family-level phylogenetic groupings, the variation of which is most strongly associated with DNA extraction methods (RBB, PBB, FDSS, PQIAmini) and fractions (RF, $\circ$ and FC, $\triangle$ ). The canonical axes are labelled with percentage of total variance explained (\%). Arrow length indicates the variance explained by extraction methods and fractions. The GS100 diet has duplicate DNA extracts presented as individual datapoints.

Bacterial community analysis - A more detailed compositional analysis of RF and FC samples showed that the rumen bacterial community consisted of 15 phyla (data not shown), among which on average Firmicutes $(46.9 \pm 16.1 \%$ RF, $39.7 \pm 15.7 \%$ FC) and Bacteroidetes $(58.2 \pm$ $15.7 \% \mathrm{RF}, 26.9 \pm 11.2 \% \mathrm{FC}$ ) were most predominant. The bacterial profiles of RF and FC fractions appeared to be very distinct at the family level (Fig. 3A and 3B). Overall, the relative 
abundance of Prevotellaceae was significantly higher in RF samples than in FC samples ( $\mathrm{p}=$ 0.001; Fig. 4A and Table S1A) but was not significantly affected by any of the DNA extraction methods ( $p>0.05$; Fig. 4A and Table S1B). The relative abundance of Fibrobacteraceae was higher in FC compared to RF ( $p=0.020$; Fig. 4B and Table S1A), and was found to be higher ( $p$ $=0.028$ ) in extracts obtained using the FDSS method as compared to the PBB method (Fig. 4B and Table S1B). The RBB method also resulted in DNA extracts with a higher relative abundance of Fibrobacteraceae in comparison to the PBB method ( $\mathrm{p}=0.038$; Fig. 4B and Table $\mathrm{S} 1 \mathrm{~B})$. Differences were also observed between RF and FC fractions for Ruminococcaceae. FC samples had significantly higher relative abundances of Ruminococcaceae compared to RF samples ( $\mathrm{p}=0.040$; Fig. $4 \mathrm{C}$ and Table S1A). The PBB extraction method gave significantly higher relative abundances of Ruminococcaceae compared to the FDSS method $(p=0.038$; Fig. 4C and Table S1B). Members of the Lachnospiraceae appeared to be predominant in both RF and FC samples, and their relative abundance in FC samples was significantly higher than those in RF samples ( $p=0.006$; Fig. 4D and Table S1A). However, there was no effect of DNA extraction methods on Lachnospiraceae (Fig. 4D and Table S1B). Finally, relative abundances of two other minor $(<1 \%$ ) families (Anaerolinaceae and Halomonadaceae) were significantly affected by DNA extraction methods (Table S1B) and one minor family (Desulfobulbaceae) was affected by fraction (Table S1A).

At the genus level, Selenomonas, Succiniclasticum, Ruminococcus, Prevotella, Butyrivibrio, Paraeggerthella, Fibrobacter, Desulfobulbus, Pseudobutyrivibrio, Syntrophococcus and Oscillibacter significantly differed in relative abundance when comparing $\mathrm{RF}$ and FC $(\mathrm{p}<0.05$; Table S1A). The genera with higher relative abundance in RF compared to FC fraction were Desulfobulbus, Succiniclasticum, Paraeggerthella, Prevotella, and Selenomonas, whereas Syntrophococcus, Pseudobutyrivibrio, Butyrivibrio, Oscillibacter, Ruminococcus and Fibrobacter were significantly higher in their relative abundance in the FC fraction as compared to the RF fraction. In contrast, only the genus Fibrobacter was found to be significantly affected by DNA extraction method. The relative abundance of Fibrobacter was higher in FDSS extracts compared to those prepared using the PBB method $(\mathrm{p}=0.038)$, and higher also in the RBB extracts compared to the PBB $(p=0.038)$ (Table S1B). 


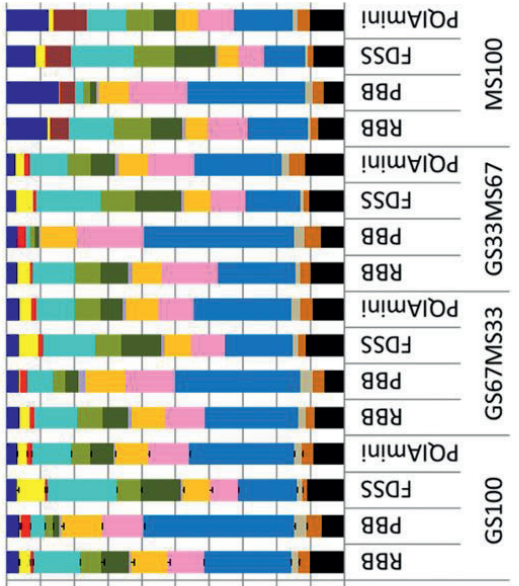

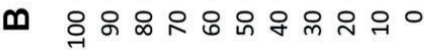

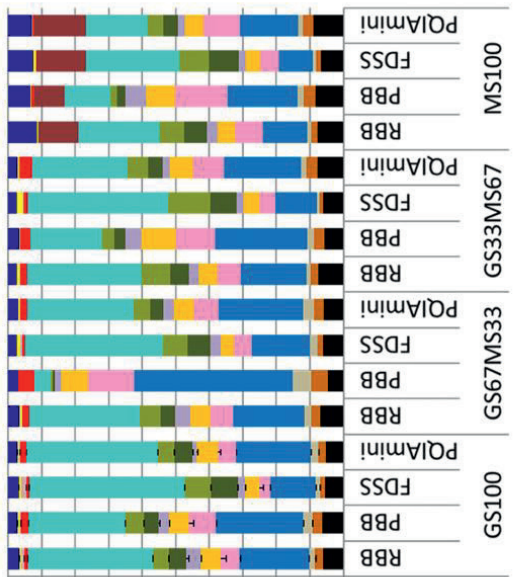

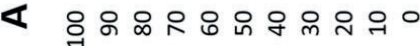

(\%) әэuepunqe әл!!e|әу

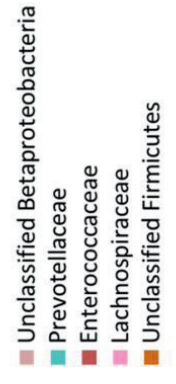

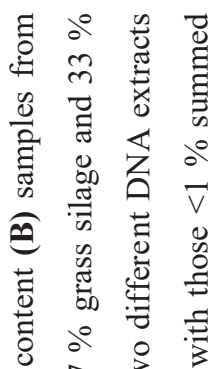
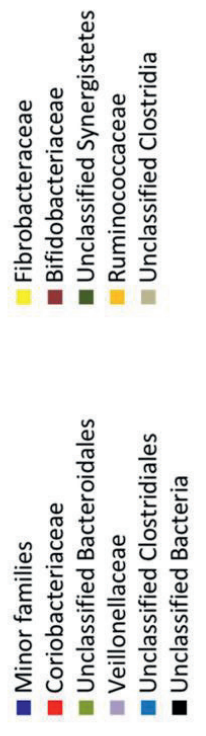

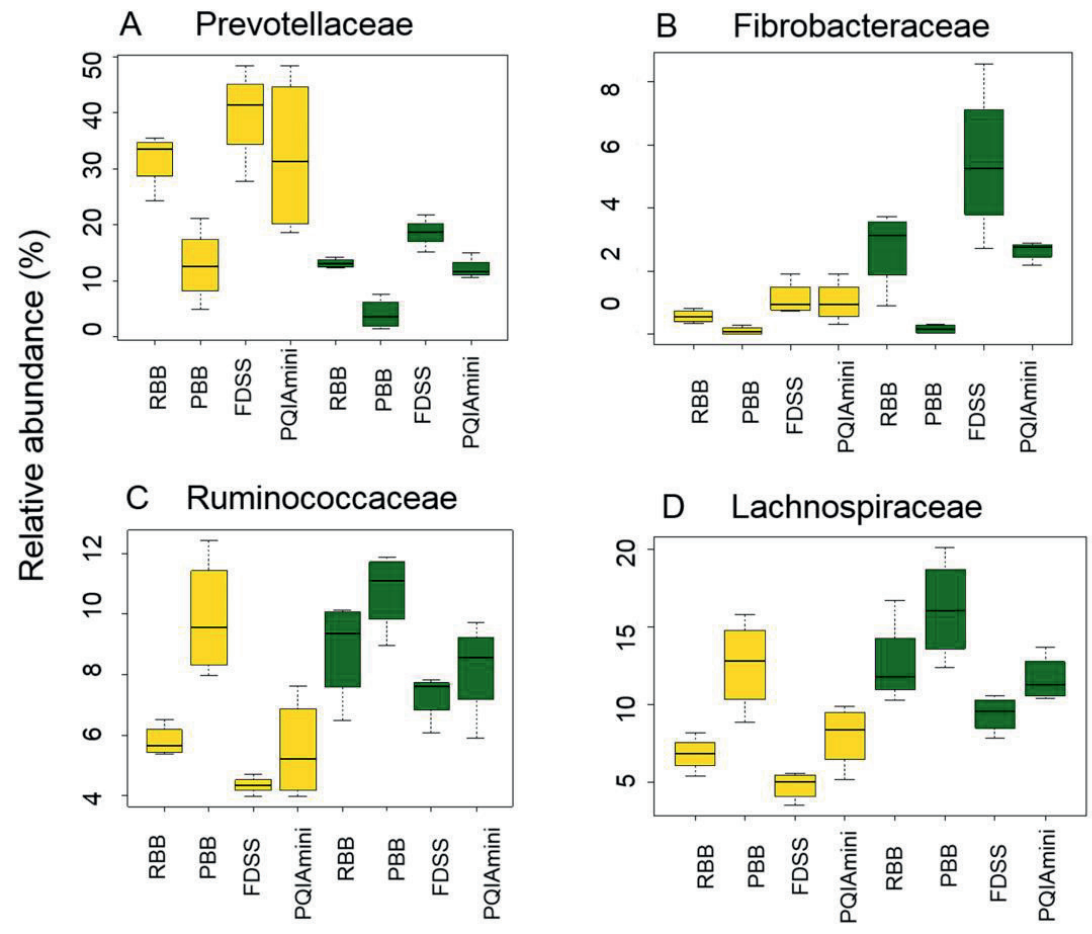

Figure 4. The effect of DNA extraction method (RBB, PDD, FDSS \& PQIAmini) on the relative abundance of the bacterial families Prevotellaceae (A) Fibrobacteraceae (B) Ruminococcaceae (C) and Lachnospiraceae (D) in rumen fluid (yellow) and fibrous content (green) samples. The boxplots represent the data from 5 observations per rumen fraction, and show the 25 th, 50 th and 75 th percentiles, with whiskers showing the extremes of the data.

Bacterial diversity and richness - Estimates of bacterial sequence richness and diversity were calculated at the OTU level to assess if these parameters were affected by fraction or DNA extraction method. The PBB extracts from RF and FC fractions of GS67MS33 and MS100 fed cows appeared to generally have the lowest bacterial richness (total number of OTUs present in a community) as calculated by the Chaol index than the corresponding RBB, FDSS and PQIAmini RF and FC extracts (Fig. 5A). A similar trend of the PBB extracts was also seen for diversity (Shannon's index, Fig. 5B). Within the GS100 sample, the Chao1 richness index generally showed higher variability within RF than in FC samples (Fig. 5A). On the other hand, the technical replicates for GS100 appeared to give sim ilar values throughout Shannon's index 
analyses (Fig. 5B). The RF sam ples seem ed to have lower Shannon's index values com pared to the FC samples, which was not always the case with Chaol index values.

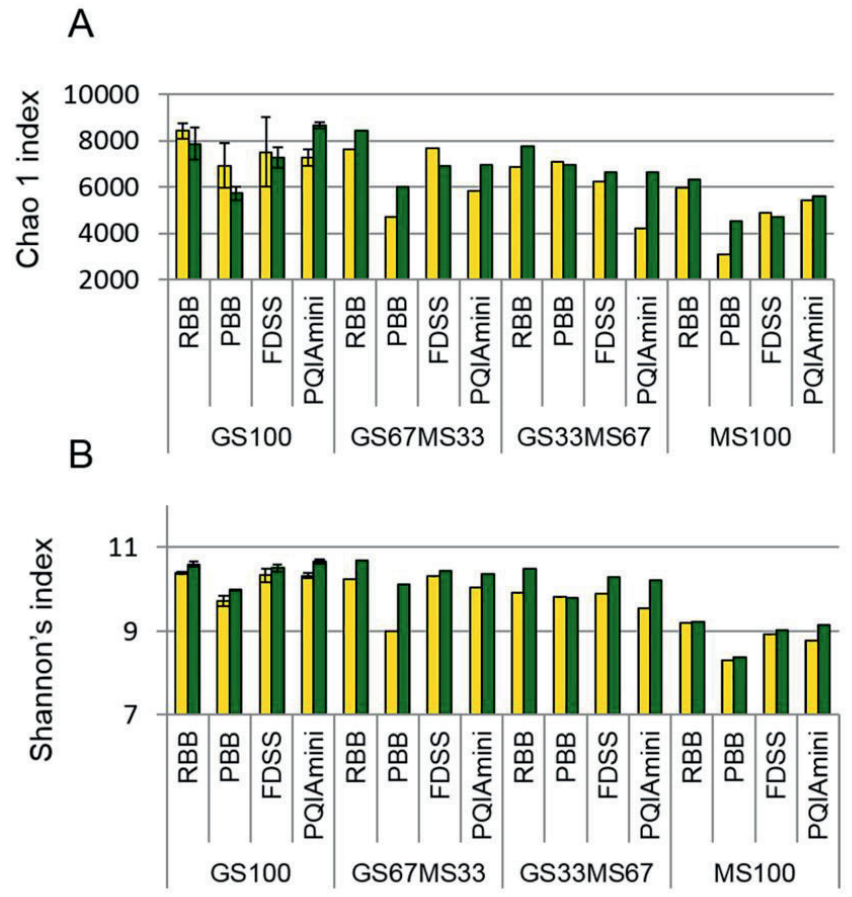

Figure 5. Chaol richness index (A) and Shannon's diversity index (B) values for all four DNA extraction methods (RBB, PBB, FDSS \& PQIAmini) applied to rumen fluid (yellow) and fibrous content (green) samples from four dairy cows each fed different ratios of grass silage (GS) to maize silage (MS), e.g. GS67MS33 is a diet containing 67\% grass silage and 33\% maize silage. The GS100 samples represent the mean of two different DNA extracts, and the error bars represent their standard deviation.

\section{Archaeal community analysis}

The RF and FC samples were analysed to identify the rumen archaea associated with the different fractions, and how the different DNA extraction methods influenced their detection (Fig. 6A and 6B). Some of the DNA extracts did not yield amplicons for sequencing, despite the fact that all samples were successfully amplified in the archaeal 16S rRNA qPCR. Furthermore, 
the PCR failure could also not be directly correlated with either the fraction, sample source (cow/diet) or any of the DNA extraction methods. The FDSS method, however, consistently failed with all the RF samples (Fig. 6A).

Two families belonging to the phylum Euryarchaeota, i.e. Methanobacteriaceae and Thermoplasmata-incertae-sedis represented the majority of the sequences. Within the Methanobacteriaceae, two known genera were detected, Methanobrevibacter ( $>83 \%$ to $98 \%$ ) and Methanosphaera ( $\sim 1 \%$ to $4 \%)$. An unidentified genus within the Methanobacteriaceae was also detected $(<1 \%)$ (Fig. 6A and 6B). Within Thermoplasmatales-incertae-sedis, only the genus Thermogymnomonas $(<1 \%)$ was identified. Of the samples for which sequence information could be generated, there was no consistent difference in the relative abundances of archaeal genera found relative to the different DNA extraction methods. However, from the two fractions there was generally more Methanosphaera seen in the RF as compared to the FC.

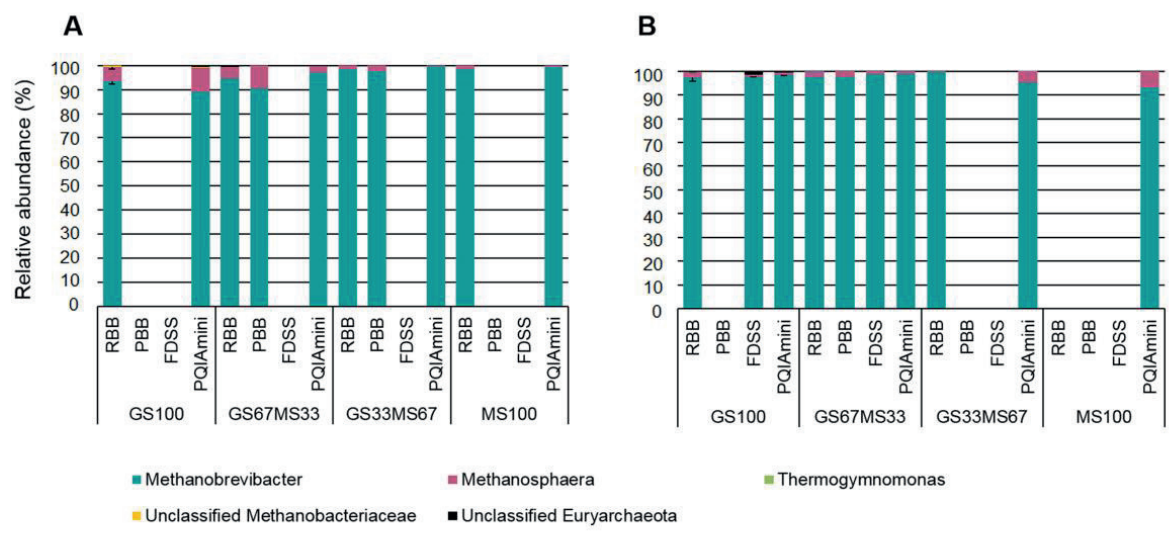

Figure 6 Relative abundance of archaeal taxa at genus level within rumen fluid (A) and fibrous content (B) samples from dairy cows each fed different ratios of grass silage (GS) to maize silage (MS), e.g. GS67MS33 is a diet containing $67 \%$ grass silage and $33 \%$ maize silage. All samples were subjected to each of the four different DNA extraction methods (RBB, PBB, FDSS and PQIAmini). Missing bars indicate that it was not possible to generate an archaeal PCR product for sequencing. Error bars for the GS100 samples represent the standard deviation associated with two different extracts, except for the PQIAmini extracted GS100 rumen fluid sample (A) where $\mathrm{n}=1$. 


\section{Fungal community analysis}

Pyrosequencing analysis of amplified fungal ITS regions revealed the presence of several fungal phyla in both the RF and FC samples, and included aerobic (Ascomycota and Basidiomycota) as well as anaerobic fungi (Neocallimastigomycota). Unidentified fungal taxa (including but not differentiating between unidentified anaerobic and aerobic) and not assigned fungi were dominant (Table $2 \mathrm{~A}$ and $2 \mathrm{~B}$ ). The identified anaerobic fungi represented less than $1 \%$ of the reads in the RF samples (Table 2A). The FC samples on the other hand were characterized by much higher relative abundances of the anaerobic fungi, which were represented by four genera: Cyllamyces (0 to 3.2\%), Anaeromyces (0 to $5.2 \%$ ), Neocallimastix ( 0 to $8.1 \%$ ) and Piromyces (0 to $31.5 \%$ ) (Table $2 \mathrm{~B}$ ). Due to the limited and variable number of anaerobic fungal reads, an in depth analysis of this phylum relative to the DNA extraction method was not possible.

\section{DISCUSSION}

\section{DNA quantity, purity and integrity}

The different cell wall composition and structure of bacteria, archaea and fungi largely determines their susceptibility to mechanical or enzymatic lysis methods (Fredricks et al., 2005; Henderson et al, 2013). In this study, all the methods employed mechanical disruption of cells by bead beating, albeit with differences in agitation times and type of beads. Several studies have shown that disruption of bacteria with tough cell walls, such as those belonging to the phyla Firmicutes and Actinobacteria, is more efficient with a mechanical approach than by an enzymebased protocol (Lazarevic et al., 2013). In the present study, all four DNA extraction methods yielded high molecular weight DNA ( $>3 \mathrm{~kb}$ ), from both RF and FC fractions based on agarose gel analysis but the mechanical disruption caused shearing of DNA to different extents. The RBB method yielded the most intact genomic DNA compared to the PBB, FDSS and PQIAmini methods. Although the RBB method employs two rounds of bead beating in the presence of high concentrations of SDS, salt and EDTA, the physical damage of DNA is minimized by removing the lysate from the first round of bead beating to a new micro centrifuge tube followed by a second bead beating step to lyse any remaining intact cells. The DNA yields for RBB were lower compared to the other methods assessed. DNA yields previously reported for faecal samples (10$30 \mu \mathrm{g} / \mathrm{g}$ faeces: (Zoetendal, 2006) were slightly higher compared to the range observed for RF, and lower than that observed for the FC. 
It has previously been shown that different agitation speeds can affect DNA extraction, as samples subjected to disruption at 4,800 rpm yielded more DNA than those subjected to 2,400 rpm (Fujimoto, 2004). In our study, although RBB and PQIAmini methods both used an agitation speed of $5.5 \mathrm{~m} / \mathrm{s}$, the DNA yields for PQIAmini were 3.0 and 3.8 times higher as compared to the RBB method for RF and FC samples, respectively. In this case, either the reagents used during lysis or the different disruption times $(3 \times 1 \mathrm{~min}$ for $\mathrm{RBB}$ and $3 \times 45 \mathrm{~s}$ for PQIAmini) might be responsible for the different DNA yields obtained from these two methods for $\mathrm{RF}$ and $\mathrm{FC}$.

In this study, the average 260/230 ratios observed for RF $(1.4 \pm 0.6)$ and $\mathrm{FC}(1.2 \pm 0.5)$ samples indicated the presence of humic acids or guanidine carried over during the washing steps of the silica columns and the beads. For some extraction methods, the 260/230 ratio seemed particularly low for FC samples as compared to RF samples, presumably due to impurities associated with the lignocellulose components of a plant fibrous material rich in aromatic ring structures similar to humic acids. The 260/230 ratio for samples extracted with the FDSS method were the lowest as compared to the other extraction methods (Table 1). The FDSS protocol has previously been reported to give high DNA yields with soil samples, but still containing contaminants such as humic acid residues (Devi et al., 2015). It is also important to note that phenol-based DNA extraction methods, including the PBB and PQIAmini methods, can give higher 260/280 ratios as any residual phenol absorbs at 280nm. Nevertheless, no PCR inhibition was evident in any of the qPCR analyses performed. For PCR based community analyses, we observed that bacterial and fungal pyrosequencing PCR was successful. However, the pyrosequencing PCR targeting archaeal 16S rRNA genes did not work for all samples. This is presumably due to the lower number of PCR cycles used with this method ( 25 cycles) compared to that of the bacteria (30 cycles) and fungi (35 cycles). Noteworthy is the observation that only PQIAmini DNA extracts generated archaeal amplicons for both fractions for all the samples.

\section{Pyrosequencing analysis}

Bacteria community analysis - The clustering of bacterial communities was distinct for the PBB method and FDSS method as compared to the RBB and PQIAmini methods (Fig. 2). From the PCoA plots (Fig. S3), the latter three methods however, had a gradual shift of the bacterial communities between methods, suggesting that all four DNA extraction methods had an effect on the observed bacterial community structure to some extent. Further analysis of the data 
confirmed that DNA extraction method affected the relative abundances of various families and genera.

The predominant phyla detected in this study were Firmicutes and Bacteroidetes, which is in line with other bovine rumen based studies (De Menezes et al., 2011b; Li et al., 2014; Huws et al., 2016; Van Lingen et al., 2017a). The predominant family-level taxa belonging to Firmicutes in the RF fraction were: Ruminococcaceae, Lachnospiraceae and unclassified Clostridiales. Within the Bacteroidetes, Prevotellaceae was the predominant family. These observed families were in line with a previous study (Mao et al., 2015). The FC fraction showed a significantly higher relative abundance of Fibrobacteraceae, Ruminococcaceae and Lachnospiraceae compared to the RF fraction. These three families were also pre-dominant in our study, which is in accordance with another bovine rumen microbiota study (McCann, 2014). Ruminococcaceae were observed at significantly higher relative abundances in extracts prepared with the PBB method as compared to the FDSS method. This suggests that the PBB method was more effective in lysing these cells, or conversely that it was less effective in lysing cells of other microbial groups since the data is based on relative abundance. Lachnospiraceae, on the other hand, was not affected by any extraction method. In a study from Fouts et al. (2012), two members of the Lachnospiraceae, namely Butyrivibrio and Blautia, were reported to have significantly higher relative abundance in the FC as compared to the RF fraction. Partly in agreement with this, we observed a fraction effect for Butyrivibrio but not for Blautia. There was a significant decrease of the family Fibrobacteraceae for the PBB method as compared to the $\mathrm{RBB}$ and FDSS for the FC fraction samples, indicating that the PBB method was less effective in extracting Fibrobacter DNA compared to other methods. Similarly, for many other genera like Selenomonas, Succiniclasticum, Ruminococcus, Prevotella, Paraeggerthella, Syntrophococcus, Fibrobacter, Oscillibacter, Desulfobulbus and Pseudobutyrivibrio we observed a fraction effect indicating a distinct separation of microbial communities associated with RF and FC fractions, which is line with the bovine rumen study of (Fouts et al., 2012). This fraction effect might be explained by the different feed components available in the RF and FC fractions (insoluble polymers versus soluble monomers), as well as the difference in ability of cells to adhere to the plant fibres.

Together, these data reinforce the notion that not all bacterial community members and rumen fractions are equally affected by the tested extraction methods, making it difficult to come up with informed decisions as to which extraction method generates DNA that is most 
representative of the rumen bacterial community. To this end, synthetic communities of defined bacterial composition could provide additional insight, in analogy to defined mock communities assembled at the DNA level that have been used to assess the influence of different steps during molecular community assessment (Ramiro-Garcia, 2016). One could argue, however, that such synthetic communities would not sufficiently represent in vivo rumen conditions, especially for the FC fraction, and thus, particular attention will need to be paid to the design of such analyses.

Archaea community analysis - The DNA extracts obtained from the four extraction methods amplified well for qPCR but when used for 16S rRNA gene-based archaeal community assessment, not all the samples yielded PCR products. One of the possible reasons for this observation, as mentioned above, is the lower number of PCR cycles used for this particular taxon. Furthermore, archaeal diversity was found to be very limited compared to bacteria. A previous study on the comparison of DNA extraction methods on rumen fractions revealed Methanobrevibacter spp. as the most dominant methanogen from all extraction methods applied (Henderson et al, 2013). In the Henderson et al. (2013) study one universal primer pair was used to simultaneously amplify the $16 \mathrm{~S}$ and $18 \mathrm{~S}$ rRNA genes of bacteria, archaea and ciliate protozoa. This type of approach would avoid the issues encountered in this study with limited amplification of the archaeal 16S rRNA gene in some samples. A universal 16S rRNA sequencing approach, simultaneously amplifying 16S rRNA genes of both the bacteria and archaea, could also be used (Van Lingen et al., 2017). A potential drawback of a universal primer approach could be that if bacteria are more abundant, archaea might not be detected at all. As a consequence, attention should be paid to an appropriate sequencing depth that would safeguard detection and identification of archaeal populations of relative abundances $>1 \%$.

The relative distribution of different archaeal populations has previously been shown to be affected by several factors such as diet, host age or species, season and geographical region (Huang et al., 2016). In this study, in the samples for which a PCR product could be generated, the genera Methanobrevibacter followed by Methanosphaera were the dominant archaeal taxa in all the RF and FC samples. Similar to our results, both Methanobrevibacter and Methanosphaera were found to be conserved members of the methanogenic population in other bovine studies which focused on physiological interactions within the rumen microbial food web (Janssen and Kirs, 2008; Henderson et al, 2013; De Mulder et al., 2016). Methanobrevibacter species can utilize $\mathrm{H}_{2}, \mathrm{CO}_{2}$ and formate, whereas Methanosphaera species can produce $\mathrm{CH}_{4}$ only via reduction of methanol with $\mathrm{H}_{2}$ (Carberry et al., 2014b). From a recent study by (Van Lingen, 
2016) it was shown that there is no benefit for the methane producers if $\mathrm{H}_{2}$ or formate are consumed, as there is no energetic limitation due to $\mathrm{H}_{2}$ /formate accumulation in the rumen.

Interestingly in the current study, qPCR showed high numbers of methanogenic archaea in the FC fraction as compared to the RF fraction. This is consistent with the results obtained in a recent study by de Mulder and co-authors (De Mulder et al., 2016) indicating that the methanogenic archaea make up an intrinsic part of the solid fraction in the cow rumen. The presence of archaea in the FC fraction, however, is not surprising considering the close physical and metabolic interactions of methanogens with anaerobic fungi, which extensively colonise and invade rumen FC (Cheng, 2009; Jin et al., 2011). It was noted in this study that Methanosphaera seemed to have a lower relative abundance in the FC fraction compared to the RF fraction, however, further work is needed to verify this due to the limited number of biological samples used in this study.

Fungal community analysis - Sequences from anaerobic fungi (Neocallimastigomycota phylum) were obtained from five genera: Piromyces, Anaeromyces, Neocallimastix, Cyllamyces and Orpinomyces. These fungi are involved in the degradation of the lignocellulose fraction of plant material in the rumen (Kittelmann, 2012). In line with this, a larger proportion of anaerobic fungal reads was on average observed in the FC fraction as compared to the RF fraction in the fungal community analysis. This is also consistent with the qPCR analysis, which revealed a higher abundance of anaerobic fungi in FC relative to RF fractions. In our study, the anaerobic fungal community in FC fraction samples was mainly composed of the genera Cyllamyces (2 to $3 \%$ ), Neocallimastix (1 to $3 \%$ ) and Piromyces (1 to $2 \%$ ) with sequences assigned to Orpinomyces only detected in the GS33MS67 FC sample subjected to the RBB method (Table 2B). On the other hand in RF samples, no sequences from Orpinomyces were detected and a more limited amount of all of the other genera were detected compared to FC samples (Table 2A). The overall higher detection of anaerobic fungal genera in FC, as compared to the RF fraction, is likely to be due to the motile zoospores being only transiently present within rumen fluid for a short time after feeding (Orpin, 1974; 1975; 1976; 1977; Griffith et al., 2009).

Besides the identification of the five genus level groups mentioned above belonging to Neocallimastigomycota, we observed a large number of unidentified fungi belonging to both anaerobic and aerobic fungi (Table $2 \mathrm{~A}$ and $2 \mathrm{~B}$ ) as well as a high proportion of sequences that could not be further assigned to any phylum. As Neocallimastigomycota are considered to be the 
key fungal phylum relative to rumen function, community assessment of this specific community using targeted anaerobic fungal primers would provide a better approach, as amplification of aerobic fungi associated with ingested feed and water would be avoided. The larger read depth this would generate would also improve the ability to interpret the impact of different experimental factors on the taxa within the phylum, particularly as there is an increasing evidence of anaerobic fungal niche differentiation within the rumen (Griffith et al., 2009). Furthermore, a custom ITS1 database is also available specifically for the Neocallimastigomycota phylum (Koetschan, 2014).

\section{CONCLUSIONS}

DNA extraction methods clearly have an impact on the outcome of downstream rumen microbial community analyses, including relative abundances of specific community members. From this study, this effect was evident with the bacterial community, however, no single extraction method could be concluded as being ineffective. Rather, every extraction method presented its own strengths and weaknesses in observing specific bacterial families. DNA extracted using the PBB method resulted in higher relative abundance of Ruminococcaceae than the FDSS method, whereas relative abundance of Fibrobacteraceae was lower compared to the RBB method. Whilst the effect of DNA extraction method was limited compared to that of rumen fraction, differences due to both DNA extraction method and fraction were observed for certain taxa. Further investigation is needed to determine if this is due to an issue with the physical nature of the different fractions, or merely due to the inherent differences in the microbes present within the fractions. Furthermore, careful selection of the microbial community assessment approach is needed to avoid the issues encountered within this study with respect to archaea and anaerobic fungi. Archaeal 16S rRNA gene barcoded amplicons are best generated in combination with other taxa (bacteria or bacteria and protozoa), whilst anaerobic fungi should be generated with phylum specific primers rather than those designed to cover the entire fungal kingdom. In summary, the comprehensive assessment of observed communities of bacteria, archaea and fungi described here provides insight into a rational basis for selecting an optimal methodology to obtain a representative picture of the rumen microbiome. 


\section{ACKNOWLEDGEMENTS}

This work was funded by TI Food and Nutrition, a public-private partnership on precompetitive research in food and nutrition. We thank the staff of the experimental facilities (Carus, Wageningen, the Netherlands) for their assistance. Special thanks to Sven Alferink (Wageningen University \& Research, the Netherlands) for his assistance during sampling. 


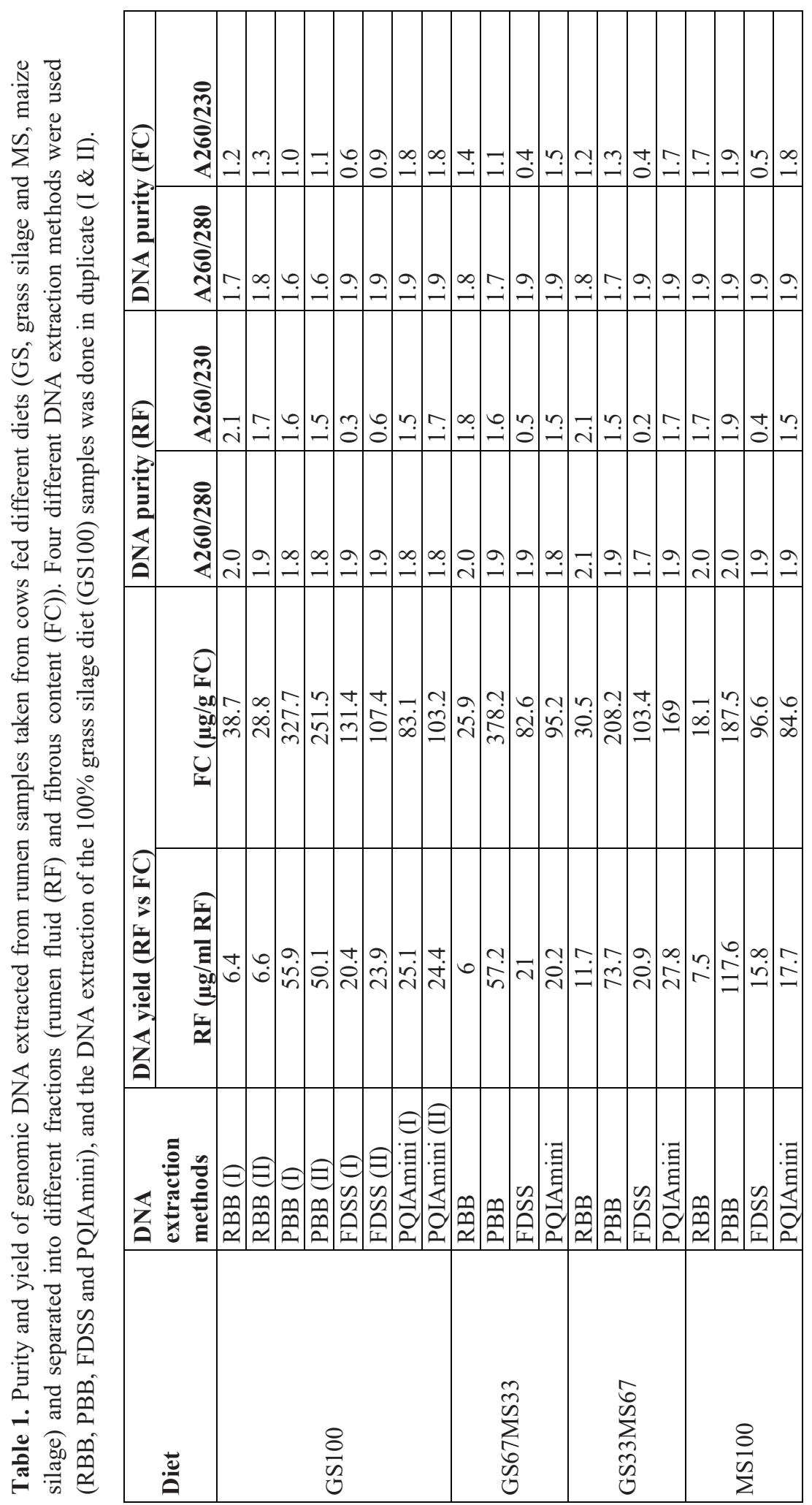




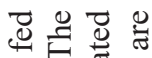

过

의.$\Xi$ च

क कै

ชั 요

글 흐음

完

घ

을

क व

용

है

की

ขิ

矛。․

ठํㅇ웡

을

음. 灵

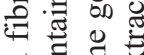

긍 웡

过吾艺

들

象要

चี

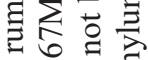

뉼

o bo है

\pm i

可 0

○

可

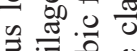

ज的。

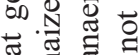

.을 훙ㅎㅀ

牙.

웅응 풯

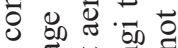

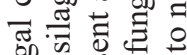

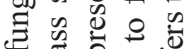

4

등

员

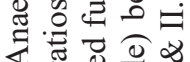

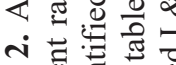

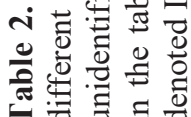
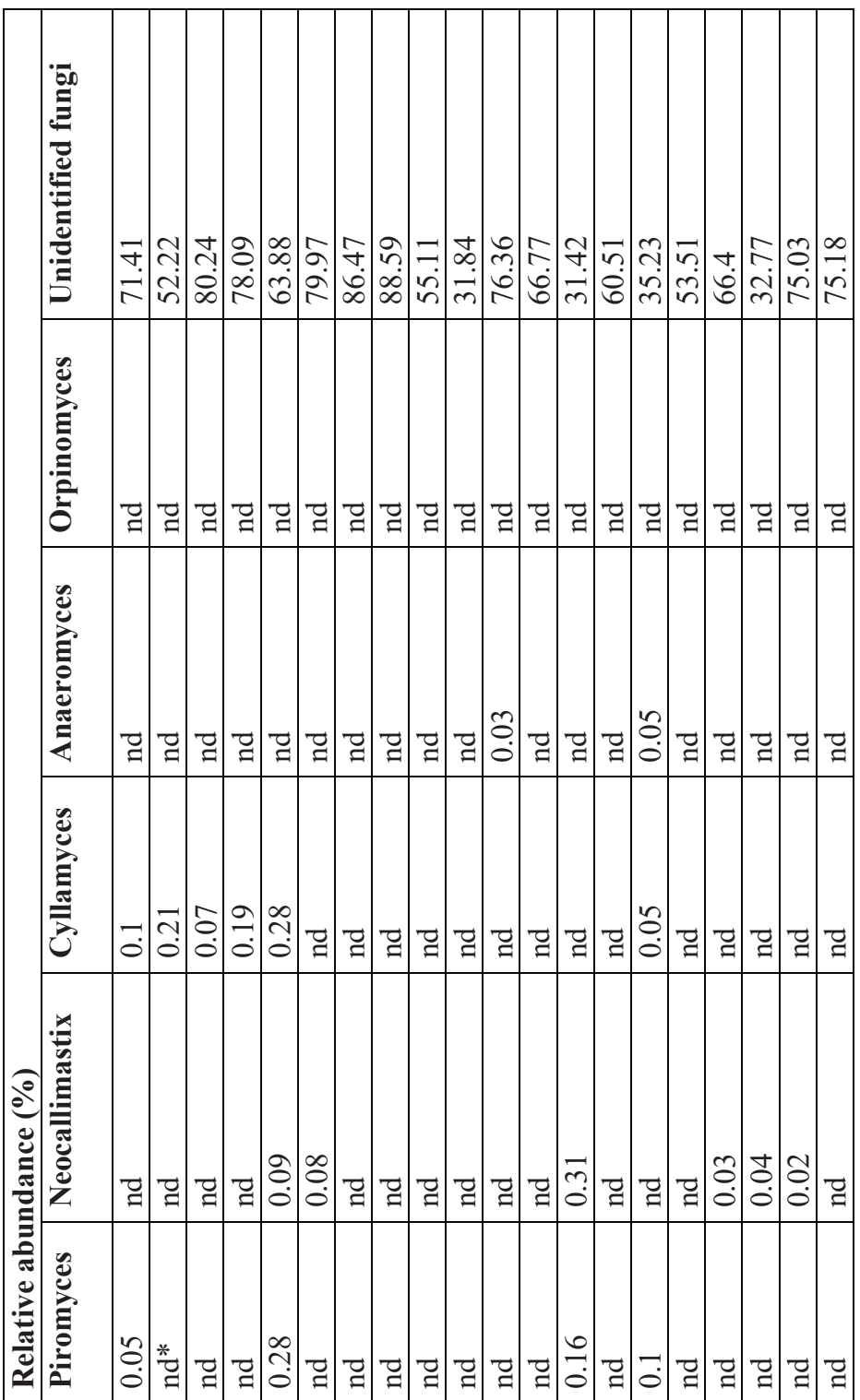

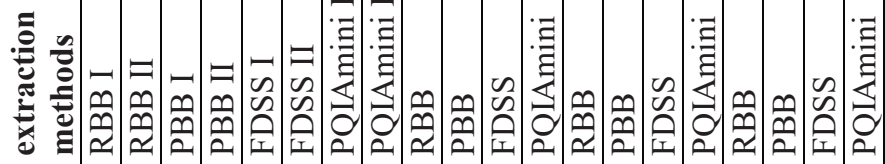

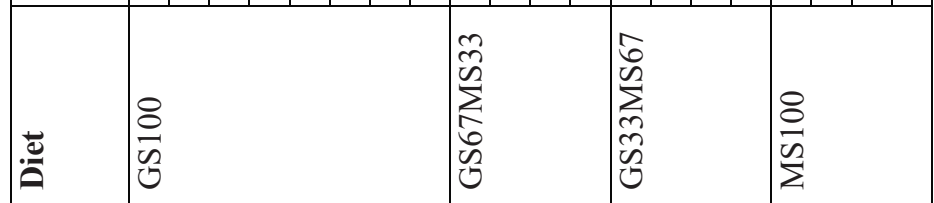




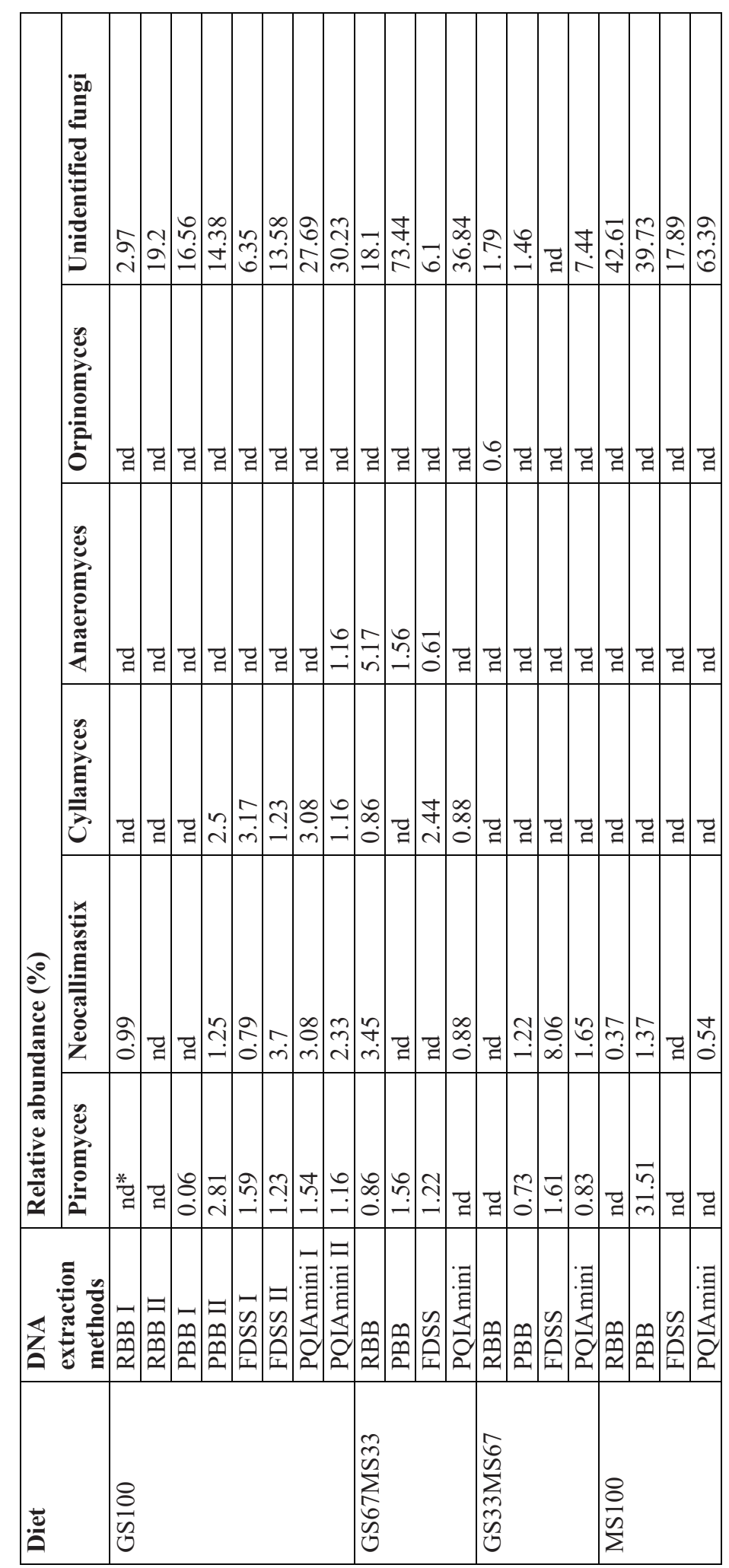




\section{REFERENCES}

Abarenkov, K., Henrik Nilsson, R., Larsson, K.H., Alexander, I.J., Eberhardt, U., Erland, S., et al. (2010). The UNITE database for molecular identification of fungi--recent updates and future perspectives. New Phytol 186(2), 281-285. doi: 10.1111/j.14698137.2009.03160.x.

Altschul, S.F., Gish, W., Miller, W., Myers, E.W., and Lipman, D.J. (1990). Basic local alignment search tool. J Mol Biol 215(3), 403-410. doi: 10.1016/S0022-2836(05)803602.

Bauchop, T. (1979). Rumen anaerobic fungi of cattle and sheep. Appl Environ Microbiol 38(1), $148-158$.

Caporaso, J.G., Kuczynski, J., Stombaugh, J., Bittinger, K., Bushman, F.D., Costello, E.K., et al. (2010). QIIME allows analysis of high-throughput community sequencing data. Nat Meth 7(5), 335-336.

Carberry, C.A., Waters, S.M., Kenny, D.A., and Creevey, C.J. (2014). Rumen methanogenic genotypes differ in abundance according to host residual feed intake phenotype and diet type. Appl Environ Microbiol 80(2), 586-594. doi: 10.1128/AEM.03131-13.

Cheng, Y.F., Edwards, J. E., Allison, G. G., Zhu, W. Y., Theodorou, M. K. (2009). Diversity and activity of enriched ruminal cultures of anaerobic fungi and methanogens grown together on lignocellulose in consecutive batch culture. Bioresour Technol 100(20), 4821-4828. doi: 10.1016/j.biortech.2009.04.031.

Creevey, C.J., Kelly, W.J., Henderson, G., and Leahy, S.C. (2014). Determining the culturability of the rumen bacterial microbiome. Microb Biotechnol 7(5), 467-479. doi: 10.1111/17517915.12141.

Daims, H., Bruhl, A., Amann, R., Schleifer, K.H., and Wagner, M. (1999). The domain-specific probe EUB338 is insufficient for the detection of all Bacteria: development and evaluation of a more comprehensive probe set. Syst Appl Microbiol 22(3), 434-444. doi: 10.1016/S0723-2020(99)80053-8.

De Menezes, A.B., Lewis, E., O'Donovan, M., O'Neill, B.F., Clipson, N., and Doyle, E.M. (2011). Microbiome analysis of dairy cows fed pasture or total mixed ration diets. FEMS Microbiol Ecol 78(2), 256-265. doi: 10.1111/j.1574-6941.2011.01151.x.

De Mulder, T., Goossens, K., Peiren, N., Vandaele, L., Haegeman, A., De Tender, C., et al. (2016). Exploring the methanogen and bacterial communities of rumen environments: solid adherent, fluid and epimural. FEMS Microbiol Ecol. doi: 10.1093/femsec/fiw251.

Dehority, B.A. (1991). Effects of microbial synergism on fibre digestion in the rumen. Proc Nutr Soc 50(2), 149-159.

Devi, S.G., Fathima, A.A., Radha, S., Arunraj, R., Curtis, W.R., and Ramya, M. (2015). A rapid and economical method for efficient DNA extraction from diverse soils suitable for metagenomic applications. PLoS One 10(7), e0132441. doi: 10.1371/journal.pone.0132441.

Dojka, M.A., Hugenholtz, P., Haack, S.K., and Pace, N.R. (1998). Microbial diversity in a hydrocarbon- and chlorinated-solvent-contaminated aquifer undergoing intrinsic bioremediation. Appl Environ Microbiol 64(10), 3869-3877.

Edwards J.E., M.N.R., Travis A.J., Wallace, R.J. (2004). 16S rDNA library-based analysis of ruminal bacterial diversity. Antonie Van Leeuwenhoek 86(3), 263-281. doi: 10.1023/B:ANTO.0000047942.69033.24.

Edwards, J.E., Kingston-Smith, A.H., Jimenez, H.R., Huws, S.A., Skøt, K.P., Griffith, G.W., et al. (2008). Dynamics of initial colonization of nonconserved perennial ryegrass by 
anaerobic fungi in the bovine rumen. FEMS Microbiol Ecol 66(3), 537-545. doi: 10.1111/j.1574-6941.2008.00563.x.

Fliegerova, K., Tapio, I., Bonin, A., Mrazek, J., Callegari, M.L., Bani, P., et al. (2014). Effect of DNA extraction and sample preservation method on rumen bacterial population. Anaerobe 29, 80-84. doi: 10.1016/j.anaerobe.2013.09.015.

Fouts, D.E., Szpakowski, S., Purushe, J., Torralba, M., Waterman, R.C., MacNeil, M.D., et al. (2012). Next generation sequencing to define prokaryotic and fungal diversity in the bovine rumen. PLoS One 7(11), e48289. doi: 10.1371/journal.pone.0048289.

Fredricks, D.N., Smith, C., and Meier, A. (2005). Comparison of six DNA extraction methods for recovery of fungal DNA as assessed by quantitative PCR. J Clin Microbiol 43(10), 5122-5128. doi: 10.1128/JCM.43.10.5122-5128.2005.

Fujimoto, S., Nakagami, Y., Kojima, F. (2004). Optimal bacterial DNA isolation method using bead-beating technique, an original study in the lab of Dr. Fujimoto, Kyusyu University. 3, 33-38.

Gantner, S., Andersson, A.F., Alonso-Saez, L., and Bertilsson, S. (2011). Novel primers for 16S rRNA-based archaeal community analyses in environmental samples. J Microbiol Methods 84(1), 12-18. doi: 10.1016/j.mimet.2010.10.001.

Griffith, G.W., Ozkose, E., Theodorou, M.K., and Davies, D.R. (2009). Diversity of anaerobic fungal populations in cattle revealed by selective enrichment culture using different carbon sources. Fun Ecol 2(2), 87-97. doi: 10.1016/j.funeco.2009.01.005.

Gruninger, R.J., Puniya, A.K., Callaghan, T.M., Edwards, J.E., Youssef, N., Dagar, S.S., et al. (2014). Anaerobic fungi (phylum Neocallimastigomycota): advances in understanding their taxonomy, life cycle, ecology, role and biotechnological potential. FEMS Microbiol Ecol 90(1), 1-17. doi: 10.1111/1574-6941.12383.

Guss, A.M., Roeselers, G., Newton, I.L., Young, C.R., Klepac-Ceraj, V., Lory, S., et al. (2011). Phylogenetic and metabolic diversity of bacteria associated with cystic fibrosis. ISME J 5(1), 20-29. doi: 10.1038/ismej.2010.88.

Haas, B.J., Gevers, D., Earl, A.M., Feldgarden, M., Ward, D.V., Giannoukos, G., et al. (2011). Chimeric 16S rRNA sequence formation and detection in Sanger and 454-pyrosequenced PCR amplicons. Genome Res 21(3), 494-504. doi: 10.1101/gr.112730.110.

Haitjema, C.H., Solomon, K.V., Henske, J.K., Theodorou, M.K., and O'Malley, M.A. (2014). Anaerobic gut fungi: Advances in isolation, culture, and cellulolytic enzyme discovery for biofuel production. Biotechnol Bioeng 111(8), 1471-1482. doi: 10.1002/bit.25264.

Hamady, M., Walker, J.J., Harris, J.K., Gold, N.J., and Knight, R. (2008). Error-correcting barcoded primers for pyrosequencing hundreds of samples in multiplex. Nat Methods 5(3), 235-237. doi: 10.1038/nmeth.1184.

Henderson, G., Cox, F., Kittelmann, S., Miri, V.H., Zethof, M., Noel, S.J., et al. (2013). Effect of DNA extraction methods and sampling techniques on the apparent structure of cow and sheep rumen microbial communities. PLoS One 8(9), e74787. doi: 10.1371/journal.pone.0074787.

Huang, X.D., Martinez-Fernandez, G., Padmanabha, J., Long, R., Denman, S.E., and McSweeney, C.S. (2016). Methanogen diversity in indigenous and introduced ruminant species on the Tibetan plateau. Archaea 2016, 5916067. doi: 10.1155/2016/5916067.

Hungate, R.E. (1966a). Chapter II - The rumen bacteria. The Rumen and its Microbes, 8-90. doi: 10.1016/B978-1-4832-3308-6.50005-X.

Hungate, R.E. (1966b). Chapter III - The rumen protozoa. The Rumen and its Microbes, 91-147. doi: 10.1016/B978-1-4832-3308-6.50006-1. 
Huws, S.A., Edwards, J.E., Creevey, C.J., Rees Stevens, P., Lin, W., Girdwood, S.E., et al. (2016). Temporal dynamics of the metabolically active rumen bacteria colonizing fresh perennial ryegrass. FEMS Microbiol Ecol 92(1). doi: 10.1093/femsec/fiv137.

Jaeggi, T., Kortman, G.A., Moretti, D., Chassard, C., Holding, P., Dostal, A., et al. (2014). Iron fortification adversely affects the gut microbiome, increases pathogen abundance and induces intestinal inflammation in Kenyan infants. Gut. doi: 10.1136/gutjnl-2014307720.

Janssen, P.H., and Kirs, M. (2008). Structure of the archaeal community of the rumen. Appl Environ Microbiol 74(12), 3619-3625. doi: 10.1128/AEM.02812-07.

Jin, W., Cheng, Y.F., Mao, S.Y., and Zhu, W.Y. (2011). Isolation of natural cultures of anaerobic fungi and indigenously associated methanogens from herbivores and their bioconversion of lignocellulosic materials to methane. Bioresour Technol 102(17), 79257931. doi: 10.1016/j.biortech.2011.06.026.

Jones, E., Oliphant, T., Peterson, P., et al. (2001). Open source scientific tools for python. URL http://www.scipy.org/

Kittelmann, S., Naylor, G.E., Koolaard, J.P., Janssen, P.H. (2012). A proposed taxonomy of anaerobic fungi (class Neocallimastigomycetes) suitable for large-scale sequence-based community structure analysis. PLOS ONE 7(5), e36866.

Koetschan, C., Kittelmann, S., Lu, J., Al Halbouni, D., Jarvis, G.N., Müller,T., Wolf,M., Janssen, P.H. (2014). Internal transcribed spacer 1 secondary structure analysis reveals a common core throughout the anaerobic fungi (Neocallimastigomycota). PLoS ONE 9(3), e91928. doi: 10.1371/journal.pone.0091928.

Lazarevic, V., Gaïa, N., Girard, M., François, P., and Schrenzel, J. (2013). Comparison of DNA extraction methods in analysis of salivary bacterial communities. PLoS ONE 8(7), e67699.

Leimena, M., Ramiro-Garcia, J., Davids, M., van den Bogert, B., Smidt, H., Smid, E., et al. (2013). A comprehensive metatranscriptome analysis pipeline and its validation using human small intestine microbiota datasets. BMC Genomics 14(1), 530.

Li, Y.D., Ma, S., Zhang, X.J., Huang, S.W., Yang, H., Zhao, F., et al. (2014). Evaluation of bacterial and archaeal diversity in the rumen of Xiangxi yellow cattle (Bos taurus) fed Miscanthus sinensis or common mixed feedstuff. Annals of Microbiology 64(3), 1385 1394. doi: 10.1007/s13213-013-0783-x.

Liggenstoffer, A.S., Youssef, N.H., Couger, M.B., and Elshahed, M.S. (2010). Phylogenetic diversity and community structure of anaerobic gut fungi (phylum Neocallimastigomycota) in ruminant and non-ruminant herbivores. 4(10), 1225-1235.

Lu, L., Xing, D., Ren, N. (2012). Bioreactor performance and quantitative analysis of methanogenic and bacterial community dynamics in microbial electrolysis cells during large temperature fluctuations. Environ Sci Technol 46(12), 6874-6881. doi: 10.1021/es300860a.

Mao, S., Zhang, M., Liu, J., and Zhu, W. (2015). Characterising the bacterial microbiota across the gastrointestinal tracts of dairy cattle: membership and potential function. Sci Rep 5, 16116. doi: 10.1038/srep16116.

Marvin-Sikkema, F.D., Richardson, A. J., Stewart, C. S., Gottschal, J. C., Prins, R. A. (1990). Influence of hydrogen-consuming bacteria on cellulose degradation by anaerobic fungi. Appl Environ Microbiol 56(12), 3793-3797.

McCann, J.C., Wickersham, T.A., Loor, J.J., (2014). High-throughput methods redefine the rumen microbiome and its relationship with nutrition and metabolism. Bioinformatics and Biology Insights 8, 109-125. doi: 10.4137/bbi.s15389. 
Meale, S.J., McAllister, T.A., Beauchemin, K.A., Harstad, O.M., Chaves, A.V. (2012). Strategies to reduce greenhouse gases from ruminant livestock. Acta Agriculturae Acandinavica, Section A - Animal Science 62(4), 199-211. doi: 10.1080/09064702.2013.770916.

Orpin, C.G. (1974). The rumen flagellate Callimastix frontalis: does sequestration occur? J Gen Microbiol 84(2), 395-398. doi: 10.1099/00221287-84-2-395.

Orpin, C.G. (1975). Studies on the rumen flagellate Neocallimastix frontalis. J Gen Microbiol 91(2), 249-262. doi: 10.1099/00221287-91-2-249.

Orpin, C.G. (1976). Studies on the rumen flagellate Sphaeromonas communis. J Gen Microbiol 94(2), 270-280. doi: 10.1099/00221287-94-2-270.

Orpin, C.G. (1977). The rumen flagellate Piromonas communis: its life-history and invasion of plant material in the rumen. J Gen Microbiol 99(1), 107-117. doi: 10.1099/00221287-99$1-107$.

Paul, K., Nonoh, J. O., Mikulski, L., Brune, A. (2012). "Methanoplasmatales," Thermoplasmatales-related archaea in termite guts and other environments, are the seventh order of methanogens. Appl Environ Microbiol 78(23), 8245-8253. doi: 10.1128/AEM.02193-12.

Ramiro-Garcia, J., Hermes, GDA., Giatsis, C., Sipkema, D., Zoetendal, EG., Schaap, PJ., Smidt, $\mathrm{H}$ (2016). NG-Tax, a highly accurate and validated pipeline for analysis of $16 \mathrm{~S}$ rRNA amplicons from complex biomes [version 1; referees: awaiting peer review]. 5.

Russell, J.B., Hespell, R.B. (1981). Microbial rumen fermentation. J Dair Sci 64(6), 1153-1169. doi: 10.3168/jds.S0022-0302(81)82694-X.

Smilauer, P., Leps, J. (2014). Multivariate analysis of ecological data using Canoco 5, 2nd edn. New York, NY: Cambridge University Press.

Suzuki, M.T., Beja, O., Taylor, L.T., and Delong, E.F. (2001). Phylogenetic analysis of ribosomal RNA operons from uncultivated coastal marine bacterioplankton. Environ Microbiol 3(5), 323-331. doi: DOI 10.1046/j.1462-2920.2001.00198.x.

Suzuki, M.T., Taylor, L.T., and DeLong, E.F. (2000). Quantitative analysis of small-subunit rRNA genes in mixed microbial populations via 5'-nuclease assays. Appl Environ Microbiol 66(11), 4605-4614.

Ter Braak, C.J.F., Smilauer, P. (2012). Canoco reference manual and user's guide: software for ordination, version 5.0.

Teunissen, M.J., Kets, E. P. W., Op den Camp, H. J. M., Huis in't Veld, J. H. J., Vogels, G. D. (1992). Effect of coculture of anaerobic fungi isolated from ruminants and non-ruminants with methanogenic bacteria on cellulolytic and xylanolytic enzyme activities. Archives of Microbiology 157(2), 176-182. doi: 10.1007/bf00245287.

van den Bogert, B., De Vos, W.M., Zoetendal, E.G., and Kleerebezem, M. (2011). Microarray analysis and barcoded pyrosequencing provide consistent microbial profiles depending on the source of human intestinal samples. Appl Environ Microbiol 77(6), 2071-2080. doi: 10.1128/AEM.02477-10.

van den Bogert, B., Erkus, O., Boekhorst, J., de Goffau, M., Smid, E.J., Zoetendal, E.G., et al. (2013). Diversity of human small intestinal Streptococcus and Veillonella populations. FEMS Microbiol Ecol 85(2), 376-388. doi: 10.1111/1574-6941.12127.

van Gastelen, S., Antunes-Fernandes, E.C., Hettinga, K.A., Klop, G., Alferink, S.J., Hendriks, W.H., et al. (2015). Enteric methane production, rumen volatile fatty acid concentrations, and milk fatty acid composition in lactating Holstein-Friesian cows fed grass silage- or corn silage-based diets. J Dairy Sci 98(3), 1915-1927. doi: 10.3168/jds.2014-8552.

van Lingen, H., Edwards, J., Vaidya, J., van Gastelen, S., van den Bogert, B., Saccenti, E., et al. (2017). Diurnal dynamics of gaseous and dissolved metabolites and microbiota 
composition in the bovine rumen. Frontiers in Microbiology 8(425). doi: 10.3389/fmicb.2017.00425.

van Lingen, H., Plugge, C. M., Fadel, J. G., Kebreab, E., Bannink, A., Dijkstra, J. (2016). Thermodynamic driving force of hydrogen on rumen microbial metabolism: A theoretical investigation. PLOS ONE 11(10), e0161362.

Villegas-Rivera, G., Vargas-Cabrera, Y., Gonzalez-Silva, N., Aguilera-Garcia, F., GutierrezVazquez, E., Bravo-Patino, A., et al. (2013). Evaluation of DNA extraction methods of rumen microbial populations. World J Microbiol Biotechnol 29(2), 301-307. doi: 10.1007/s11274-012-1183-2.

Wang, Q., Garrity, G.M., Tiedje, J.M., and Cole, J.R. (2007). Naive Bayesian classifier for rapid assignment of rRNA sequences into the new bacterial taxonomy. Appl Environ Microbiol 73(16), 5261-5267. doi: 10.1128/AEM.00062-07.

Yu, Y., Lee, C., Kim, J., and Hwang, S. (2005). Group-specific primer and probe sets to detect methanogenic communities using quantitative real-time polymerase chain reaction. Biotechnol Bioeng 89(6), 670-679. doi: 10.1002/bit.20347.

$\mathrm{Yu}, \mathrm{Z}$., and Morrison, M. (2004). Improved extraction of PCR-quality community DNA from digesta and fecal samples. Biotechniques 36(5), 808-812.

Zhou, M., Hernandez-Sanabria, E., and Guan, L.L. (2009). Assessment of the microbial ecology of ruminal methanogens in cattle with different feed efficiencies. Appl Environ Microbiol 75(20), 6524-6533. doi: 10.1128/AEM.02815-08.

Zoetendal, E.G., Heilig, H.G.H.J., Klaassens, E.S., Booijink, C.C.G.M., Kleerebezem, M., Smidt, H., et al. (2006). Isolation of DNA from bacterial samples of the human gastrointestinal tract. 1(2), 870-873.

Zoetendal, E.G., Heilig, H.G.H.J., Klaassens, E.S., Booijink, Carien C.G.M., Kleerebezem, M., Smidt, H., De Vos, W.M. (2006). Isolation of DNA from bacterial samples of the human gastrointestinal tract. 1(2), 870-873. 
RF

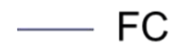

FC

RF

FC
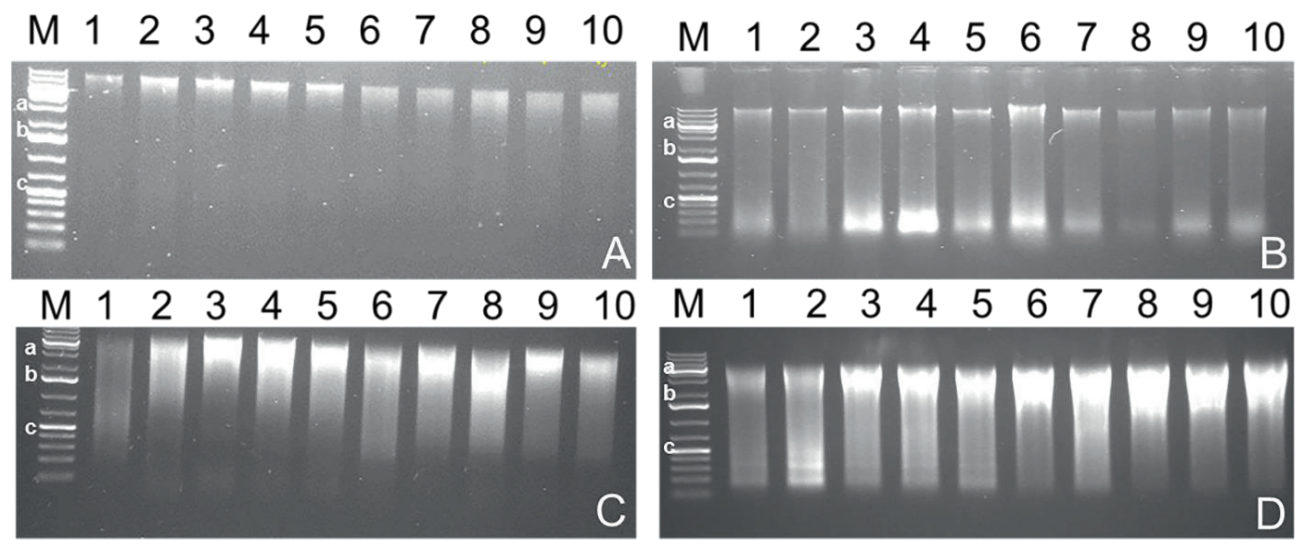

Figure S1 Integrity of genomic DNA extracted with different methods visualized on a $1 \%$ agarose gel. DNA obtained from rumen fluid (RF: lanes 1-5) and fibrous content (FC: 6-10) samples using method RBB (A), PBB (B), FDSS (C) and PQIAmini (D). Lanes represent cows fed the different diets as follows: MS100 (1 \& 6), GS33MS67 (2 \& 7), GS100 (3, 4, 8, and 9, as two technical replicates for this diet) and GS67MS33 (5 and 10). Lane M: $1 \mathrm{~kb}$ plus DNA size marker was used for all gels, a: $5000 \mathrm{bp}, \mathrm{b}: 1000 \mathrm{bp}$, c: $500 \mathrm{bp}$. 
A
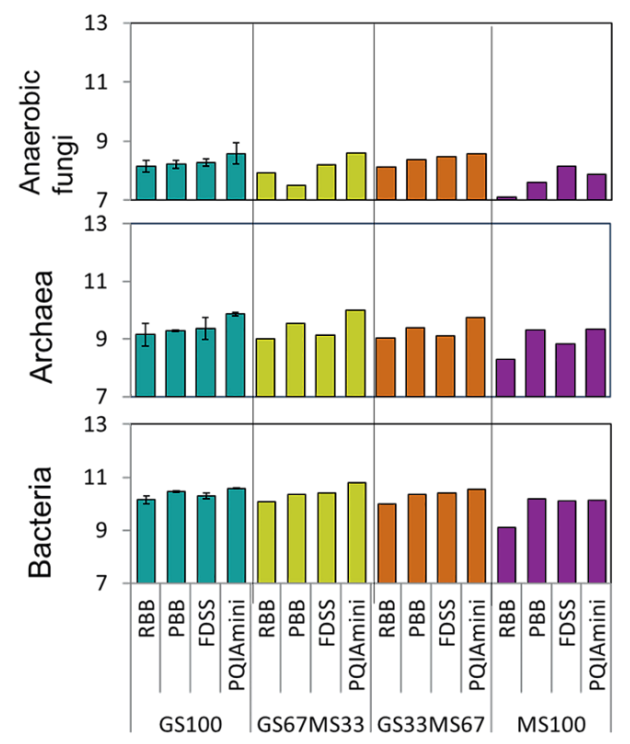

B

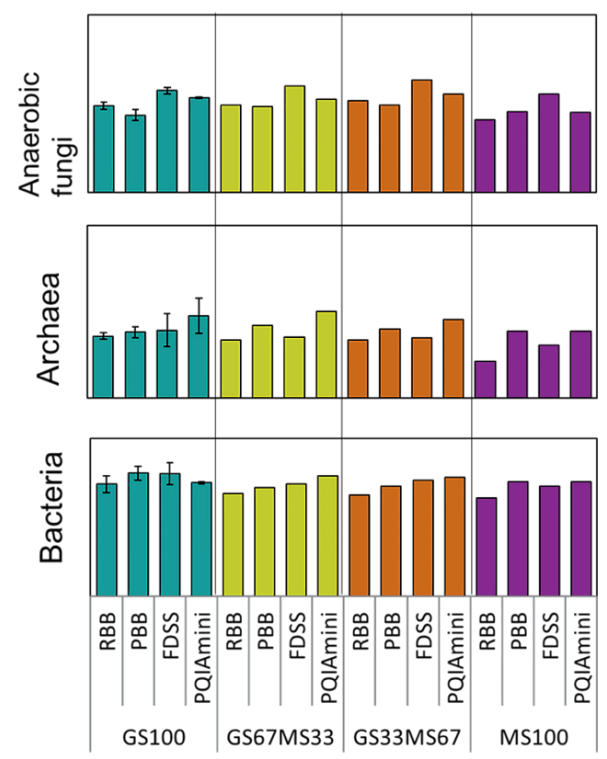

Figure S2. Bacterial and archaeal 16S rRNA and anaerobic fungal 5.8S rRNA gene copy numbers per $\mathrm{ml}$ of rumen fluid (RF) or gram fibrous content (FC) samples from dairy cows fed different ratios of grass silage (GS) to maize silage (MS), as measured in DNA extracted using four different methods (RBB, PBB, FDSS and PQIAmini). Bars represent the mean of triplicate qPCR determinations for a single sample DNA extract with the exception of GS100, where they represent the mean of duplicate DNA extracts and the error bars represent their variation. Data is presented as $\log 10$ copy numbers per ml RF (A) and gram FC (B). 
A

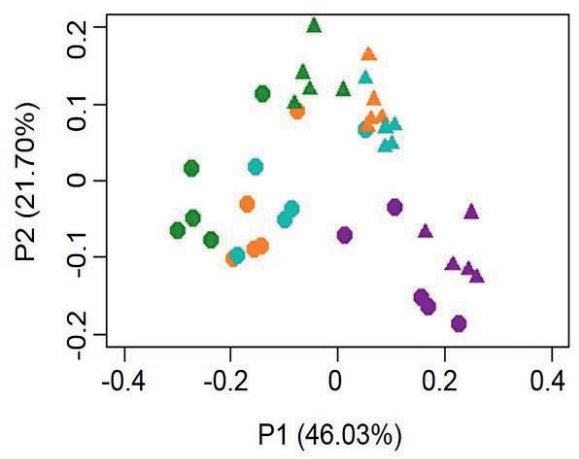

B

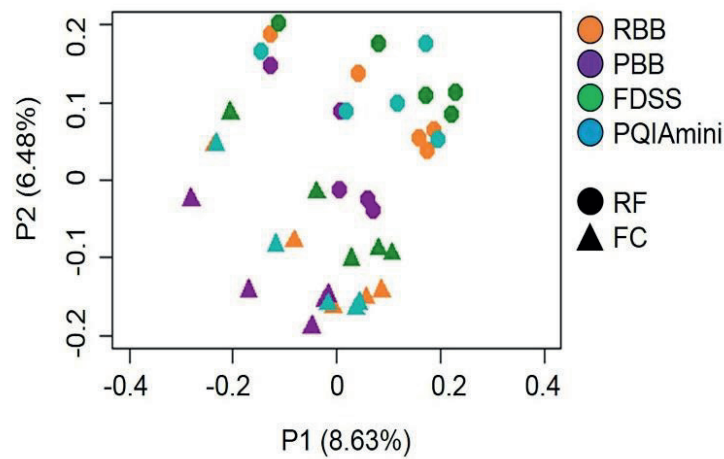

Figure S3. Weighted (A) and unweighted (B) UniFrac principal coordinate analysis (PCoA) of the rumen bacterial community at the OTU level. Datapoints are coded in terms of DNA extraction method (RBB, PBB, FDSS and PQIAmini) and fraction (rumen fluid (RF) and fibrous content (FC)). The GS100 diet has duplicate DNA extracts presented as individual datapoints. The percentages given at P1 and P2 indicate the amount of variation represented by the co-ordinate axes. 
Table S1. Bacterial families and genera that significantly differ $(\mathrm{p}<0.05)$ in relative abundance in rumen fluid (RF) versus fibrous content (FC) fraction are shown in (A), and different DNA extraction method (RBB, PBB, FDSS and PQIAmini) comparisons are shown in (B). Relative abundance (\%) values presented are the mean \pm standard deviation.

$\mathbf{A}$

\begin{tabular}{llll}
\hline Taxon & RF & FC & p value \\
\hline Family & & $0.0 \pm 0.0$ & \\
Desulfobulbaceae & $0.1 \pm 0.1$ & $2.7 \pm 2.3$ & 0.030 \\
Fibrobacteraceae & $0.6 \pm 0.5$ & $12.5 \pm 3.3$ & 0.020 \\
Lachnospiraceae & $8.0 \pm 3.5$ & $11.6 \pm 3.1$ & 0.006 \\
Prevotellaceae & $29.4 \pm 11.1$ & $9.0 \pm 1.9$ & 0.001 \\
Ruminococcaceae & $6.1 \pm 1.7$ & & 0.040 \\
Genus & & $1.7 \pm 0.8$ & \\
Butyrivibrio & $0.8 \pm 0.3$ & $0.0 \pm 0.0$ & 0.0001 \\
Desulfobulbus & $0.1 \pm 0.0$ & $2.8 \pm 2.3$ & 0.036 \\
Fibrobacter & $0.5 \pm 0.4$ & $0.1 \pm 0.1$ & 0.021 \\
Oscillibacter & $0.0 \pm 0.0$ & $0.0 \pm 0.0$ & 0.027 \\
Paraeggerthella & $0.1 \pm 0.0$ & $4.7 \pm 2.9$ & 0.0002 \\
Prevotella & $18.4 \pm 8.1$ & $0.5 \pm 0.2$ & $<0.0001$ \\
Pseudobutyrivibrio & $0.2 \pm 0.1$ & $1.0 \pm 0.5$ & 0.010 \\
Ruminococcus & $0.3 \pm 0.2$ & $0.0 \pm 0.0$ & $<0.0001$ \\
Selenomonas & $0.2 \pm 0.1$ & $0.5 \pm 0.3$ & $<0.0001$ \\
Succiniclasticum & $2.1 \pm 1.1$ & $0.3 \pm 0.1$ & $<0.0001$ \\
Syntrophococcus & $0.2 \pm 0.1$ & & 0.009 \\
\hline
\end{tabular}

B

\begin{tabular}{lll}
\hline Taxon & DNA extraction method & p value \\
\hline Family & & \\
Anaerolineaceae & PQIAmini $(0.1 \pm 0.1)$ vs PBB $(0.3 \pm 0.1)$ & 0.027 \\
Anaerolineaceae & PBB $(0.3 \pm 0.1)$ vs RBB $(0.1 \pm 0.0)$ & 0.038 \\
Fibrobacteraceae & FDSS $(3.2 \pm 1.4)$ vs PBB $(0.2 \pm 0.1)$ & 0.028 \\
Fibrobacteraceae & PBB $(0.2 \pm 0.1)$ vs RBB $(1.6 \pm 0.7)$ & 0.038 \\
Halomonadaceae & FDSS $(0.02 \pm 0.0)$ vs PQIAmini $(0.01 \pm 0.01)$ & 0.008 \\
Halomonadaceae & PBB $(0.2 \pm 0.1)$ vs FDSS $(0.02 \pm 0.0)$ & 0.028 \\
Ruminococcaceae & FDSS $(5.8 \pm 0.6)$ vs PBB $(9.6 \pm 1.8)$ & 0.038 \\
Genus & & \\
Fibrobacter & RBB $(1.6 \pm 1.4)$ vs PBB $(0.1 \pm 0.1)$ & 0.038 \\
Fibrobacter & PBB $(0.1 \pm 0.1)$ vs FDSS $(3.5 \pm 3.0)$ & 0.038 \\
\hline
\end{tabular}


Chapter 2 


\section{Chapter 3}

\section{Characterization of dairy cow rumen bacterial and archaeal communities associated with grass silage and maize silage based diets}

Jueeli D. Vaidya ${ }^{1,2}$, Sanne van Gastelen ${ }^{1,3}$, Hauke Smidt ${ }^{2}$, Caroline M. Plugge ${ }^{2}$, Joan E. Edwards ${ }^{1,2}$

${ }^{1}$ Top Institute Food and Nutrition, Wageningen, The Netherlands

2 Laboratory of Microbiology, Wageningen University \& Research, Wageningen, The Netherlands

${ }^{3}$ Animal Nutrition Group, Wageningen University \& Research, Wageningen, The Netherlands

Submitted 


\begin{abstract}
Replacing grass silage (GS) with maize-silage (MS) in the diets of dairy cattle offers an effective strategy to decrease enteric methane $\left(\mathrm{CH}_{4}\right)$ production without negatively affecting dairy cow performance. The present study aimed to characterise the rumen bacterial and archaeal communities in dairy cows fed different ratios of MS and GS, and places the findings in the context of ruminal fermentation as well as previously reported $\mathrm{CH}_{4}$ emissions. Rumen fluid samples from 12 rumen cannulated dairy cows were collected after 10 and 17 days of feeding one of four diets. All diets had a roughage: concentrate ratio of $80: 20$ based on dry matter (DM). Roughage consisted of either $1000 \mathrm{~g} / \mathrm{kg}$ DM GS (GS100), $1000 \mathrm{~g} / \mathrm{kg}$ DM MS (GS0), or a mixture of both silages [667 g/kg DM GS and $333 \mathrm{~g} / \mathrm{kg}$ DM MS (GS67); $333 \mathrm{~g} / \mathrm{kg}$ DM GS and $677 \mathrm{~g} / \mathrm{kg}$ DM MS (GS33)]. In terms of ruminal VFA, no significant diet effects were found but the molar proportions of isovalerate were affected by time, being lower on day 17 than day 10. Bacterial and archaeal concentrations were not affected by diet, but increased from day 10 to day 17 . Bacterial community composition was affected by diet, time and diet $\times$ time, whereas archaeal community composition was only affected by diet. Several bacterial and archaeal genera could be associated with diet, but not with time. In the case of archaea, relative abundance of Methanobrevibacter was positively associated with the GS0 diet. Bacterial genera belonging to the Succinivibrionaceae and Ruminococcaceae were among those associated with maize silage diets, suggesting a role in the low methane emissions observed in a previous study. The observed time effects indicate that the rumen microbiome was not stable after 10 days of feeding the diets.
\end{abstract}

\title{
KEYWORDS
}

Dairy cow; rumen fluid; grass silage; maize silage; rumen bacterial community; rumen archaeal community; fermentation products 


\section{INTRODUCTION}

Dietary composition, geographical location, cow breed and the health of the host animal are known factors that influence the rumen microbial community structure (De Menezes et al., 2011a; Henderson et al., 2015b). Of all these factors, diet is considered to be the largest driver of change in ruminal fermentation, as well as of changes in the associated microbiota and enteric methane $\left(\mathrm{CH}_{4}\right)$ production (van Lingen et al., 2016; van Lingen et al., 2017b). Enteric $\mathrm{CH}_{4}$ is produced by ruminal methanogenic archaea and not only contributes to $16 \%$ of the total anthropogenic global greenhouse gas emissions but also represents $2-12 \%$ energy loss for the host (Johnson and Johnson, 1995; IPCC, 2006). Enteric fermentation in ruminants is considered the largest source of $\mathrm{CH}_{4}$ emissions in agriculture (IPCC, 2014). Decreasing $\mathrm{CH}_{4}$ emissions has, therefore, become a major concern in ruminant livestock production, and has been a prime research focus in recent years. One of the most effective ways of reducing $\mathrm{CH}_{4}$ emissions from dairy cattle is through dietary strategies.

Grass silage (GS) and maize silage (MS) represent the major components in dairy cow diets. Generally, GS has a higher fibre content (i.e., neutral detergent fibre and acid detergent fibre), whereas MS has a higher starch content. Fermentation of starch favours the ruminal production of propionate and decreases ruminal $\mathrm{pH}$, which reduces hydrogen availability and activity of rumen methanogens and consequently enteric $\mathrm{CH}_{4}$ production (van Kessel, 1996; Hook et al., 2010; Brask et al., 2013). Recently, van Gastelen et al. (2015) demonstrated that replacing GS with MS in dairy cow diets has an impact on ruminal fermentation and $\mathrm{CH}_{4}$ emission. Replacing GS with MS led to a decrease in $\mathrm{CH}_{4}$ emissions and an increase in the molar proportions of butyrate, whereas the total volatile fatty acid (VFA) concentration and the molar proportions of acetate and propionate were unaffected (van Gastelen et al., 2015).

It is unclear how the changes reported by van Gastelen et al. (2015) in $\mathrm{CH}_{4}$ emissions and fermentation characteristics are related to changes in the rumen microbiota. Additionally, the majority of rumen microbial studies to date have primarily focussed on starch in the context of cereal grains (Pitta et al., 2010; De Menezes et al., 2011a; Jiang et al., 2015) rather than different types of roughages. Hence, the objectives of the present study were (1) to investigate the effect of replacing fibre-rich GS with starch-rich MS on the rumen bacterial and archaeal diversity and concentrations using samples collected 10 and 17 days after the 
introduction of the experimental diets, and (2) to place the findings in the context of ruminal fermentation as well as previously reported data on $\mathrm{CH}_{4}$ emission (van Gastelen et al., 2015).

\section{MATERIALS AND METHODS}

\section{Samples and ethics statement}

The rumen fluid (RF) samples used in the present study were collected from 12 rumen cannulated dairy cows. These animals represented a subset of the 32 dairy cows used in a previously published study (van Gastelen et al., 2015) that was conducted at the animal research facilities of Wageningen University \& Research (Wageningen, the Netherlands). As described by van Gastelen et al. (2015), all the experimental procedures were in accordance with Dutch law and approved by the Animal Care and Use Committee of Wageningen University.

\section{Study design and diets}

The study design is similar to van Gastelen et al. (2015). In short, 12 rumen cannulated dairy cows, were allocated into groups of four cows according to lactation stage, parity, and milk production. Within each group cows were randomly assigned to one of four dietary treatments. All dietary treatments had a roughage-to-concentrate ratio of 80:20 based on dry matter (DM) content. The composition of the concentrate was similar for all four treatments, whereas the roughage was GS, MS, or a mixture of both (ingredient as percentage of the total amount of roughage in the diet; DM basis): 100\% GS (GS100), 67\% GS and 33\% MS (GS67), 33\% GS and 67\% MS (GS33), and 100\% MS (GS0). The treatment period lasted 17 days consisting of a dietary adaptation period of 12 days followed by a 5 day period in climate respiration chambers to determine $\mathrm{CH}_{4}$ emission. The cows were fed ad libitum during the first 7 days of the adaptation period. From day 8 to 17, feed intake was restricted to $95 \%$ of the ad libitum dry matter intake (DMI) of the cow within a group consuming the lowest amount of feed during day 5 to 8 . During the study one of the cows was diagnosed with mastitis and treated locally (i.e., in the udder directly) with antibiotics and intravenously with a painkiller. However, the cow was retained in the study as it was otherwise healthy and eating well. 


\section{Rumen sampling}

The RF was sampled on days 10 and 17 , i.e., before and directly after the climate respiration chamber phase, respectively. The RF was collected 4 hours after morning feeding according to the method described by van Zijderveld et al. (2010) and collected in three equal volumes from the front and middle of the ventral sac and from the cranial sac of the rumen. The RF sampled from the three regions was subsequently pooled, aliquoted in $\sim 50 \mathrm{~mL}$ portions, immediately frozen on dry ice, and within 2 hours of collection transported to the lab where it was stored at $-80{ }^{\circ} \mathrm{C}$ until DNA extraction and VFA analysis. The sampling tube was rinsed with warm water between sampling from different cows.

\section{Determination of rumen VFA concentrations}

RF aliquots $(1 \mathrm{~mL})$ from the 12 cows at the two time points (i.e., day 10 and day 17) were centrifuged at 10,000 $\mathrm{g}$ for $10 \mathrm{~min}$, after which the metabolites dissolved in the supernatant were separated by a Spectrasystem HPLC (Thermo Scientific, Breda) equipped with a Metacarb $67 \mathrm{H}$ column (Agilent, $300 \times 65 \mathrm{~mm}$ ) and quantified with a Refractive Index detector. Column temperature was $45^{\circ} \mathrm{C}$, and $5 \mathrm{mM}$ sulphuric acid was used as eluent. Flow rate was set at $0.9 \mathrm{~mL} / \mathrm{min}$. HPLC data analysis was performed in Chromeleon 7 software. The internal standard used was DMSO $\left(10 \mathrm{mM}\right.$ in $\left.0.1 \mathrm{~N} \mathrm{H}_{2} \mathrm{SO}_{4}\right)$.

\section{DNA extraction}

Total genomic DNA was extracted from 24 RF samples (i.e., two time points for each of the 12 animals). Prior to DNA extraction, RF aliquots $(1 \mathrm{~mL})$ were centrifuged at $15,000 \mathrm{~g}$ for 10 min at $4{ }^{\circ} \mathrm{C}$, and the cell pellets were used for DNA extraction as previously described (van Lingen et al., 2017b). Briefly, cells were lysed using repeated bead beating, and the lysate was further processed in a customized MaxWell ${ }^{\circledR} 16$ Tissue LEV Total RNA Purification kit cartridge (XAS 1200) (Promega Biotech AB, Stockholm, Sweden) (van Lingen et al., 2017b). The quantity and purity of the DNA in the obtained extracts were assessed using a NanoDrop ND-1000 spectrophotometer (NanoDrop ${ }^{\circledR}$ Technologies, Wilmington, DE, USA).

\section{qPCR analysis}

Quantitative PCR (qPCR) assays targeting bacterial and archaeal 16S ribosomal RNA (rRNA) genes were performed using a BioRad CFX96 system (Bio-Rad Laboratories). The qPCR 
reactions were carried out in triplicate as previously described by van Lingen et al. (2017b), except that the reaction volumes were $25 \mu 1$.

For standard curve preparation, a bacterial and an archaeal 16S rRNA gene PCR product was prepared as previously described (van Lingen et al., 2017b). DNA concentration and amplicon size were used to calculate the number of amplicon copies, and 10-fold serial dilutions were prepared in water from $10^{8}$ to $10^{0}$ amplicon copies $/ \mu 1$.

\section{Barcoded 16S rRNA gene amplicon sequencing}

For the analysis of bacterial and archaeal community composition, barcoded amplicons of the 16S rRNA genes were generated using a 2-step PCR strategy (Tian et al., 2016). For bacterial composition profiling, the forward primer 27F-DegS: 5'- GTTYGATYMTGGCTCAG -3' (van den Bogert et al., 2011), and the reverse primer mix of 338R-I: GCWGCCTCCCGTAGGAGT (Daims et al., 1999a) and 338R-II: GCWGCCACCCGTAGGTGT (van den Bogert et al., 2013) were used with attached UniTag1 (forward primer: GAGCCGTAGCCAGTCTGC) and UniTag2 (reverse primer mix: GCCGTGACCGTGACATCG) linkers, respectively (Tian et al., 2016). For archaea com position profiling, 518F (5' - CAGCMGCCGCGGTAA -3') (Wang and Qian, 2009) was used as the forward primer with UniTag1, and the reverse primer 905R (5' CCCGCCAATTCCTTTAAGTTC - 3') (Kvist et al., 2007) with UniTag2. The first PCR step was performed in a total volume of $50 \mu \mathrm{L}$ containing $10 \mu \mathrm{L} 1 \times \mathrm{HF}$ buffer (Finnzymes, Vantaa, Finland), $1 \mu \mathrm{L}$ dNTP Mix (10 mM; Promega), $1 \mathrm{U}$ of Phusion ${ }^{\circledR}$ Hot Start II HighFidelity DNA polymerase (2 U/ $\mu \mathrm{L})$ (Finnzymes), $500 \mathrm{nM}$ each of the primers UniTag1-27f Deg S and UniTag2-338R-I + II (for bacteria) or UniTag1-518f and UniTag2-905r (for archaea) and $20 \mathrm{ng}$ of sample DNA. The cycling conditions for the first step consisted of an initial denaturation at $98{ }^{\circ} \mathrm{C}$ for $30 \mathrm{~s} ; 25$ cycles of denaturation at $98{ }^{\circ} \mathrm{C}$ for $10 \mathrm{~s}$, annealing at $56{ }^{\circ} \mathrm{C}$ (for bacteria) or $60{ }^{\circ} \mathrm{C}$ (for archaea) for $20 \mathrm{~s}$, and elongation at $72{ }^{\circ} \mathrm{C}$ for $20 \mathrm{~s}$; with a final extension at $72{ }^{\circ} \mathrm{C}$ for $10 \mathrm{~min}$.

The second PCR step was then employed to add an 8-nucleotide sample specific barcode to the UniTag primer target sequences obtained from the first amplicon, as previously described (Hamady et al., 2008). The second step PCR was performed in a total volume of $100 \mu \mathrm{L}$ containing: $1 \times$ HF buffer, $2 \mu \mathrm{L}$ of dNTP Mix, $1 \mathrm{U}$ of Phusion ${ }^{\circledR}$ Hot Start II HighFidelity DNA polymerase $(2 \mathrm{U} / \mu \mathrm{L})$ and $500 \mathrm{nM}$ of a forward and reverse primer targeting the 
UniTag1 and UniTag2 sequences, respectively, that were each appended with an 8 nt sample specific barcode at the 5' end of the respective primer. The cycling conditions of the second step for both bacteria and archaea consisted of an initial denaturation at $98{ }^{\circ} \mathrm{C}$ for $30 \mathrm{~s}$ followed by 5 cycles of: $98{ }^{\circ} \mathrm{C}$ for $10 \mathrm{~s}, 52{ }^{\circ} \mathrm{C}$ for $20 \mathrm{~s}$ and $72{ }^{\circ} \mathrm{C}$ for $20 \mathrm{~s}$, and a final extension at $72{ }^{\circ} \mathrm{C}$ for $10 \mathrm{~min}$. Incorporation of the sample specific barcodes, yielding a PCR product of $\sim 350 \mathrm{bp}$ and $\sim 385 \mathrm{bp}$ for bacteria and archaea, respectively, was confirmed by agarose gel electrophoresis. Control PCR reactions were performed alongside each separate amplification with no addition of template, and consistently yielded no product. PCR products were then purified using HighPrep ${ }^{\mathrm{TM}}$ (MagBio Europe Ltd, Kent, United Kingdom) and quantified using a Qubit fluorometer in combination with the dsDNA BR Assay Kit (Invitrogen, Carlsbad, CA). Purified PCR products were mixed in equimolar amounts into pools together with defined synthetic mock communities that allowed assessment of potential technical biases (Ramiro-Garcia et al., 2016). Pools then underwent adaptor ligation followed by sequencing on the Illumina MiSeq platform (GATC-Biotech, Konstanz, Germany).

\section{Sequence data quality control and processing}

The 16S rRNA gene sequencing data was analyzed using NG-Tax Galaxy version 1.0, an inhouse pipeline (Afgan et al., 2016; Ramiro-Garcia et al., 2016). Paired-end libraries were filtered to contain only read pairs with perfectly matching barcodes, and those barcodes were used to demultiplex reads by sample. Operational taxonomic units (OTUs) were defined at $100 \%$ identity using an open reference approach, and taxonomy was assigned to those OTUs using the SILVA version 128 16S rRNA gene reference database (Quast et al., 2013).

\section{Data analysis and visualization}

Parameters related to ruminal fermentation and microbial concentrations were analyzed using the MIXED procedure in SAS (edition 9.3, SAS Institute Inc., Cary, NC, USA). The parameters were subjected to repeated measures ANOVA to take repeated sampling from the same animal into account. The model included dietary treatment, time, and dietary treatment $\times$ time as fixed effects, and group and cow as random effects. Post-hoc analyses were carried out using the Tukey-Kramer test for pairwise comparisons. Significance of treatment effects was declared at $\mathrm{P} \leq 0.05$, and trends at $0.05<\mathrm{P}<0.10$.

Alpha diversity of the $16 \mathrm{~S}$ rRNA gene data was estimated with the phylogenetic diversity (PD) index. Normality of the bacterial and archaeal PD dataset was assessed using 
the Shapira-Wilk's norm ality m ethod, with a Pvalue $>0.05$ confirming normal distribution. Consequently, effects of diet, and diet $\times$ time were assessed using Kruskal-Wallis test on the PD dataset while the time effect on the PD was assessed by a paired T-test. To assess the beta diversity in bacterial and archaeal communities in the cows across all four experimental diets, unweighted and weighted UniFrac distances were used to perform principal co-ordinate analysis (PCoA). Adonis was used to test for significance of sample groupings in the PCoA with respect to diet, time and diet $\times$ time (Anderson, 2001). The $\mathrm{R}$ packages used to perform and visualise the community based analysis in RStudio were: ape, vegan, microbiome, phyloseq, picante and ggplot2 (Philip, 2003; Paradis et al., 2004; Kembel et al., 2010; Lahti and Shetty, 2017).

Constrained partial redundancy analysis (RDA) of bacterial and archaeal 16S rRNA gene sequence data was performed to assess the relationship between genus-level phylogenetic groupings and explanatory variables diet with covariance time, time with covariance diet and diet $\times$ time, using Canoco 5 (Smilauer, 2014). Significance of explanatory variables was tested using a Monte Carlo permutation test with a total of 999 permutations.

All P-values for the alpha and beta-diversity statistical analysis were corrected for multiple testing using False discovery rate (FDR) correction, and significant effects were declared at $\mathrm{P} \leq 0.05$, and trends at $0.05<\mathrm{P}<0.10$.

\section{Data availability}

The 16S rRNA amplicon sequencing data for the bacterial and archaeal composition analysis has been deposited as one study in European Nucleotide Archive (ENA) under accession number PRJEB24373.

\section{RESULTS}

\section{Ruminal fermentation characteristics}

Ruminal fermentation products are presented in Table 1. The molar proportions of butyrate tended to be affected by diet $(\mathrm{P}=0.065)$. Total VFA tended to be affected by time $(\mathrm{P}=0.076)$ and the molar proportions of isovalerate were affected by time $(\mathrm{P}=0.002)$, being lower on day 17 than on day 10 . 


\section{Quantification of bacteria and archaea}

The rumen bacterial and archaeal concentrations are presented in Table 1. The bacterial concentrations were affected by $\operatorname{diet}(\mathrm{P}=0.026)$ and time $(\mathrm{P}=0.008)$. The bacterial concentrations were lower for the GS0 diet compared with the other three diets (GS100, GS67, and GS33), and the bacterial concentrations were higher on day 17 compared with day 10. The archaeal concentrations were only affected by time $(P=0.022)$ with the archaeal concentration being higher on day 17 compared with day 10 .

\section{Changes in rumen bacterial community composition}

Overall, the genus-level taxon Prevotella $1(58.1 \% \pm 0.06)$ dominated in all the samples. The next most predominant genus level taxon was the NK4A214 group belonging to Ruminococcaeae $(5.5 \% \pm 0.01)$, with all other genus level groupings being $<1 \%$ on average (Fig.1). Whilst these two predominant taxa did not vary greatly in relative abundance, other genus level groups did, such as Prevotella UCG-003 (as evidenced by the large standard deviations in Fig. 1), indicating inter animal variation.

With respect to alpha diversity, the PD values were confirmed to have a normal sample distribution $(\mathrm{P}=0.196)$. There was no significant effect of $\operatorname{diet}(\mathrm{P}=0.500)$, time $(\mathrm{P}=0.761)$ or diet $\times$ time $(\mathrm{P}=0.697)$ on bacterial $\mathrm{PD}($ Fig. $2 \mathrm{~A}$ and $2 \mathrm{~B})$.

PCoA analysis at the OTU-level, using unweighted UniFrac distances (Fig. 2C), showed significant clustering of the bacterial RF samples with diet $(\mathrm{P}=0.006)$ and time $(\mathrm{P}=$ 0.005), with no diet $\times$ time interaction $(\mathrm{P}=0.763)$. With respect to diet, profiles of GS100 diet fed animals generally clustered at the top of PCoA axis 2 and the GS0 diet generally clustered at the bottom of the PCoA axis 2, with the mixed proportion diets (GS67 and GS33) generally situated between the two extreme diets (Fig. 2C). With respect to time, samples taken at day 17 and day 10 were generally separated along PCoA axis 1 (Fig. 2C). In the corresponding weighted UniFrac analysis, there was a tendency for an effect of diet $(\mathrm{P}=0.062)$, whereas no time effect $(\mathrm{P}=0.139)$ or diet $\times$ time interaction $(\mathrm{P}=0.911)$ were seen $($ Fig. $\mathrm{S} 1)$.

In order to assess the contribution of diet, time and diet $\times$ time interaction to the observed variation in the bacterial community composition at the genus level, constrained RDA analyses were performed. Diet significantly contributed to explaining the observed variation in bacterial community composition $(\mathrm{P}=0.002)$ and was associated with $24.5 \%$ of 
the total variation in the bacterial community. In the RDA triplot (Fig. 3A), samples of animals fed the different experimental diets separated along the first canonical axis according to the decreasing proportion of GS (i.e., from left to right). Several of the genera had highest relative abundance with one of the extreme diets (i.e., either GS100 or GS0). The following genera were positively associated with the GS0 diet: the UCG-002 group belonging to the Succinivibrionaceae, a genus containing Eubacterium coprostanoligenes, Moryella, the UCG014 group belonging to the Ruminococcaceae, Lactobacillus, Succinivibrio, the YAB-2003 group belonging to the Prevotellaceae and a genus that could only be reliably annotated to the phylum Saccharibacteria. In contrast, the genera Prevotella 2, Leuconostoc, and Candidatus 'Saccharim onas' were positively associated with the GS100 diet, along with several genus level groupings that could only be annotated to the family (Piscirickettsiaceae, vadin BE-97) or phylum level (SR1(Absconditabacteria)).

Partial RDA analysis with diet as covariate that time had an effect $(\mathrm{P}=0.015)$ on the bacterial composition and explanatory variables accounted for $10.56 \%$ of the residual variation in the bacterial community (Fig. 3B). The full RDA analysis showed that there was a diet $\times$ time interaction $(\mathrm{P}=0.011)$ which accounted for $39.04 \%$ of the total variation in the bacterial community (Fig. S2). Generally, the diets separated along the first canonical axis (GS decreasing from left to right) and time on the second canonical axis (day 10 to the top and day 17 to the bottom). The extent of the differences between days 10 and 17 varied with diet, with the differences being smallest for GS67 and largest for GS33. 
Chapter 3

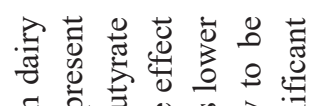

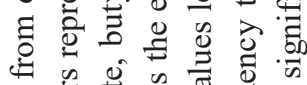

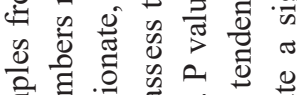

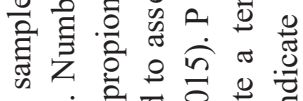

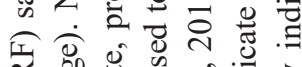

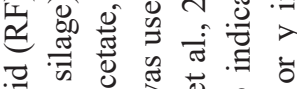

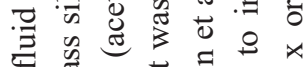

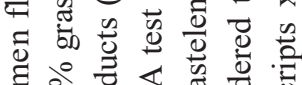

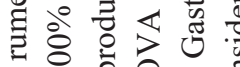
o. 으의 क

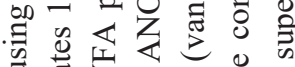

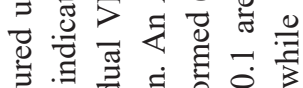
\%

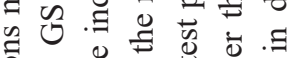

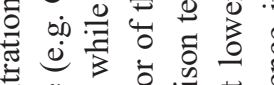

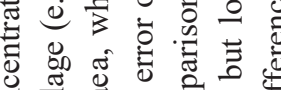

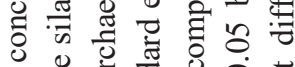

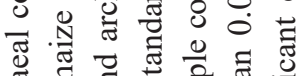

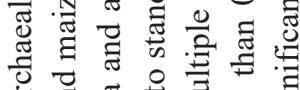

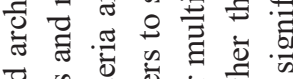
들

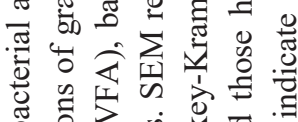

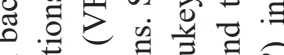
등

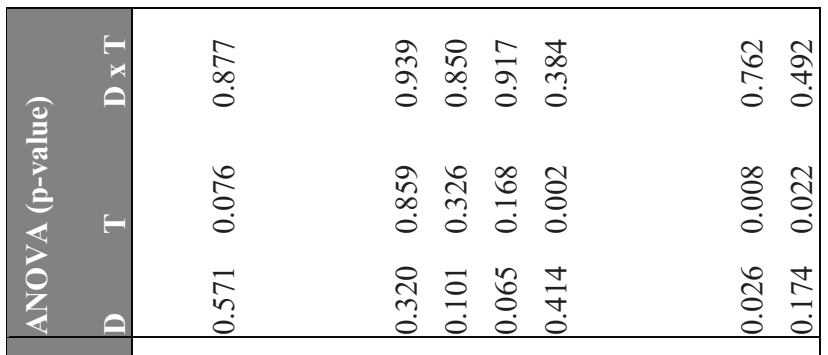

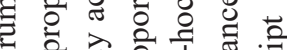

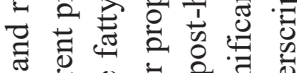

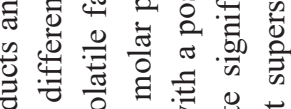
응

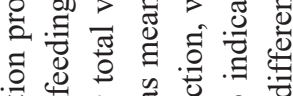

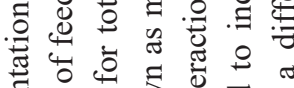

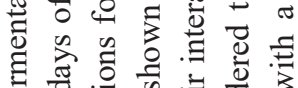

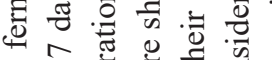
要

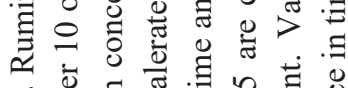
㰻

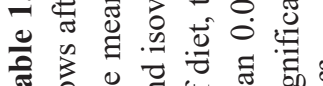

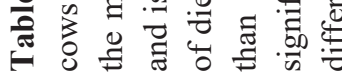

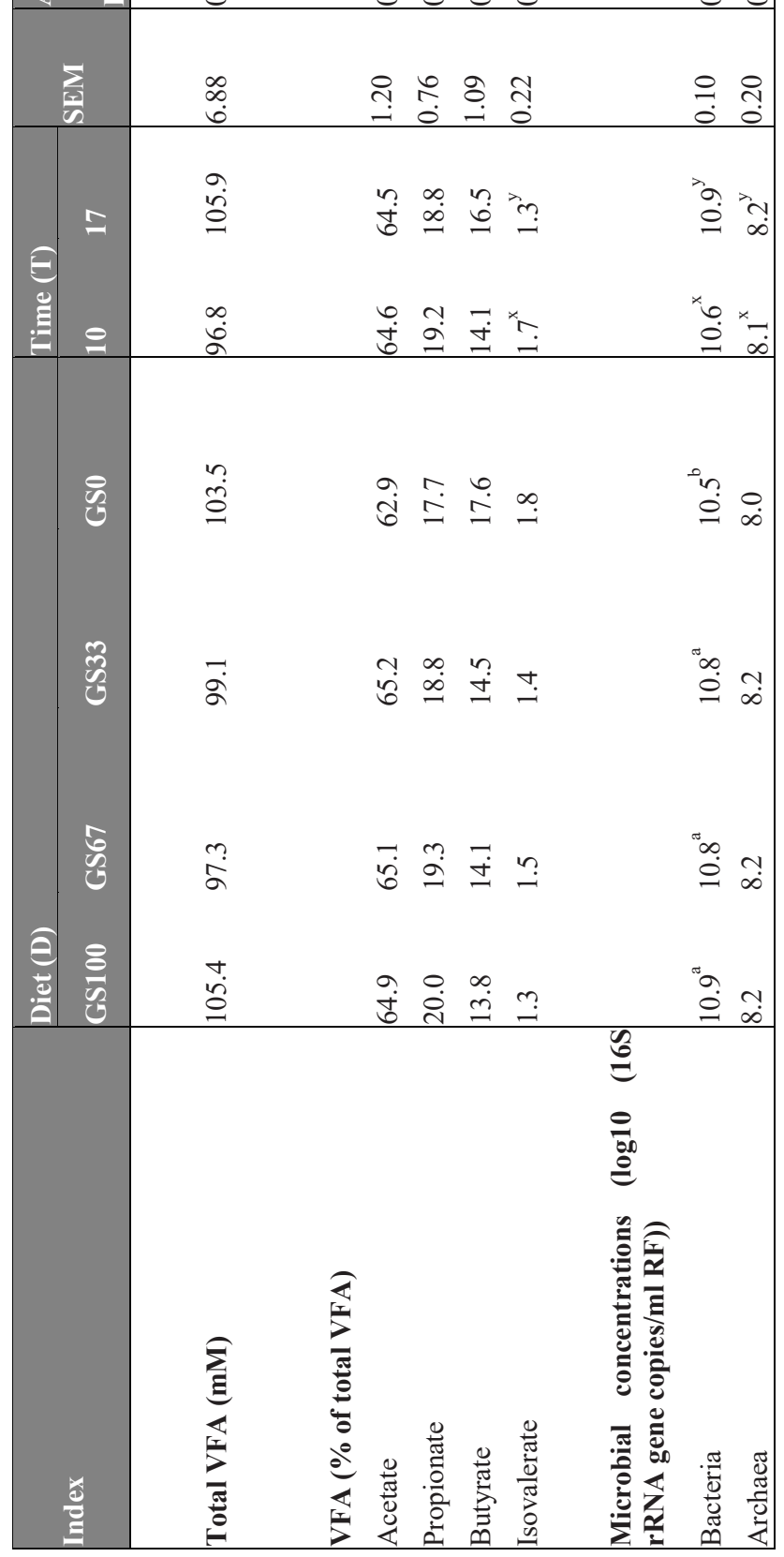


Chapter 3

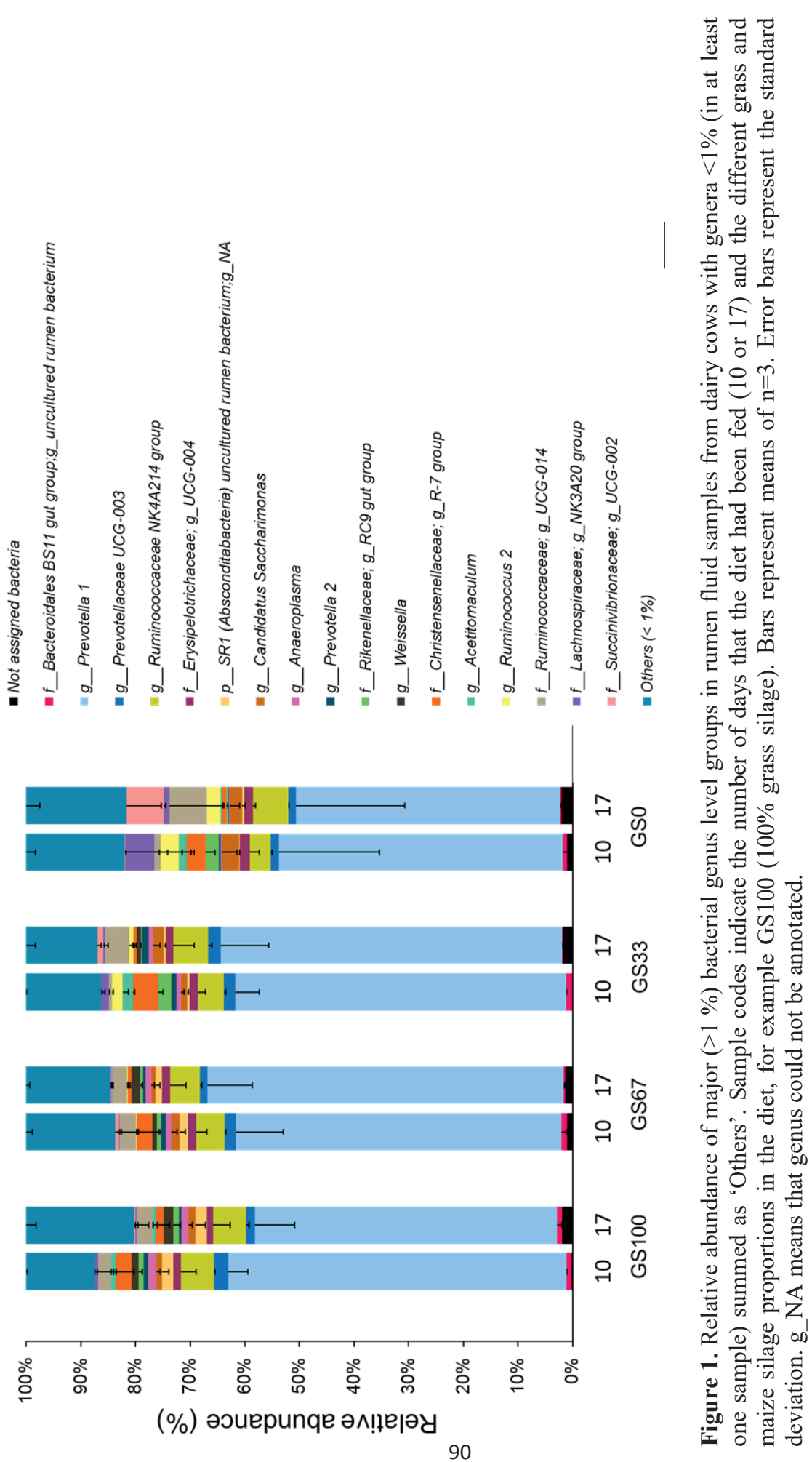


A

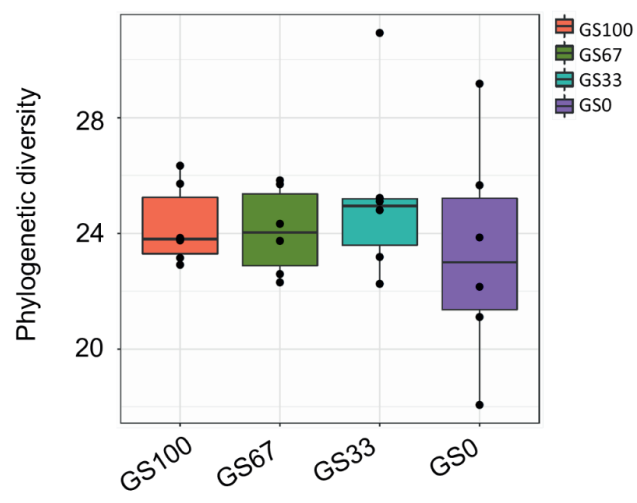

B

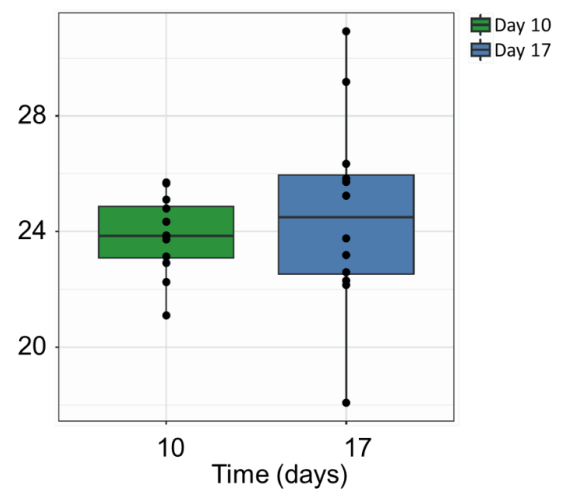

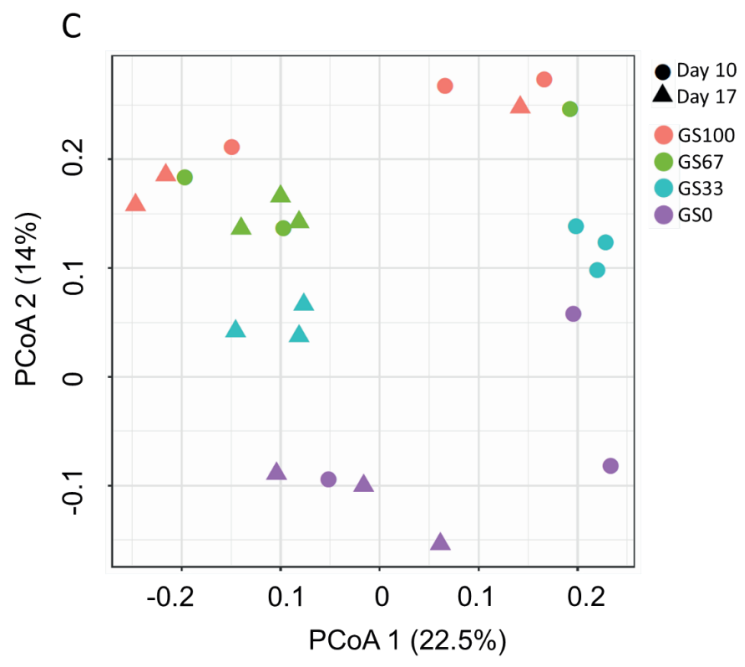

Figure 2. Phylogenetic diversity (PD) of bacterial communities associated to different ratios of grass and maize silage (A) and different time points (B). Sample codes indicate the number of days that the diet had been fed (10 or 17) and the different grass and maize silage proportions in the diet, for example GS100 (100\% grass silage). Principal co-ordinate analysis (PCoA) analysis of bacterial community composition from rumen fluid samples $(n=24)$ using the unweighted UniFrac distance metric (C). The percentage of variation explained is indicated

on the

respective axes. 


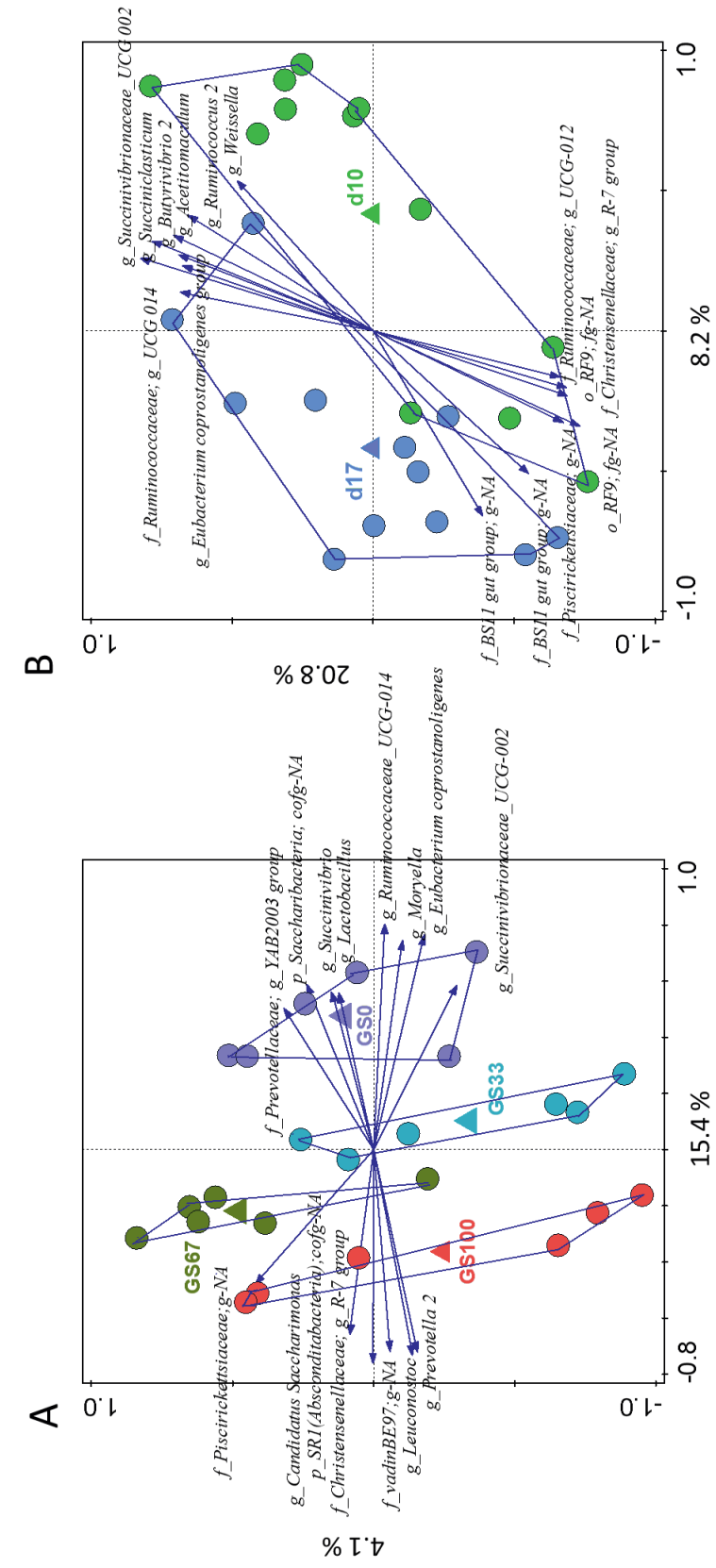

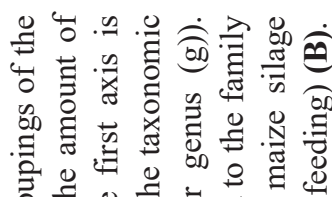
言导

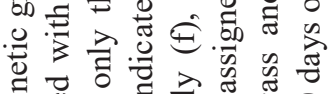
可

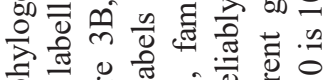

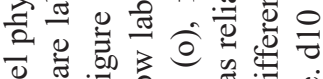
ब

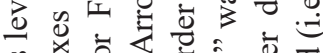

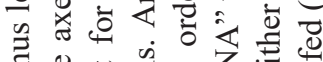

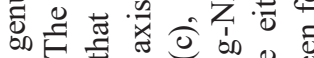
$\because \dot{0} \tilde{0}$

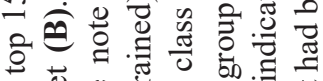

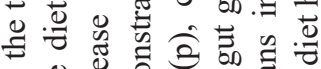

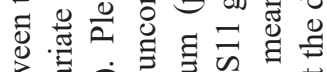

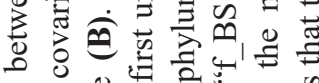

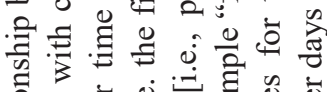

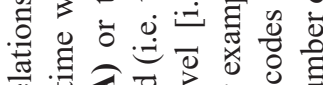

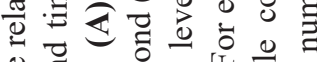

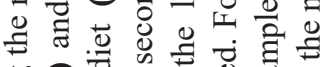

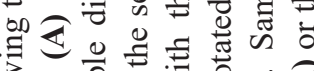

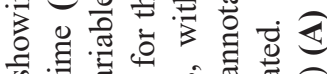

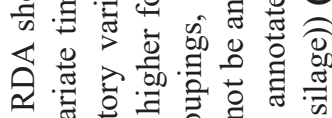
. 矛专造

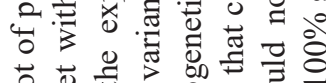
늠

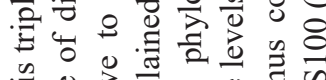

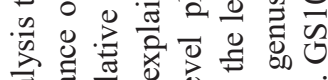

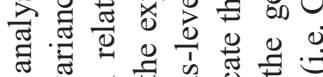

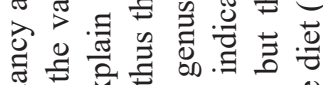

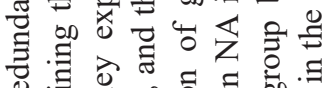

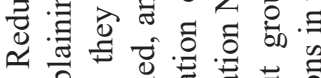
m 希.

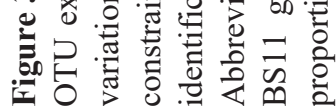




\section{Changes in rumen archaea community composition}

Annotation of the 347 detected OTUs showed that Methanobrevibacter was the predominant archaeal genus followed by Methanosphaera (Fig. 4). Archaeal PD values were confirmed to have a normal distribution $(\mathrm{P}=0.189)$. There was no effect of diet $(\mathrm{P}=0.300)$, time $(\mathrm{P}=$ $0.525)$ or diet $\times$ time $(\mathrm{P}=0.272)$ on the archaeal $\mathrm{PD}$ (Fig. 5A and 5B). With unweighted UniFrac PCoA of the archaeal community, a tendency for an effect of diet was noted $(\mathrm{P}=$ 0.075), whereas no effect of time $(\mathrm{P}=0.505)$ or diet $\times$ time $(\mathrm{P}=0.582)$ was observed (Fig. 5C). In the weighted UniFrac analysis there was no effect of diet $(\mathrm{P}=0.862)$, time $(\mathrm{P}=0.430)$ or diet $\times$ time $(\mathrm{P}=0.534)$ (Fig. S3).

The contribution of diet, time and diet $\times$ time interaction to variation in the archaeal community composition at the genus level was assessed using partial RDA analyses. The effect of diet was significant $(\mathrm{P}=0.032$ ), and explanatory variables accounted for $28.34 \%$ of the residual variation in the dataset when time was used as covariate (Fig. 6). Almost all of this variance was represented by the first canonical axis, where both GS100 and GS67 separated from GS33 and GS0 (which did not differ from each other). Methanobrevibacter showed a positive association with the GS0 and GS33 diets. The GS100 diet appeared to be most positively associated with Methanosphaera. The GS67 diet was most positively associated with a non-annotated genus level group that belonged to the family Methanobacteriaceae. RDA analysis further showed that time did not affect the archaeal community composition $(\mathrm{P}=0.284)$, and only accounted for $1.24 \%$ of the residual variation with diet being used as covariate (Fig. 6B). No diet $\times$ time interaction was observed $(\mathrm{P}=$ 0.312) (data not shown). 
Chapter 3

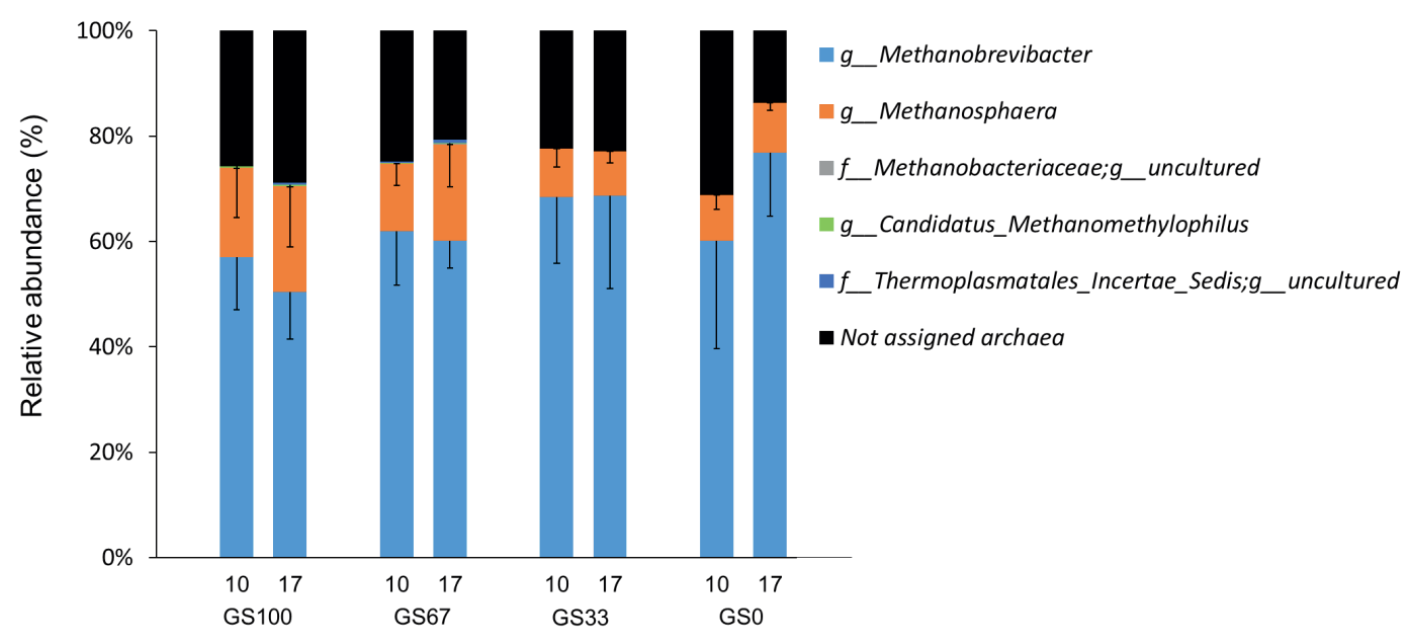

Figure 4. Relative abundance of all archaeal taxa within rumen fluid samples from dairy cows fed different proportions of grass silage (GS) to maize silage (MS). Sample codes indicate different grass and maize rations in the diet, for example GS100 (100\% grass silage) and the number of days that the diet was fed (i.e. 10 or 17). Bars represent sample means from cows fed the same diet $(n=3)$, and error bars represent their standard deviation. 
A

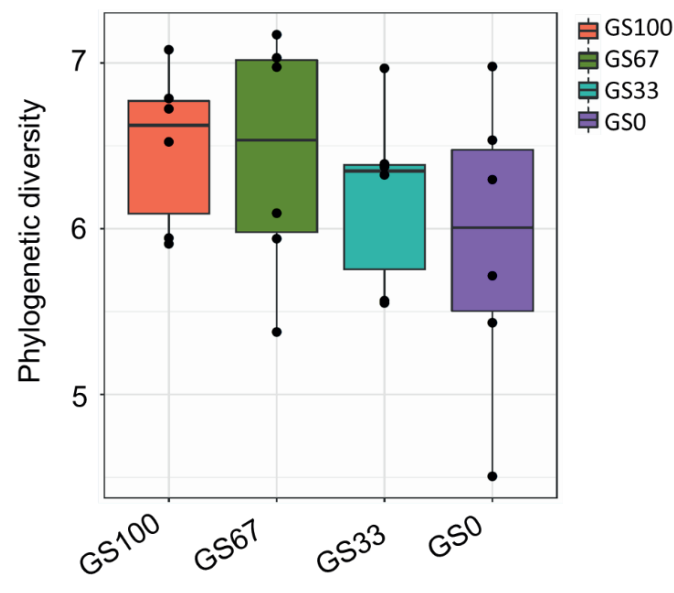

B

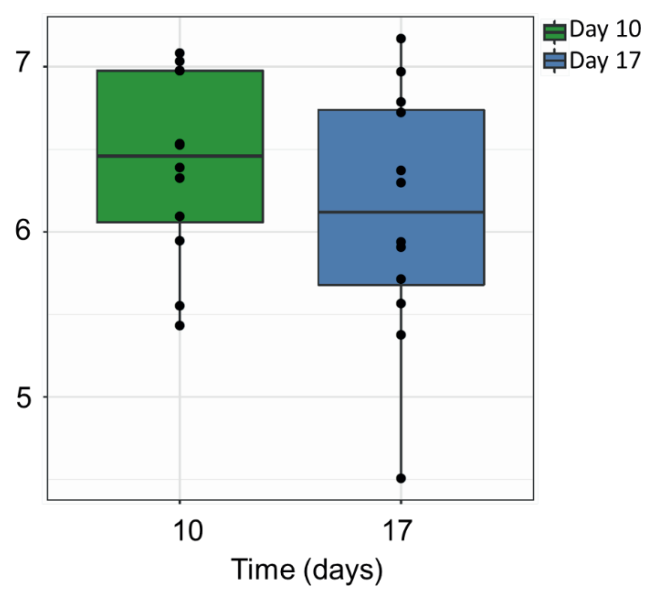

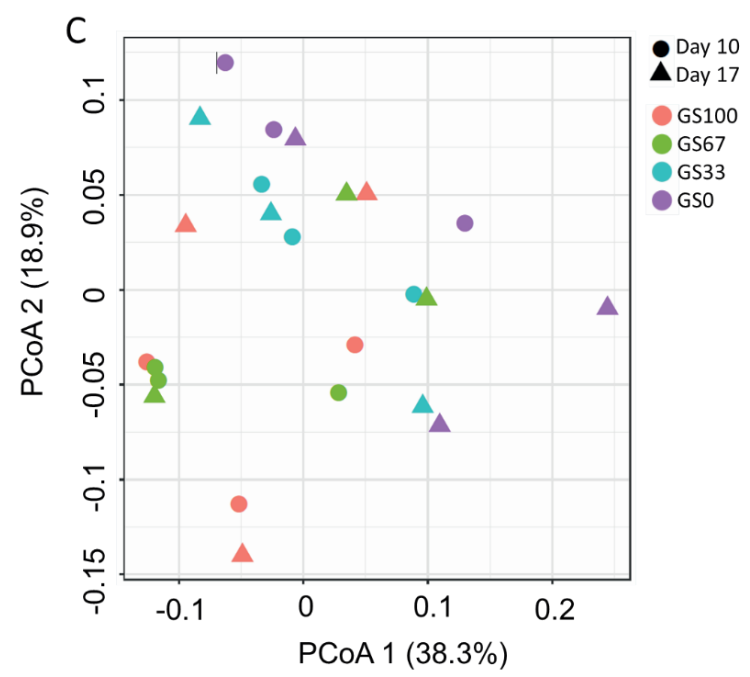

Figure 5. Phylogenetic diversity (PD) comparisons of archaeal communities associated to different ratios of grass and maize silage (A) and those associated to the different number of days the diet had been fed (B). Diet sample codes indicate different grass and maize silage proportions in the diet, for example GS100 (100\% grass silage). Principal co-ordinate analysis (PCoA) analysis of archaeal community composition from rumen fluid samples $(n=24)$ using the unweighted UniFrac distance metric (C). The percentage of variation explained is indicated on the respective axes. 
Chapter 3

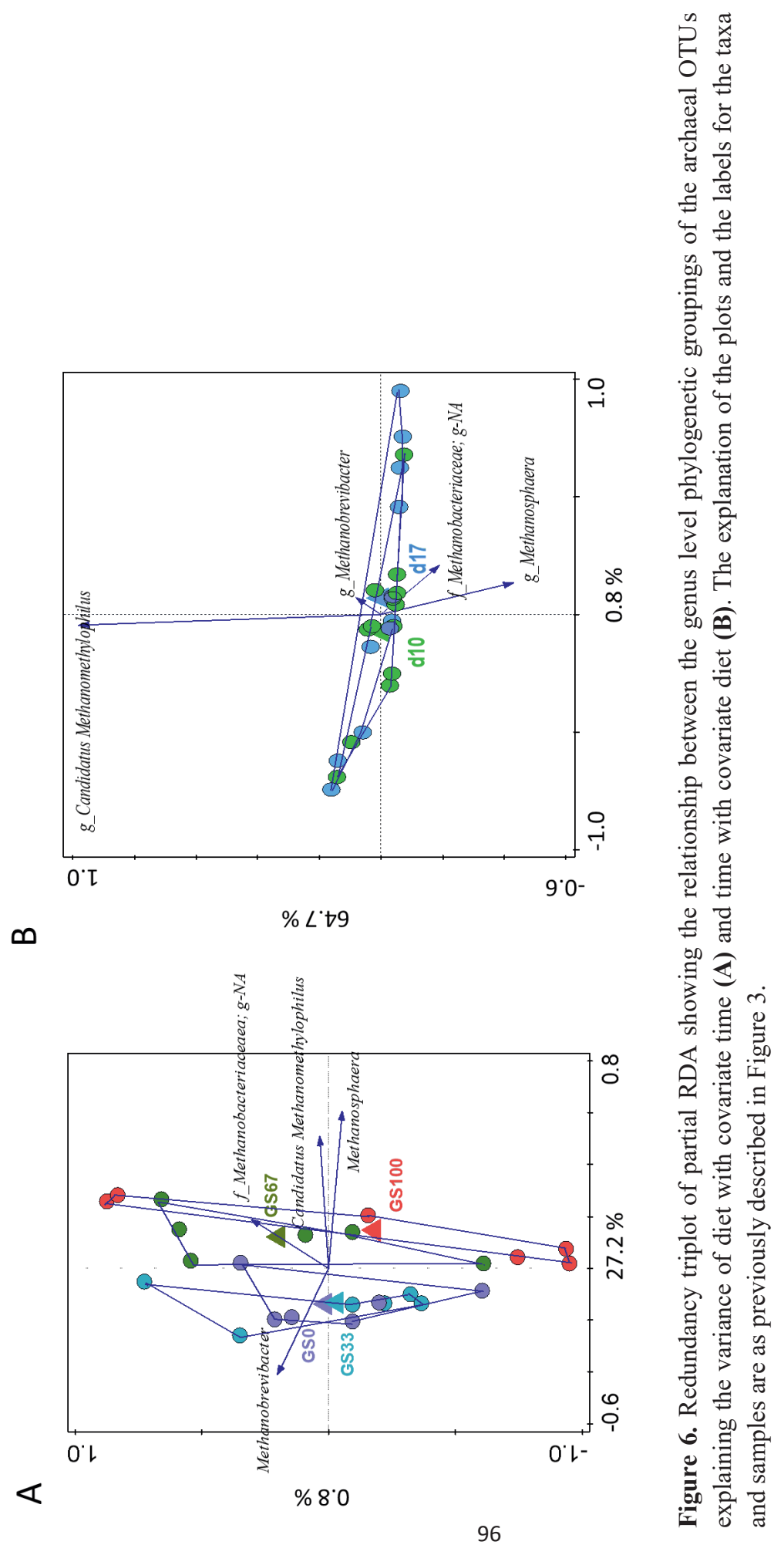




\section{DISCUSSION}

The potential of reducing $\mathrm{CH}_{4}$ emissions from lactating dairy cows has been shown in a previous study (van Gastelen et al., 2015) where, in comparison with the GS100 diet, $\mathrm{CH}_{4}$ yield (g/kg DMI) was $11 \%$ reduced for the GS0 diet. The objective of the current study was to explore whether the rumen bacteria and archaea were also affected by the different ratios of grass and maize silage used, as well as by the number of days the diet had been fed. These aforementioned analyses will aid in understanding how observed changes in VFA and $\mathrm{CH}_{4}$ relate to underlying changes in the rumen microbiome.

\section{Effect of diet and time on VFA production}

The results of the rumen fermentation products (i.e., total VFA and molar proportions of individual VFA) in this study are largely in agreement with the results reported previously by van Gastelen et al. (2015). Both the present study and van Gastelen et al. (2015) report no effect of diet on total VFA and the molar proportions of acetate and propionate. In the present study, however, the molar proportions of butyrate tended to be affected by diet, whereas van Gastelen et al. (2015) reported a linear increase in molar proportions of butyrate upon increasing the level of MS at the expense of GS. Additionally, van Gastelen et al. (2015) reported that isovalerate tended to be affected by diet, whereas in the current study no diet effect on isovalerate was found. These differences between the two studies are likely to be associated with the differences in frequency and timing of sampling.

In the present study, the RF samples were collected on day 10 (before the climate respiration chamber phase) and day 17 (after the climate respiration chamber phase), but only $4 \mathrm{~h}$ after morning feeding. In the study of van Gastelen et al. (2015) the RF samples were collected $1 \mathrm{~h}$ before and 1, 2, 4, 6 and $8 \mathrm{~h}$ after morning feeding on days 10 and 11 (i.e. before the climate respiration chamber phase). It is well documented that there are significant temporal variations in the molar proportions of individual VFA after feeding (van Lingen et al., 2017b). Furthermore, differences in VFA sample preparation and analysis between the two studies may have affected the results. Hence, direct comparison between the VFA results of the present study with those reported by van Gastelen et al. (2015) is not feasible.

Isovalerate molar proportions were affected by time in the present study, with a decrease of isovalerate from day 10 to day 17. Usually, isovalerate is associated with microbial protein synthesis and fermentation of plant cell walls (Fenner et al., 1970). The decrease in isovalerate 
molar proportions might suggest a reduction of the cellulolytic bacterial populations for which isovalerate is an essential growth factor, as has been previously demonstrated in pigs (Liu et al., 2016). However, this seems unlikely, as no bacterial genera could be clearly associated with the effect of time on the bacterial community composition (Fig. 3B).

\section{Effect of diet and time on rumen microbial concentrations}

Diet affected bacterial concentrations, which were lower for the GS0 diet compared with the other three diets. This is despite the expectation of higher bacterial concentrations in the rumen liquid of animals fed the GS0 diet that contains starch, as starch is a more easily fermented substrate for bacteria than the fibre in the GS100 diet (Deckardt et al., 2013). This decrease in bacterial concentrations in the absence of grass silage in the diet is interesting. This finding suggests that the bacterial concentrations might not be directly MS related, as we did not observe a linear decrease in bacterial concentration upon increasing levels of MS. our findings are in contrast to the study of Lettat et al. (2013), who used a $3 \times 3$ latin square design where all nine dairy cows received all dietary treatments. Lettat et al. (2013) reported increased bacterial concentrations upon replacing fibre-rich alfalfa completely with starch-rich maize silage, and in this study samples were collected 4 hours after morning feeding. Starch in maize silages is generally readily available for the ruminant due to the moisture and softness of the kernel (Indugu et al., 2017). However, this availability of starch also depends upon maturity and processing of the maize kernel at harvest (Indugu et al., 2017). This might contribute to the observed decrease of bacterial concentrations with increasing amounts of maize silage in the present study, although we are not aware of any peculiarities with respect to harvest of the maize used in this study. There was no diet effect on archaeal concentrations which is in line with the study of Lettat et al. (2013), who also did not observe any effect of diet on the methanogenic archaea.

The observed increase in bacterial concentrations from day 10 to day 17 is suggestive of an increase in fermentation. However, total VFA only tended to be affected by time indicating the increase in bacterial concentration was not biologically significant. Also archaeal concentrations were found to increase from day 10 to day 17. The reason for this increase is presumably linked to the similar change in the bacterial concentrations, as no significant change in archaeal community composition occurred with time (Fig. 6B). The biological significance of this change in archaeal concentrations is not known, as $\mathrm{CH}_{4}$ emissions were only measured from days 12 to 17 in the study of van Gastelen et al. (2015). 


\section{Effect of diet and time on rumen bacterial composition}

Bacterial alpha diversity was not affected by diet but bacterial community composition was (Fig. 2). This effect was observed in the unweighted UniFrac PCoA analysis (Fig. 2C) but not the corresponding weighted analysis (Fig. S1). This suggests that the diet effect was mainly due to differences in the presence or absence of low abundant bacterial taxa, rather than differences in the relative abundance of predominant bacterial taxa. In both the unweighted PCoA and the RDA, the bacterial community composition showed a transition that was consistent with the decreasing amount of GS. The RDA analysis showed that several genus-level groupings were positively associated with the GS0 diet: the UCG-002 group belonging to the Succinivibrionaceae, a genus represented by Eubacterium coprostanoligenes, Moryella, the UCG-014 group belonging to the Ruminococcaceae, Lactobacillus, Succinivibrio, an unidentified genus (cofg-NA) within the phylum Saccharibacteria, and the YAB-2003 group belonging to the Prevotellaceae.

The higher amount of starch present in MS has been associated with increased relative abundances of members of the families Ruminococcaceae and Succinivibrionaceae (Kozakai et al., 2007; Deusch et al., 2017), which is consistent with the positive association of UCG-002, Succinivibrio and UCG-014 with the GS0 fed cows in the present study. Low $\mathrm{CH}_{4}$ producing cows have been positively associated with lactate and succinate producing bacteria (Danielsson et al., 2017). This is also consistent with the positive association of Lactobacillus (a lactate producer) and Succinivibrio (a succinate producer) in the GS0 diet, as this diet was also associated with the lowest $\mathrm{CH}_{4}$ emission by van Gastelen et al. (2015). A metagenomics study has linked increased abundance of Succinivibrionaceae with reduced $\mathrm{CH}_{4}$ emission in dairy cows (Wallace et al., 2015). This can be explained by the fact that Succinivibrionaceae compete with hydrogenotropic methanogenic archaea for $\mathrm{H}_{2}$ and produce succinate, which is then converted to propionate (McCabe et al., 2015). Moryella, which was positively associated with the GS0 diet in our study, has also been reported as one of the dominant groups in a maize starch fed diet (Li et al., 2012).

The relevance of the positive association of a genus-level group that includes Eubacterium coprostanoligenes with the GS0 diet in the present study is not clear, as the characterized species $E$. coprostanoligenes does not hydrolyse starch (Freier et al., 1994). Also, only a few other Eubacterium spp from the rumen (i.e. Eubacterium uniforme and Eubacterium xylanophilus) have been previously associated with maize silage derived feeds (Deusch et al., 2017). However, E. coprostanoligenes is interesting as until now it has been associated with hydrolysis of cholesterol 
esters to produce coprostanol (Madden et al., 1999). Species in the Eubacterium genus are saccharolytic and ammonia producing, playing a role in amino acid fermentation. As ammonia production in the rumen consumes $\mathrm{H}_{2}$ gas, Eubacterium spp. might play a role in decreasing $\mathrm{CH}_{4}$ emissions by depriving methanogens of $\mathrm{H}_{2}$ (van Zijderveld et al., 2010; Cunha et al., 2018). The relation between the unclassified group belonging to the Saccharibacteria and the YAB-2003 group belonging to the Prevotellaceae and the decreasing amount of GS is also unclear due to the limited knowledge with respect to the physiology of these organisms.

Several genera were positively associated with the GS100 diet. The positive association of Prevotella 2 with the GS100 diet (Fig. 3A; which also suggests a negative association with GS0) suggests that Prevotella 2 plays a role in fibre degradation. The majority of the characterized species within this genus have been isolated from the human oral cavity (for example Prevotella marshii, P. shahii) (Sakamoto et al., 2004; Downes et al., 2005) while others have been isolated from human faeces (for example P. stercorea) (Hayashi et al., 2007). Among these species, $P$. shahii and P.stercorea were abundant in deers fed oak leaves in the study of Li et al. (2013). The positive association of Leuconostoc to GS100 observed in this study is harder to explain in the context of fermentation. Leuconostoc spp. are lactic acid bacteria that are typical inhabitants of silage, and fermentation of maize silage is generally faster than that of grass silage. Members of Christensenellaceae have been associated with degradation of fibre (Mao et al., 2015), in line with the positive association of this group with the GS100 diet.

The alpha diversity of the bacterial communities was affected by time, suggesting that the community was not completely stable following 10 days of diet adaptation (Fig. 2B). Indeed, this is also reflected in the finding that bacterial concentrations were found to be higher on day 17 compared to day 10 . Whilst separation of day 10 and day 17 samples occurred in the RDA, no taxa were strongly associated with either of the days (Fig. 3). Although all animals were on the same dietary treatment on day 10 and day 17 , these treatments were restricted to $95 \%$ from day 8 as reported in van Gastelen et al. (2015) which might at least contribute to the observed shift from day 10 to day 17.

\section{Effect of diet and time on archaea}

Our analysis did not show any significant differences in the archaeal alpha diversity in response to diet, time or diet $\times$ time (Fig. 5A and 5B). Changes in feed fermentation products can induce changes in the methanogenic community structure, however, as only limited changes occurred in 
this study it is perhaps not surprising that the weighted and unweighted PCoA showed no significant diet effect in archaeal beta diversity (Fig. 5). However, significant diet effects were observed in the RDA analysis, which was based on relative abundance distributions, whereas PCoA analyses were based on the phylogenetically weighted Unifrac distances. The relative abundance of Methanobrevibacter was positively associated with the GS0 diet, whereas Methanosphaera and Candidatus Methanomethylophilus were negatively associated with the GS0 diet. Methanobrevibacter and Methanosphaera are two pre-dominant archaea found in all dietary treatments. Methanobrevibacter spp. are usually formate, $\mathrm{H}_{2}$ and $\mathrm{CO}_{2}$ dependent hydrogenotrophs while Methanosphaera spp. are $\mathrm{H}_{2}$ dependent methylotrophs (Carberry et al., 2014a). The weak associations with diet may indicate competition for $\mathrm{H}_{2}$ between Methanobrevibacter and Methanosphaera within the rumen (Carberry et al., 2014a), suggesting that the concentrations and partial pressures of $\mathrm{H}_{2}$ in the rumen are key factors affecting methanogenesis (van Lingen et al., 2016).

\section{CONCLUSIONS}

In this study, we assessed changes in the rumen microbiota in response to dietary treatments differing in the roughage composition after 10 and 17 days of feeding. These changes were used to help understand corresponding changes in ruminal VFA and previously observed $\mathrm{CH}_{4}$ measurements. In conclusion, diet had a significant effect in shaping the bacterial and archaeal communities in the rumen of dairy cows. The bacterial families Succinivibrionaceae and Ruminococcaceae were among the bacterial taxa were associated with the maize silage diets, indicating their role in the low methane observed from the previous study. Methanobrevibacter was positively associated with maize silage diet. Furthermore, time had a significant effect on both bacterial and archaeal concentrations, but only on bacterial community composition. These findings indicate that the rumen microbiome had not stabilized after for 10 days of feeding the experimental diets, which might at least in part be due to the fact that feeding was restricted to $95 \%$ of the DMI of the cow eating the least within each group from day 8.

\section{ACKNOWLEDGEMENTS}

This work was funded by TI Food and Nutrition, a public-private partnership on precompetitive research in food and nutrition. We thank the staff of the experimental facilities (Carus, Wageningen, the Netherlands) for their assistance. We also thank Tom van den Bogert for his help during sampling. 


\section{REFERENCES}

Afgan, E., Baker, D., van den Beek, M., Blankenberg, D., Bouvier, D., Cech, M., et al. (2016). The galaxy platform for accessible, reproducible and collaborative biomedical analyses: 2016 update. Nucleic Acids Res 44(W1), W3-W10. doi: 10.1093/nar/gkw343.

Anderson, M.J. (2001). A new method for non-parametric multivariate analysis of variance. Austral Ecol 26(1), 32-46. doi: 10.1111/j.1442-9993.2001.01070.pp.x.

Brask, M., Lund, P., Hellwing, A.L.F., Poulsen, M., and Weisbjerg, M.R. (2013). Enteric methane production, digestibility and rumen fermentation in dairy cows fed different forages with and without rapeseed fat supplementation. Anim Feed Sci and Tech 184(1-4), 67-79. doi: 10.1016/j.anifeedsci.2013.06.006.

Carberry, C.A., Waters, S.M., Kenny, D.A., and Creevey, C.J. (2014). Rumen methanogenic genotypes differ in abundance according to host residual feed intake phenotype and diet type. Appl Environ Microbio 80(2), 586-594. doi: 10.1128/AEM.03131-13.

Cunha, C.S., Marcondes, M.I., Veloso, C.M., Mantovani, H.C., Pereira, L.G.R., Tomich, T.R., et al. (2018). Compositional and structural dynamics of the ruminal microbiota in dairy heifers and its relationship to methane production. J Sci Food Agric 0(0). doi: 10.1002/jsfa.9162.

Daims, H., Bruhl, A., Amann, R., Schleifer, K.H., and Wagner, M. (1999). The domain-specific probe EUB338 is insufficient for the detection of all Bacteria: development and evaluation of a more comprehensive probe set. Syst Appl Microbio 22(3), 434-444. doi: 10.1016/S0723-2020(99)80053-8.

Danielsson, R., Dicksved, J., Sun, L., Gonda, H., Muller, B., Schnurer, A., et al. (2017). Methane production in dairy cows correlates with rumen methanogenic and bacterial community structure. Front Microbiol 8, 226. doi: 10.3389/fmicb.2017.00226.

De Menezes, A.B., Lewis, E., O'Donovan, M., O'Neill, B.F., Clipson, N., and Doyle, E.M. (2011). Microbiome analysis of dairy cows fed pasture or total mixed ration diets. FEMS Microbiol Eco 78(2), 256-265. doi: 10.1111/j.1574-6941.2011.01151.x.

Deckardt, K., Khol-Parisini, A., and Zebeli, Q. (2013). Peculiarities of enhancing resistant starch in ruminants using chemical methods: opportunities and challenges. Nutrients 5(6), 1970-1988. doi: $10.3390 /$ nu5061970.

Deusch, S., Camarinha-Silva, A., Conrad, J., Beifuss, U., Rodehutscord, M., and Seifert, J. (2017). A structural and functional elucidation of the rumen microbiome influenced by various diets and microenvironments. Front Microbiol 8, 1605. doi: 10.3389/fmicb.2017.01605.

Downes, J., Sutcliffe, I., Tanner, A.C., and Wade, W.G. (2005). Prevotella marshii sp. nov. and Prevotella baroniae sp. nov., isolated from the human oral cavity. Int J Syst Evol Microbiol 55(Pt 4), 1551-1555. doi: 10.1099/ijs.0.63634-0.

Fenner, H., Damon, R.A., Jr., and Barnes, H.D. (1970). Effects of a stepwise replacement of hay with corn silage on $\mathrm{pH}$, some organic metabolites, and their changes in the rumen fluid of the bovine after feeding. Jour of Dairy Sci 53(11), 1568-1577. doi: 10.3168/jds.S00220302(70)86438-4.

Freier, T.A., Beitz, D.C., Li, L., and Hartman, P.A. (1994). Characterization of Eubacterium coprostanoligenes sp. nov., a cholesterol-reducing anaerobe. Int J Syst Bacteriol 44(1), 137142. doi: 10.1099/00207713-44-1-137.

Hamady, M., Walker, J.J., Harris, J.K., Gold, N.J., and Knight, R. (2008). Error-correcting barcoded primers for pyrosequencing hundreds of samples in multiplex. Nat Methods 5(3), 235-237. doi: 10.1038/nmeth.1184.

Hayashi, H., Shibata, K., Sakamoto, M., Tomita, S., and Benno, Y. (2007). Prevotella copri sp. nov. and Prevotella stercorea sp. nov., isolated from human faeces. Int J Syst Evol Microbiol 57(Pt 5), 941-946. doi: 10.1099/ijs.0.64778-0. 
Henderson, G., Cox, F., Ganesh, S., Jonker, A., Young, W., Janssen, P.H., et al. (2015). Rumen microbial community composition varies with diet and host, but a core microbiome is found across a wide geographical range. Scient Rep 5, 14567. doi: 1456710.1038/Srep14567.

Hook, S.E., Wright, A.D., and McBride, B.W. (2010). Methanogens: methane producers of the rumen and mitigation strategies. Archaea 2010, 945-785. doi: 10.1155/2010/945785.

Indugu, N., Vecchiarelli, B., Baker, L.D., Ferguson, J.D., Vanamala, J.K.P., and Pitta, D.W. (2017). Comparison of rumen bacterial communities in dairy herds of different production. $B M C$ Microbiol 17(1), 190. doi: 10.1186/s12866-017-1098-z.

IPCC (2006). Intergovernmental Panel on Climate Change. Guidelines for National Greenhouse Gas Inventories. Agriculture, Forestry and Other Land Use. 4.

IPCC (2014). "Intergovernmental Panel on Climate Change. Climate change 2014. Synthesis report 2014.".).

Jiang, S.Z., Yang, Z.B., Yang, W.R., Li, Z., Zhang, C.Y., Liu, X.M., et al. (2015). Diets of differentially processed wheat alter ruminal fermentation parameters and microbial populations in beef cattle. J Anim Sci 93(11), 5378-5385. doi: 10.2527/jas.2015-9547.

Johnson, K.A., and Johnson, D.E. (1995). Methane emissions from cattle. J Anim Sci 73(8), 24832492. doi: $10.2527 / 1995.7382483 x$.

Kembel, S.W., Cowan, P.D., Helmus, M.R., Cornwell, W.K., Morlon, H., Ackerly, D.D., et al. (2010). Picante: R tools for integrating phylogenies and ecology. Bioinformatics 26(11), 1463-1464. doi: 10.1093/bioinformatics/btq166.

Kozakai, K., Nakamura, T., Kobayashi, Y., Tanigawa, T., Osaka, I., Kawamoto, S., et al. (2007). Effect of mechanical processing of corn silage on in vitro ruminal fermentation, and in situ bacterial colonization and dry matter degradation. Canad J Anim Sci 87(2), 259-267. doi: 10.4141/A06-028.

Kvist, T., Ahring, B.K., and Westermann, P. (2007). Archaeal diversity in Icelandic hot springs. FEMS Microbiol Ecol 59(1), 71-80. doi: 10.1111/j.1574-6941.2006.00209.x.

Lahti, L., and Shetty, S. (2017). Tools for microbiome analysis in R. Microbiome package version 1.1.10012. . Bioconductor.

Lettat, A., Hassanat, F., and Benchaar, C. (2013). Corn silage in dairy cow diets to reduce ruminal methanogenesis: effects on the rumen metabolically active microbial communities. $J$ Dairy Sci 96(8), 5237-5248. doi: 10.3168/jds.2012-6481.

Li, R.W., Wu, S., Baldwin, R.L., Li, W., and Li, C. (2012). Perturbation dynamics of the rumen microbiota in response to exogenous butyrate. PLoS One 7(1), e29392. doi: 10.1371/journal.pone.0029392.

Li, Z.P., Liu, H.L., Li, G.Y., Bao, K., Wang, K.Y., Xu, C., et al. (2013). Molecular diversity of rumen bacterial communities from tannin-rich and fiber-rich forage fed domestic Sika deer (Cervus nippon) in China. BMC Microbiol 13, 151. doi: 10.1186/1471-2180-13-151.

Liu, Q., Wang, C., Zhang, Y.L., Pei, C.X., Zhang, S.L., Wang, Y.X., et al. (2016). Effects of isovalerate supplementation on growth performance and ruminal fermentation in pre- and post-weaning dairy calves. J Agri Sci 154(8), 1499-1508. doi: 10.1017/S0021859616000630.

Madden, U.A., Osweiler, G.D., Knipe, L., Beran, G.W., and Beitz, D.C. (1999). Effects of Eubacterium coprostanoligenes and Lactobacillus on $\mathrm{pH}$, Lipid Content, and Cholesterol of Fermented Pork and Mutton Sausage-Type Mixes. Jour of Food Sci 64(5), 903-908. doi: 10.1111/j.1365-2621.1999.tb15937.x.

Mao, S., Zhang, M., Liu, J., and Zhu, W. (2015). Characterising the bacterial microbiota across the gastrointestinal tracts of dairy cattle: membership and potential function. Sci Rep 5, 16116. doi: 10.1038/srep16116.

McCabe, M.S., Cormican, P., Keogh, K., O'Connor, A., O'Hara, E., Palladino, R.A., et al. (2015). Illumina MiSeq phylogenetic amplicon sequencing shows a large reduction of an 
uncharacterised Succinivibrionaceae and an increase of the Methanobrevibacter gottschalkii clade in feed restricted cattle. Plos One 10(7), e0133234. doi: ARTNe013323410.1371/journal.pone.0133234.

Paradis, E., Claude, J., and Strimmer, K. (2004). APE: Analyses of phylogenetics and evolution in R language. Bioinformatics 20(2), 289-290.

Philip, D. (2003). VEGAN, a package of R functions for community ecology. J Veget Sci 14(6), 927-930. doi: 10.1111/j.1654-1103.2003.tb02228.x.

Pitta, D.W., Pinchak, E., Dowd, S.E., Osterstock, J., Gontcharova, V., Youn, E., et al. (2010). Rumen bacterial diversity dynamics associated with changing from bermudagrass hay to grazed winter wheat diets. Microb Ecol 59(3), 511-522. doi: 10.1007/s00248-009-9609-6.

Quast, C., Pruesse, E., Yilmaz, P., Gerken, J., Schweer, T., Yarza, P., et al. (2013). The SILVA ribosomal RNA gene database project: improved data processing and web-based tools. Nucleic Acids Res 41(Database issue), D590-596. doi: 10.1093/nar/gks1219.

Ramiro-Garcia, J., Hermes, G., Giatsis, C., Sipkema, D., Zoetendal, E., Schaap, P., et al. (2016). NG-Tax, a highly accurate and validated pipeline for analysis of 16S rRNA amplicons from complex biomes [version 1; referees: 2 approved with reservations, 1 not approved]. F1000 Res 5. doi: 10.12688/f1000research.9227.1.

Sakamoto, M., Suzuki, M., Huang, Y., Umeda, M., Ishikawa, I., and Benno, Y. (2004). Prevotella shahii sp. nov. and Prevotella salivae sp. nov., isolated from the human oral cavity. Int $J$ Syst Evol Microbiol 54(Pt 3), 877-883. doi: 10.1099/ijs.0.02876-0.

Smilauer, P., Leps, J. (2014). Multivariate analysis of ecological data using Canoco 5, 2nd edn. Camb Univ Press.

Tian, L., Scholte, J., Borewicz, K., van den Bogert, B., Smidt, H., Scheurink, A.J., et al. (2016). Effects of pectin supplementation on the fermentation patterns of different structural carbohydrates in rats. Mol Nutr Food Res 60(10), 2256-2266. doi: 10.1002/mnfr.201600149.

van den Bogert, B., De Vos, W.M., Zoetendal, E.G., and Kleerebezem, M. (2011). Microarray analysis and barcoded pyrosequencing provide consistent microbial profiles depending on the source of human intestinal samples. Appl Environ Microbiol 77(6), 2071-2080. doi: 10.1128/AEM.02477-10.

van den Bogert, B., Erkus, O., Boekhorst, J., De Goffau, M., Smid, E.J., Zoetendal, E.G., et al. (2013). Diversity of human small intestinal Streptococcus and Veillonella populations. FEMS Microbiol Ecol 85(2), 376-388. doi: 10.1111/1574-6941.12127.

van Gastelen, S., Antunes-Fernandes, E.C., Hettinga, K.A., Klop, G., Alferink, S.J., Hendriks, W.H., et al. (2015). Enteric methane production, rumen volatile fatty acid concentrations, and milk fatty acid composition in lactating Holstein-Friesian cows fed grass silage- or corn silage-based diets. J Dairy Sci 98(3), 1915-1927. doi: 10.3168/jds.2014-8552.

van Kessel, J. (1996). The effect of pH on ruminal methanogenesis. FEMS Microbio Eco 20(4), 205-210. doi: 10.1016/0168-6496(96)00030-x.

van Lingen, H.J., Edwards, J.E., Vaidya, J.D., van Gastelen, S., Saccenti, E., van den Bogert, B., et al. (2017). Diurnal dynamics of gaseous and dissolved metabolites and microbiota composition in the bovine rumen. Front Microbiol 8(425), 425. doi: 10.3389/fmicb.2017.00425.

van Lingen, H.J., Plugge, C.M., Fadel, J.G., Kebreab, E., Bannink, A., and Dijkstra, J. (2016). Thermodynamic driving force of hydrogen on rumen microbial metabolism: A theoretical investigation. PLOS ONE 11(10), e0161362. doi: 10.1371/journal.pone.0161362.

van Zijderveld, S.M., Gerrits, W.J., Apajalahti, J.A., Newbold, J.R., Dijkstra, J., Leng, R.A., et al. (2010). Nitrate and sulfate: Effective alternative hydrogen sinks for mitigation of ruminal methane production in sheep. J Dairy Sci 93(12), 5856-5866. doi: 10.3168/jds.2010-3281. 
Wallace, R.J., Rooke, J.A., McKain, N., Duthie, C.A., Hyslop, J.J., Ross, D.W., et al. (2015). The rumen microbial metagenome associated with high methane production in cattle. $B M C$ Genomics 16(1), 839. doi: 10.1186/s12864-015-2032-0.

Wang, Y., and Qian, P.Y. (2009). Conservative fragments in bacterial 16S rRNA genes and primer design for $16 \mathrm{~S}$ ribosomal DNA amplicons in metagenomic studies. PLoS One 4(10), e7401. doi: 10.1371/journal.pone.0007401. 


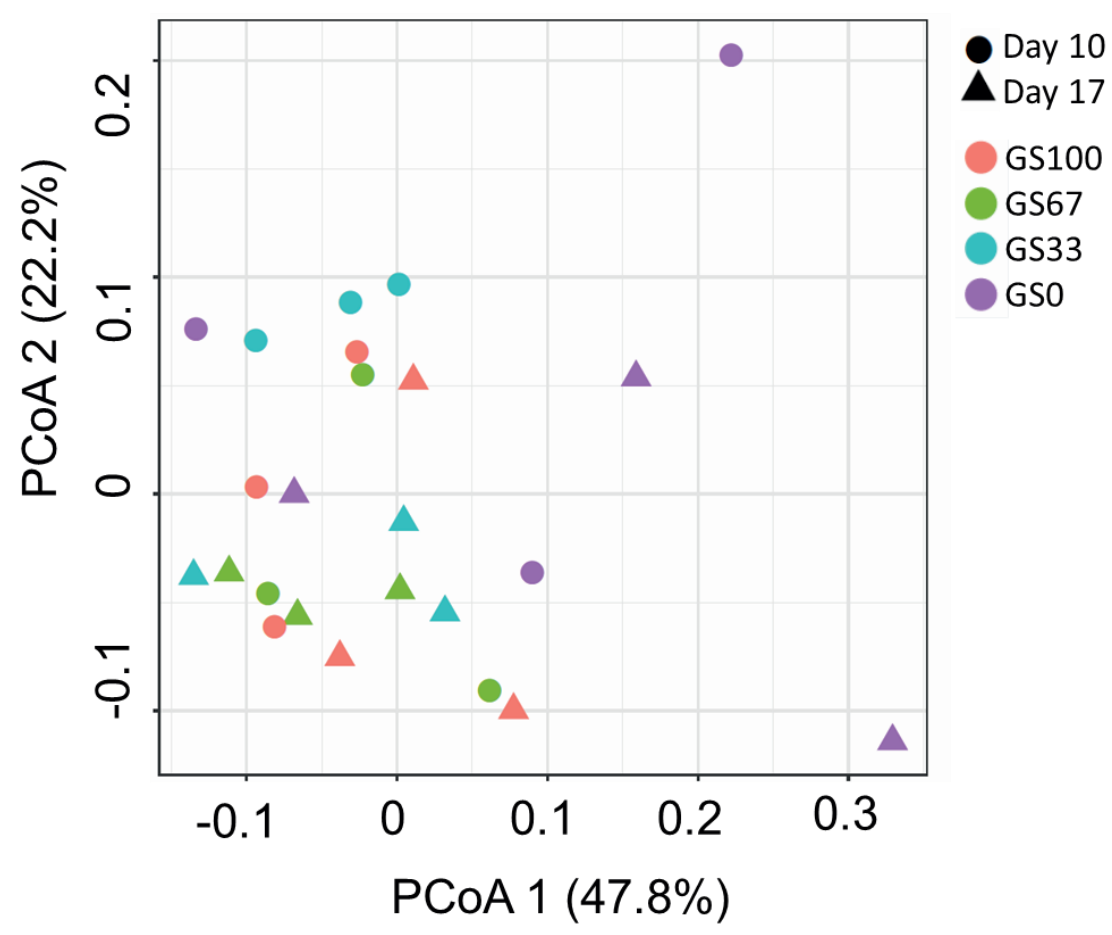

Figure S1. Principal co-ordinate analysis (PCoA) analysis of rumen fluid bacterial community composition $(n=24)$ using weighted UniFrac distance metrics. Colours indicate the different grass and maize silage proportions in the diet (i.e. GS67 (67\% grass silage and 33\% maize silage)), and the symbol shapes indicate the number of days that the diet had been fed (10 or 17).The percentage of variation explained is indicated on the respective axes. 


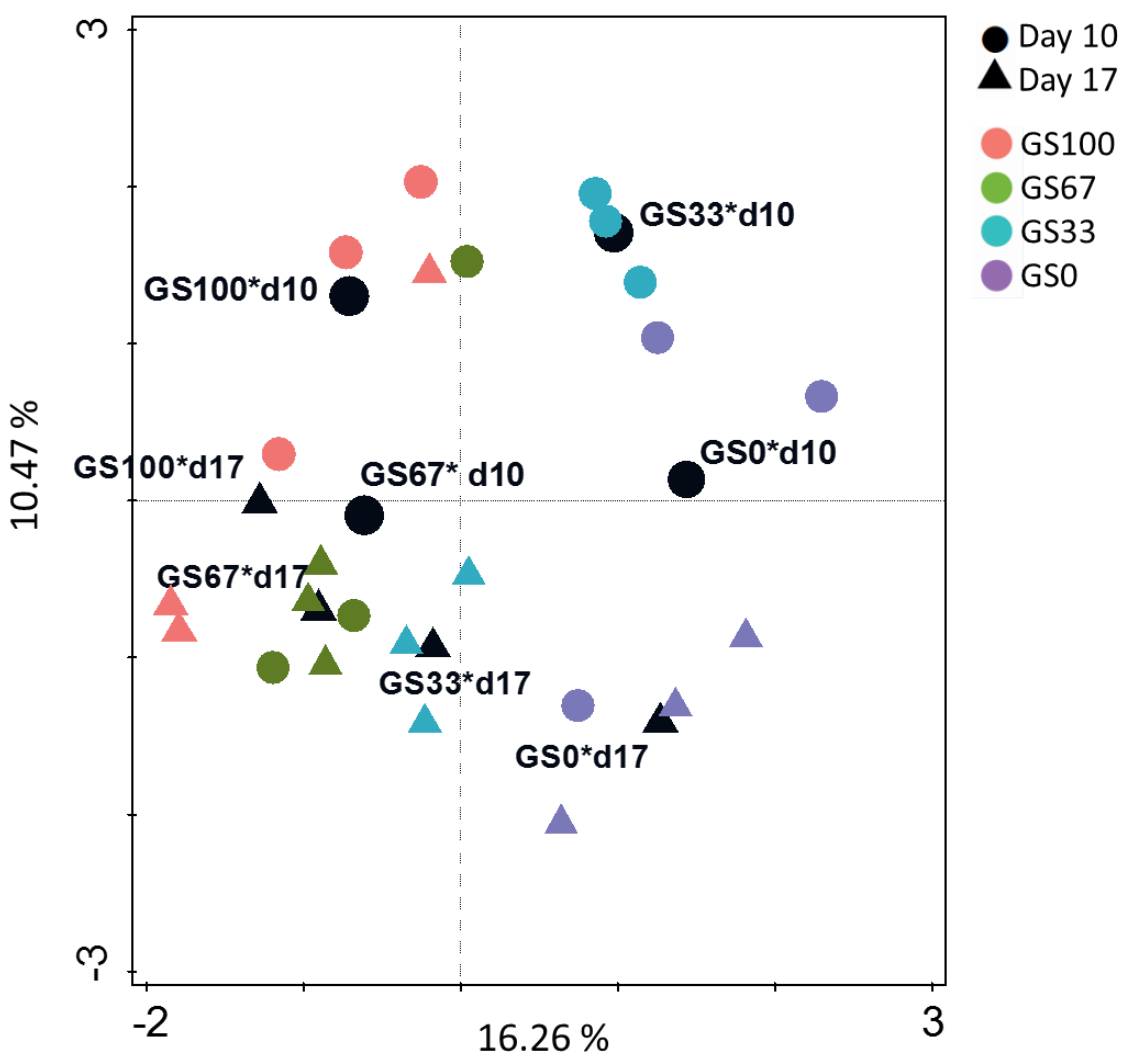

Supplementary Figure S2. Redundancy analysis triplot explaining the variance associated with the diet $\times$ time. The canonical axis are labelled with the amount of variation they explain relative to the explanatory variable diet $\times$ time. Sample codes for the means indicate different grass and maize silage proportions in the diet (i.e. GS67 (67\% grass silage and 33\% maize silage)) and the number of days that the diet had been fed (d10 or d17). 


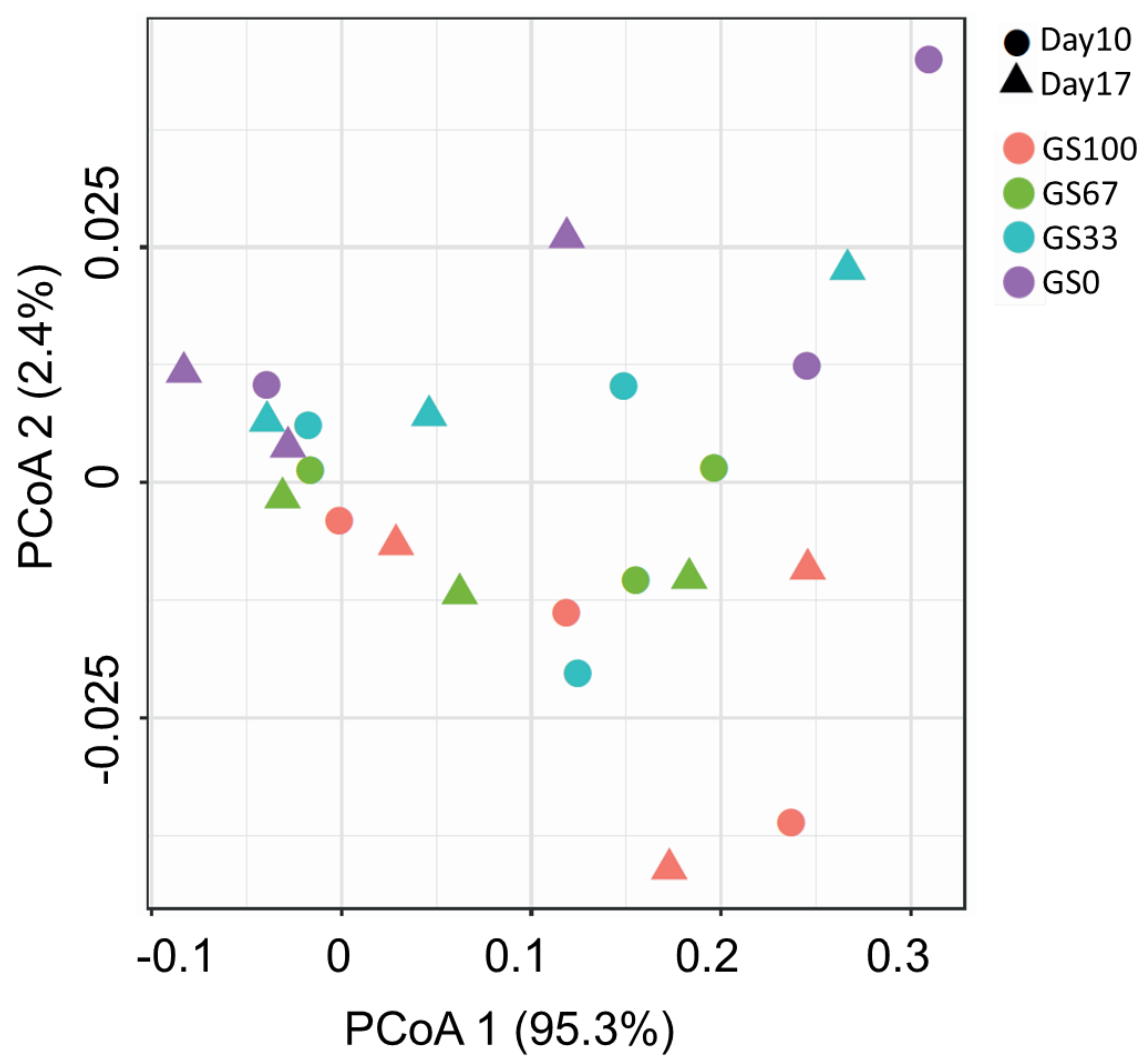

Figure S3. Principal co-ordinate analysis (PCoA) analysis of archaeal community composition from rumen fluid samples $(n=24)$ using the weighted UniFrac distance metric. Colours indicate the different grass and maize silage proportions in the diet (i.e. GS67 (67\% grass silage and 33\% maize silage)), and the symbol shapes indicate the number of days that the diet had been fed (10 or 17). The percentage of variation explained is indicated on the respective axes. 


\section{Chapter 4}

\section{Enrichment of rumen fibre associated bacteria derived from ruminal fibrous content in dairy cows fed grass or maize silage}

Jueeli D. Vaidya ${ }^{1,2}$, Chen $\mathrm{Ye}^{1,2}$, Colores Uwamariya ${ }^{1,2}$, Joan E. Edwards $^{1,2}$, Hauke Smidt ${ }^{2}$, Caroline M. Plugge ${ }^{2}$

\footnotetext{
${ }^{1}$ Top Institute Food and Nutrition, Wageningen, The Netherlands

${ }^{2}$ Laboratory of Microbiology, Wageningen University \& Research, Wageningen, The Netherlands
} 


\begin{abstract}
Ruminant animals gain most of their energy from plant fibres, which are degraded by complex microbial communities in the rumen. In the past, rumen microbiologists focused on elucidating the attachment of bacteria to feed particles and their role in initial fibre degradation. Nonetheless, many fibre associated microbes remain uncultured and unidentified. Therefore, in this study rumen fibre associated microbes were enriched from grass silage (GS) or maize silage (MS) fibres recovered from the bovine rumen. Enrichments used pre-autoclaved ruminal silage fibres (GS or MS, respectively, for each isolation source) as an attachment matrix in bottles containing different fibre related components (cellulose, amylopectin or xylan) in duplicate. Furthermore, bottles without any additional $\mathrm{C}$ source other than the pre-autoclaved silage fibres were included as well. All these bottles, termed the primary enrichments $(\mathrm{PE})$, were incubated at $39^{\circ} \mathrm{C}$ for 14 days during which samples were obtained (day $0,3,5,7$, and 14) for analysis of metabolite production and substrate degradation. The fibres from the PE bottles were transferred as the inoculum for the sub-enrichment 1 (SE1) bottles, which were incubated again for 14 days under the corresponding conditions with intermittent cold storage between transfers. A similar approach was taken to further enrich four more times (SE2-SE5). Genus Ruminofilibacter dominated all the MS SE5 bottles, whereas all GS SE5 bottles contained a more diverse community (Prevotella 1 and Bacteroides). The in vitro experimental approach of serial two week incubation, seems likely to be important to enrich for fibre associated bacteria, i.e. Ruminofilibacter that are not favoured by shorter incubation times.
\end{abstract}

\title{
KEYWORDS
}

Rumen fibre, enrichments, grass silage, maize silage, fermentation 


\section{INTRODUCTION}

\section{Rumen microbial fermentation of feed}

The cow rumen microbiota is a complex community of bacteria, methanogenic archaea, protozoa, anaerobic fungi and viruses. Of these, the bacteria are the most diverse. The ruminant is dependent on rumen microbes for digestion of complex plant lignocellulosic compounds provided as feed. The conversion of complex plant polysaccharides to simple compounds initially involves microbial attachment to the plant fibres, which is a key limiting step for ruminal feed degradation (McAllister et al., 1994). The microbial attachment is then followed by fibre degradation which involves hydrolysis and fermentation of the degradation products into volatile fatty acids (VFAs) namely acetate, propionate and butyrate, and some minor branched-chain VFAs (iso-butyrate, iso-valerate and valerate) in addition to products like hydrogen $\left(\mathrm{H}_{2}\right)$, carbon dioxide $\left(\mathrm{CO}_{2}\right)$, formate and methylcontaining compounds. Acetate, formate (formed in the production of acetate), $\mathrm{H}_{2}, \mathrm{CO}_{2}$, and methyl-containing com pounds then subsequently serve as substrates for m ethanogenesis. VFA's ae not commonly used as substrates in the rumen since these are absorbed by the animal as energy substrates (Hook et al., 2010). Fibrous feed like grass silage fermentation is associated with higher methane formation as compared to corn or maize silage based diets in dairy cows (van Gastelen et al., 2015). Investigation of fibre associated rumen microbes that are involved in the breakdown of the fibrous components of feed can contribute to improved understanding of the link between fibre attachment, degradation and methane formation.

Plant material contains fibres that have two main constituents: cellulose and hemicellulose. Cellulose is com posed of $\beta 1$, 4-linked glucose residues, whereas hemicellulose mainly consists of xylan assem bled from $\beta 1,4$-linked xylose residues and is substituted with acetyl, arabinosyl and glucuronyl residues. Rumen microbes require hydrolytic enzymes to utilize these fibre components. Bacteria and anaerobic fungi produce a wide range of highly active plant cell wall degrading enzymes, contributing to $80 \%$ of the total fibre degrading activity in rumen (Dijkstra, 1995). Due to the slower generation times of anaerobic fungi (6-9 hrs) in comparison to bacteria (0.5-3.5 hrs) (Varga and Kolver, 1997) bacteria are considered to be the pre-dominant players in the degradation of dietary fibre (Petri et al., 2012).

The variation in rumen microbiota composition depends on the diet of the host, with diet causing the most profound changes in bacterial communities compared to the archaea (Pitta et al., 2010; De Menezes et al., 2011b). Bacteria inhabiting the rumen are classified into 1) free-living 
bacteria associated with the rumen liquid 2) bacteria loosely bound to the fibrous content 3) bacteria tightly attached to the fibrous content (FC), and 4) bacteria associated/attached to the epithelial wall of the rumen (Cheng and Costerton, 1980; McAllister et al., 1994). Bacteria loosely bound and/or attached (i.e. associated) to the fibrous content represent 70-80\% of the total bacterial microbiota (Craig et al., 1987) whereas the free-floating bacteria represent $\sim 30 \%$ (Petri et al., 2012). Bacteria associated to epithelial cells constitute a very small fraction $(\sim 1 \%)$ of the total ruminal bacterial microbiota and have no significant contribution to ruminal digestion (Petri et al., 2012). Bacteria associated with feed particles are responsible for $88 \%$ to $91 \%$ of ruminal endoglucanase and xylanase activity, $70 \%$ of the amylase activity, and $75 \%$ of the protease activity in the rumen (Cheng and Costerton, 1980; Miron et al., 2001). This information indicates that fibre-associated bacteria are pivotal for ruminal fibre degradation.

The first characterised rumen cellulolytic micro-organism was Fibrobacter succinogenes isolated by Robert Hungate (Hungate, 1950). F. succinogenes was identified as an anaerobic, Gram negative micro-organism, which produced succinic acid and acetic acid as major fermentation products from carbohydrates. Later, Ruminococcus albus and Ruminococcus flaveflaciens were also identified as cellulose degraders (Hungate, 1957). Since then, these three bacteria have been considered the key-stone species associated with ruminal fibre degradation. Moreover, these three species have been tested in vivo previously for their attachment and degradation capability, confirming their role in ruminal fibre utilization (Miron et al., 2001).

Degradation of complex polymers requires hydrolytic enzymes. In 2009, the genes encoding hydrolytic enzymes were identified in Fibrobacter succinogenes, Ruminococcus albus and Ruminococcus flavefaciens (Koike and Kobayashi, 2009; Morrison et al., 2009). Additionally, genome sequencing also revealed genes encoding multiple glycosyl hydrolases in all three species (Krause et al., 2003). In both $R$. flavefaciens and $R$. albus, a cellulosome structure has been identified where the cellulosomal protein containing is involved in protein anchoring to the Grampositive bacterial cell envelope (Rincon et al., 2005; Jindou et al., 2008).

Non-fibrolytic bacteria, that are able to degrade one or more plant components, can stimulate the activity of fibrolytic bacteria through interactions, particularly cross-feeding. For example, cellulolytic species (F. succinogenes, R.albus or R.flavefaciens), when co-cultured with Treponema bryantii, Prevotella ruminicola and Selenomonas ruminantium, show improved fibre digestion compared to the corresponding monocultures (Wolin et al., 1997). The non-fibrolytic species are 
motile and move inside the plant cells facilitating the entry of non-motile fibrolytic species (Sawanon et al., 2011). These findings indicate that there is a close association between specific bacteria when degrading ruminal plant fibrous content. Other known non-cellulolytic rumen bacterial species involved in fibre degradation include Clostridium longisporum, Clostridium lochheadii, Butyrivibrio fibrosolvens, Prevotella ruminicola, Eubacterium ruminantium and Eubacterium cellulosolvens (Stewart et al., 1997).

Evaluation of ruminal microbial communities through next generation sequencing techniques using 16S ribosomal RNA (rRNA) gene based PCR approaches has expanded our knowledge of the composition of rumen microbial communities associated with rumen fibrous content and liquid fraction across different diets, ruminant species and geographical locations (De Menezes et al., 2011b; Fouts et al., 2012; Pitta et al., 2014; Henderson et al., 2015b; Noel et al., 2017). The microbial communities adhering to the fibrous content are distinct from those in the liquid fraction (Fouts et al., 2012). The liquid fraction of the rumen is characterized by high relative abundances of bacteria belonging to the genera Zhangella, Tannerella (both members of the order Bacteroidales) and Prevotella, whereas the genera Blautia and Butyrivibrio (both members of the order Clostridiales) are generally more abundant in the fibrous content (Fouts et al., 2012).

Among the known members of fibre associated bacterial communities, only 2-31\% have more than $97 \%$ similarity with cultivated species (Koike et al., 2003a; Kobayashi, 2006). This highlights the need to perform enrichment, isolation and characterization of bacteria that are associated with the fibrous content in order to better understand the metabolism and role of microorganisms involved in fibre-attachment and degradation. Therefore, the objective of this study was to enrich fibre associated bacteria using a range of different fibre based substrates from both ruminal maize silage and grass silage fibres and characterise their metabolism and bacterial community composition.

\section{MATERIALS AND METHODS}

\section{Ethics statement}

The ruminal fibrous content (FC) samples used in this study represented a subset of those collected as part of a larger study, the details of which have been published elsewhere (van Gastelen et al., 2015). The current study was conducted in accordance with Dutch law and approved by the Animal Care and Use Committee of Wageningen University \& Research. 


\section{Fibres for inoculum \& cultivation medium composition}

The ruminal FC was sampled from two Holstein Friesian dairy cows fed different diets. Both diets had a roughage-to-concentrate ratio of 80:20 based on dry matter, and for one cow the roughage consisted of $100 \%$ grass silage (GS) and for the other cow 100\% maize silage (MS). The solid (fibrous) fraction was collected via the rumen cannula after 4 hours of feeding, and then firmly squeezed by hand. All samples were collected within a time span of $30 \mathrm{~min}$, after which they were transported to the laboratory. The ruminal GS and MS fibres were immediately stored in anoxic $25 \%$ glycerol - phosphate buffered saline (PBS) stock at $-80^{\circ} \mathrm{C}$ until use as an inoculum for the primary enrichments $(\mathrm{PE})$.

In addition, approximately $7.5 \mathrm{~g}$ wet weight (WW) of GS and MS fibres were collected and placed in a dry ice box before being transferred to the laboratory where the fibres were transferred into falcon tubes and stored at $-80{ }^{\circ} \mathrm{C}$. These fibres were used in all the enrichment bottles as a matrix for attachment and substrate, with the type of fibre used (i.e. GS or MS) matched to the type of inoculum fibre.

\section{Experimental design}

An overview of the study design is provided in Fig 1. For both the MS and GS fibre enrichments, serum bottles were prepared in duplicate containing an anaerobic, bicarbonate buffered mineral salt medium (BM, see next section for details) supplemented with the following: one representative plant substrate ( (i.e. 1g/L of either cellulose (Avicel), xylan from birchwood or amylopectin (Sigma-Aldrich, Steinheim, Germany)), $0.1 \mathrm{~g} / \mathrm{L}$ yeast extract and the corresponding type of fibre (0.1 g/bottle) (as an attachment matrix/substrate). Additionally, there were duplicate bottles supplemented without any representative plant substrate and containing only the respective type of fibre $(0.1 \mathrm{~g})$ (as an attachment matrix/substrate). The inoculated serum bottles for the primary enrichment (PE) were incubated for 14 days at $39^{\circ} \mathrm{C}$ and then stored at $4^{\circ} \mathrm{C}$ for $\sim 20$ days. To further enrich the bacteria attached to the fibrous matrix, sub-enrichments (SE) were made by transferring the fibres (GS or MS) from the PE serum bottles to the sub-enrichment 1 (SE1) serum bottles (Fig. 1). These bottles were prepared in the same manner as for the PE, and were incubated for 14 days at $39^{\circ} \mathrm{C}$ followed by transferring the fibres from SE1 to SE2 (14 days enrichment period at $39^{\circ} \mathrm{C}$ ) and similarly until SE5 (Fig. 1). There was a cold storage of three to four weeks in between each transfer of fibres from primary enrichment to sub-enrichment and further. All inoculations and transfers were performed aseptically and in an anaerobic glove box. 


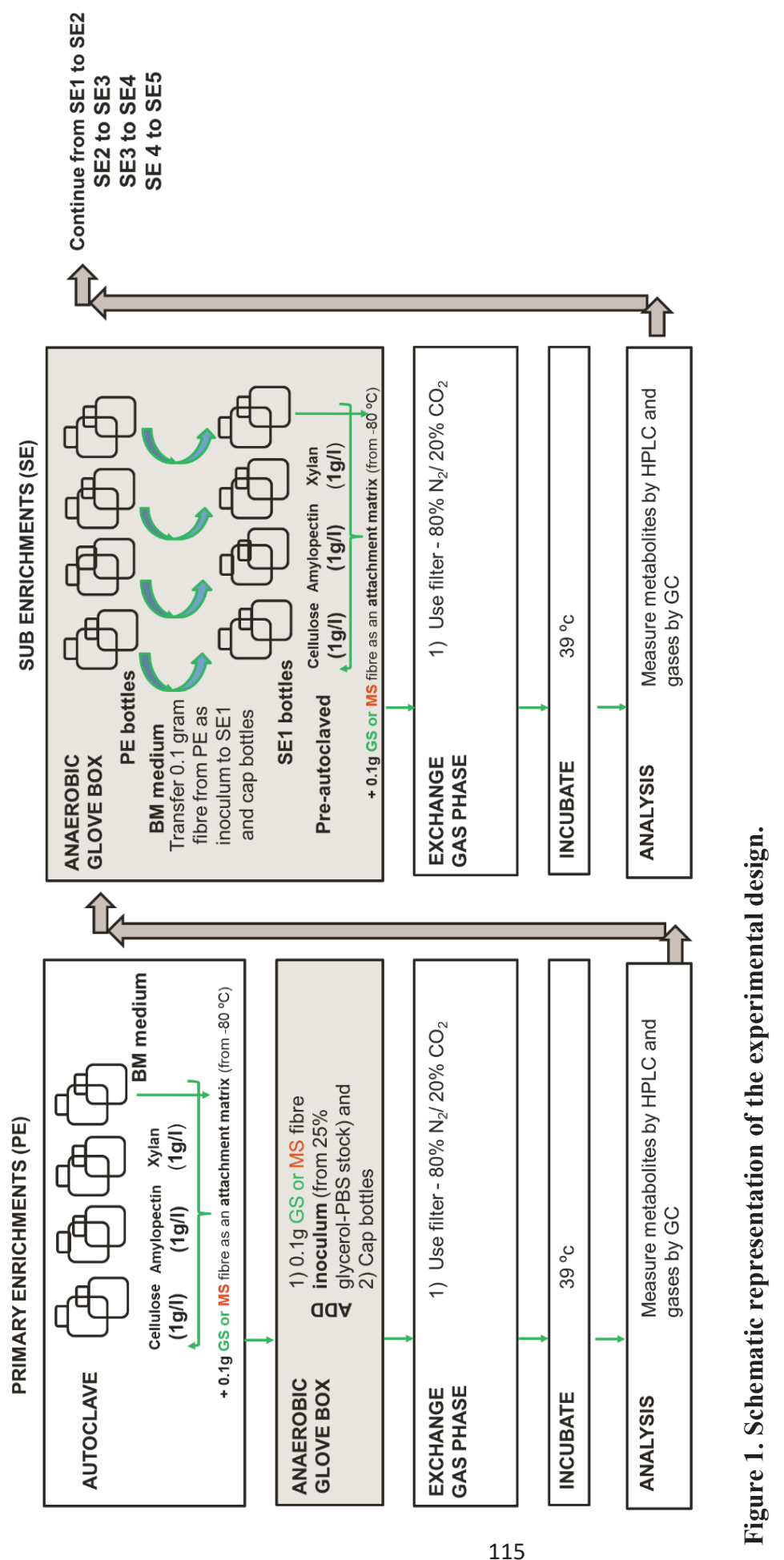




\section{Media composition \& preparation}

The BM was used as previously described (Plugge, 2005). Prior to adding $48 \mathrm{ml}$ of BM to the $117 \mathrm{ml}$ serum bottles, all serum bottles were supplemented with yeast extract $(0.1 \mathrm{~g} / \mathrm{L}$ final concentration) in addition to either ruminal grass (GS) or maize (MS) fibres (0.1g WW per bottle) which would serve as an attachment matrix. Either cellulose, xylan or amylopectin was also added before dispensing the BM medium. These representative plant components were weighed as a powder ( $1 \mathrm{~g} / \mathrm{L}$ final concentration). All serum bottles were sealed with rubber septa and aluminium crimp caps after addition of BM, the headspace was flushed with a mixture of $\mathrm{N}_{2}-\mathrm{CO}_{2}(80: 20, \mathrm{v} / \mathrm{v} ; 1.7 \mathrm{~atm})$ and autoclaved at $121^{\circ} \mathrm{C}$ for $20 \mathrm{~min}$. After sterilization, the medium was supplemented with an anoxic filter-sterilized calcium/vitamin stock solution (i.e. $10 \mathrm{ml} \mathrm{CaCl} 2(11 \mathrm{~g} / \mathrm{L})+1 \mathrm{ml}$ vitamin solution per $\mathrm{L}$ of medium) (Stams et al., 1993) and reduced with filter-sterilized a Cysteine-HCl-Na2 $\mathrm{S}_{-} \mathrm{NaHCO}_{3}$ solution (i.e. $50 \mathrm{ml}$ $\mathrm{NaHCO}_{3}$ solution $(80 \mathrm{~g} / \mathrm{L})+1 \mathrm{ml} \mathrm{Na} 2 \mathrm{~S} .9 \mathrm{H}_{2} \mathrm{O}$ solution $(240 \mathrm{~g} / \mathrm{L})+0.5 \mathrm{~g}$ cysteine $\cdot \mathrm{HCl}$ per $\mathrm{L}$ of medium (Stams et al., 1993). Furthermore, final concentrations of hemin (5 mg/L) and vitamin $\mathrm{K} 1(50 \mathrm{mg} / \mathrm{L})$ were filter-sterilized and added after the autoclaved the medium was reduced. The final $\mathrm{pH}$ of the medium was 7.0.

\section{Inoculating the primary enrichments from glycerol stock fibres}

GS and MS fibres from the $25 \%$ glycerol stock (stored at $-80^{\circ} \mathrm{C}$ ) (inoculum) were washed with anoxic sterile phosphate buffered saline (PBS) twice to remove excess glycerol attached to the fibres, as well as any loosely associated microbes. The washed fibres were then inoculated $(0.4 \% \mathrm{w} / \mathrm{v})$ into the serum bottles as outlined above (see experimental design section). All manipulations were done in an anaerobic glove box (tent). The serum bottles were then tightly capped with the rubber stopper and aluminium cap inside the glove box, brought outside the glove box, and the headspace of each bottle was flushed with a mixture of $\mathrm{N}_{2}-\mathrm{CO}_{2}(80: 20, \mathrm{v} / \mathrm{v} ; 1.7 \mathrm{~atm})$ through a sterile $0.2 \mu \mathrm{m}$ filter. All bottles were incubated at $39^{0} \mathrm{C}$, in the dark.

\section{Sampling for metabolite and microbial analyses}

From each serum bottle liquid samples $(1 \mathrm{ml})$ were collected aseptically into $1.5 \mathrm{ml}$ microcentrifuge tubes using $1 \mathrm{ml}$ syringes (BD Plastipak ${ }^{\mathrm{TM}}$, Spain) and $0.5 \mathrm{~mm}$ x $0.16 \mathrm{~mm}$ needles (BD Microlance ${ }^{\mathrm{TM}}$ 3, Ireland) at the following times after inoculation: $0,3,5,7,14$ 
days. These liquid samples were centrifuged at 14,000 g for $5 \mathrm{~min}$, and the supernatant then used for VFA analysis using HPLC (as described below). Headspace gas samples (0.8 mL) were also collected at the same time points as the liquid phase samples using a $1 \mathrm{ml}$ gas-tight syringe connected to a needle. Gas samples were directly injected to the GC for analysis (as described below).

Fibres from the original inoculum (OI) along with fibres from sub enrichment 5 (SE5) were collected after 14 days of incubation for microbial composition analysis with bacterial 16S rRNA gene amplicon barcoded sequencing. Fibres were sampled by opening the bottles inside the anaerobic glove box and using sterile forceps to transfer the fibres (approx. $0.15 \mathrm{~g}$ WW) to a $1.5 \mathrm{ml}$ eppendorf tube. Sampled fibres were then stored at $-80^{\circ} \mathrm{C}$ until DNA extraction. .

\section{Analysis of VFA and gaseous metabolites}

The VFA in the culture supernatants were separated by a Spectra system HPLC (Thermo Scientific, Breda) equipped with a Metacarb 67H column (Agilent, $300 \times 65 \mathrm{~mm}$ ). Column temperature was $45^{\circ} \mathrm{C}$. A $5 \mathrm{mM}$ sulphuric acid solution was used as an eluent. Flow rate was set at $0.8 \mathrm{~mL} / \mathrm{min}$. Metabolites were quantified with a refractive index detector.

The concentration of methane and hydrogen in the headspace samples was analyzed using a gas chromatograph (GC-14B, Shimadzu, Kyoto, Japan) with a packed column (Molsieve 12X column 60/80 mesh, 2m x 3 mm, Varian, Middleburg, The Netherlands) and a thermal conductivity detector (TCD) with a current of $70 \mathrm{~mA}$. The column temperature and injection temperature was $100{ }^{\circ} \mathrm{C}$. Argon was used as carrier gas (flow rate $30 \mathrm{~mL} \mathrm{~min}-1$ ). After measurement, the concentration of the gases was calculated based on the headspace volumes in each bottle.

\section{DNA extraction}

Genomic DNA was extracted from fibre samples using the Maxwell system as previously described (van Lingen et al., 2017b). The quantity and purity of the resulting DNA extracts was assessed using a NanoDrop ND-1000 spectrophotometer (NanoDrop ${ }^{\circledR}$ Technologies, Wilmington, DE, USA).

\section{MiSeq sequencing of 16S rRNA gene amplicons}


For bacterial composition profiling, barcoded amplicons from the V1-V2 region of 16S rRNA genes were generated using a 2-step PCR strategy. The forward primer (UniTag1-27F-DegS) included UniTag1 (5'-GAGCCGTAGCCAGTCTGC-3') at the 5'-end, and the reverse primer mix (UniTag2-338R-I + II) had UniTag2 (5'-GCCGTGACCGTGACATCG-3') at the 5'-end (Tian et al., 2016). The first PCR step was performed in a total volume of $50 \mu \mathrm{L}$ containing $10 \mu \mathrm{L} 1 \times$ HF buffer (Finnzymes, Vantaa, Finland), $1 \mu \mathrm{L}$ dNTP Mix (10 mM; Promega), $1 \mathrm{U}$ of Phusion ${ }^{\circledR}$ Hot Start II High-Fidelity DNA polymerase (2 U/ $\left.\mu \mathrm{L}\right)$ (Finnzymes, Vantaa, Finland), $500 \mathrm{nM}$ each of the primers and $20 \mathrm{ng}$ of sample DNA. The cycling conditions for the first step consisted of an initial denaturation at $98^{\circ} \mathrm{C}$ for $30 \mathrm{~s} ; 25$ cycles of denaturation at $98{ }^{\circ} \mathrm{C}$ for $10 \mathrm{~s}$, annealing at $56{ }^{\circ} \mathrm{C}$ for $20 \mathrm{~s}$, and elongation at $72{ }^{\circ} \mathrm{C}$ for $20 \mathrm{~s}$; and a final extension at $72{ }^{\circ} \mathrm{C}$ for $10 \mathrm{~min}$. The presence and size of the amplification products were determined by agarose gel electrophoresis containing 1X SYBR Safe ${ }^{\circledR}$ (Invitrogen).

The second PCR step was then employed to add an 8 nucleotide sample specific barcode to the 5'- and 3' -end of the PCR products. The PCR was performed in a total volume of $100 \mu \mathrm{L}$ containing $1 \times$ HF buffer, $2 \mu \mathrm{L}$ of dNTP Mix, $1 \mathrm{U}$ of Phusion ${ }^{\circledR}$ Hot Start II HighFidelity DNA polymerase $(2 \mathrm{U} / \mu \mathrm{L}), 500 \mathrm{nM}$ of a forward and reverse primer equivalent to the Unitag1 and UniTag2 sequences, respectively, that were each appended with an 8 nt sample specific barcode and $5 \mu 1$ of the PCR product from the first step PCR. The cycling conditions of the second step consisted of an initial denaturation at $98{ }^{\circ} \mathrm{C}$ for $30 \mathrm{~s} ; 5$ cycles of $98{ }^{\circ} \mathrm{C}$ for $10 \mathrm{~s}, 52{ }^{\circ} \mathrm{C}$ for $20 \mathrm{~s}$ and $72{ }^{\circ} \mathrm{C}$ for $20 \mathrm{~s}$; and a final extension at $72{ }^{\circ} \mathrm{C}$ for $10 \mathrm{~min}$. Incorporation of the sample specific barcodes, yielding a PCR product of $\sim 350 \mathrm{bp}$, was confirmed by agarose gel electrophoresis. Control PCR reactions were performed alongside each separate amplification with no addition of template, and consistently yielded no PCR product. PCR products were then purified using HighPrep ${ }^{\mathrm{TM}}$ (MagBio Europe Ltd, Kent, United Kingdom) and quantified using a Qubit dsDNA BR Assay Kit (Invitrogen). Purified PCR products were mixed in equimolar amounts into pools together with defined synthetic mock communities that allow controlling for potential technical biases (Ramiro-Garcia et al., 2016). Pools then underwent adaptor ligation followed by sequencing on the MiSeq platform (GATC-Biotech, Konstanz, Germany). 


\section{RESULTS AND DISCUSSION}

In the present study, two enrichment series from ruminal grass silage (GS) and maize silage (MS) fibres were obtained through serial transfers into mineral medium supplemented with sterile fibres and representative plant substrates, starting from PE to SE5 (Fig. 2 and 3). All enrichments were incubated at $39^{\circ} \mathrm{C}$ for a 14 day period, with storage at $4^{\circ} \mathrm{C}$ for $3-4$ weeks between transfers. Although overall activity in all the enrichments was low (Fig. 2 and 3), fibre-degrading bacteria were considered to be enriched as visual inspection of PE bottles from both the MS and GS enrichment series showed initial fragmentation or breaking up of the fibre structure. Cultures also produced metabolites indicative of substrate utilization during PE for both the GS (Fig. 2) and MS (Fig. 3).

\section{Grass silage enrichments}

The GS enrichments produced acetate as the major metabolite from all enrichments ranging from PE to SE5 (Fig. 2A). Propionate and butyrate were also formed in lower concentrations, although not in all the later enrichments (Fig. 2B and 2C). Generally, after SE2 only acetate was formed at concentrations $>1 \mathrm{mM}$, indicating that the cold storage in between the sub enrichments might have resulted in the loss of populations associated with propionate and butyrate production.

In GS PE bottles supplemented with cellulose, $7 \mathrm{mM}$ acetate was produced after 14 days incubation whereas the SE1 bottle supplemented with cellulose produced less acetate (5 $\mathrm{mM}$ ) indicating lower concentrations and/or activity of cellulose degrading bacteria over the sub-enrichments (Fig. 2A). In SE2, acetate production was further reduced to $2 \mathrm{mM}$, but increased again to $8 \mathrm{mM}$ in SE3 cellulose enrichments. From SE3, acetate production by day 14 decreased to around $1 \mathrm{mM}$ for SE5 bottles on day 14 (Fig. 2A). Since the amount of acetate produced by the GS SE5 cellulose enrichment was lower than that formed by the corresponding enrichment without any additional polysaccharide added (GS SE5 fibre) on day 14 (Fig. S1), it can be concluded that the cellulose was no longer utilized by this point.

In GS bottles supplemented with xylan, high acetate production was observed on day 14 for SE2 (12 mM), with lower concentrations being observed in subsequent sub-enrichments (i.e. $4 \mathrm{mM}$ in SE4 and SE5 bottles). Although xylan has been suggested to be more easily degraded compared to cellulose (Horn et al., 2012), our results show that by SE3 the 
concentration of acetate produced by the GS xylan enrichments was lower than that observed for the corresponding GS cellulose enrichments (Fig. 2A).

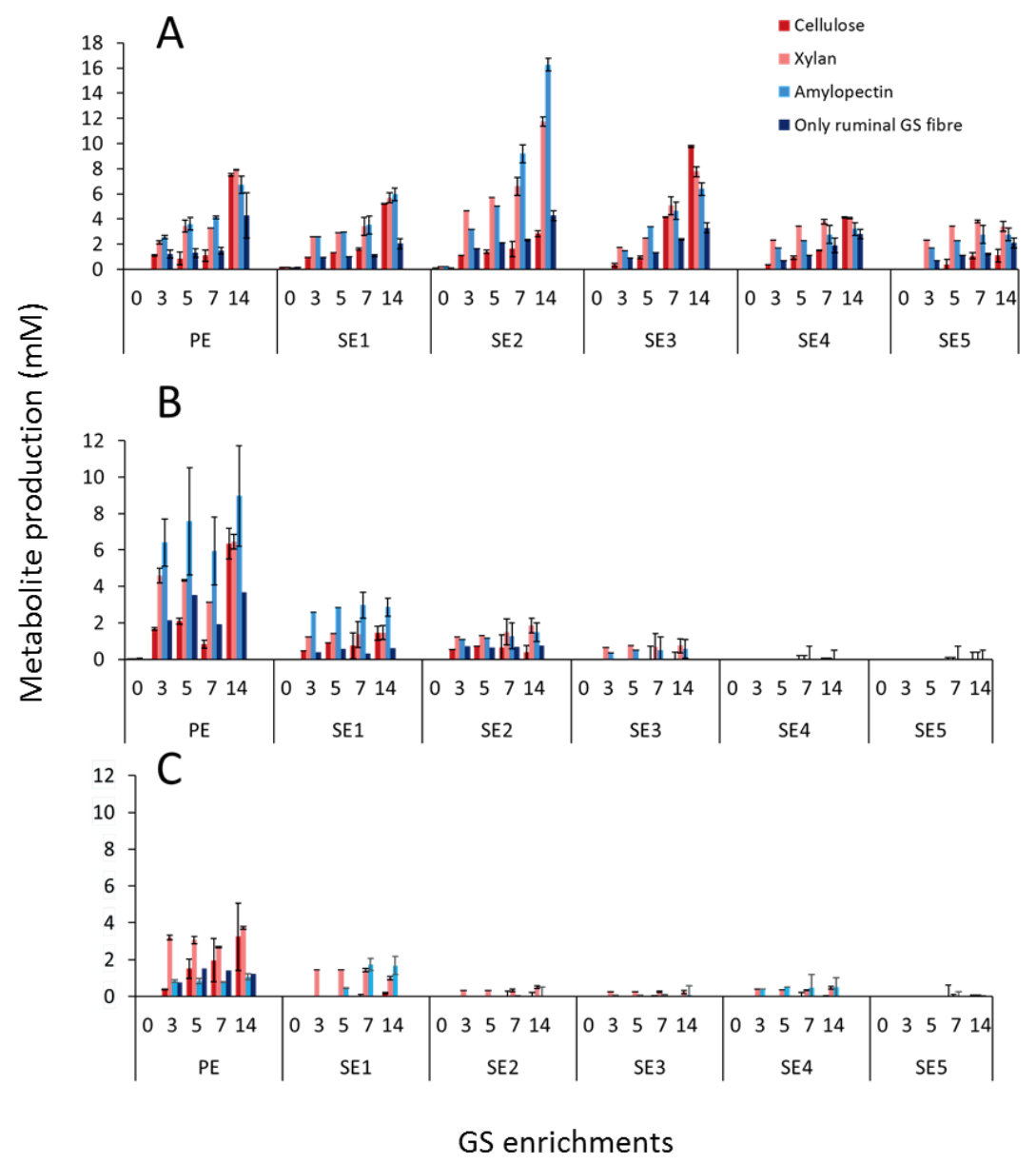

Figure 2. Acetate $(\mathbf{A})$, propionate $(\mathbf{B})$ and butyrate $(\mathbf{C})$ production from primary $(\mathrm{PE})$ and sub enrichments (SE1 to SE5) in the presence of grass silage (GS) fibres and different polysaccharides during incubation for 14 days, with samples taken at $0,3,5,7$ and 14 days of each incubation. The error bars represent variation in the duplicate bottles.

In GS bottles supplemented with amylopectin, acetate production was the highest in SE2 suggesting that the additional substrate was readily utilized by the microbial consortia (Fig. 2A). However, acetate production in SE4 and SE5 on day 14 did not differ from that 
observed for the GS-fibre only bottles, suggesting that the amylopectin degradation in the latter enrichments was minimal. It is speculated that this low activity might have been due to the cold storage periods. Moreover, as the sub-enrichments were proceeding, the fibres were losing integrity and therefore during transfers of inoculum (fibres from one sub-enrichment to another) there might have been less bacteria (attached onto fibres) transferred.

Propionate production was seen in PE bottles with all four substrates (cellulose, xylan, amylopectin and only GS fibres) at a final concentration of 6.2, 5.9, 8.4 and $3.1 \mathrm{mM}$ respectively. During further sub-enrichments, however, propionate production declined steadily to almost undetectable values in SE4 and SE5 (Fig. 2B). Butyrate was only produced in low concentrations $(<4 \mathrm{mM})$ from cellulose and xylan enrichments during the PE (Fig. 2C). The rest of the substrates (amylopectin and only GS fibres) showed limited butyrate production $(\sim 1 \mathrm{mM})$ in all bottles.

\section{Maize silage enrichments}

The MS enrichments also showed acetate as the major metabolite produced, irrespective of the presence of an additional plant substrate (Fig. 3). In all cases, the amount of acetate produced was higher than that observed in enrichments that only contained the MS-fibre, suggesting that the additional substrates (cellulose, amylopectin and xylan) were always utilized to some extent (Fig. 3A). The cold storage period in between the transfers did not seem to affect acetate production by the MS fibre enrichments (Fig. 3A).

The MS enrichments produced propionate in PE and SE1 enrichments with or without any additional substrates (Fig. 3B). The propionate production in SE1 ranged from 4 to $6 \mathrm{mM}$. In further subcultures, lower concentrations of propionate $(<1 \mathrm{mM})$ were detected.

The MS enrichment bottles produced butyrate from all substrates from PE to SE5, except for cellulose, amylopectin and MS-fibre only enrichment bottles during SE1 and SE2. During PE, butyrate could be measured from day 7 in all bottles.

\section{Gaseous metabolites}

Overall, $\mathrm{CH}_{4}$ production was low $(<0.2 \mathrm{mM})$ in all the PE for the GS and MS enrichments. In SE2, xylan $(\sim 2 \mathrm{mM})$ and amylopectin $(\sim 5 \mathrm{mM})$ had more $\mathrm{CH}_{4}$ detected than cellulose and only fibres GS and MS enrichments (Fig. S1). In later transfers (SE5), $\mathrm{CH}_{4}$ was mainly 


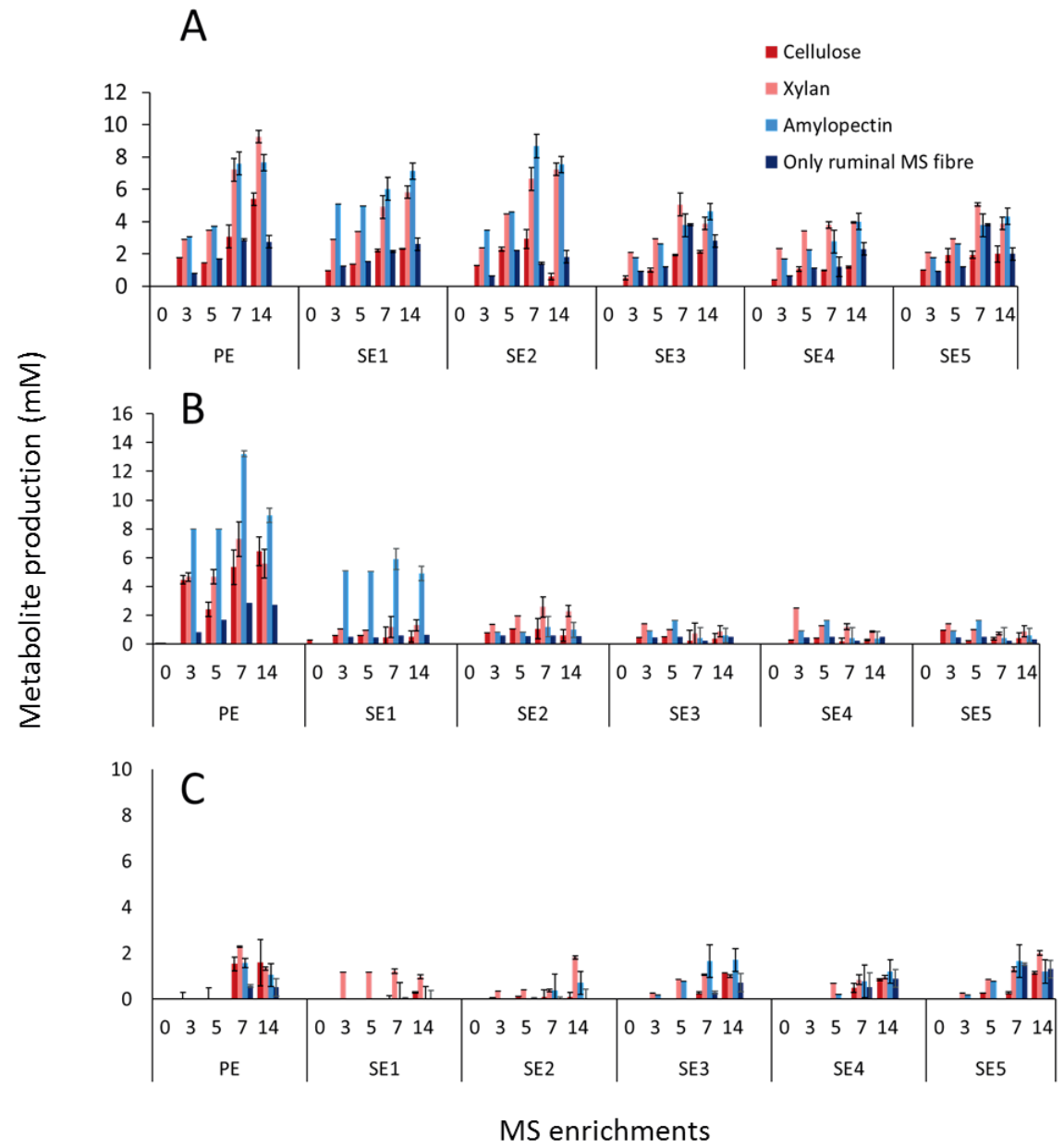

Figure 3. (A) Acetate, (B) propionate and (C) butyrate production (mM) from primary (PE) and sub enrichments (SE) in maize silage (MS) and different polysaccharides during incubation for 14 days, with samples taken at $0,3,5,7$ and 14 days of each incubation. The error bars represent variation in the duplicate bottles.

observed from amylopectin in GS and MS enrichments (Fig. S1). $\mathrm{H}_{2}$ was not detected in any of the enrichments.

\section{Bacterial community analysis using MiSeq}

Bacterial community analysis was performed on the original inoculum (OI) (Fig. 4A) and the last sub-enrichment (SE5) using bacterial 16S rRNA gene barcoded amplicon sequencing 
(Fig. 4B). A number of bacterial genera present in SE5 differed in their relative abundances compared to the original inoculum, for both the GS and MS fibre enrichments. These differences could be due to low abundant bacteria becoming further enriched following sub culturing and/or more abundant bacteria dying off, although the cold storage between subcultures may also have influenced the bacterial community composition.

Compared to the bacterial communities in the original inocula, those observed in SE5 were characterized by a lower alpha diversity and were dominated by specific genera (Fig. 4). The predominant genus-level taxon in both the GS and MS inocula was Prevotella 1, accounting for $37.8 \%$ and $41.3 \%$ of the fibre-associated communities, respectively. The same group was consistently predominant in all the GS SE5 enrichments, ranging from $18.8 \%-$ $51.9 \%$. In contrast, this genus was no longer observed in any of the MS sub-enrichments. Instead, the MS SE5 enrichments were dominated by Ruminofilibacter (range 66.4 to $85.0 \%$ ) (Fig. 4).

Compared to the OI, the GS SE5 bottles with fibre as the sole carbon source were also enriched in Ruminoclostridium 1 (23.7\%), Bacteroides (18.7\%), Prevotella 1 (18.8\%) and Aminobacterium (14.6\%). In the GS SE5 bottles with cellulose, Prevotella 1 (51.9 \%) became the dominant member that was enriched, indicating their preference for grass silage fibres. In contrast, Proteiniphylum (45.1 \%) and Prevotella 1 (31.3\%) were both highly enriched with xylan. The GS SE5 bottles with amylopectin was enriched mainly with Aminobacterium (31.3\%) and Bacteroides (14.9 \%) (Fig. 4). Members of Prevotella 1 (example Prevotella ruminicola) are usually correlated with propionate production and are potentially involved in hemi-cellulose degradation, along with their importance in utilization of proteins and peptides (Emerson, 2017). Our in vitro study not only shows their enrichment in the presence of hemicellulolytic components, like xylan, but also suggests their capability to utilize other complex insoluble substrates such as cellulose and amylopectin in the GS enrichments. Bacteroides spp. have been reported as being cellulose degraders capable of producing acetate, propionate or succinate (Chassard et al., 2010). However, succinate is not accumulated in the rumen but gets rapidly de-carboxylated to propionate. In our study, although Bacteroides was observed in all GS sub-enrichment bottles, there was neither succinate nor propionate production seen in SE5 indicating there must be co-fermentation of cellulose by Bacteroides and other fibre associated microbes, resulting in acetate production (Scheifinger, 1973). Finally, the genus Gracilibacter was detected in GS SE5 bottles with no 
additional carbon source. Members of this genus are known to ferment glucose to produce mainly lactate, acetate, and ethanol (Lee et al., 2006).

In all maize silage (MS) enrichment bottles, Ruminofilibacter was highly enriched, suggesting this genus to be associated with the degradation of maize fibre. In contrast, this genus was only present at $0.1 \%$ and $0.2 \%$ relative abundance in the GS and MS inocula, respectively. This genus has been reported to be a rumen bacterium capable of digesting xylan (Krober et al., 2009). It has also been detected in a biogas plant fed with maize silage, green rye and liquid manure (Krober et al., 2009), as well as in birch and conifer pulp fermentations (Nissila et al., 2012). More recently, Ruminofilibacter, a genus from the family of Marilinabiaceae, has also been detected in anaerobic biogas plants supplemented with maize silage as the main substrate (Wojcieszak et al., 2017). It is interesting to note that this genus appeared only after 42 days of fermentation in an in vitro system (Nissila et al., 2012), suggesting that this genus was a minor member of the bacterial community and required a long enrichment period. This also reflects the outcome of our study, although as only the OI and SE5 were sequenced it is not clear how long it took before this genus dominated the MS enrichments.

In cellulose and xylan MS enrichments, Aminobacterium was enriched to $11.9 \%$ and $11.7 \%$ relative abundance. Moreover, in the cellulose MS enrichment bottles the $R-7$ group (1.9\%) belonging to Christensenallaceae, and Desulfovibrio (2.6\%) were detected which were high relative to the OI. The MS enrichment bottles with amylopectin as an additional carbon source were enriched for Pyramidobacter (12.7\%) and Proteiniphylum (9.5\%) compared to the MS OI (Fig. 4B). Members of the genus Pyramidobacter have been reported previously as anaerobic bacteria that are asaccharolytic that produce mainly acetate and minor amounts of phenylacetic, isobutyric, propionic and succinic acid mainly from the proteolytic activity (Downes, 2009). Proteolytic activity in rumen is known to occur immediately after feeding (Wallace et al., 2000). The products observed from the enrichment bottles might be associated with the proteins from the maize kernels. Members of the genus Proteiniphilum are known to be strictly anaerobic and proteolytic, and they are also able to use pyruvate, peptone, yeast extract, glycine, L-arginine as carbon sources. However, they are not able to degrade carbohydrates, alcohols, and fatty acids with the exception of pyruvate (Chen and Dong, 2005). This suggests that members of this non-fibrolytic genus may play a role in the 
rumen by possibly supporting other fibrolytic bacteria by cross feeding, and should be addressed in future studies.

A.

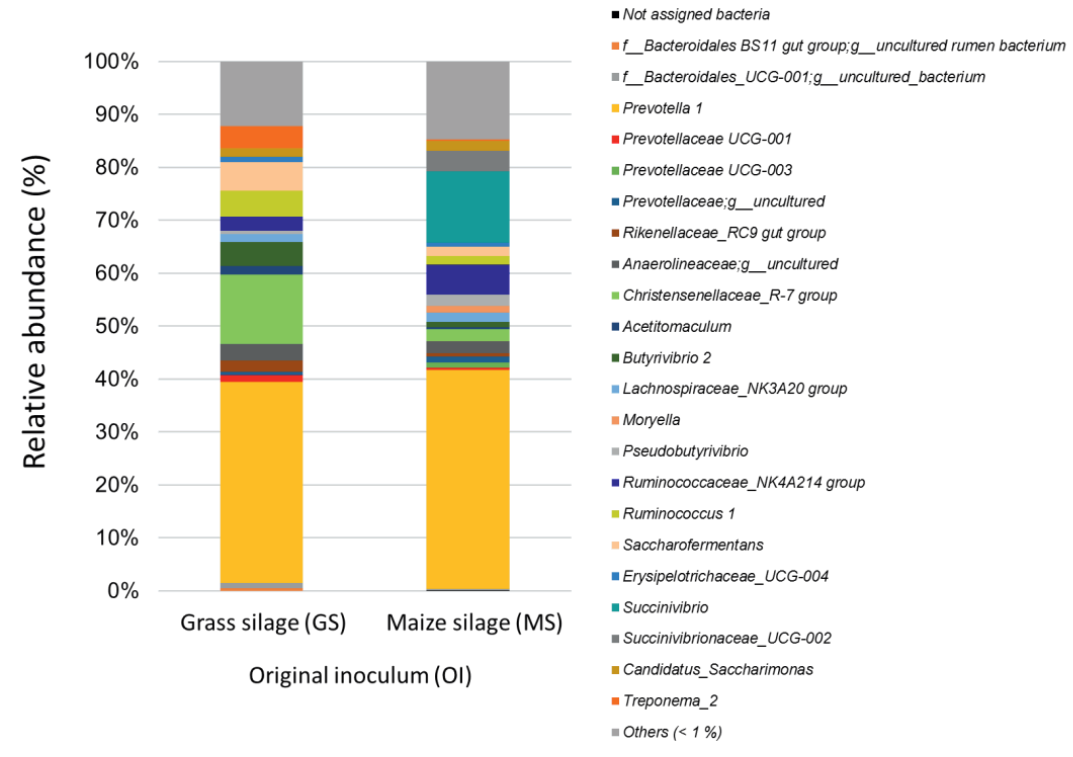

B.

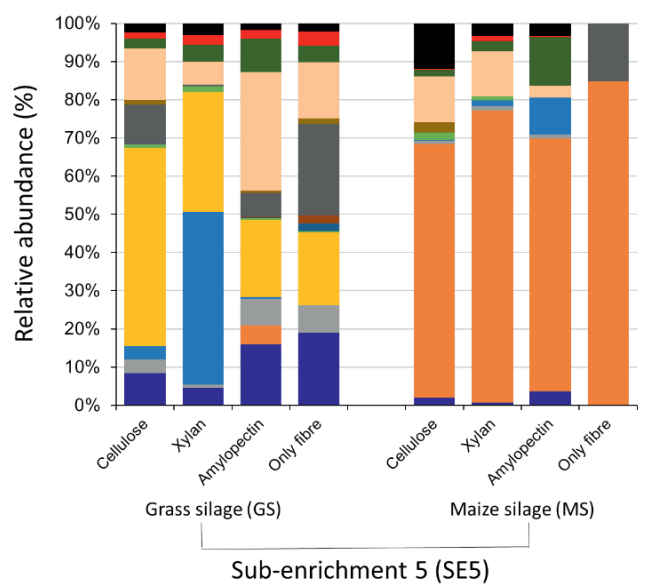

- Bacteroides
= Ruminofilibacter
= Petrimonas
- Proteiniphilum
- Prevotella 1
- Christensenellaceae R-7 group
- Gracilibacteraceae;g_unclassified Firmicutes
- Gracilibacter
- Ruminiclostridium 1
- Desulfovibrio
Aminobacterium
- Pyramidobacter
- Synergistes
- Others (<1\%)

Figure 4. Genus level composition of the original inoculum (A) from silage derived rumen fibres, and the subsequent SE5 bottles (B). All genera found at average relative abundances of less than $1 \%$ are regarded as "Others". 
In conclusion, this study gives insight into rumen fibre-associated communities that are capable of utilising different plant fibre components. The enrichment of microorganisms from ruminal GS and MS fibres resulted in primarily acetate production. Ruminofilibacter dominated all the MS enrichments, whereas a more diverse range of bacteria (including Prevotella 1 and Bacteroides) were associated with GS derived ruminal fibres. Enrichments of bacteria associated with ruminal GS and MS fibres had limited activity in sub-enrichments, presumably as the biomass was cold stored for long periods (2-3 weeks) in between transfers. The in vitro experimental approach of serial two week incubations seems likely to be important in enriching fibre associated bacterial groups that are otherwise not favoured by shorter incubation times, i.e. Ruminofilibacter.

\section{ACKNOWLEDGEMENT}

This work was funded by TI Food and Nutrition, a public-private partnership on precompetitive research in food and nutrition. The Carus facilities from Wageningen University \& Research are acknowledged for their help with the sampling of the ruminal fibrous content.

\section{REFERENCES}

Chassard, C., Delmas, E., Robert, C., and Bernalier-Donadille, A. (2010). The cellulosedegrading microbial community of the human gut varies according to the presence or absence of methanogens. FEMS Microbiol Ecol 74(1), 205-213. doi: 10.1111/j.15746941.2010.00941.x.

Chen, S., and Dong, X. (2005). Proteiniphilum acetatigenes gen. nov., sp. nov., from a UASB reactor treating brewery wastewater. Int J Syst Evol Microbiol 55(6), 2257-2261. doi: 10.1099/ijs.0.63807-0.

Cheng, K.J., and Costerton, J.W. (1980). Adherent rumen bacteria - their role in the digestion of plant material, urea and epithelial cells. Dig Physiol and Metabol in Rumin, 227-250. doi: 10.1007/978-94-011-8067-2_11.

Craig, W.M., Broderick, G.A., and Ricker, D.B. (1987). Quantitation of microorganisms associated with the particulate phase of ruminal ingesta. $J$ Nutr 117(1), 56-62.

De Menezes, A.B., Lewis, E., O'Donovan, M., O'Neill, B.F., Clipson, N., and Doyle, E.M. (2011). Microbiome analysis of dairy cows fed pasture or total mixed ration diets. FEMS Microbiol Ecol 78(2), 256-265. doi: 10.1111/j.1574-6941.2011.01151.x.

Dijkstra, J., Tamminga,S (1995). Simulation of the effects of diet on the contribution of rumen protozoa to degradation of fibre in the rumen. Br J Nutr 74(5), 617-634.

Downes, J., Vartoukian, S. R., Dewhirst, F. E., Izard, J., Chen, T., Yu, W. H., Sutcliffe, I. C., Wade, W. G (2009). Pyramidobacter piscolens gen. nov., sp. nov., a member of the phylum 'Synergistetes' isolated from the human oral cavity. Int J Syst Evol Microbiol 59(Pt 5), 972-980. doi: 10.1099/ijs.0.000364-0. 
Emerson, E.L., Weimer, P. J (2017). Fermentation of model hemicelluloses by Prevotella strains and Butyrivibrio fibrisolvens in pure culture and in ruminal enrichment cultures. Appl Microbiol Biotechnol 101(10), 4269-4278. doi: 10.1007/s00253-0178150-7.

Fouts, D.E., Szpakowski, S., Purushe, J., Torralba, M., Waterman, R.C., MacNeil, M.D., et al. (2012). Next generation sequencing to define prokaryotic and fungal diversity in the bovine rumen. PLoS One 7(11), e48289. doi: 10.1371/journal.pone.0048289.

Henderson, G., Cox, F., Ganesh, S., Jonker, A., Young, W., Janssen, P.H., et al. (2015). Rumen microbial community composition varies with diet and host, but a core microbiome is found across a wide geographical range. Scient Rep 5, 14567. doi: $1456710.1038 /$ Srep 14567.

Hook, S.E., Wright, A.D., and McBride, B.W. (2010). Methanogens: methane producers of the rumen and mitigation strategies. Archaea 2010, 945-785. doi: $10.1155 / 2010 / 945785$.

Horn, S.J., Vaaje-Kolstad, G., Westereng, B., and Eijsink, V.G. (2012). Novel enzymes for the degradation of cellulose. Biotechnol Biofuels 5(1), 45. doi: 10.1186/1754-6834-545.

Hungate, R.E. (1950). The anaerobic mesophilic cellulolytic bacteria. Bacteriol Rev 14(1), 149.

Hungate, R.E. (1957). Microorganisms in the rumen of cattle fed a constant ration. Can $J$ Microbiol 3(2), 289-311.

Jindou, S., Brulc, J.M., Levy-Assaraf, M., Rincon, M.T., Flint, H.J., Berg, M.E., et al. (2008). Cellulosome gene cluster analysis for gauging the diversity of the ruminal cellulolytic bacterium Ruminococcus flavefaciens. FEMS Microbiol Lett 285(2), 188-194. doi: 10.1111/j.1574-6968.2008.01234.x.

Kobayashi, Y. (2006). Inclusion of novel bacteria in rumen microbiology: Need for basic and applied science. Anim Sci Jour 77(4), 375-385. doi: 10.1111/j.17400929.2006.00362.x.

Koike, S., and Kobayashi, Y. (2009). Fibrolytic Rumen Bacteria: Their Ecology and Functions. Asian Austral J Anim 22(1), 131-138. doi: 10.5713/ajas.2009.r.01.

Koike, S., Pan, J., Kobayashi, Y., and Tanaka, K. (2003). Kinetics of in sacco fiberattachment of representative ruminal cellulolytic bacteria monitored by competitive PCR. J Dairy Sci 86(4), 1429-1435. doi: 10.3168/jds.S0022-0302(03)73726-6.

Krause, D.O., Denman, S.E., Mackie, R.I., Morrison, M., Rae, A.L., Attwood, G.T., et al. (2003). Opportunities to improve fiber degradation in the rumen: microbiology, ecology, and genomics. FEMS Microbiol Rev 27(5), 663-693.

Krober, M., Bekel, T., Diaz, N.N., Goesmann, A., Jaenicke, S., Krause, L., et al. (2009). Phylogenetic characterization of a biogas plant microbial community integrating clone library 16S-rDNA sequences and metagenome sequence data obtained by $454-$ pyrosequencing. J Biotechnol 142(1), 38-49. doi: 10.1016/j.jbiotec.2009.02.010.

Lee, Y.J., Romanek, C.S., Mills, G.L., Davis, R.C., Whitman, W.B., and Wiegel, J. (2006). Gracilibacter thermotolerans gen. nov., sp. nov., an anaerobic, thermotolerant bacterium from a constructed wetland receiving acid sulfate water. Int J Syst Evol Microbiol 56(Pt 9), 2089-2093. doi: 10.1099/ijs.0.64040-0.

McAllister, T.A., Bae, H.D., Jones, G.A., and Cheng, K.J. (1994). Microbial attachment and feed digestion in the rumen. J Anim Sci 72(11), 3004-3018.

Miron, J., Ben-Ghedalia, D., and Morrison, M. (2001). Invited review: adhesion mechanisms of rumen cellulolytic bacteria. J Dairy Sci 84(6), 1294-1309. doi: 10.3168/jds.S00220302(01)70159-2. 
Morrison, M., Pope, P.B., Denman, S.E., and McSweeney, C.S. (2009). Plant biomass degradation by gut microbiomes: more of the same or something new? Curr Opin Biotechnol 20(3), 358-363. doi: 10.1016/j.copbio.2009.05.004.

Nissila, M.E., Li, Y.C., Wu, S.Y., Lin, C.Y., and Puhakka, J.A. (2012). Hydrogenic and methanogenic fermentation of birch and conifer pulps. Applied Energy 100(Supplement C), 58-65. doi: 10.1016/j.apenergy.2012.06.015.

Noel, S.J., Attwood, G.T., Rakonjac, J., Moon, C.D., Waghorn, G.C., and Janssen, P.H. (2017). Seasonal changes in the digesta-adherent rumen bacterial communities of dairy cattle grazing pasture. PLoS One 12(3), e0173819. doi: 10.1371/journal.pone.0173819.

Petri, R.M., Forster, R.J., Yang, W., McKinnon, J.J., and McAllister, T.A. (2012). Characterization of rumen bacterial diversity and fermentation parameters in concentrate fed cattle with and without forage. J Appl Microbiol 112(6), 1152-1162. doi: 10.1111/j.1365-2672.2012.05295.x.

Pitta, D.W., Parmar, N., Patel, A.K., Indugu, N., Kumar, S., Prajapathi, K.B., et al. (2014). Bacterial diversity dynamics associated with different diets and different primer pairs in the rumen of Kankrej cattle. PLoS One 9(11), e111710. doi: 10.1371/journal.pone.0111710.

Pitta, D.W., Pinchak, E., Dowd, S.E., Osterstock, J., Gontcharova, V., Youn, E., et al. (2010). Rumen bacterial diversity dynamics associated with changing from bermudagrass hay to grazed winter wheat diets. Microb Ecol 59(3), 511-522. doi: 10.1007/s00248-0099609-6.

Plugge, C.M. (2005). Anoxic media design, preparation, and considerations in Methods in Enzymology. Academic Press, 3-16.

Ramiro-Garcia, J., Hermes, G., Giatsis, C., Sipkema, D., Zoetendal, E., Schaap, P., et al. (2016). NG-Tax, a highly accurate and validated pipeline for analysis of $16 \mathrm{~S}$ rRNA amplicons from complex biomes [version 1; referees: 2 approved with reservations, 1 not approved]. F1000 Res 5. doi: 10.12688/f1000research.9227.1.

Rincon, M.T., Cepeljnik, T., Martin, J.C., Lamed, R., Barak, Y., Bayer, E.A., et al. (2005). Unconventional mode of attachment of the Ruminococcus flavefaciens cellulosome to the cell surface. J Bacteriol 187(22), 7569-7578. doi: 10.1128/JB.187.22.75697578.2005 .

Sawanon, S., Koike, S., and Kobayashi, Y. (2011). Evidence for the possible involvement of Selenomonas ruminantium in rumen fiber digestion. FEMS Microbiol Lett 325(2), 170-179. doi: 10.1111/j.1574-6968.2011.02427.x.

Scheifinger, C.C., Wolin, M. J (1973). Propionate formation from cellulose and soluble sugars by combined cultures of Bacteroides succinogenes and Selenomonas ruminantium. Appl Microbiol 26(5), 789-795.

Stams, A.J.M., Van Dijk, J.B., Dijkema, C., and Plugge, C.M. (1993). Growth of syntrophic propionate-oxidizing bacteria with fumarate in the absence of methanogenic bacteria. Appl Environ Microbiol 59(4), 1114-1119. doi: 10.1023/A:1020539323190.

Stewart, C.S., Flint, H.J., and Bryant, M.P. (1997). "The rumen bacteria," in The Rumen Microbial Ecosystem, eds. P.N. Hobson \& C.S. Stewart. (Dordrecht: Springer Netherlands), 10-72.

Tian, L., Scholte, J., Borewicz, K., van den Bogert, B., Smidt, H., Scheurink, A.J., et al. (2016). Effects of pectin supplementation on the fermentation patterns of different structural carbohydrates in rats. Mol Nutr Food Res 60(10), 2256-2266. doi: 10.1002/mnfr.201600149.

van Gastelen, S., Antunes-Fernandes, E.C., Hettinga, K.A., Klop, G., Alferink, S.J., Hendriks, W.H., et al. (2015). Enteric methane production, rumen volatile fatty acid 
concentrations, and milk fatty acid composition in lactating Holstein-Friesian cows fed grass silage- or corn silage-based diets. J Dairy Sci 98(3), 1915-1927. doi: 10.3168/jds.2014-8552.

van Lingen, H.J., Edwards, J.E., Vaidya, J.D., van Gastelen, S., Saccenti, E., van den Bogert, B., et al. (2017). Diurnal dynamics of gaseous and dissolved metabolites and microbiota composition in the bovine rumen. Front Microbiol 8(425), 425. doi: 10.3389/fmicb.2017.00425.

Varga, G.A., and Kolver, E.S. (1997). Microbial and animal limitations to fiber digestion and utilization. J Nutr 127(5 Suppl), 819S-823S. doi: 10.1093/jn/127.5.819S.

Wallace, R.J., Wallace, S.J.A., and McKain, N. (2000). Proteolytic activity of ruminal digesta during the feeding cycle in sheep receiving grass hay/concentrate or maize silage/concentrate diets. Lett App Microbiol 30(4), 317-319. doi: 10.1046/j.1472765x.2000.00721.x.

Wojcieszak, M., Pyzik, A., Poszytek, K., Krawczyk, P.S., Sobczak, A., Lipinski, L., et al. (2017). Adaptation of methanogenic inocula to anaerobic digestion of maize Silage. Front Microbiol 8(1881), 1881. doi: 10.3389/fmicb.2017.01881.

Wolin, M.J., Miller, T.L., and Stewart, C.S. (1997). Microbe - microbe interactions. The Rumen Microbial Ecosystem, 2nd edn (Hobson PN \& Stewart CS, eds), pp. 467-491. Blackie Academic and Professional, London. 


\section{SUPPLEMENTARY MATERIAL}

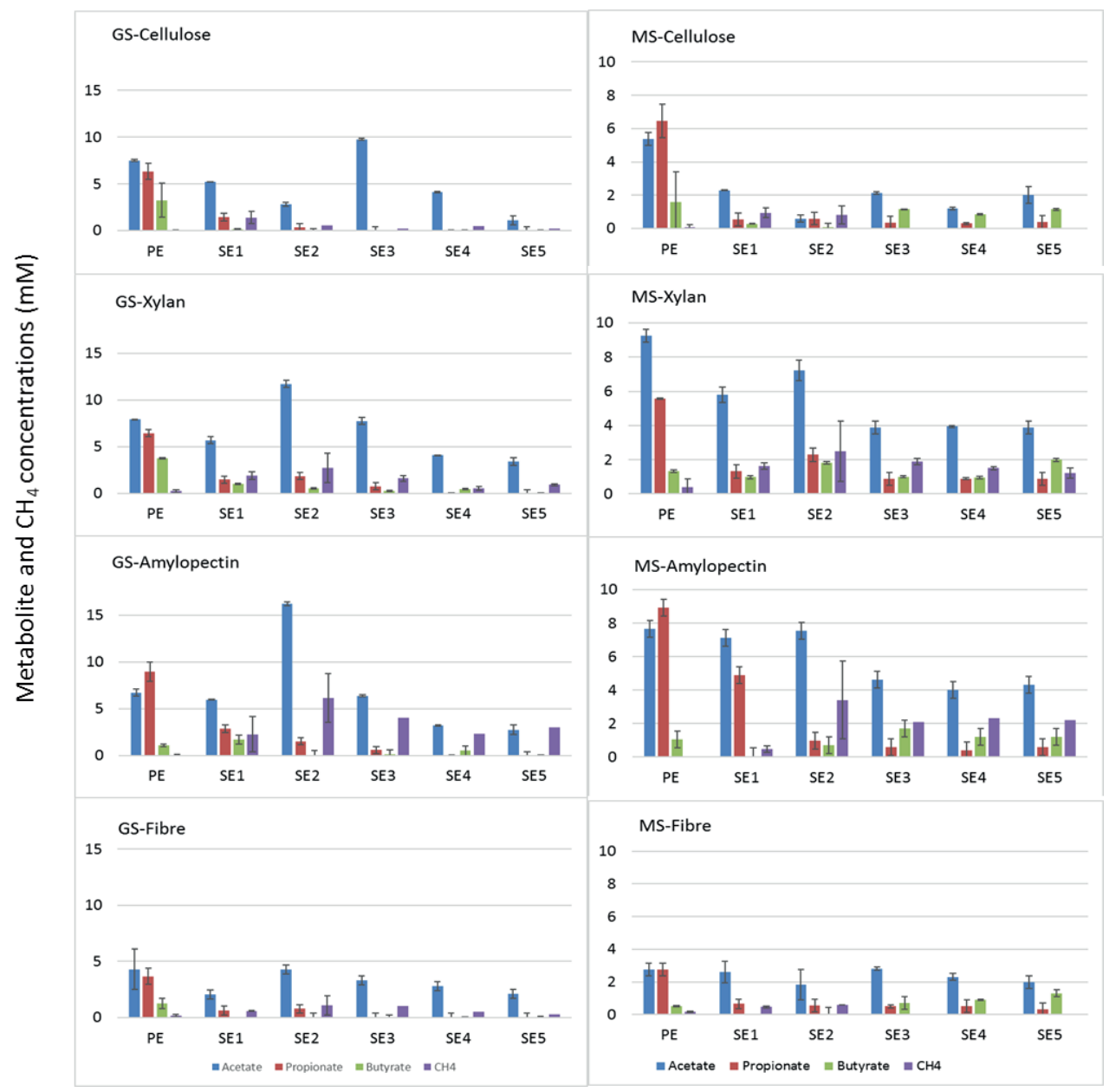

Figure S1. Volatile fatty acids (acetate, propionate and butyrate) and methane $\left(\mathrm{CH}_{4}\right)$ concentrations on day 14 obtained from primary enrichments (PE) and sub-enrichments (SE) 1-5 using grass and maize silage rumen derived fibres. The bottles with GS-fibre or MS-fibre indicate grass or maize derived pre-autoclaved rumen fibres as the sole carbon source while bottles with GS/MS-Cellulose, GS/MS-Xylan, GS/MS-Amylopectin have cellulose, xylan, and amylopectin as an additional carbon source, respectively. 


\section{Chapter 5}

\section{Characterization of Propionibacterium ruminifibrarum sp. nov., isolated from cow rumen fibrous content}

Jueeli D. Vaidya ${ }^{1,2}$, Bastian V.H. Hornung ${ }^{1,3}$, Hauke Smidt ${ }^{2}$, Joan E. Edwards ${ }^{1,2}$ and Caroline M. Plugge ${ }^{2}$

${ }^{1}$ Top Institute Food and Nutrition, Wageningen, Netherlands

${ }^{2}$ Laboratory of Microbiology, Wageningen University \& Research, Wageningen, Netherlands

${ }^{3}$ Laboratory of Systems and Synthetic Biology, Wageningen University \& Research, Wageningen, Netherlands

Submitted 


\section{ABSTRACT}

A novel propionate producing bacterium, strain $\mathrm{JV5}^{\mathrm{T}}$, was isolated from the rumen fibrous content of a Holstein Friesian dairy cow. Strain JV5 $5^{\mathrm{T}}$ tested Gram-positive, is non-motile and oxygen tolerant. Growth occurred between $35^{\circ} \mathrm{C}$ and $45^{\circ} \mathrm{C}$, with an optimum at $39{ }^{\circ} \mathrm{C}$. The $\mathrm{pH}$ range for growth is 6.5-8, with an optimum at $\mathrm{pH} 7$. The $16 \mathrm{~S}$ rRNA gene sequence of strain $\mathrm{JV}^{\mathrm{T}}$ is $98.4 \%$ and $96.5 \%$ identical to that of $P$. australiense (DSM $15818^{\mathrm{T}}$ ) and $P$. acidifaciens (DSM 21887 $)$, respectively. Genome wide average nucleotide identity and digital DNA-DNA hybridization were $88.3 \%$ and $35.5 \%$, respectively, against $P$. australiense (DSM $15818^{\mathrm{T}}$ ). The $\mathrm{G}+\mathrm{C} \%$ of JV5 $5^{\mathrm{T}}$ was $66 \%$. JV5 ${ }^{\mathrm{T}}$ did not produce urea and was able to metabolize glutamate but not aspartate and glycine. $\mathrm{JV}^{\mathrm{T}}$ was able to ferment a range of substrates including certain simple and complex carbohydrates, sugar alcohols and amino acids. Chemotaxonomic analysis of $\mathrm{JV}^{\mathrm{T}}$ revealed the presence of meso - diamino pimelic acid isomers similar to what has been found in $P$. australiense but different from $P$. acidifaciens. The observed major $(>10 \%)$ cellular fatty acids in $\mathrm{JV}^{\mathrm{T}}\left(\mathrm{C}_{18}: 1 \mathrm{w} 9 \mathrm{c}\right.$, anteiso $\mathrm{C}_{15}$ : $1 \mathrm{~A}, \mathrm{C}_{16: 0}$ and $\mathrm{C}_{17: 0}$ and alcohol $\left.\mathrm{C}_{16}: 0 \mathrm{~N}\right)$ were also different from those observed in $P$. australiense and $P$. acidifaciens. Based on these findings, a novel species is proposed within the genus Propionibacterium, Propionibacterium ruminifibrarum sp. nov. (type strain $\mathrm{JV} 5^{\mathrm{T}}=$ DSM $\left.106771^{\mathrm{T}}\right)$.

\section{KEYWORDS}

Rumen fibres, Propionibacterium, 16S rRNA, methylcellulose, dairy cow, propionate 
Ruminants, such as dairy cows, have evolved to effectively utilise fibrous plant material due to the presence of a specially adapted forestomach. The forestomach is comprised of three compartments, the largest of which is the rumen. The anaerobic microorganisms present in the rumen degrade the fibrous material in a step-wise process: i) hydrolysis of complex plant structural carbohydrates into monomers; ii) fermentation of the monomers into short chain fatty acids (SCFA's), lactate, succinate, (m )ethanol, $\mathrm{H}_{\mathrm{k}}$ and $\mathrm{CO}_{2}$; iii) methanogenesis from $\mathrm{H}_{2}$ and $\mathrm{CO}_{2}$, formate and methanol. Knowledge on the range of microorganisms involved in initial fibre attachment and breakdown, and their physiology, however, is still limited.

In 1909, the genus Propionibacterium was first described by Orla-Jensen and is comprised of species that produce propionate as the main fermentation end-product (OrlaJensen, 1909; Goodfellow and Williams, 1983). Propionate is a valuable energy source to the ruminant when it is absorbed by the ruminal epithelial cells, as it is the only major volatile fatty acid that directly contributes to gluconeogenesis. Members of the genus Propionibacterium are Gram-positive and have a versatile physiology, from anaerobic to aero tolerant, and are non-spore forming. Traditionally, species within this genus were grouped as classical or cutaneous based on phenotypic traits, 16S rRNA gene analysis and source of isolation such as mature cheese, cattle rumen, human skin, fermented vegetables and silage (Merry and Davies, 1999; Lucena-Padros et al., 2014).

Recently, the taxonomy of the whole family of Propionibacteriaceae was re-evaluated (Scholz and Kilian, 2016). The re-evaluation was based on decreasing the genus Propionibacterium to one branch containing the classic Propionibacterium, and creating a new genus for the other branches. Members of the redefined genus Propionibacterium possess meso-2,6-diaminopimelic acid as the diagnostic amino acid in their peptidoglycan (Scholz and Kilian, 2016), which separates them from the other genera (Acidopropionibacterium, Cutibacterium and Pseudopropionibacterium) that are characterized by LL-diaminopimelic acid (LL-2 $\mathrm{A}_{2} \mathrm{PM}$ ) (Goodfellow et al., 2012).

Propionibacterium spp. have the ability to perform bio-hydrogenation of polyunsaturated fatty acids (PUFA) to generate health-promoting fatty acids like conjugated linoleic acid (Raeth-Knight et al., 2007; Hennessy et al., 2012). Moreover, Propionibacterium spp. are dominant in silage and consequently are ingested with the silage, or are used as direct-fed microbials to increase ruminal propionate (Elghandour et al., 2015). Propionate has 
been shown to improve energetic efficiency, reduce ketosis (Wolin, 1960) and decrease methane $\left(\mathrm{CH}_{4}\right)$ emissions from dairy cows (Dean et al., 2018a). In this study, we describe the properties of strain $\mathrm{JV}^{\mathrm{T}}$, a novel propionate producing bacterium isolated from enrichments derived from rumen fibrous content.

The rumen fibrous content was collected from a rumen fistulated Holstein Friesian cow fed grass silage and concentrate (80:20), which was part of a larger study conducted in accordance with Dutch law and approved by the Animal Care and Use Committee of Wageningen University (van Gastelen et al., 2015). The fibrous content was sampled manually through the rumen fistula, squeezed to remove excess liquid and immediately stored in a glycerol/phosphate buffered saline (1:3) solution at $-80^{\circ} \mathrm{C}$ until cultivation. Cultivation was routinely carried out in $120 \mathrm{ml}$ serum bottles filled with $50 \mathrm{ml}$ of bicarbonate-buffered anaerobic medium (BM) supplemented with a substrate. BM medium composition was as follows (per litre): $0.4 \mathrm{~g} \mathrm{KH} \mathrm{KH}_{2} \mathrm{PO}_{4} ; 0.53 \mathrm{~g} \mathrm{Na} \mathrm{HPO}_{4} ; 0.3 \mathrm{~g} \mathrm{NH} 4 \mathrm{Cl} ; 0.3 \mathrm{~g} \mathrm{NaCl} ; 0.1 \mathrm{~g}$ $\mathrm{MgCl}_{2} .6 \mathrm{H}_{2} \mathrm{O} ; 0.11 \mathrm{~g} \mathrm{CaCl}_{2} ; 1 \mathrm{ml}$ alkaline trace element solution; $1 \mathrm{ml}$ acid trace element solution; $1 \mathrm{ml}$ vitamin solution; $0.5 \mathrm{mg}$ resazurin; $4 \mathrm{~g} \mathrm{NaHCO}_{3} ; 0.25 \mathrm{~g} \mathrm{Na}_{2} \mathrm{~S} .7-9 \mathrm{H}_{2} \mathrm{O}$; $0.5 \mathrm{~g}$ cysteine; $0.1 \mathrm{~g}$ yeast extract; $10 \mathrm{ml}$ of haemin $(5 \mathrm{mg}$ in $1 \mathrm{ml} 1 \mathrm{~N} \mathrm{NaOH}$ dissolved in $100 \mathrm{ml}$ distilled $\left.\mathrm{H}_{2} 0\right)$; $0.2 \mathrm{ml}$ of vitamin $\mathrm{K} 1$ (0.1 ml vitamin $\mathrm{K} 1$ dissolved in $10 \mathrm{ml}$ 95\% ethanol). The trace element and vitamin solutions were prepared as described previously (Stams et al., 1993). All compounds were sterilised by autoclaving except for the vitamin solution, haemin and vitamin $\mathrm{K} 1$, which were all added as filter sterilised solutions to the medium prior to inoculation. The final $\mathrm{pH}$ of the medium was 7.0, and all experiments were carried out at $39{ }^{\circ} \mathrm{C}$ without shaking unless stated otherwise.

Preparation of the inoculum for the enrichments involved detachment of the bacteria from the rumen fibres using a previously described methylcellulose method (Alterskjær and Svein, 1998). Briefly, fibres were transferred to BM medium containing $0.1 \%(\mathrm{v} / \mathrm{v})$ methylcellulose and incubated for 5 minutes. The bacteria that detached from the fibres into the liquid phase were then serially diluted 10 -fold into $50 \mathrm{ml}$ bottles containing BM medium supplemented with $1 \%(\mathrm{w} / \mathrm{v})$ insoluble cellulose (Avicel) as the carbon source. Microbial activity was monitored by measurement of metabolites using HPLC. After 2 weeks of incubation, the highest dilution $\left(10^{-2}\right)$ where metabolites were produced was used to prepare another dilution series. A liquid sample from the $10^{-2}$ dilution was plated on BM medium supplemented with $0.8 \%(\mathrm{w} / \mathrm{v})$ agar and $0.5 \mathrm{~g} / \mathrm{L}$ cellulose (Avicel), and then anaerobically 
incubated in an anaerobic box for 3 weeks at $39^{\circ} \mathrm{C}$. After this, streak plating was performed from individual colonies. After 3 to 4 weeks, small round white colonies appeared on the BM cellulose plates. Single colonies were then transferred into reinforced clostridium medium (RCM) for rich/fast growth, and 10-fold serial dilutions were prepared in $35 \mathrm{ml}$ serum bottles, which were then incubated at $39^{\circ} \mathrm{C}$. Cell morphology and purity of strains was examined routinely during this process with light microscopy, and a pure culture was obtained that was termed strain $\mathrm{JV}^{\mathrm{T}}$.

Culture (1ml) was sampled aseptically using a needle and syringe from JV5 ${ }^{\mathrm{T}}$ grown on RCM medium and the cell pellet (13,000 $\mathrm{g}$ for $7 \mathrm{~min})$ used for genomic DNA extraction using the repeated bead beating (RBB) protocol (Vaidya et al., 2018). The 16S rRNA gene was then amplified using universal bacterial primers $27 \mathrm{~F}$ and 1492R (Lane et al., 1991), and the product purified using a PCR purification kit (Qiagen, Germany) before being Sanger sequenced (GATC-Biotech, Konstanz, Germany). Sequences were manually checked for errors using Chromas software programme, and the subsequent alignment and contigs were prepared using DNA Baser (version 4.20.0). Based on BLASTN search of the NCBI database, the 16S rRNA sequence $(1430 \mathrm{bp})$ of strain $\mathrm{JV}^{\mathrm{T}}$ was most closely related to that of Propionibacterium australiense (DSM 15818 ${ }^{\mathrm{T}}$ ) (98\%) and Propionibacterium acidifaciens (DSM $\left.21887^{\mathrm{T}}\right)(96 \%)$. Pairwise sequence similarities calculated for the 16S rRNA sequences via the GGDC web server (Meier-Kolthoff et al., 2013) confirmed that the 16S rRNA sequence of strain $\mathrm{JV5}^{\mathrm{T}}$ was $98.4 \%$ similar to $P$. australiense (DSM $15818^{\mathrm{T}}$ ) and $96.5 \%$ similar to $P$. acidifaciens (DSM $21887^{\mathrm{T}}$ ). The phylogenetic relationship of strain $\mathrm{JV}^{\mathrm{T}}$ and its closest related species (P. australiense (DSM 15818 ${ }^{\mathrm{T}}$ ) and P. acidifaciens (DSM 21887 ${ }^{\mathrm{T}}$ )) along with other distantly related Propionibacterium species was assessed using the $16 \mathrm{~S}$ rRNA gene. Sequences were aligned using Clustal X2 and a neighbour joining tree was constructed in MEGA version 6.0 (Tamura et al., 2013) from distance matrices generated using a maximum composite likelihood method (Fig. 1). Clustering revealed strain JV5 $5^{\mathrm{T}}$ to be closest to $P$. australiense and $P$. acidifaciens, in addition to known Propionibacterium spp. that were of dairy origin. The GenBank/EMBL/DBBJ accession number for the 16S rRNA gene sequence of strain $\mathrm{JV}^{\mathrm{T}}\left(\mathrm{DSM}=106771^{\mathrm{T}}\right)$ is MG783038. 


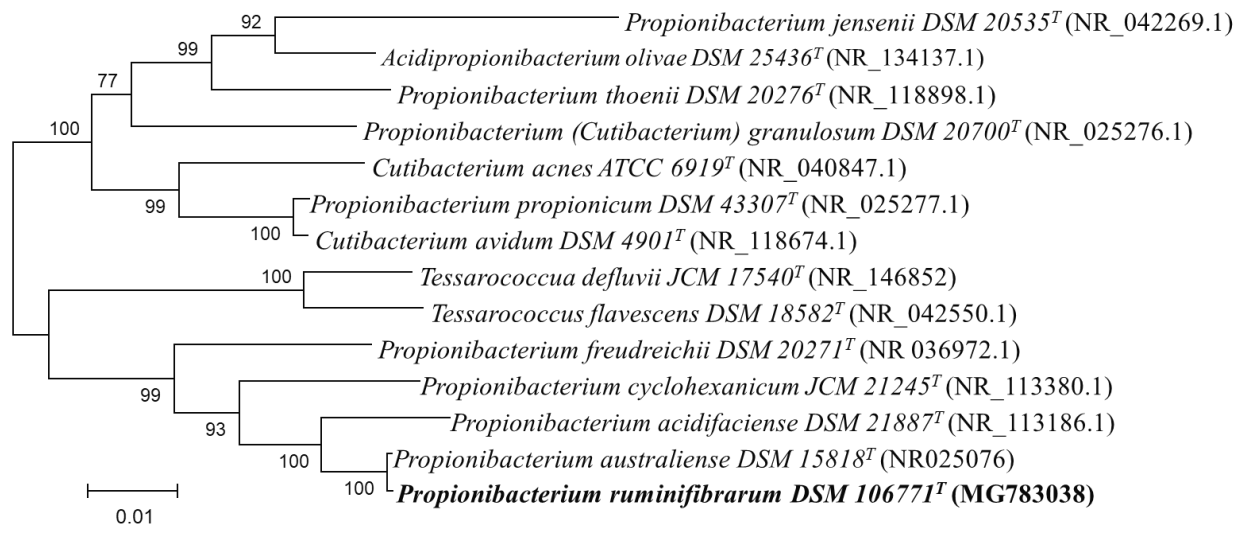

Figure 1. 16S rRNA gene based phylogenetic tree showing the relationship of strain $\mathrm{JV}^{\mathrm{T}}$ (in bold) with related species within the genus Propionibacterium. Bar represents 1\% sequence divergence. Numbers on the tree next to the branch nodes indicate percentage bootstrap values determined

As the identity of the $16 \mathrm{~S}$ rRNA gene sequences of $J V 5^{\mathrm{T}}$ and $P$. australiense is on the borderline with the most recently described threshold $(98.7 \%)$ to delineate a new species (Rossello-Mora and Amann, 2015), further taxonomic analyses were performed with strains of $P$. australiense (DSM $15818^{\mathrm{T}}$ ) and P. acidifaciense (DSM $21887^{\mathrm{T}}$ ) obtained from the German Collection of Microorganisms and Cell Cultures (DSMZ), Braunschweig, Germany. Genome-based comparison tools (Rosselló-Móra and Amann, 2015) were applied to confirm the difference between the strain $\mathrm{JV}^{\mathrm{T}}$ and $P$. australiense (DSM $15818^{\mathrm{T}}$ ) and P. acidifaciens $\left(\right.$ DSM $21887^{\mathrm{T}}$ ). Genomic DNA was extracted from cells of $\mathrm{JV}^{\mathrm{T}}$ and P. australiense (DSM $15818^{\mathrm{T}}$ ), pre-grown in BHI medium incubated at $39^{\circ} \mathrm{C}$ for 72 hours, using the MasterPure DNA kit, and the genome was sequenced at GATC on an Illumina MiSeq sequencer. The draft genome sequence of strain $\mathrm{JV}^{\mathrm{T}}$ has been uploaded to the EBI database under accession number ERS1670027 in project PRJEB19533, with contigs OMOH01000001OMOH01000036. Subsequently, the draft genome sequences of strain $\mathrm{JV}^{\mathrm{T}}$ and $P$. australiense (DSM $15818^{\mathrm{T}}$ ) were compared along with the genome of P.acidifaciens, which was obtained from NCBI (DSM 21887 ${ }^{\mathrm{T}}$ ). Genome wide average nucleotide identity (gANI) values were calculated with JSpecies version 1.2.1 (Richter and Rossello-Mora, 2009), while the digital DNA-DNA hybridization ( $\mathrm{dDDH})$ was calculated using the genome BLAST distance phylogeny version 2.1 web browser from DSMZ (Meier-Kolthoff et al., 2013). 
gANI for strain $\mathrm{JV}^{\mathrm{T}}$ was $88.3 \%$ compared to $P$. australiense (DSM $15818^{\mathrm{T}}$ ), and $84.2 \%$ compared to $P$. acidifaciens (DSM $21887^{\mathrm{T}}$ ). Both of these values are lower than the species cut-off value of $96.5 \%$ (Varghese et al., 2015). dDDH between strain $\mathrm{JV5}^{\mathrm{T}}$ and $P$. australiense (DSM $15818^{\mathrm{T}}$ ) was $35.5 \%$, and between strain $\mathrm{JV}^{\mathrm{T}}$ and $P$. acidifaciens (DSM $21887^{\mathrm{T}}$ ) $12.9 \%$. Again, both values were significantly lower than the $70 \%$ threshold value (Wayne et al., 1987). Both the gANI and dDDH results can, therefore, be used confidently for species delineation (Goris et al., 2007; Rossello-Mora and Amann, 2015). The genomic DNA $\mathrm{G}+\mathrm{C}$ content of strain $\mathrm{JV} 5^{\mathrm{T}}$ was calculated using an in house custom python script and found to be $66 \%$ (Table 1). This value lies within the DNA G+C content range (57-70\%) described for many other species of the genus Propionibacterium (Lucena-Padros et al., 2014; Aubin et al., 2016).

Fatty acid composition, analysis of diaminopimelic acid (DAP) and respiratory quinones was performed at DSMZ for strain $\mathrm{JV}^{\mathrm{T}}, P$. australiense (DSM $15818^{\mathrm{T}}$ ) and $P$. acidifaciens $\left(\mathrm{DSM} 21887^{\mathrm{T}}\right)$. Major cellular fatty acids (>10\%) observed for strain $\mathrm{JV} 5^{\mathrm{T}}$ were the unsaturated fatty acid $\mathrm{C}_{18}: 1 \mathrm{w} 9 \mathrm{c}$, the branched unsaturated anteiso $\mathrm{C}_{15}: 1 \mathrm{~A}$, the two saturated fatty acids $\mathrm{C}_{16: 0}$ and $\mathrm{C}_{17}: 0$ and the alcohol $\mathrm{C}_{16: 0} \mathrm{~N}$ (Table S1). The cellular fatty acid profile of strain $\mathrm{JV5}^{\mathrm{T}}$ differed from that of $P$. australiense (DSM 15818 ) and $P$. acidifaciens (DSM $21887^{\mathrm{T}}$ ). From the above mentioned major cellular fatty acids, anteiso $\mathrm{C}_{15}$ : 1. A was not detected in P. australiense (DSM $15818^{\mathrm{T}}$ ). Conversely, $\mathrm{C}_{15: 0}$ was not detected in strain $\mathrm{JV} 5^{\mathrm{T}}$ but was detected as a major cellular fatty acid ( $>10 \%$ in total) in $P$. australiense $\left(\right.$ DSM $15818^{\mathrm{T}}$ ). Differences between strain $\mathrm{JV}^{\mathrm{T}}$ and $P$. acidifaciens (DSM 21887 ${ }^{\mathrm{T}}$ ) were more in terms of minor $(<10 \%)$ cellular fatty acids (Table S1). Whole cell hydrolysates were used for DAP analysis, and were examined using thin layer chromatography on cellulose plates (Rhuland et al., 1955). Strain JV5 ${ }^{\mathrm{T}}$ contained meso-DAP isomers which were similar to those observed for $P$. australiense (DSM $15818^{\mathrm{T}}$ ), whilst both were different from $P$. acidifaciens (DSM $21887^{\mathrm{T}}$ ) (Table 1).There were no respiratory quinones detected in strain $\mathrm{JV}^{\mathrm{T}}, P$. australiense or $P$. acidifaciens.

Cell wall morphology of strain $\mathrm{JV}^{\mathrm{T}}$ was determined using a standard method (Plugge et al., 2000), with cells pre-grown in brain heart fusion (BHI) medium at $39{ }^{\circ} \mathrm{C}$. Cell morphology was examined with a light microscope (Leica, Heerbrugg, Switzerland). For electron microscopy, strain $\mathrm{JV}^{\mathrm{T}}$ was grown for 24 hours in pre-autoclaved BM medium supplemented with plant fibres retrieved from the rumen (10 fibre pieces of $\sim 1.5 \mathrm{~cm}$ length). 
The fibres grown with strain $\mathrm{JV} 5^{\mathrm{T}}$ were then fixed in $2.5 \%$ glutaraldehyde buffered with 0.1 $\mathrm{M}$ phosphate buffer at room temperature for 2 hours. Subsequently the fibres were rinsed in $0.1 \mathrm{M}$ phosphate buffer ( $\mathrm{pH} 7.2$ ), and stained with $1 \%$ osmium tetroxide in $0.1 \mathrm{M}$ phosphate buffer. After washing in $0.1 \mathrm{M}$ phosphate buffer, the samples were dehydrated in graded ethanol solutions $30 \%, 50 \%, 70 \%, 80 \%, 90 \%, 96 \%, 2 \times 100 \%$ (for 10 min each). The samples were subsequently critical point dried (CPD) with carbon dioxide in a Leica EM CPD300 before being mounted on an SEM stub by carbon adhesive tabs (EMS Washington USA) and coated with $12 \mathrm{~nm}$ Tungsten (Leica MED 020). Samples were analysed at $2 \mathrm{KV}, 6$ pA, in a field emission scanning electron microscope (Magellan 400, FEI, Eindhoven, the Netherlands). Strain JV5 ${ }^{\mathrm{T}}$ stained gram positive, and is a non-motile, short curved rod, present as single cells $(0.5-0.8 \mu \mathrm{m}$ wide by $1.0-1.2 \mu \mathrm{m}$ long) or in small clusters. Cells were also observed to from micro-colonies on the surface of silage derived plant fibres (Fig. 2).

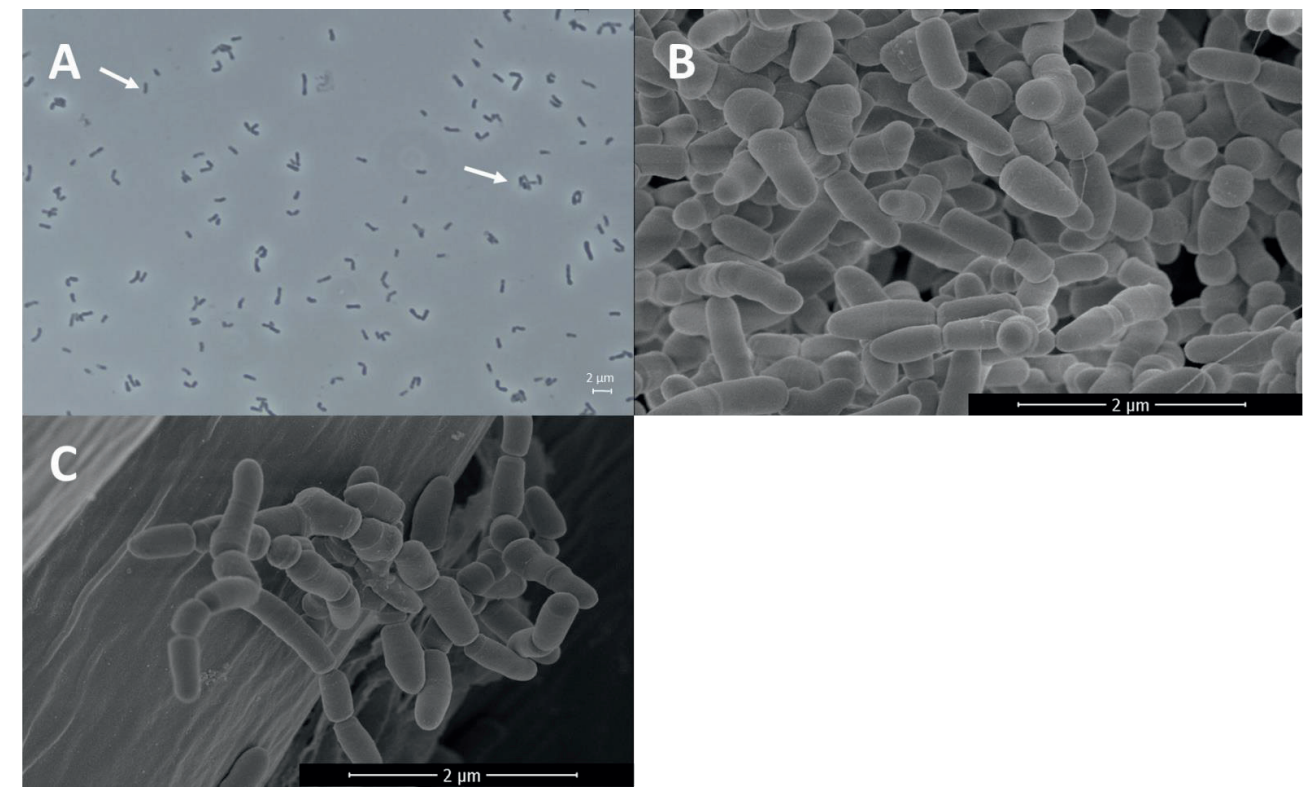

Figure 2. Strain $J V 5^{\mathrm{T}}$ visualised by light microscopy (A) and scanning electron microscopy (B and C). Cells of Strain $\mathrm{JV5}^{\mathrm{T}}$ are present as single cells or in clusters of more than two (indicated with arrows) (A). Cells associate to silage derived plant fibres where they form micro-colonies (C). 
For biochemical characterization, strain $\mathrm{JV}^{\mathrm{T}}, P$. australiense (DSM $15818^{\mathrm{T}}$ ) and $P$. acidifaciens (DSM 21887 ) were pre-grown in peptone-yeast-glucose (PYG) medium (pH 7.2) at $39^{\circ} \mathrm{C}$ unless stated otherwise. Carbohydrate assimilation was assessed using API 50 CHB and API 20A kits (bioMérieux, France), whilst enzyme profiling was performed using API ZYM kits (bioMérieux, France). Differentiating characteristics found by the kits were as follows. From the API $50 \mathrm{CHB}$ kit, strain $\mathrm{JV}^{\mathrm{T}}$ produced acid from D-turanose and erythritol while the closest relatives $P$. australiense (DSM $15818^{\mathrm{T}}$ ) and $P$. acidifaciens $\left(\mathrm{DSM} 21887^{\mathrm{T}}\right.$ ) did not (Table 1, S2 and S3). API 20A profiling showed that strain $\mathrm{JV}^{\mathrm{T}}$ is urea, gelatin, indole and catalase negative whilst being esculin positive (Table 1 and Table S4). These properties differed between one or more of the closely related strains, particularly in terms of urea hydrolysis activity, which both $P$. australiense and $P$. acidifaciens possessed unlike strain $\mathrm{JV} 5^{\mathrm{T}}$. API ZYM profiling showed strain $\mathrm{JV} 5^{\mathrm{T}}$ was positive for valine aminopeptidase, cysteine aminopeptidase and beta - glucosidase, whilst its close relatives were negative (Table 1 and Table S5).

Fermentation of selected substrates and electron donors $(20 \mathrm{mM})$ and concomitant metabolite production by strain $\mathrm{JV}^{\mathrm{T}}$ was tested in bottles (BM medium with $0.1 \mathrm{~g} / 1$ yeast extract, in duplicate) for 14 days (Table S2). D-adonitol, galactose, glucose, inositol, DLlactate, mannose, meso-erythritol, ribose and sorbitol were converted to mainly propionate and acetate, and sometimes succinate and/or formate. Pyruvate and aspartate were fermented to only acetate. D-arabinose, L-arabinose, cellobiose, glutamate, glycerol, glycine, L-sorbose, rhamnose and xylose were not utilized (Table S2).

Fermentation products and the carbon balance of strain $\mathrm{JV}^{\mathrm{T}}$ was determined in $\mathrm{BM}$ medium with $30 \mathrm{mM}$ glucose. A liquid sample $(1 \mathrm{ml})$ was centrifuged for $7 \mathrm{~min}$ at 13,000 rpm, and the metabolites dissolved in the supernatant were measured with HPLC while gas formation from the bottle was measured by gas chromatography (GC) (van Lingen et al., 2017b). After 14 days, strain $\mathrm{JV5}^{\mathrm{T}}$ produced $23.9 \mathrm{mM}$ propionate, $14.7 \mathrm{mM}$ acetate, $18.4 \mathrm{mM}$ formate and $2.4 \mathrm{mM}$ succinate from $30 \mathrm{mM}$ glucose. The redox balance was used to calculate the $\mathrm{CO}_{2}$. The calculated carbon recovery was $74.4 \%$ (without accounting for biomass).

The glucose fermentation stoichiometry for strain $\mathrm{JV}^{\mathrm{T}}$ was:

1 glucose $+0.8 \mathrm{CO}_{2}$------>> 0.9 Propionate +0.5 Acetate +0.7 Formate +0.1 Succinate No hydrogen $\left(\mathrm{H}_{2}\right)$ was detected. 
The ability of strain $\mathrm{JV}^{\mathrm{T}}$ to utilize representative plant polymeric components was tested with xylan from oat spelt (2 g/L), xylan from birch wood $(2 \mathrm{~g} / \mathrm{L})$, pectin $(2 \mathrm{~g} / \mathrm{L})$, cellulose $(2 \mathrm{~g} / \mathrm{L})$ and soluble starch $(2 \mathrm{~g} / \mathrm{L})$ in BM medium supplemented with $0.5 \mathrm{~g} / \mathrm{L}$ yeast extract. Uninoculated bottles of BM medium with polymeric substances served as negative controls. Strain $\mathrm{JV5}^{\mathrm{T}}$ was able to produce trace amounts of acetate from xylan (oat spelt: 2 $\mathrm{mM}$; birchwood: $3 \mathrm{mM})$ as well as succinate and propionate in very low concentrations $(<1$ $\mathrm{mM})$. Cellulose degradation resulted in only succinate production $(1.2 \mathrm{mM})$, while soluble starch was not utilized at all. These results suggest that strain $\mathrm{JV}^{\mathrm{T}}$ could not directly use plant polymeric components, but probably can associate with fibres to use the compounds that are released from them.

The optimal temperature for growth of strain $\mathrm{JV}^{\mathrm{T}}$ was assessed in duplicate at a range of 10 to $60{ }^{\circ} \mathrm{C}$ (with intervals of $5^{\circ} \mathrm{C}$ ) in bottles with $10 \mathrm{ml}$ PYG medium. The test was also performed using a narrower temperature range $\left(39-47^{\circ} \mathrm{C}\right)$ with intervals of $1{ }^{\circ} \mathrm{C}$. Bottles were incubated for two weeks. Growth was assessed using optical density $\left(\mathrm{OD}_{660}\right)$ measurements. Strain $\mathrm{JV}^{\mathrm{T}}$ was able to grow at temperatures ranging from 35 to $45^{\circ} \mathrm{C}$ with an optimum at 39 ${ }^{\circ} \mathrm{C}$, which is different for $P$. australiense (DSM $15818^{\mathrm{T}}$ ) and P. acidifaciens (DSM $21887^{\mathrm{T}}$ ) (Table 1). The $\mathrm{pH}$ range and optimum for strain $\mathrm{JV}^{\mathrm{T}}$ was determined from 4.0 to 9.0 (with intervals of 0.5 ) in $10 \mathrm{ml}$ PYG medium in duplicates using $20 \mathrm{mM}$ Tris-Borate buffer $(\mathrm{pH} 8.0$ to 9.0 ) or $20 \mathrm{mM} \mathrm{NaHCO}_{3}$ for $(\mathrm{pH}<8.0$ ). The $\mathrm{pH}$ of the bottles was adjusted using $1 \mathrm{M} \mathrm{NaOH}$ or $\mathrm{HCl}$. Bottles were incubated for two weeks at $39{ }^{\circ} \mathrm{C}$. Growth was assessed using optical density $\left(\mathrm{OD}_{660}\right)$ measurements. Strain $\mathrm{JV}^{\mathrm{T}}$ was able to grow in a $\mathrm{pH}$ range from $6.5-8.0$ with an optimum at pH 7.0 (Table 1). To define salt tolerance, strain $\mathrm{JV}^{\mathrm{T}}$, P. australiense $\left(\right.$ DSM $\left.15818^{\mathrm{T}}\right)$ and $P$. acidifaciens $\left(\mathrm{DSM} 21887^{\mathrm{T}}\right.$ ) were grown in BM medium in duplicate with $0.5 \%-6 \% \mathrm{NaCl}(\mathrm{w} / \mathrm{v}$; at intervals of $0.5 \%)$ and incubated for four weeks. Strain JV5 ${ }^{\mathrm{T}}$ tolerated up to $5 \% \mathrm{NaCl}$, which was higher than what has been observed for $P$. australiense (DSM $15818^{\mathrm{T}}$ ) and $P$. acidifaciens (DSM $21887^{\mathrm{T}}$ ) (Table 1).Oxygen tolerance was tested by growing strain $\mathrm{JV}^{\mathrm{T}}$, P.australiense (DSM $15818^{\mathrm{T}}$ ) and P. acidifaciens (DSM 21887 $)$ in BM medium without any reducing agent with $0.5 \%, 1 \%, 5 \%$ or $21 \% \mathrm{O}_{2}$ in the headspace. Growth was monitored using optical density $\left(\mathrm{OD}_{660}\right)$ measurements. All three strains were able to tolerate oxygen up to $5 \%$ but did not grow at atmospheric (21\%) oxygen levels, indicating they are micro-aero tolerant. 
Table 1: Differential characteristics of strain $J V 5^{\mathrm{T}}$ and closely related reference strains. 1 -

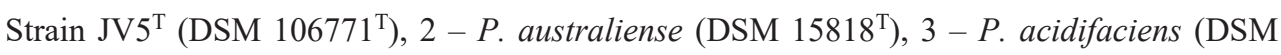
$21887^{\mathrm{T}}$ ). The temperature, $\mathrm{pH}$, and colony colour for $\mathbf{2}$ and $\mathbf{3}$ are taken from (Bernard et al., 2002) and (Downes and Wade, 2009), respectively. NR indicates not reported.

\begin{tabular}{|c|c|c|c|}
\hline Characteristics & 1 & 2 & 3 \\
\hline Cell morphology & Short curved rods & Short rods & Short curved rods \\
\hline Cell size $(\mu \mathrm{m})$ & $0.5-0.8 \times 1.0-2$ & $0.6-0.7 \times 1.2$ & $0.7-0.8 \times 1.2-4$ \\
\hline Colony colour & White & Cream & $\begin{array}{l}\text { White to pale } \\
\text { cream }\end{array}$ \\
\hline Isolation source & Cow rumen fibres & Bovine lesions & Human mouth \\
\hline $\mathrm{pH}$ range/ optimum & $6.5-8.0 / 7.0$ & $\mathrm{NR} / 7$ & $6.0-6.72 / \mathrm{NR}$ \\
\hline Temperature range/ optimum $\left({ }^{\circ} \mathrm{C}\right)$ & $35-45 / 39$ & $\mathrm{NR} / 35-37$ & $\mathrm{NR} / 37$ \\
\hline Salt $(\mathrm{NaCl})$ tolerance range & 0.5 to $5 \%$ & 0.5 to $3 \%$ & 0.5 to $3 \%$ \\
\hline $\begin{array}{l}\text { DAP (Di-amino pimelic acid) } \\
\text { isomer }\end{array}$ & meso-DAP & meso-DAP & LL-DAP \\
\hline $\mathrm{G}+\mathrm{C}$ content $(\%)$ & 66 & 68.3 & 70 \\
\hline \multicolumn{4}{|l|}{ Hydrolysis of } \\
\hline Esculin & + & + & - \\
\hline Gelatin & - & - & + \\
\hline Urea & - & + & + \\
\hline Glucose fermentation products & $\begin{array}{l}\text { Propionate, Acetate, } \\
\text { Formate, Succinate }\end{array}$ & $\begin{array}{l}\text { Propionate, Acetate, } \\
\text { Succinate }\end{array}$ & $\begin{array}{l}\text { Propionate, } \\
\text { Acetate, } \\
\text { Succinate }\end{array}$ \\
\hline \multicolumn{4}{|l|}{$\begin{array}{l}\text { API } 50 \text { CH: Acid formation } \\
\text { from }\end{array}$} \\
\hline Arbutin & - & + & - \\
\hline D-Adonitol & + & + & - \\
\hline D-Mannitol & - & + & - \\
\hline D-Maltose & + & + & - \\
\hline D-Raffinose & - & + & - \\
\hline D-Ribose & + & + & - \\
\hline D-Sorbitol & + & + & - \\
\hline D-Trehalose & + & + & - \\
\hline D-Turanose & + & - & - \\
\hline Dulcitol & - & + & - \\
\hline D-Xylose & - & + & - \\
\hline Erythritol & + & - & - \\
\hline Inositol & - & + & - \\
\hline Inulin & - & - & + \\
\hline Salicin & - & + & - \\
\hline \multicolumn{4}{|l|}{ API ZYM } \\
\hline Valine aminopeptidase & + & - & - \\
\hline Cysteine aminopeptidase & + & - & + \\
\hline Beta-glucosidase & + & - & + \\
\hline
\end{tabular}




\section{DESCRIPTION OF PROPIONIBACTERIUM RUMINIFIBRARUM SP. NOV.}

\section{Propionibacterium ruminifibrarum}

ruminifibrarum (ru.mi.ni.fi.bra'rum. L. neut. n. rumen gullet, rumen; L. fem. n. fibra a fibre; N.L. gen. pl. n. ruminifibrarum of rumen fibres).

Cells are Gram-positive, non-motile, small short curved rod-shape, 0.5-0.8 $\times 1.0-2 \mu \mathrm{m}$ and are present as single cells or in clusters. Cell growth is observed at temperatures ranging from 35 to $45^{\circ} \mathrm{C}$ with an optimal temperature of $39{ }^{\circ} \mathrm{C}$. The $\mathrm{pH}$ for growth is 6.5 to 8.5 with an optimal $\mathrm{pH}$ of 7.0. Can tolerate salt concentrations up to $5 \%$. Micro-aero tolerant. Major cellular fatty acids ( $>10 \%$ in total) observed were $\mathrm{C}_{18}: 1 \mathrm{w} 9 \mathrm{c}, \mathrm{C}_{15}: 1 \mathrm{~A}, \mathrm{C}_{16: 0}$ and $\mathrm{C}_{17: 0}$ and alcohol $\mathrm{C}_{16}: 0 \mathrm{~N}$ (Table $\mathrm{S} 1$ ). Characterized by meso-diaminopimelic isomers. No respiratory quinones detected. Using API $50 \mathrm{CHB}, \mathrm{JV} 5^{\mathrm{T}}$ produced acid from D-turanose and erythritol while the closest relatives $P$. australiense (DSM $15818^{\mathrm{T}}$ ) and $P$. acidifaciens $\left(\mathrm{DSM} 21887^{\mathrm{T}}\right.$ ) did not (Table S3). Urea, gelatin, indole and catalase negative while esculin positive from API 20A (Table S4). From a bottle test, D-adonitol, galactose, glucose, inositol, DL-lactate, mannose, meso-erythritol, ribose and sorbitol were converted to mainly propionate and acetate, and succinate and/or formate in some cases (Table S2). Degradation of pyruvate only generated acetate. Able to metabolize the amino acid aspartate producing acetate, but not glutamate and glycine (Table S2). Using the API ZYM kit, positive for valine aminopeptidase, cysteine aminopeptidase, beta-glucosidase phosphatase alkaline, esterase, esterase lipase, lipase, leucine aminopeptidase, phosphatase acid, phosphoamidase and betaglucorinidase (Table S5). Although originating from rumen derived plant fibres, Strain JV5 ${ }^{\mathrm{T}}$ could not use any of the tested major plant components directly. The type strain, $\mathrm{JV} 5^{\mathrm{T}}(=$ DSM $106771^{\mathrm{T}}$ ), was isolated from ruminal fibrous content obtained from Holstein Friesian dairy cow in the Netherlands. The DNA G+C (mol \%) content of the type strain is $66 \mathrm{~mol} \%$. 


\section{REFERENCES}

Alterskjær, O.M., and Svein, M.D. (1998). The bacterial population adherent to plant particles in the rumen of reindeer fed lichen, timothy hay or silage. Rangifer 18(2). doi: 10.7557/2.18.2.1370.

Aubin, G.G., Bemer, P., Kambarev, S., Patel, N.B., Lemenand, O., Caillon, J., et al. (2016). Propionibacterium namnetense sp. nov., isolated from a human bone infection. Int J Syst Evol Microbiol 66(9), 3393-3399. doi: 10.1099/ijsem.0.001204.

Bernard, K.A., Shuttleworth, L., Munro, C., Forbes-Faulkner, J.C., Pitt, D., Norton, J.H., et al. (2002). Propionibacterium australiense sp. nov., derived from granulomatous bovine lesions. Anaerobe 8(1), 41-47. doi: 10.1006/anae.2000.0408.

Dean, J.F., Middelburg, J.J., Rockmann, T., Aerts, R., Blauw, L.G., Egger, M., et al. (2018). Methane Feedbacks to the Global Climate System in a Warmer World. Reviews of Geophysics 56(1), 207-250. doi: 10.1002/2017RG000559.

Downes, J., and Wade, W.G. (2009). Propionibacterium acidifaciens sp. nov., isolated from the human mouth. Int $J$ Syst Evol Microbiol 59(Pt 11), 2778-2781. doi: 10.1099/ijs.0.010470-0.

Elghandour, M.M.Y., Salem, A.Z.M., Castaneda, J.S.M., Camacho, L.M., Kholif, A.E., and Chagoyan, J.C.V. (2015). Direct-fed microbes: A tool for improving the utilization of low quality roughages in ruminants. Journal of Integrative Agriculture 14(3), 526-533. doi: 10.1016/S2095-3119(14)60834-0.

Goodfellow, M., and Williams, S.T. (1983). Ecology of actinomycetes. Annu Rev Microbiol 37(1), 189-216. doi: 10.1146/annurev.mi.37.100183.001201.

Goris, J., Konstantinidis, K.T., Klappenbach, J.A., Coenye, T., Vandamme, P., and Tiedje, J.M. (2007). DNA-DNA hybridization values and their relationship to whole-genome sequence similarities. Int $J$ Syst Evol Microbiol 57(Pt 1), 81-91. doi: 10.1099/ijs.0.64483-0.

Hennessy, A.A., Barrett, E., Paul Ross, R., Fitzgerald, G.F., Devery, R., and Stanton, C. (2012). The production of conjugated alpha-linolenic, gamma-linolenic and stearidonic acids by strains of bifidobacteria and propionibacteria. Lipids 47(3), 313327. doi: 10.1007/s11745-011-3636-z.

Lucena-Padros, H., Gonzalez, J.M., Caballero-Guerrero, B., Ruiz-Barba, J.L., and Maldonado-Barragan, A. (2014). Propionibacterium olivae sp. nov. and Propionibacterium damnosum sp. nov., isolated from spoiled packaged Spanish-style green olives. Int $J$ Syst Evol Microbiol 64(Pt 9), 2980-2985. doi: 10.1099/ijs.0.063032-0.

Meier-Kolthoff, J.P., Auch, A.F., Klenk, H.P., and Goker, M. (2013). Genome sequencebased species delimitation with confidence intervals and improved distance functions. BMC Bioinformatics 14(1), 60. doi: 10.1186/1471-2105-14-60.

Merry, R.J., and Davies, D.R. (1999). Propionibacteria and their role in the biological control of aerobic spoilage in silage. EDP Sci J 79(1), 149-164.

Orla-Jensen, S. (1909). Die hauptlinien des naturlichen Bakteriensystems, Zentralblaat fur Bacteriologie usw. Abt. 2. 22, 305-346.

Plugge, C.M., Zoetendal, E.G., and Stams, A.J. (2000). Caloramator coolhaasii sp. nov., a glutamate-degrading, moderately thermophilic anaerobe. Int J Syst Evol Microbiol 50 Pt 3(3), 1155-1162. doi: 10.1099/00207713-50-3-1155.

Raeth-Knight, M.L., Linn, J.G., and Jung, H.G. (2007). Effect of direct-fed microbials on performance, diet digestibility, and rumen characteristics of Holstein dairy cows. $J$ Dairy Sci 90(4), 1802-1809. doi: 10.3168/jds.2006-643. 
Rhuland, E., Lionel, W., Elizabeth, F., Denman, R.S., and Hoare, D. (1955). The behavior of the isomers of $\alpha, \varepsilon$-diaminopimelic ccid on paper chromatograms. $J$ Amer Chem Socie. doi: $10.1021 / \mathrm{ja} 01623 \mathrm{a} 047$.

Richter, M., and Rossello-Mora, R. (2009). Shifting the genomic gold standard for the prokaryotic species definition. Proc Natl Acad Sci U S A 106(45), 19126-19131. doi: 10.1073/pnas.0906412106.

Rossello-Mora, R., and Amann, R. (2015). Past and future species definitions for bacteria and archaea. Syst Appl Microbiol 38(4), 209-216. doi: 10.1016/j.syapm.2015.02.001.

Scholz, C.F., and Kilian, M. (2016). The natural history of cutaneous propionibacteria, and reclassification of selected species within the genus Propionibacterium to the proposed novel genera Acidipropionibacterium gen. nov., Cutibacterium gen. nov. and Pseudopropionibacterium gen. nov. Int J Syst Evol Microbiol 66(11), 4422-4432. doi: 10.1099/ijsem.0.001367.

Tamura, K., Stecher, G., Peterson, D., Filipski, A., and Kumar, S. (2013). MEGA6: Molecular evolutionary genetics analysis version 6.0. Mol Biol Evol 30(12), 2725-2729. doi: 10.1093/molbev/mst197.

Vaidya, J.D., Van den Bogert, B., Edwards, J.E., Boekhorst, J., van Gastelen, S., Saccenti, E., et al. (2018). The effect of DNA extraction methods on observed microbial communities from fibrous and Liquid rumen fractions of dairy cows. Front Microbiol 9(92), 92. doi: 10.3389/fmicb.2018.00092.

Van Gastelen, S., Antunes-Fernandes, E.C., Hettinga, K.A., Klop, G., Alferink, S.J., Hendriks, W.H., et al. (2015). Enteric methane production, rumen volatile fatty acid concentrations, and milk fatty acid composition in lactating Holstein-Friesian cows fed grass silage- or corn silage-based diets. J Dairy Sci 98(3), 1915-1927. doi: $10.3168 /$ jds.2014-8552.

Van Lingen, H.J., Edwards, J.E., Vaidya, J.D., Van Gastelen, S., Saccenti, E., van den Bogert, B., et al. (2017). Diurnal dynamics of gaseous and dissolved metabolites and microbiota composition in the bovine rumen. Front Microbiol 8(425), 425. doi: 10.3389/fmicb.2017.00425.

Varghese, N.J., Mukherjee, S., Ivanova, N., Konstantinidis, K.T., Mavrommatis, K., Kyrpides, N.C., et al. (2015). Microbial species delineation using whole genome sequences. Nucleic Acids Res 43(14), 6761-6771. doi: 10.1093/nar/gkv657.

Wayne, L.G., Brenner, D.J., Colwell, R.R., Grimont, P.A.D., Kandler, O., Krichevsky, M.I., et al. (1987). Report of the ad-hoc-committee on reconciliation of approaches to bacterial systematics. Internat $J$ System Bacteriol 37(4), 463-464. doi: 10.1099/00207713-37-4-463.

Wolin, M.J. (1960). A theoretical rumen fermentation balance. Journal of Dairy Science 43(10), 1452-1459. doi: 10.3168/jds.S0022-0302(60)90348-9. 


\section{SUPPLEMENTARY MATERIAL}

Table S1 Cellular fatty acid profiles (\% of totals) of strain $\mathrm{JV} 5^{\mathrm{T}}$ and closely related reference strains. $1-$ Strain $\mathrm{JV5}^{\mathrm{T}}\left(\mathrm{DSM} 106771^{\mathrm{T}}\right), 2-P$. australiense $\left(\mathrm{DSM} 15818^{\mathrm{T}}\right), 3-P$. acidifaciens $\left(\mathrm{DSM} 21887^{\mathrm{T}}\right.$ ), ND - not detected. Bold numbers indicate large differences in cellular fatty acid profiles between strains 1,2 and 3 .

\begin{tabular}{|c|c|c|c|}
\hline Cellular fatty acids & 1 & 2 & 3 \\
\hline \multicolumn{4}{|l|}{ Saturated } \\
\hline $\mathrm{C}_{13: 0}$ & 0.56 & 0.59 & 0.20 \\
\hline $\mathrm{C}_{14: 0}$ & 2.61 & 1.36 & 0.58 \\
\hline $\mathrm{C}_{15: 0}$ & ND & 39.37 & ND \\
\hline $\mathrm{C}_{16: 0}$ & 10.07 & 5.43 & 2.69 \\
\hline $\mathrm{C}_{17: 0}$ & 15.27 & 8.70 & 6.16 \\
\hline $\mathrm{C}_{18: 0}$ & ND & 0.8 & 0.46 \\
\hline \multicolumn{4}{|l|}{ Unsaturated } \\
\hline $\mathrm{C}_{18: 1}$ w6c $(6,9,12)$ & ND & 0.94 & ND \\
\hline $\mathrm{C}_{18: 1 \mathrm{w}} \mathrm{wc}$ & ND & ND & 0.49 \\
\hline $\mathrm{C}_{18: 1 \mathrm{w} 9 \mathrm{c}}$ & 10.11 & 10.16 & 8.42 \\
\hline \multicolumn{4}{|l|}{ Branched saturated } \\
\hline iso $\mathrm{C}_{14: 0}$ & 1.04 & ND & 0.52 \\
\hline iso $\mathrm{C}_{15: 0}$ & 5.19 & 3.10 & 15.75 \\
\hline iso $\mathrm{C}_{16: 0}$ & 1.52 & ND & 1.08 \\
\hline iso $\mathrm{C}_{17: 0}$ & ND & ND & 1.15 \\
\hline iso $\mathrm{C}_{18: 1}$ & 4.78 & ND & ND \\
\hline anteiso $\mathrm{C}_{17: 0}$ & ND & ND & 3.30 \\
\hline anteiso $\mathrm{C}_{15: 0}$ & 3.27 & 1.97 & 25.25 \\
\hline \multicolumn{4}{|l|}{ Branched unsaturated } \\
\hline iso- $\mathrm{C}_{18: 1} \mathrm{H}$ & ND & 3.74 & 2.26 \\
\hline iso $\mathrm{C}_{17: 1} \mathrm{I}$ and/or anteiso $\mathrm{B}$ & ND & ND & 1.21 \\
\hline anteiso $\mathrm{C}_{15: 1} \mathrm{~A}$ & 13.83 & ND & 8.92 \\
\hline alcohol $\mathrm{C}_{16: 0} \mathrm{~N}$ & 8.65 & 2.59 & 0.94 \\
\hline \multicolumn{4}{|l|}{ Hydroxy } \\
\hline $\mathrm{C}_{18: 1} 2 \mathrm{OH}$ & ND & 0.62 & ND \\
\hline
\end{tabular}


Table S2 Metabolites produced from substrate fermentation by strain JV5 ${ }^{\mathrm{T}}$. All incubations were performed in BM medium (with $0.1 \mathrm{~g} / \mathrm{L}$ yeast extract and Cysteine- $\mathrm{Na}_{2} \mathrm{~S}$ as the reducing agent) with $20 \mathrm{mM}$ of substrate in $120 \mathrm{ml}$ serum bottles incubated at $39^{\circ} \mathrm{C}$ for a period of 14 days. A BM bottle with only yeast extract $(0.1 \mathrm{~g})$ was also tested for metabolite production. Metabolites were measured on day 14 by HPLC and the symbols in the table indicate which metabolites were produced (+) or not (-). All analyses were carried out in duplicate.

\begin{tabular}{|c|c|c|c|c|}
\hline Substrate & Propionate & Acetate & Formate & Succinate \\
\hline BM with yeast & - & - & - & - \\
\hline Adonitol & + & + & + & + \\
\hline D-arabinose & - & - & - & - \\
\hline L-arabinose & - & - & - & - \\
\hline Aspartate & - & + & - & - \\
\hline Cellobiose & - & - & - & - \\
\hline Galactose & + & + & + & + \\
\hline Glucose & + & + & + & + \\
\hline Glutamate & - & - & - & - \\
\hline Glycerol & - & - & - & - \\
\hline Glycine & - & - & - & - \\
\hline Inositol & + & + & - & + \\
\hline DL-Lactate & + & + & + & - \\
\hline Mannose & + & + & + & - \\
\hline Meso-erythritol & + & + & - & - \\
\hline Pyruvate & - & + & - & - \\
\hline Rhamnose & - & - & - & - \\
\hline Ribose & + & + & + & + \\
\hline Sorbitol & + & + & + & + \\
\hline L-Sorbose & - & - & - & - \\
\hline Xylose & - & - & - & - \\
\hline
\end{tabular}


Table S3. Carbohydrate metabolism of 1 - strain JV5 $5^{\mathrm{T}}, 2$ - P. australiense (DSM $15818^{\mathrm{T}}$ ) and 3 - P. acidifaciens (DSM 21887 ) as derived from the API 50CH test performed using duplicates. Symbols indicate acid formation (+) or no acid production (-) in the test.

\begin{tabular}{|c|c|c|c|}
\hline Carbohydrate & 1 & 2 & 3 \\
\hline Amygdalin & - & - & - \\
\hline Arbutin & - & + & - \\
\hline D-Adonitol & + & + & - \\
\hline D-Arabinose & - & - & - \\
\hline D-Arabitol & - & - & - \\
\hline D-Cellobiose & - & - & - \\
\hline D-Fructose & + & + & + \\
\hline D-Fucose & - & - & - \\
\hline D-Galactose & + & + & + \\
\hline D-Glucose & + & + & + \\
\hline D-Lactose & + & + & + \\
\hline D-Lyxose & - & - & - \\
\hline D-Mannose & + & + & + \\
\hline D-Mannitol & + & + & - \\
\hline D-Maltose & + & + & - \\
\hline D-Melibiose & - & - & - \\
\hline D-Melezitose & - & - & - \\
\hline D-Raffinose & - & + & - \\
\hline D-Ribose & + & + & - \\
\hline D-Saccharose & + & + & + \\
\hline D-Sorbitol & + & + & - \\
\hline D-Trehalose & + & + & - \\
\hline D-Turanose & + & - & - \\
\hline D-Tagatose & - & - & - \\
\hline Dulcitol & - & + & - \\
\hline D-Xylose & - & + & - \\
\hline Erythritol & + & - & - \\
\hline Esculin ferric citrate & - & - & - \\
\hline Gentiobiose & - & - & - \\
\hline Glycerol & - & - & - \\
\hline Glycogen & - & - & - \\
\hline L-Arabinose & - & - & - \\
\hline L-Arabitol & - & - & - \\
\hline L-Fucose & - & - & - \\
\hline L-Rhamnose & - & - & - \\
\hline L-Sorbose & - & - & - \\
\hline L-Xylose & - & - & - \\
\hline Methyl- $\alpha \mathrm{D}$-mannopyranoside & - & - & - \\
\hline Methyl- $\alpha$ D-glucopyranoside & - & - & - \\
\hline Methyl- $\beta \mathrm{D}$-xylopyranoside & - & - & - \\
\hline Inositol & - & + & - \\
\hline Inulin & - & - & + \\
\hline N-Acetylglucosamine & - & - & - \\
\hline Potassium gluconate & - & - & - \\
\hline Potassium-2-ketogluconate & - & - & - \\
\hline Potassium-4-ketogluconate & - & - & - \\
\hline Salicin & - & + & - \\
\hline Xylitol & - & - & - \\
\hline
\end{tabular}


Table S4. Characteristics of 1 - strain $\mathrm{JV5}^{\mathrm{T}}, 2-P$. australiense (DSM 15818 $)$ and $3-P$. acidifaciens (DSM $21887^{\mathrm{T}}$ ) from API 20A test performed using duplicates. Symbols indicate positive reaction $(+)$ or negative reaction $(-)$ in the test.

\begin{tabular}{llll}
\hline API 20A & $\mathbf{1}$ & $\mathbf{2}$ & $\mathbf{3}$ \\
Arabinose & - & - & - \\
Catalase & - & - & - \\
Cellobiose & - & - & - \\
Esculin & + & + & - \\
Gelatin & - & - & + \\
Glucose & + & + & + \\
Glycerol & - & - & + \\
Indole & - & - & - \\
Lactose & + & - & + \\
Mannose & + & - & + \\
Maltose & + & - & + \\
Melizitose & - & - & - \\
Raffinose & - & - & - \\
Rhamnose & - & - & - \\
Saccharose & + & - & + \\
Salicin & + & - & - \\
Sorbitol & + & - & - \\
Trehalose & + & - & - \\
Urease & - & + & - \\
Xylose & - & - & + \\
\hline
\end{tabular}


Table S5. Characteristics of $1-$ strain $\mathrm{JV5}^{\mathrm{T}}, 2-P$. australiense (DSM 15818 $)$ and $3-P$. acidifaciens (DSM $21887^{\mathrm{T}}$ ) from API ZYM test performed using duplicates. Symbols indicate positive reaction $(+)$ or negative reaction $(-)$ in the test.

\begin{tabular}{llll}
\hline APIzym & $\mathbf{1}$ & $\mathbf{2}$ & $\mathbf{3}$ \\
\hline Phosphatase alkaline & + & + & - \\
Esterase (C4) & + & + & - \\
Esterase lipase (C8) & + & + & - \\
Lipase (C 14) & + & + & - \\
Leucine aminopeptidase & + & + & + \\
Valine aminopeptidase & + & - & - \\
Cystine aminopeptidase & + & - & + \\
Trypsin & - & - & - \\
Chymotrypsin & - & - & - \\
Phosphatase acid & + & + & + \\
Phosphoamidase & + & + & + \\
$\alpha$ - galactosidase & - & - & + \\
$\beta$ - galactosidase & - & - & + \\
$\beta$ - glucorinidase & + & + & + \\
$\alpha$ - glucosidase & - & - & + \\
$\beta$ - glucosidase & + & - & - \\
$\beta$ - glucosiaminidase & - & - & - \\
$\alpha$ - mannosidase & - & - & - \\
$\alpha$ - fucosidase & - & - & + \\
\hline
\end{tabular}


Chapter 5 


\section{Chapter 6}

\section{General discussion}


Ruminal fermentation is performed by the diverse rumen microbiota consisting of bacteria, archaea, protozoa and anaerobic fungi (Mackie et al., 2000). The rumen is the largest digestive organ of ruminants and provides the animal with energy in the form of proteins from microbial cell protein and volatile fatty acids (VFAs) (Hungate, 1966a). VFAs are taken up in the blood stream of the host via diffusion across the rumen epithelium. Breakdown products of microbial proteins are absorbed after digestion in the small intestine as amino acids, dipeptides and tri-peptides (Webb, 1990). In turn, another end product of feed degradation, methane, is non-desirable as it represents a loss of energy to the animal and also contributes to the greenhouse gas effect. Therefore the development of strategies for the mitigation of methane emissions from dairy cows has received ample attention. Most of the rumen methane mitigation studies to date have focused on manipulating the rumen by changing feed composition, adding chemical agents, enzymes as feed additives or microbial agents (e.g. probiotics) (Haque, 2018). However, characterizing ruminal microbiota with respect to its composition and activity remains vital to any rumen manipulation studies. Furthermore, the rumen microbial communities associated with the rumen fluid and fibrous content are different (Jewell et al., 2015). A prerequisite to understanding rumen microbial composition and function is to study the physiological and metabolic capabilities of rumen microorganisms with respect to fibre degradation. The focus on rumen fibre degradation stems from the fact that it is an important key step to overall ruminal feed degradation, and thus directly linked to ruminal methane emissions. There still is, however, a knowledge gap on the microbes that are involved in metabolizing the fibrous fraction.

In this thesis, Chapter 1 introduced the current knowledge of the animal associated and experimental factors influencing rumen microbiota composition. This chapter particularly addressed the need for understanding rumen microbes using culture independent and culture dependent approaches to be able to perform rumen manipulations with an aim to reduce levels of rumen methane emissions. The central objective of Chapter 2 was to determine the effect of different DNA extraction methods on the observed rumen microbial composition of liquid as well as fibrous rumen fractions of dairy cows. Our results showed that DNA extraction methods affected the apparent microbial community composition, and more specifically that of the bacteria. Chapter 3 described the effects of different diets on rumen microbial composition and related it to the previously reported methane emissions, which were found reduced in animals fed a maize silage based diet. These analyses revealed that diet, i.e. the ratio of grass and maize silage in the roughage, and time after the introduction of the 
experimental diets, significantly affected the bacterial composition but not the archaeal composition. Several genus-level taxa were positively associated with maize silage, with some of these taxa being members of the family Succinibrionaceae, which have been linked to low $\mathrm{CH}_{4}$ emissions in other studies.

Attachment of microbes to feed fibres is important in ruminal feed degradation (McAllister et al., 1994). Microorganisms in the rumen have a variety of surfaces to which they may attach and distinct communities adhere to each surface available (Huws et al., 2014). From an ecological point of view, microorganisms and typically bacteria that attach on feed particles have an advantage over the free floating bacteria that are passing faster through the rumen. Moreover, fibre-attached microorganisms have first access to the nutrients. Three bacterial species (Fibrobacter succinogenes, Ruminococcus albus and $R$. flavefaciens) have been established and well characterized as primary degraders of forage cell walls and are known to adhere to cellulose fibres (Bera-Maillet et al., 2004). Furthermore, primary cellulolytic populations have complex interactions with a range of non-cellulolytic fibre degraders, including e.g. Prevotella ruminicola, Ruminobacter amylophilus, Selenomonas ruminatium, Streptococcus bovis, Succinimonas amylolytica and Succinivibrio dextrinosolvens (Weimer, 1996a). Most of the non-cellulolytic bacteria utilize carbohydrates as growth substrates and/or ferment various di- and monosaccharides. In the research described in this thesis, enrichments of fibre associated microbial communities were made, and bacteria possibly involved in fibre degradation could be identified (Chapter 4). Some of the enriched rumen fibre associated bacteria were similar to genera known to be associated with fibre degradation. However, we were also able to enrich several novel rumen bacterial genera including Ruminofilibacter. These were possibly enriched due to the cold shock in between the sub-enrichments (SE), as this enrichment approach that was initially implemented due to experimental constraints in this study, is unconventional and has not been systematically used before. In Chapter $\mathbf{5}$ a novel fibre associated bacterium was isolated. The results of this chapter describe a novel Propionibacterium species in terms of its physiological, biochemical and chemotaxonomic characteristics.

Overall, the work in this thesis complements existing knowledge by assessing rumen microbial composition with respect to rumen feed degradation and characterizing novel bacterial taxa. An overview of cultivation dependent and molecular approaches used in the different studies included in this thesis is presented in Table 1. 
Table 1. Overview of rumen microbiota analysis in this thesis

\begin{tabular}{|c|c|c|c|c|c|c|}
\hline Study & Samples & $\begin{array}{l}\text { Number } \\
\text { of cows }\end{array}$ & Cow Diet & Groups & $\begin{array}{l}\text { Sampling } \\
\text { time (day) }\end{array}$ & Method \\
\hline & Rumen & & & & & \\
\hline Chapter 2 & $\begin{array}{l}\text { fluid and } \\
\text { fibrous } \\
\text { content }\end{array}$ & 4 & $\begin{array}{l}\text { GS100,GS67, } \\
\text { GS33,GS0 }\end{array}$ & 4 & 17 & $\begin{array}{l}\text { Pyrosequencing } \\
\text { qPCR }\end{array}$ \\
\hline Chapter 3 & $\begin{array}{l}\text { Rumen } \\
\text { fluid }\end{array}$ & $12 *$ & $\begin{array}{l}\text { GS100,GS67, } \\
\text { GS33,GS0 }\end{array}$ & $3,4,7$ & 10,17 & $\begin{array}{l}\text { MiSeq } \\
\text { qPCR }\end{array}$ \\
\hline Chapter 4 & $\begin{array}{l}\text { Fibrous } \\
\text { content }\end{array}$ & 1 & GS100 & 4 & 17 & Enrichment \\
\hline Chapter 5 & $\begin{array}{l}\text { Fibrous } \\
\text { content }\end{array}$ & 1 & GS100 & 4 & 17 & Isolation \\
\hline
\end{tabular}

*The cows were clustered in groups of four, with each of the four cows fed one of four different diets differing in the ratio of grass (GS) and maize (MS) silage.

\section{ASSESSMENT OF RUMEN MICROBIAL DIVERSITY}

The rumen is a fermentation chamber which allows input of feed, removal of microbial biomass and end products whilst enabling microbial growth. Many factors influence the rumen microbial community and can be broadly grouped into animal associated and experimental factors, including, e.g., breed, diet, housing and age. Furthermore, methodological aspects, such as sampling, sample storage and DNA extraction methods, influence the way we see these microbial communities (Chapter 1 and Chapter 2). Many studies have evaluated a variety of technical biases when analysing rumen microbial community composition. For example DNA extraction methods, sampling and storage conditions have impact on the observed rumen microbial community composition (Henderson et al., 2013; Fliegerova et al., 2014; Paz et al., 2016; Granja-Salcedo et al., 2017). The method of DNA extraction has been identified as the main factor determining observed microbial composition changes, rather than the sampling method (cheesecloth squeezed, centrifuges, filtered), storage temperature $\left(-80^{\circ} \mathrm{C}\right.$, room temperature) or cryoprotectants (PBS-Glycerol, ethanol) (Fliegerova et al., 2014; Paz et al., 2016). Commercial DNA extraction kits specifically designed for rumen contents are to the best of our knowledge unavailable, and kits that are designed for other sample types (soil or biofilm or faeces) are often used. 
Chapter 2 involved testing of four routinely used DNA extraction methods (Repeated bead beating: RBB; Phenol dependent bead beating: PBB; Fast DNA SPIN Soil Kit: FDSS; and PQIAmini) on rumen fluid (RF) and fibrous content (FC). The methods were evaluated based on DNA yield, quality and molecular microbial analyis (i.e. qPCR and barcoded amplicon sequencing). The results showed that the DNA extraction method impacts the outcome of the bacterial community analysis more than the picture obtained for archaeal and fungal communities. Moreover, every DNA extraction method had its own strengths and weaknesses. In our study, high molecular weight DNA was always recovered, although all methods employed a bead beating step, with differences in agitation times and types of beads. However, there was some shearing of the DNA mainly due to the mechanical force employed by our methods, albeit not to the same extent with the different methods. DNA yields differed between extraction methods tested (Chapter 2), which was also noted in the study of Henderson et al. (2013). At the phylum level, Bacteroidetes and Firmicutes dominated all samples. However, more prominent differences between rumen fractions and DNA extraction methods were observed at the genus level within these and other phyla, such as the Fibrobacteres (Chapter 2).

\section{INFLUENCE OF DIET ON RUMEN MICROBIOTA COMPOSITION}

The rumen microbiome is complex and can be influenced by many factors. The study described in Chapter 3 aimed to characterise the rumen bacterial and archaeal communities in dairy cows fed different ratios of maize silage (MS) and grass silage (GS) wherein the composition of the concentrate was similar for all four treatments, whereas the roughage was GS, MS, or a mixture of both (ingredient as percentage of the total amount of roughage in the diet; DM basis): 100\% GS (GS100), 67\% GS and 33\% MS (GS67), 33\% GS and 67\% MS (GS33), and 100\% MS (GS0). We placed the findings in context of ruminal fermentation as well as previously reported $\mathrm{CH}_{4}$ emissions (van Gastelen et al., 2015). Overall, no effect of diet on total VFA and the molar proportions of acetate and propionate was observed (Chapter 3 and van Gastelen et al. (2015). Both studies differed with respect to the molar proportions of butyrate and isovalerate. Additionally, Van Gastelen et al. (2015) reported that isovalerate tended to be affected by diet, whereas in the current study no diet effect on isovalerate was found. These differences between the two studies are likely associated with the frequency and timing of sampling, which differed between both studies. More specifically, samples analyzed in this study were taken on days 10 and $17,4 \mathrm{~h}$ after morning feeding, whereas van Gastelen 
and coworkers (2015) analysed samples taken one hour before and 1, 2, 4, 6 and $8 \mathrm{~h}$ after morning feeding on days 10 and 11, before animals entered a respiration chamber from day 12-17. The observed differences could also be partly attributed to mild stress of the cows. After day 17 (last milking/feeding), cows were moved from the respiration chamber to the free barn and tied. During this process animals may have experienced some mild stress and a small period of time that they would not be able to eat or lie/ruminate.

Due to different ratios of GS and MS in their diet (Chapter 3), ruminants can harbour distinct rumen microbial communities. Bacterial communities in our study were most affected by dietary interventions (Chapter 3). In the study of Zhu et al. (2017), alfa alfa hay feed increased the proportions of Prevotella and Selenomonas compared to a maize stalk diet. The differences in the $\mathrm{m}$ icrobial com position can affect the rum inant's feedingfficiency through production of VFAs as the microbes are involved in various fermentation pathways and have associations with each other (Malmuthuge and Guan, 2017). One of the strongest associations was between succinate producing, succinate utilizing and amino acid fermenting bacteria and methanogens (namely Methanomassillicoccaceae and Methanosphaera). In our study, bacterial families Succinivibrionaceae and Ruminococcaceae were associated with the MS diets, indicating a possible role in the lower methane emissions observed by van Gastelen et al. (2015). Methanobrevibacter was also positively associated with MS in the diet. Future studies should focus on mechanistic aspects of such bacteria: archaea interactions, and how this knowledge can be applied towards methane mitigation strategies.

In this thesis, maize (which is mainly starch) silage fed cows showed a neutral $\mathrm{pH}$ in their rumen content (Van Gastelen, 2015) (Chapter 3). Amylolytic bacteria are important in the rumen of animals fed concentrate diets and starch. Lactic acid is a typical product of their metabolism, however, this does not accumaulate as it is rapidly utilized by propionate producers. Propionate is a hydrogen sink and contributes to reduced methane emission. However, there are different consequences to increasing the amount of starch in the diet. It can increase the passage rate, which subsequently lead to a shift of methanogenesis to the hind gut, abolishing the effect in reducing $\mathrm{CH}_{4}$ emissions. Also, rapid degradation of easily fermentable substrates can increase the rate of VFA production beyond the absorptive capacity, resulting in $\mathrm{pH}$ drop and disruption of rumen microbiota or acidosis (Hook et al., 2011). Also, limited rumination can reduce the inflow of acid neutralizing saliva, and decrease rumen motility resulting in decreased passage rate. Therefore associations of the 
rumen microbiota with the rumen size, physiological changes, and passage rates as well as role of host genetics should be considered for defining strategies to rumen manipulation.

\section{FIBRE ASSOCIATED BACTERIA}

Ruminal plant fibre digestion relies on colonization and breakdown of the fibre by complex microbial communites (Weimer, 1996b). Fibre-attached bacteria capable of degrading cellulose and/or hemicellulose are pivotal to the maintenance of rumen function, and hydrolysis of plant polysaccharides into monomers which are then utilized by other rumen microbes. Only $2-31 \%$ of fibre associated bacterial communities in the rumen, however, are represented by cultivated species (Koike et al., 2003b; Creevey et al., 2014), highlighting the need to isolate these uncultured bacteria to increase our knowledge of their involvement in ruminal fibre degradation and the underlying mechanisms. In this thesis, we identified clear differences in the rumen bacterial communities associated with the rumen fibrous content and the liquid fraction (Chapter 2), and enriched in vitro fibre associated consortia (Chapter 4).

Fibrolytic bacteria include cellulose, pectin and xylan degraders while the non-fibrolytic bacteria ferment simple carbohydrates including various monosaccharides and disaccharides (Hungate, 1966a). Feeding grain or maize diets has shown to change the ruminal microbial community from fibrolytic to amylolytic (Fernando et al., 2010). This is possibly why starch or soluble carbohydrates utilizing bacteria, a.o. Proteiniphilum or Bacteroides were enriched in our study when maize fibres were used (Chapter 4). Some previously uncultured rumen bacterial genera (a.o. Pyramidobacter, Ruminofilibacter) were enriched through serial transfers, with cold shock in between the sub-enrichments (SE) to avoid further fibre fragmentation that might have lead to no inoculum to transfer in the next sub-enrichment and time issues in setting up the enrichment cultures (Chapter 4). Of the cultured bacterial representatives obtained from rumen content known to date (Creevey et al., 2014), those associated with rumen fibre degradation are represented by only be a handful of species.

Combining a culture dependent (in vitro) approach for the isolation of fibre-associated bacteria and a culture independent approach, i.e. 16S rRNA profiling of the fibre-associated microbiota, can expand our understanding of fibre degradation in the rumen. Ruminofilibacter xylanolyticum S1 (belonging to the Rikenellaceae) has caught our interest to target this genus for future fibre associated studies, as this genus was dominant in our MS enrichments (Chapter 4), suggesting its preference for maize derived fibres as substrates. Indeed 
Ruminofilibacter xylanolyticum S1 was previously identified from an anaerobic biogas plant fed with maize silage, green rye and liquid manure (Krober et al., 2009).

Many attempts have been made to cultivate bacteria from the liquid fraction, however, the use of a solid surface as an attachment matrix in order to cultivate fibre associated rumen microbes has been limited. Most probably, the main reason for this is the difficulty of this approach to enrich microorganisms from a fibrous inoculum, as the microbes often remain attached to the fibres in the inoculum. Furthermore, taking samples of rumen fibrous material requires fistulated cows, which are a limited resource due to ethical reasons as well as high costs associated with maintaining fistulated animals.

Previously, Nyonyo et al. (2014) applied an isolation strategy where blended ruminal fibrous content and the liquid fraction was inoculated on an agar- or gellan gum modified basal medium with azo-carboxymethylcellulose as the carbon source (Nyonyo et al., 2014). This study yielded 129 isolates that grouped in 6 phyla with Firmicutes as the most represented. However, 19\% of the isolates grouped in unclassified taxa at family level, indicating a largely uncharacterized biodiversity mostly within the family Lachnospiraceae. The cellulose degrading populations were believed to be derived from the fibre-adherent microbiota, and carboxymethylcellulase and xylanase acitivities were measured (Nyonyo et al., 2014). The rumen microbial communities associated with fibres have been previously shown to be dominated by Firmicutes and Bacteroidetes (Koike et al., 2003b). At genus level, Ruminococcus, Fibrobacter, Pseudobutyrivibrio, unclassified Lachnospiraceae, Butyrivibrio, Streptococcus, Enterococcus, Saccharofermentans and Prevotella were able to degrade filter paper as a measure of cellulose degrading capacity (Nyonyo et al., 2014).

The addition of methylcellulose inhibits bacterial attachment on fibrous particles (Kim et al., 2013). Treatment with methylcellulose has been shown to cause the detachment of Fibrobacter succinogenes, Ruminococcus albus and Ruminococcus flavefaciens from cellulose fibres (Kudo et al., 1987). In this thesis, methylcellulose was used to specifically detach bacteria from rumen derived fibres (Chapter 5). In this way specific enrichments with fibre-associated bacteria could be developed. From these enrichments a novel Propionibacterium specie, P. ruminifibrarum strain $\mathrm{JV}^{\mathrm{T}}$, could be isolated and further characterised. 
Strain $J V 5^{\mathrm{T}}$ produced propionate as a major end-product from glucose fermentation. As propionate can be an effective $\mathrm{H}_{2}$ sink for reducing ruminal methane formation, the capacity of strain $\mathrm{JV}^{\mathrm{T}}$ to attach to fibres was assessed.

\section{PROPIONIBACTERIUM RUMINIFIBRARUM: ITS POTENTIAL ROLE IN FIBRE ATTACHMENT AND DEGRADATION AND METHANE MITIGATION}

With the novel strain Propionibacterium ruminifibrarum JV5 ${ }^{\mathrm{T}}$ in hand (Chapter 5), we further investigated in vitro its ability to colonise and utilize silage derived sterilized grass fibres. The metabolites produced were measured after 24 hours of incubation, and bacterial cells were quantified and visualized on the fibre over the time course of incubation.

Scanning Electron Microscopy (SEM) revealed that strain $\mathrm{JV}^{\mathrm{T}}$ attached to the fibres and formed micro-colonies (Fig. 1). The micro-colonies typically formed in the cavities of the fibres (Fig. $1 \mathrm{~A}$ and B) or around damaged spots in the fibres (Fig. 1C). This characteristic formation of micro-colonies was previously observed for Propionibacterium jensii strain S1 on fruit fibres present in a cannery medium (van Schalkwyk, 2003). Furthermore, the fruit fibre - P. jensii complex was covered with an extracellular polymer matrix (EPS), and was stable even after five months of cold storage indicating that EPS is important in biofilm formation and stabilization (van Schalkwyk, 2003).

The physiological role of EPS can be: (i) cell protection from changes in temperature, $\mathrm{pH}$ and osmotic pressure, (ii) cell-cell interactions and (iii) adhesion to surfaces (RuasMadiedo et al., 2002; Donot et al., 2012). No EPS could be observed on the outside of strain $\mathrm{JV5}^{\mathrm{T}}$ (Chapter 5), although the liquid of batch grown cells on soluble substrates was viscous (visual observation). This might be indicative of EPS production as bacterial EPS can be secreted into the media or tightly attached onto the cell wall. The viscosity of the growth medium has been speculated to be associated with EPS (Cerning, 1990). Recently, it was found with $P$. freundreichii that EPS production was affected by medium composition and fermentation conditions (Belgrano et al., 2018). P. freudenreichii subsp. shermanii strain JS, which belongs to the dairy group of propionibacteria, also produces large quantities of EPS (Belgrano et al., 2018).

qPCR measurements of strain $\mathrm{JV}^{\mathrm{T}}$ indicated that no increase in the $16 \mathrm{~S}$ rRNA gene copy numbers on silage derived grass fibres occurred within $1 \mathrm{~h}$ of incubation (Fig. 2), 
suggesting that strain $\mathrm{JV}^{\mathrm{T}}$ requires a longer time to attach to fibres before subsequently multiplying and forming micro-colonies by $24 \mathrm{~h}$. After $24 \mathrm{~h}$, some acetate was produced indicating that the fibres served as a carbon source as well as an attachment matrix. These preliminary findings suggest a potential role of strain $\mathrm{JV}^{\mathrm{T}}$ in the utilization of dietary fibres in the rumen.

In the past, there have been few in vitro studies that investigated specifically fibre attachment or adherence (Cheng et al., 1984; Shinkai and Kobayashi, 2007). It is well documented that bacteria have a close association with plant cell wall materials (McAllister et al., 1990). This has been also clearly demonstrated in the past through microbiological examinations from grain (wheat and barley) and maize particles (McAllister et al., 1990). Digestive processes require physiologically complementing bacterial species that interact and form a consortium on the surface of plant tissues. Attachment of primary colonizers $(F$. succinogenes, $R$. albus, and $R$. flavefaciens) is pivotal for a sequential establishment of microbial consortia. Affinity of rumen microbes for specific plant or fibre components varies (Huws et al., 2014). For example, Selenomonas bovis employs non-specific attachment, while Ruminococcus amylophilus prefers to attach to the surface of starch granules. Butyrivibrio fibriosolvens is known to colonize the endosperm cell wall and digests starch granules (Mc Allister et al, 1994). Initial attachment to feed particles is established via the glycocalyx and associated binding proteins of the microbes. The primary colonizers and their hydrolytic enzymes attack the insoluble substrates creating pits and releasing soluble nutrients. This attracts the secondary colonizers from the fluid fraction to further ferment soluble substrates. These secondary colonizers many times attach to the primary colonizers forming microcolonies resulting in a biofilm that performs the fibre degradation. The microbial species change depending on the available insoluble substrate. Microbial interactions with fibrous material or fibre components have been only been associated with Fibrobacter succinogenes, Ruminococcus flavefaciens and Ruminococcus albus that are known to be involved in cellulose and hemicellulose degradation (Shinkai and Kobayashi, 2007). In the study of Shinkai and Kobayashi (2007), it was demonstrated using FISH analysis that the cell distribution of $F$. succinogenes and $R$. flavefaciens also changed depending on the plant tissues used as growth substrates. Moreover, numerous genes encoding enzymes necessary for plant fibre digestion have been isolated from $F$. succinogenes, $R$. flavefaciens and $R$. albus. To illustrate, F. succinogenes possesses 31 putative cellulase encoding genes, including ten members of glycosyl hydrolase family 5 (GH5), six members of GH8, nine members of GH9, 
four members of GH45, and two members of GH51 and genes encoding proteins with a wide range of annotated hemicellulolytic activities including a large number of xylanases, arabinoxylanases, mannanases, curdlanases ( $\beta-1,3$ glucanases), licheninases ( $\beta-1,4$ glucanases), and xyloglucanases. These enzymes come from a range of $\mathrm{GH}$ families including GH10, GH11, GH18, and GH26) (Suen et al., 2011). These three bacteria, F. succinogenes, $R$. flavefaciens and $R$. albus, are the core microbiota associated with the fibrous fraction in the rumen. These bacteria are known to attach to fibrous fractions in the rumen within 5 to 15 minutes and subsequently form a biofilm (Edwards et al., 2017). Bacterial enzymes attack plant cell walls initially, and subsequently the more recalcitrant polymers. Moreover, crossfeeding takes place of fibre breakdown intermediates and end-products that are produced by the fibre degraders (Flint et al., 2008). This suggests that attachment might not necessarily mean that the attached bacteria are primary fibre degrading bacteria. This close proximity to the fibrous fraction for fibrolytic bacteria might be due to the complexity of enzymes involved in the degradation of polymeric cellulose (Flint et al., 2008).

The ability of P.ruminifibrarum to attach to silage derived grass fibres suggests that this isolate could serve as a potential direct fed microbial, which could offer an effective means of increasing propionate production (Jeyanathan et al., 2014) and as such contribute to reducing enteric $\mathrm{CH}_{4}$ emissions. Recently, there have been two studies which showed the potential of several Propionibacterium strains to reduce $\mathrm{CH}_{4}$ in vivo. In the first study, a number of Propionibacterium strains, namely Propionibacterium acidipropionici P169, $P$. acidipropionici P5, and Propionibacterium jensenii P54 were inoculated daily before feeding, however, failed to increase propionate proportions and showed no effect of treatment on total $\mathrm{CH}_{4}$ emissions (Vyas et al., 2014). The strains could not persist or maintain themselves in the rumen and returned to pre-treatment levels nine hours after feeding. The follow up study ofthe same research group used ruminally cannulated heifers, which were fed different Propionibacterium strains (Vyas et al., 2016). The strains Propionibacterium freundreichii T114, Propionibacterium theonii T159 and P. freundreichii T54 were administered separately in different age grouped heifers. These microbials were added daily at the time of feeding directly into the rumen. Methane yield tended to be higher with the different Propionibacterium strains, and the relative abundance of total propionibacteria was higher with the inoculation of Propionibacterium T159 relative to the control heifers. The study of Vyas et al. (2016) concluded that the inoculation of Propionibacterium T159 decreased the ruminal acetate proportion, whereas Propionibacterium T114 increased the 
acetate: propionate ratio. However, inoculated strains failed to lower total $\mathrm{CH}_{4}$ emissions possibly due to the inability of Propionibacterium strains to elevate ruminal propionate concentrations (Vyas et al., 2016).

In another study 16 different Propionibacterium strains were screened in vitro and demonstrated that the potential of propionibacteria in reducing $\mathrm{CH}_{4}$ emission was substrate dependent, with more reduction in $\mathrm{CH}_{4}$ with maize as substrate (Alazzeh et al., 2012). To this end, it will be interesting to investigate the potential for Propionibacterium ruminifibrarum $\mathrm{JV} 5^{\mathrm{T}}$ to mitigate methane emissions. To conclude, propionibacteria are promising candidates for direct fed microbials, but the current literature contains varying data on their impact in mitigating methane and increasing propionate.

\section{KNOWLEDGE GAPS AND FUTURE RESEARCH}

The vast majority of research worldwide focusses on optimizing milk production in dairy cattle, and meat production in beef cattle. One of the aspects that contributes to the above is the microbial digestion of feed in the rumen. The diverse rumen microbial community adapts to a wide assortment of dietary feedstuffs but also to management strategies. Understanding rumen microbiota composition and function, as well as its adaptation to changes in rumen environmental conditions, has global consequences ranging from GHG emissions to applied animal production. Conventional knowledge of rumen microbiology was based on anaerobic culture-dependent methods. Next-generation sequencing and other molecular, culture independent techniques have revealed novel features of the rumen microbiome (McCann, 2014). Single cell genomics today allows the study of individual cells and add to our understanding of the metabolic potential of individual microrganisms within their natural environment (Hornung et al., 2018).

In order to have a fundamental understanding of rumen microbiota and its interactions with the host in ruminal methanogenesis, high-throughput sequencing technologies have characterized numerous microbial OTUs/phylotypes based on 16S rRNA gene sequences. Combination of these high-throughput data describing the rumen microbiome with classical 

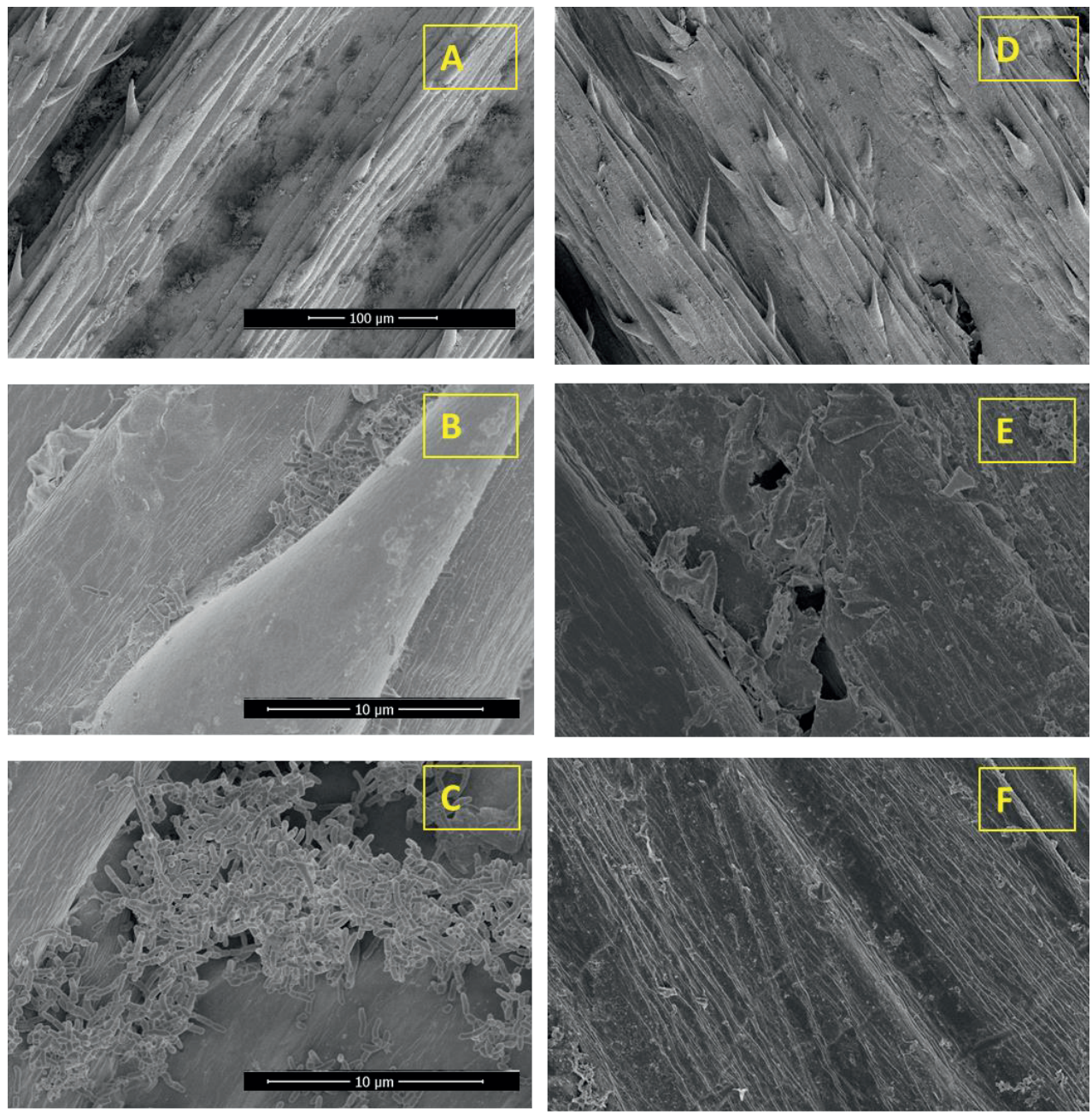

Figure 1. Scanning electron micrographs (SEM) of strain $\mathrm{JV}^{\mathrm{T}}$ micro-colonies attached to silage derived grass fibres after 24 hours of in vitro incubation in bicarbonate buffered mineral medium at $39^{\circ} \mathrm{C}(\mathrm{A}-\mathrm{C})$ and of control fibres after $24 \mathrm{~h}$ of in vitro incubation in the absence of JV5 ${ }^{\mathrm{T}}$ (D-F). 


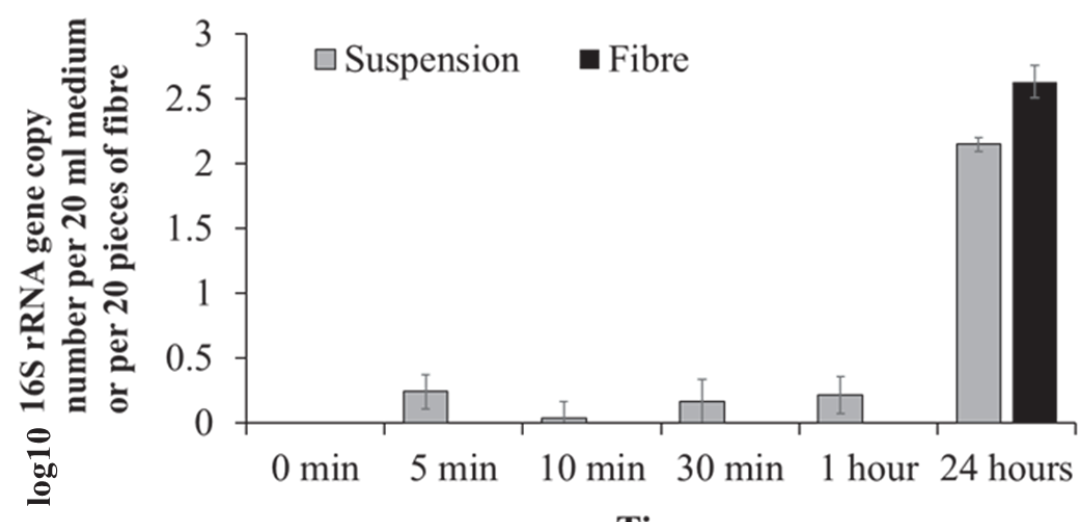

Time

Figure 2. Quantification of Strain $\mathrm{JV} 5^{\mathrm{T}}$ in suspension and on the silage derived grass fibres. QPCR results are expressed per $20 \mathrm{ml}$ of medium or 20 pieces of fibres, respectively. Error bars represent biological duplicates.

fermentations and animal performance parameters has yielded important advances and opened additional areas for further study. In addition, although dietary practices, supplements and additives that modify rumen microbiota composition for increasing feed efficiency have been identified, there is an increasing need to further understand the ecology of the rumen microbiome particularly in light of functional redundancy in the ecosystem. One way to more specifically address functionality of microbial ecosystems is through metagenomics and metatranscriptomics. This allows to obtain genomes and make metabolic maps of the genes that are associated with methanogenesis or fibre degradation thereby providing the necessary basis for a comparative analysis at the functional level. Functionality must also be confirmed at the protein and metabolite level through meta-proteomics and meta-metabolomics.

To this end, investigations of the prokaryotic rumen metaproteome are challenged by the complexity of rumen samples, which requires specific sample preparation procedures to separate archaeal and bacterial cells from the residual matter prior to protein extraction. Moreover, humic compounds are present and interfere with the meta-proteomic workflow (Chourey et al., 2010; Heyer et al., 2013). Furthermore, such omics analysis would be most interesting to perform on the fibrous fraction as it is relatively unexplored. Recently, a functional gene array targeting fibre degrading activities in the rumen ecosystem, the FibroChip, was developed (Comtet-Marre et al., 2018). Genes belonging to CAZyme families 
known to contain cellulases and hemicellulases (GH5, GH9, GH10, GH11, GH43, GH48, $\mathrm{CE} 1$, and CE6) in the genome of the major rumen fibrolytic microorganisms including bacteria, fungi, and protozoa, were targeted. This tool can help to characterize the expression of the CAZyme genes of the rumen microbiota of the cow and help in elucidating roles of the different microorganisms in fibre digestion.

Using such omics tools, new genes could be identified encoding fibre degrading activities that can be a potential target to estimate fibre degrading capabilities. Nevertheless, it remains necessary to use an integrated approach towards assessing the importance of the different members of rumen microbiota to rumen productivity and the host animal.

The metabolism of complex carbohydrates and pathways associated with $\mathrm{H}_{2}$ production have been recognized in gut microbiomes for efficient use of forage feeds and optimizing ruminal fermentation (Morgavi et al., 2012). The metabolism of methanogenic archaea, most of which are $\mathrm{H}_{2}$ utilizers, is well known, and their numbers are estimated in different ruminants, rumen locations and time (Jansen and Kirs, 2008). Methane production is closely linked to the formation of $\mathrm{H}_{2}$. Experiments such as the one described in Chapter 3 would therefore benefit from measurements of ruminal fermentation, $\mathrm{H}_{2}$ and $\mathrm{CH}_{4}$ throughout the day to monitor the fermentation dynamics associated with dietary interventions, as previously performed by (van Lingen et al., 2017b). Moreover, $\mathrm{H}_{2}$ measurements as a standard integrated tool next to the methane measurements would be beneficial.

Isolation of novel anaerobic fibre associated bacteria is relevant to obtain a deeper understanding of cow rumen physiology. In this thesis (Chapter 5), we isolated Propionibacterium ruminifibrarum described as a potential fibre associated bacterium. Assessing the genome sequence of $P$. ruminifibrarum will help in identifying genes that encode hydrolytic enzymes for cellulose, xylan or starch degradation, as well as propionate synthesis. The efficiency for fibre degradation depends on the activity of the microbial enzymes produced by the rumen microorganisms. These enzymes include glycoside hydrolases $(\mathrm{GH})$ active against the main plant structural polysaccharides (cellulose and hemicelluloses) and carbohydrate esterases (CE) which cleave polysaccharide substituents. Further growth experiments in microcosms could be started on dedicated polymeric substances, followed by RNA-seq analysis. This will provide improved in depth understanding of the metabolic capacity of the isolated novel species, and can contribute to assessing the suitability of strain $\mathrm{JV}^{\mathrm{T}}$ to be applied as a probiotic to reduce ruminal methane. 
The anaerobic fungi that are present in the rumen produce large amounts of $\mathrm{H}_{2}$ along with $\mathrm{CO}_{2}$, formate and acetate as metabolic end products depending on the diet. Methanogens in particular are found closely associated with fungal hyphae suggesting that fungal abundances might be related to methane emissions (Bauchop, 1981). A recent study by (Kittelmann et al., 2014) reported no difference in fungal community relative to methane emission. In contrast, a meta-analysis revealed that decreasing fungal abundance was associated with lower $\mathrm{CH}_{4}$ emissions (Newbold et al., 2015). Therefore, it will be interesting to further study anaerobic fungi not only in terms of their role in fibre degradation, but also for their role in ruminal methane production (Edwards et al., 2017). Additionally, anaerobic fungi are known for fibre degradation as well, and therefore cultivating fungi and understanding their physiology is valuable and needs further attention.

\section{REFERENCES}

Alazzeh, A.Y., Sultana, H., Beauchemin, K.A., Wang, Y., Holo, H., Harstad, O.M., et al. (2012). Using strains of Propionibacteria to mitigate methane emissions in vitro. Acta Agri Scandin Section Anim Sci 62(4), 263-272. doi: 10.1080/09064702.2013.773056.

Bauchop, T. (1981). The anaerobic fungi in rumen fiber digestion. Agri and Environ 6(2-3), 339-348. doi: 10.1016/0304-1131(81)90021-7.

Belgrano, F.D.S., Verçoza, B.R.F., Rodrigues, J.C.F., Hatti-Kaul, R., and Pereira, N. (2018). EPS production by Propionibacterium freudenreichii facilitates its immobilization for propionic acid production. J of Appl Microb 125(2), 480-489. doi: 10.1111/jam.13895.

Bera-Maillet, C., Ribot, Y., and Forano, E. (2004). Fiber-degrading systems of different strains of the genus Fibrobacter. Appl Environ Microbiol 70(4), 2172-2179. doi: 10.1128/aem.70.4.2172-2179.2004.

Cerning, J. (1990). Exocellular polysaccharides produced by lactic acid bacteria. FEMS Microbiol Rev 7(1-2), 113-130.

Cheng, K.J., Stewart, C.S., Dinsdale, D., and Costerton, J.W. (1984). Electron-microscopy of bacteria involved in the digestion of plant-cell walls. Animal Feed Science and Technology 10(2), 93-120. doi: 10.1016/0377-8401(84)90002-6.

Chourey, K., Jansson, J., VerBerkmoes, N., Shah, M., Chavarria, K.L., Tom, L.M., et al. (2010). Direct cellular lysis/protein extraction protocol for soil metaproteomics. $J$ Proteome Res 9(12). doi: 10.1021/pr100787q.

Comtet-Marre, S., Chaucheyras-Durand, F., Bouzid, O., Mosoni, P., Bayat, A.R., Peyret, P., et al. (2018). FibroChip, a functional DNA microarray to monitor cellulolytic and hemicellulolytic activities of rumen microbiota. Front Microbiol 9(215), 215. doi: 10.3389/fmicb.2018.00215.

Creevey, C.J., Kelly, W.J., Henderson, G., and Leahy, S.C. (2014). Determining the culturability of the rumen bacterial microbiome. Microb Biotechnol 7(5), 467-479. doi: 10.1111/1751-7915.12141.

Donot, F., Fontana, A., Baccou, J.C., and Schorr-Galindo, S. (2012). Microbial exopolysaccharides: Main examples of synthesis, excretion, genetics and extraction. Carbohyd Poly 87(2), 951-962. doi: 10.1016/j.carbpol.2011.08.083. 
Edwards, J.E., Forster, R.J., Callaghan, T.M., Dollhofer, V., Dagar, S.S., Cheng, Y., et al. (2017). PCR and Omics based techniques to study the diversity, ecology and biology of anaerobic fungi: Insights, challenges and opportunities. Front Microbiol 8(1657), 1657. doi: 10.3389/fmicb.2017.01657.

Fernando, S.C., Purvis, H.T., 2nd, Najar, F.Z., Sukharnikov, L.O., Krehbiel, C.R., Nagaraja, T.G., et al. (2010). Rumen microbial population dynamics during adaptation to a highgrain diet. Appl Environ Microbiol 76(22), 7482-7490. doi: 10.1128/AEM.00388-10.

Fliegerova, K., Tapio, I., Bonin, A., Mrazek, J., Callegari, M.L., Bani, P., et al. (2014). Effect of DNA extraction and sample preservation method on rumen bacterial population. Anaerobe 29,80-84. doi: 10.1016/j.anaerobe.2013.09.015.

Flint, H.J., Bayer, E.A., Rincon, M.T., Lamed, R., and White, B.A. (2008). Polysaccharide utilization by gut bacteria: potential for new insights from genomic analysis. Nat Rev Microbiol 6(2), 121-131. doi: 10.1038/nrmicro1817.

Granja-Salcedo, Y.T., Ramirez-Uscategui, R.A., Machado, E.G., Duarte Messana, J., Takeshi Kishi, L., Lino Dias, A.V., et al. (2017). Studies on bacterial community composition are affected by the time and storage method of the rumen content. PLoS One 12(4), e0176701. doi: 10.1371/journal.pone.0176701.

Haque, M.N. (2018). Dietary manipulation: a sustainable way to mitigate methane emissions from ruminants. J Anim Sci Technol 60(1), 15. doi: 10.1186/s40781-018-0175-7.

Henderson, G., Cox, F., Kittelmann, S., Miri, V.H., Zethof, M., Noel, S.J., et al. (2013). Effect of DNA extraction methods and sampling techniques on the apparent structure of cow and sheep rumen microbial communities. PLoS One 8(9), e74787. doi: 10.1371/journal.pone.0074787.

Heyer, R., Kohrs, F., Benndorf, D., Rapp, E., Kausmann, R., Heiermann, M., et al. (2013). Metaproteome analysis of the microbial communities in agricultural biogas plants. $N$ Biotechnol 30(6), 614-622. doi: 10.1016/j.nbt.2013.01.002.

Hook, S.E., Steele, M.A., Northwood, K.S., Dijkstra, J., France, J., Wright, A.D., et al. (2011). Impact of subacute ruminal acidosis (SARA) adaptation and recovery on the density and diversity of bacteria in the rumen of dairy cows. FEMS Microbiol Ecol 78(2), 275-284. doi: 10.1111/j.1574-6941.2011.01154.x.

Hornung, B., Van den Bogert, B., Davids, M., Martins dos Santos, V.A.P., Plugge, C.M., Schaap, P.J., et al. (2018). The rumen metatranscriptome landscape reflects dietary adaptation and methanogenesis in lactating dairy cows. BioRxiv. doi: 10.1101/275883.

Hungate, R.E. (1966). in The Rumen and its Microbes. Academic Press), v-vi.

Huws, S.A., Mayorga, O.L., Theodorou, M.K., Kim, E.J., Cookson, A.H., Newbold, C.J., et al. (2014). Differential colonization of plant parts by the rumen microbiota is likely to be due to different forage chemistries. J Microb Biochem Technol 6, 080-086. doi: 10.4172/1948-5948.1000126.

Jewell, K.A., McCormick, C.A., Odt, C.L., Weimer, P.J., and Suen, G. (2015). Ruminal bacterial community composition in dairy cows is dynamic over the course of two lactations and correlates with feed efficiency. Appl Environ Microbiol 81(14), 46974710. doi: 10.1128/AEM.00720-15.

Jeyanathan, J., Martin, C., and Morgavi, D.P. (2014). The use of direct-fed microbials for mitigation of ruminant methane emissions: a review. Animal 8(2), 250-261. doi: $10.1017 / \mathrm{S} 1751731113002085$.

Kim, M.J., Sung, H.G., Upadhaya, S.D., Ha, J.K., and Lee, S.S. (2013). Effects of methylcellulose on fibrolytic bacterial detachment and in vitro degradation of rice straw. Asian-Australas J Anim Sci 26(10), 1459-1465. doi: 10.5713/ajas.2013.13220. 
Kittelmann, S., Pinares-Patino, C.S., Seedorf, H., Kirk, M.R., Ganesh, S., McEwan, J.C., et al. (2014). Two different bacterial community types are linked with the low-methane emission trait in sheep. PLoS One 9(7), e103171. doi: 10.1371/journal.pone.0103171.

Koike, S., Yoshitani, S., Kobayashi, Y., and Tanaka, K. (2003). Phylogenetic analysis of fiber-associated rumen bacterial community and PCR detection of uncultured bacteria. FEMS Microbiol Lett 229(1), 23-30. doi: 10.1016/s0378-1097(03)00760-2.

Krober, M., Bekel, T., Diaz, N.N., Goesmann, A., Jaenicke, S., Krause, L., et al. (2009). Phylogenetic characterization of a biogas plant microbial community integrating clone library 16S-rDNA sequences and metagenome sequence data obtained by $454-$ pyrosequencing. J Biotechnol 142(1), 38-49. doi: 10.1016/j.jbiotec.2009.02.010.

Kudo, H., Cheng, K.J., and Costerton, J.W. (1987). Electron microscopic study of the methylcellulose-mediated detachment of cellulolytic rumen bacteria from cellulose fibers. Can J Microbiol 33(3), 267-272. doi: 10.1139/m87-045.

Mackie, R.I., Aminov, R.I., White, B.A., and McSweeney, C.S. (2000). Molecular ecology and diversity in gut microbial ecosystems. 61-77. doi: 10.1079/9780851994635.0061.

Malmuthuge, N., and Guan, L.L. (2017). Understanding host-microbial interactions in rumen: searching the best opportunity for microbiota manipulation. J Anim Sci Biotechnol 8, 8. doi: 10.1186/s40104-016-0135-3.

McAllister, T.A., Bae, H.D., Jones, G.A., and Cheng, K.J. (1994). Microbial attachment and feed digestion in the rumen. J Anim Sci 72(11), 3004-3018.

McAllister, T.A., Cheng, K.J., Rode, L.M., and Forsberg, C.W. (1990). Digestion of barley, maize, and wheat by selected species of ruminal bacteria. Appl Environ Microbiol 56(10), 3146-3153. doi: 103146-08\$02.00/0.

McCann, J.C., Wickersham, T.A., Loor, J.J., (2014). High-throughput methods redefine the rumen microbiome and its relationship with nutrition and metabolism. Bioinformatics and Biology Insights 8, 109-125. doi: 10.4137/bbi.s15389.

Morgavi, D.P., Kelly, W.J., Janssen, P.H., and Attwood, G.T. (2012). Rumen microbial (meta)genomics and its application to ruminant production. (1), 1-18. doi: $10.1017 / \mathrm{s} 1751731112000419$.

Newbold, C.J., de la Fuente, G., Belanche, A., Ramos-Morales, E., and McEwan, N.R. (2015). The role of ciliate protozoa in the rumen. Front Microbiol 6, 1313. doi: 10.3389/fmicb.2015.01313.

Nyonyo, T., Shinkai, T., and Mitsumori, M. (2014). Improved culturability of cellulolytic rumen bacteria and phylogenetic diversity of culturable cellulolytic and xylanolytic bacteria newly isolated from the bovine rumen. FEMS Microbiol Ecol 88(3), 528-537. doi: $10.1111 / 1574-6941.12318$.

Paz, H.A., Anderson, C.L., Muller, M.J., Kononoff, P.J., and Fernando, S.C. (2016). Rumen bacterial community composition in Holstein and Jersey cows is different under same dietary condition and is not affected by sampling method. Front Microbiol 7(1206), 1206. doi: $10.3389 /$ fmicb.2016.01206.

Ruas-Madiedo, P., Hugenholtz, J., and Zoon, P. (2002). An overview of the functionality of exopolysaccharides produced by lactic acid bacteria. Intern Dair J 12(2-3), 163-171. doi: 10.1016/S0958-6946(01)00160-1.

Shinkai, T., and Kobayashi, Y. (2007). Localization of Ruminal Cellulolytic Bacteria on Plant Fibrous Materials as Determined by Fluorescence In Situ Hybridization and RealTime PCR. Applied and Environmental Microbiology 73(5), 1646-1652. doi: 10.1128/aem.01896-06.

Suen, G., Weimer, P.J., Stevenson, D.M., Aylward, F.O., Boyum, J., Deneke, J., et al. (2011). The complete genome sequence of Fibrobacter succinogenes S85 reveals a cellulolytic and metabolic specialist. PLoS One 6(4), e18814. doi: 10.1371/journal.pone.0018814. 
van Gastelen, S., Antunes-Fernandes, E.C., Hettinga, K.A., Klop, G., Alferink, S.J., Hendriks, W.H., et al. (2015). Enteric methane production, rumen volatile fatty acid concentrations, and milk fatty acid composition in lactating Holstein-Friesian cows fed grass silage- or corn silage-based diets. J Dairy Sci 98(3), 1915-1927. doi: 10.3168/jds.2014-8552.

van Lingen, H.J., Edwards, J.E., Vaidya, J.D., van Gastelen, S., Saccenti, E., van den Bogert, B., et al. (2017). Diurnal dynamics of gaseous and dissolved metabolites and microbiota composition in the bovine rumen. Front Microbiol 8(425), 425. doi: 10.3389/fmicb.2017.00425.

van Schalkwyk, C. (2003). Extracellular polymer production and potential for aggregate formation by classical propionibacteria. World J Microbiol and Biotech 19(3), 285 289. doi: 10.1023/a:1023606308920.

Vyas, D., Alazzeh, A., McGinn, S.M., McAllister, T.A., Harstad, O.M., Holo, H., et al. (2016). Enteric methane emissions in response to ruminal inoculation of Propionibacterium strains in beef cattle fed a mixed diet. Anim Product Sci 56(7), 1035. doi: 10.1071/an14801.

Vyas, D., McGeough, E.J., Mohammed, R., McGinn, S.M., McAllister, T.A., and Beauchemin, K.A. (2014). Effects of Propionibacterium strains on ruminal fermentation, nutrient digestibility and methane emissions in beef cattle fed a corn grain finishing diet. Animal 8(11), 1807-1815. doi: 10.1017/S1751731114001657.

Webb, K.E. (1990). Intestinal absorption of protein hydrolysis products: a review. J Anim Sci 68(9), 3011-3022. doi: 10.2527/1990.6893011x.

Weimer, P.J. (1996a). Why don't ruminal bacteria digest cellulose faster? Journal of Dairy Science 79(8), 1496-1502. doi: 10.3168/jds.S0022-0302(96)76509-8.

Zhu, Z., Noel, S.J., Difford, G.F., Al-Soud, W.A., Brejnrod, A., Sorensen, S.J., et al. (2017). Community structure of the metabolically active rumen bacterial and archaeal communities of dairy cows over the transition period. PLoS One 12(11), e0187858. doi:10.1371/journal.pone.0187858. 
Chapter 6 


\section{Thesis summary}


Enteric fermentation in ruminants produces methane $\left(\mathrm{CH}_{4}\right)$ which is considered as a greenhouse gas (GHG). $\mathrm{CH}_{4}$ that comes from enteric and manure fermentation, accounts for $106 \mathrm{Tg} \mathrm{CH}_{4}$ per year from anthropogenic sources. Rumen micro-organisms (bacteria, anaerobic fungi and protozoa) break down complex compounds in the feed by hydrolysis to produce monomers which are fermented to volatile fatty acids (VFA), mainly acetate, propionate and butyrate in addition to other products like formate, hydrogen $\left(\mathrm{H}_{2}\right)$ and carbon dioxide $\left(\mathrm{CO}_{2}\right)$. Methanogenic archaea in the rumen utilize $\mathrm{H}_{2}$ and $\mathrm{CO}_{2}$ and other methyl containing compounds to produce $\mathrm{CH}_{4}$. To increase understanding of ruminal methanogenesis, it is important to gain information on the initial colonizers of fibrous dietary components that are crucial for the attachment of the fibre associated microbiota to the feed and fibre degradation in the rumen. $\mathrm{CH}_{4}$ is the end-product of feed degradation and that is not used by the ruminant itself but mainly eructated into the atmosphere. As this is posing a negative impact on the climate, a broad range of strategies like use of direct fed microbial and inhibitors of $\mathrm{CH}_{4}$ production have been assessed with the aim of $\mathrm{CH}_{4}$ mitigation. The main objective of this $\mathrm{PhD}$ project was to apply integrated cultivation based and molecular approaches to assess the microbial community composition and fibre attachment in relation to $\mathrm{CH}_{4}$ emission.

In Chapter 1 of the thesis, I summarize the currently available background knowledge on the role of microbiota in rumen feed degradation with a particular emphasis on $\mathrm{CH}_{4}$ is presented. Furthermore, the composition and function of the different microbial communities associated with rumen fluid (RF) and the fibrous fraction (FC), the pros and the cons of culture dependent and culture independent methods are discussed. Lastly the current understanding of experimental, dietary and animal associated factors that influence rumen microbiota, fermentation patterns and enteric methanogenesis are reviewed. From the experimental factors affecting the rumen microbial composition discussed, Chapter 2 addresses the potential bias of DNA extraction methods on the picture we can obtain of RFand FC-associated microbial communities, using next generation sequencing based profiling of the bacterial, archaeal and fungal composition (16S rRNA gene and fungal ITS region). In addition, bacterial and archaeal numbers were assessed by 16S rRNA based qPCR. Most importantly, DNA extraction methods have an impact on the outcome of the downstream microbial community analysis, resulting in differences in absolute abundance, and relative abundances of specific community members. DNA extracted using the PBB method resulted in higher relative abundance of Ruminococcaceae than the FDSS method, whereas relative 
abundance of Fibrobacteraceae was lower compared to the RBB method. Whilst the effect of DNA extraction method was limited compared to that of rumen fraction, differences due to both DNA extraction method and fraction were observed for certain taxa.

Following this experiment, in Chapter 3 we explore the rumen microbiome in terms of its bacterial and archaeal composition and concentrations, in order to characterize the communities associated with different ratios of grass and maize silage rations diets and identify key microbial players associated with $\mathrm{CH}_{4}$ measurements previously reported by van Gastelen et al. (2015). As these analyses focused on rumen fluid, anaerobic fungi were not measured. The changes in the rumen microbiota in response to dietary treatments having different grass/maize silage ratios (GS100, GS67, GS33, and GS0 wherein GS100 indicates $100 \%$ grass silage) after 10 and 17 days of feeding were assessed. The bacterial and archaeal composition changes were used to help understand ruminal VFA profiles and $\mathrm{CH}_{4}$ measurements. In terms of ruminal VFA, no significant diet effects were found but the molar proportions of isovalerate were affected by time, being lower on day 17 than day 10. Diet affected bacterial concentrations, which were lower for the GS0 diet compared with the other three diets. There was no diet effect on archaeal concentrations. Bacterial and archaeal concentrations significantly increased from day 10 to day 17 . This observed increase in bacterial concentrations was suggestive of an increase in fermentation, while the biological significance of increased archaeal concentrations with time could not be elucidated, as $\mathrm{CH}_{4}$ emissions were only measured from days 12 to 17 in the study of van Gastelen et al. (2015). Several bacterial and archaeal genera could be associated with diet, but not with time. The bacterial families Succinivibrionaceae and Ruminococcaceae were associated with the maize silage diets, indicating their role in the lower $\mathrm{CH}_{4}$ emissions observed before (van Gastelen et al., 2015).

Another research objective of this thesis was to explore the fibre associated microbiota as many are still uncultured and unidentified. To this end, in Chapter 4 rumen fibre associated microbes were enriched from grass silage (GS) or maize silage (MS) fibres recovered from the bovine rumen. Enrichments used pre-autoclaved ruminal silage fibres (GS or MS, respectively, for each isolation source) as an attachment matrix in bottles containing different fibre related components (cellulose, amylopectin or xylan). All enrichments were incubated at $39{ }^{\circ} \mathrm{C}$ for a 14 day period, with storage at $4{ }^{\circ} \mathrm{C}$ for $3-4$ weeks between transfers. Although overall activity in all the enrichments was low, fibre-degrading bacteria were 
considered to be enriched as visual inspection of PE bottles from both the MS and GS enrichment series showed initial fragmentation or breaking up of the fibre structure. Sequencing analysis revealed that members of the genus Ruminofilibacter dominated all the MS SE5 bottles, whereas all GS SE5 bottles contained a more diverse community predominated by members of Prevotella 1 and Bacteroides). The in vitro experimental approach of biweekly serial transfer seems likely to be important to enrich for fibre associated bacteria that are not favoured by shorter incubation times, such as e.g. Ruminofilibacter.

Chapter 5 describes a novel propionate producing bacterium, Propionibacterium ruminifibrarum strain $\mathrm{JV}^{\mathrm{T}}$, isolated from the rumen fibrous content of a Holstein Friesian dairy cow. Characterization of this strain at genomic, biochemical and physiological level provided insights into the metabolic capacity of Propionibacterium ruminifibrarum. This species was able to utilize several sugars and sugar alcohols D-adonitol, galactose, glucose, inositol, DL-lactate, mannose, meso-erythritol, ribose and sorbitol mainly converting them to propionate and acetate, and succinate and/or formate in some cases. Furthermore, the ability of strain $\mathrm{JV}^{\mathrm{T}}$ to degrade representative plant carbon sources, i.e. cellulose, xylan or starch, was tested and we observed that strain $\mathrm{JV}^{\mathrm{T}}$ could not directly use plant polymeric components, but probably can associate with fibres to use the compounds that are released by primary degraders.

Finally, Chapter 6 provides an integrated overview and discussion of results obtained in the research described in this thesis as well as findings from other studies. In this context, preliminary results regarding the ability of the novel isolate strain $\mathrm{JV}^{\mathrm{T}}$ to attach onto silage derived grass fibres are presented and discussed in light of the potential for this isolate to be developed into a probiotic feed supplement. In addition, this chapter provides future directions of research on rumen microbial management to mitigate $\mathrm{CH}_{4}$ and improve ruminal fermentation. 


\section{Appendices}

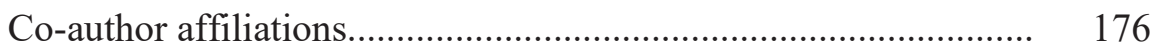

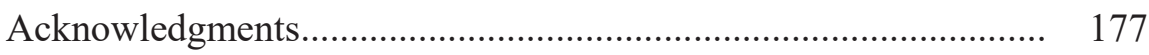

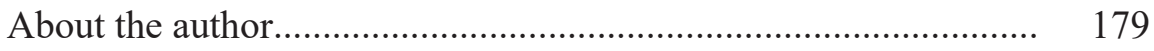

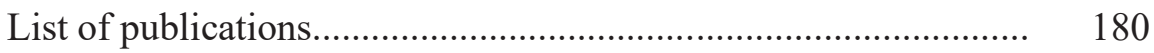

Overview of completed training activities..................................... 181 


\section{Co-author affiliations}

Bastian V.H. Hornung 3,5

Bartholomeus van den Bogert ${ }^{1,2,6}$

Chen $\mathrm{Ye}^{1,2}$

Colores Uwamariya ${ }^{1,2}$

Caroline M. Plugge ${ }^{2}$

Edoardo Saccenti ${ }^{3}$

Hauke Smidt ${ }^{2}$

Joan Edwards ${ }^{1,2}$

Jos Bokhoerst $^{7}$

Sanne van Gastelen ${ }^{1,4}$

${ }^{1}$ Top Institute Food and Nutrition, Wageningen, The Netherlands

${ }^{2}$ Laboratory of Microbiology, Wageningen University \& Research, Stippeneng 4, 6708 WE Wageningen, The Netherlands

${ }^{3}$ Laboratory of Systems and Synthetic Biology, Wageningen University \& Research, Stippeneng 4, 6708 WE, Wageningen, The Netherlands

${ }^{4}$ Animal Nutrition group, Wageningen University \& Research, Stippeneng 4, 6708 WE, Wageningen, The Netherlands

${ }^{5}$ Leiden Universitair Medisch Centrum LUMC, Albinusdreef 2, 2333 ZA Leiden, The Netherlands

${ }^{6}$ Base Clear BV, PO Box 1336, 2302 BH, Leiden, The Netherlands

${ }^{7}$ NIZO food research BV, Ede, the Netherlands 


\section{Acknowledgments}

As I am towards the end of my $\mathrm{PhD}$ thesis booklet writing, I have only been recollecting all memories from the time I had joined as a PhD and many times already feeling nostalgic about it. It is hard to put all what I feel in a 'thank you' but here is $\mathrm{m}$ y attem pt to do so.

Firstly I would like to thank my promoter Prof. Hauke Smidt for believing in me and giving me this opportunity to join his group. You inspired me to work hard and thank you for all those discussions during our project and Moleco group meetings, thank you for always explaining me concepts when required, and for being patient with me. I truly believe you were my driving force to continue working in microbiology and I cannot thank you enough for this. Also thank you to Prof. Willem de Vos to always guide me correctly during the PhD meetings which helped me to shape my project well. I also thank Prof. Fons Stams who might not have been involved in my project but still allowed me to work in his MicPhys group. I have always enjoyed MicPhys meetings as well and was happy to be a part of it.

I would also like to thank my multiple supervisors that I had right from the beginning of my $\mathrm{PhD}$. I always took this as an advantage to have different expertise in one project. Thank you Caroline for your help and supervision for the project. I have learnt to be even more critical about my work and I am glad that we found the right balance which only made this project a successful one.

I would also like to thank Tom van den Bogert who started as a Postdoctoral Researcher for this project whom I considered as one of the many supervisors. Thank you for your help and support always, we have had a great time working together and I always remember all the funny and humorous stories we used to share (specially sampling cow rumen fluid and cow saliva at 400 am was quite a memory) $(-)$. After you left your absence was felt in the project but in no time Joan came in. Thank you Joan to be my supervisor and to understand the project so quickly and taking it forward. Thank you for your support that resulted in some nice collaborative publications. Also times when I felt away from family, you were thoughtful to have given me some nice goodies or a message in a card to cheer me up, only to express that you were with me.

Also my sincere thank you to the entire Top Institute Food and Nutrition (TIFN) organization to have funded this project and the TIFN team for all the fruitful discussion during our monthly meetings. Thankful to the very successful kick-off meeting at the start of the project which helped setting goals and seeing the project as a whole and not just about microbiology. I thank Sanne van Gastelen, Elsa van Antunes, Sabine Engelen, Henk van Lingen, Henk Bovenhuis, Kasper Hettinga, Johan van Arendonk and Marleen Viskker for being a great team and help me achieve my goals.

Further, I feel fortunate to have met so many people during the course of time who have not only been great colleagues but also great friends. Thank you to my office mates from Driejen Irene, Gianina, Siawash, Jeyaram and Jorn. Thank you for all the fun conversations. Also thanks to my office mates from Helix - Susakul, Nam, Iame, Nico V, Ivette, Cata, Lara and James. Many have left now but I cherish all the moments we spent as good helpful colleagues. I also 
thank m any other Micphyser's Diana, Lot, Nikolaos (niko), Rik, Florian, Cristina, Maartijn, Noehmi, Peer, Michael, Vicente, Anna, Marjet and Yuan for being helpful colleagues and friends. Rik and Peer - I will always rem em ber your jokes (which I still m any tim es don't get). Yuan and Cristina - Many thanks for nice coffee breaks. Maartijn - You have been extremely helpful and always happy to answer all my questions and most importantly always made time for it. Lot - You have a pleasant personality and always liked hitting a conversation with you. Also I wish to have your homemade apple pie again! Niko - Thank you for always making me smile and laugh. I hope we continue to be like this. Diana - Thank you for being a great team leader but at the same time I cherish all the moments we spent as friends. Also your lovely Indian cooking skills are worth mentioning. I thank Ton van Gelder and Monika to have supported me with things in lab when required. Monika - Also thank you for the lovely Poland trip. Ton - I also appreciate that you always gave me your ideas as to how to go about rumen sampling or working on certain experiments.

I would also like to thank Steven, Merlijn, Ineke, Wilma, Phillipe, Sjon for also always willing to help me when needed. My special thanks to Wim, whom I have disturbed numerous times for my computer problems or software issues. Thank you for always helping me with a smile on your face. Special thanks to Anja for helping me and being so kind and patient with all the administrative work. I always liked to have a chatty conversation with you and coming to your office was a way to catch up with you also, hehe.

I also thank the entire team of Moleco. Some of them being Ying, Yue, Loowee, Johanna, Noora, Janneke, Siawash, Sudarshan, Menia, Leira Ruth, Yannis K, Prokopis, Detmer, Erwin, Hikmah, Tika, Taojun, Jie, Dat and many more I am sure (whom I might have missed out on names). Thank you for giving me a relaxed working atmosphere and having nice social activities together. I really enjoyed our Moleco meetings and cakes (for a very short time after which I decided to reduce my sugar intake ;) ) I learnt a lot from you all as well. Although I was having work interactions m ore with Moleco's and Micphyser's, I also thank Yannis M, Costas, Joyoshree, Prarthna, Bastian, Maarten, Benoit and Jeroen for nice healthy working atmosphere.

My special thanks to my two paranymphs Irene and Sudarshan, who have always been standing beside me through thick and thin. Without a doubt I knew I could count on you guys. I feel happy to have met you and may our friendship last forever!

Lastly my PhD would not have been possible without the love, support and sacrifice from my parents. I feel extremely fortunate to have got the opportunity to fly out of my home in Mumbai to achieve my dreams and this was only possible because of their support at every stage in my life. They have patiently listened to all my PhD life on phone and sometimes my research in my layman talk on phone ;) I cannot thank them enough but only say that I love you mom and dad and hope that I have made you proud. I also thank my grandmother, my late grandfather and all my relatives who were as much involved in my career as my parents. I hope I have made them all proud :

With this, I thank you all once again and hope we all keep in touch in future. 


\section{About the author}

Jueeli D. Vaidya was born in Pune, India brought up in Mumbai, India. After completing her secondary education, she received her Bachelor's degree in Life Sciences at St. Xavier's College, Mumbai, India in July 2010. Following month August 2010 she moved to the Netherlands for her Master degree education. In 2012 she com pleted her Master's degree in Cellular and Molecular Biotechnology, after which she started as a $\mathrm{PhD}$ candidate at the laboratory of Microbiology under the supervision of Prof. Hauke Smidt. She will defend her thesis in November 2018.

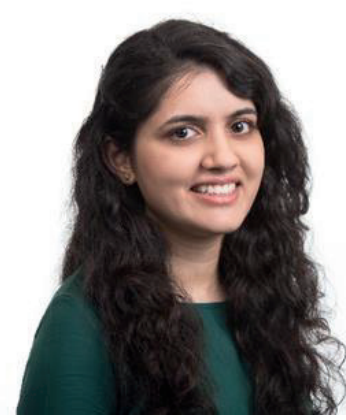




\section{List of publications}

1. Vaidya JD, van den Bogert B, Edwards JE, Boekhorst J, van Gastelen S, Saccenti E, Plugge, CM and Smidt H (2018) The Effect of DNA extraction methods on observed microbial communities from fibrous and liquid rumen fractions of dairy Cows. Front. Microbiol. 9:92. doi: 10.3389/fmicb.2018.00092

2. Van Lingen H, Edwards JE, Vaidya JD, van Gastelen S, van den Bogert B, Saccenti E, Bannink A, Smidt H, Plugge C \& Dijkstra J (2017) Diurnal dynamics of gaseous and dissolved metabolites and microbiota composition in the bovine rumen. Frontiers in Microbiology 8. doi: 10.3389/fmicb.2017.00425

3. Vaidya JD, Van Gastelen S, Smidt H, Plugge CM and Edwards JE (2018) Characterization of dairy cow rumen bacterial and archaeal communities associated with grass silage and maize silage based diets (submitted)

4. Vaidya JD, Hornung BVH, Smidt H, Edwards JE and Plugge CM (2018) Characterization of Propionibacterium ruminifibrarum sp. nov., isolated from the cow rumen fibrous content (submitted). 


\section{Overview of completed training activities}

Discipline specific courses/meetings

Ruminomics summer school, Piacenza, Italy

4th TI Food and Nutrition Annual

Conference

Ruminomics one day workshop, Aberdeen,

UK

Rowett-INRA Gut Microbiology conference

TI Food and Nutrition Annual Conference

16th Gut day symposium

Scientific Spring meeting KNVM

Arb

University Konstanz research excursion

International conference on Biogas

Microbiology (ICBM-3) conference
Graduate school/Institute

Year

Rowett-INRA

2012

ACTA Research Centre, VU Amsterdam 2013

Rowett-INRA 2014

Rowett-INRA 2014

Nutricia Research Danone 2014

Gut Flora foundation 2014

KNVM 2014

Wageningen University / Ribocon 2014

Wageningen University/Konstanz

University 2016

Wageningen University 2017

\section{General courses}

VLAG PhD week

VLAG

2012

Writing and presenting a scientific paper

WGS

2013

Project and time management

WGS

2013

Scientific writing

WGS

2013

\section{Optionals}

VLAG research proposal

VLAG

2012

$\mathrm{PhD}$ study tour

Microbiology dept, WUR

2013

Weekly group meetings

Microbiology dept, WUR

2012-2017

TIFN group meetings

TIFN

2012-2017 
The research presented here was financed by Top Institute Food \& Nutrition based in Wageningen, The Netherlands.

Financial support from the Laboratory of Microbiology (Wageningen University \& Research) for printing this thesis is gratefully acknowledged.

Cover design by Jueeli D. Vaidya, inspired and adaptation from freepik.com Layout design by Jueeli D. Vaidya

Thesis printing by Proefschriftm aken.nl II DigiForce Vianen 



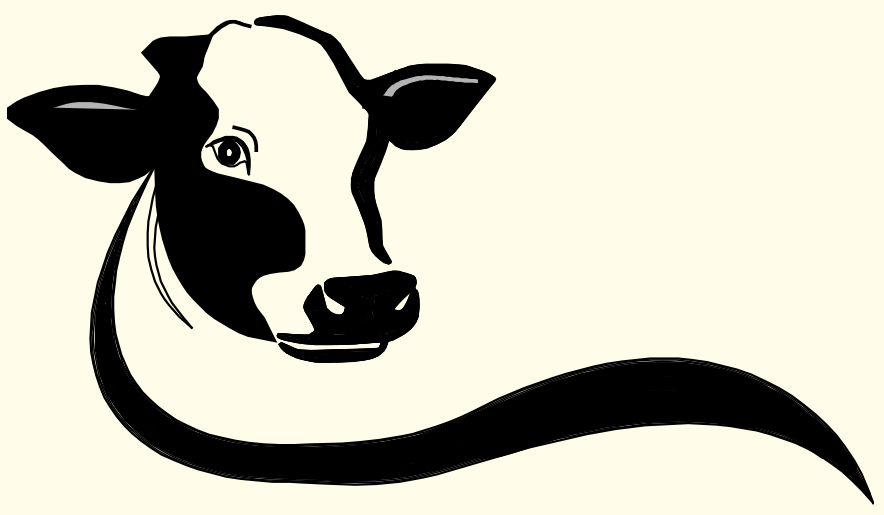

